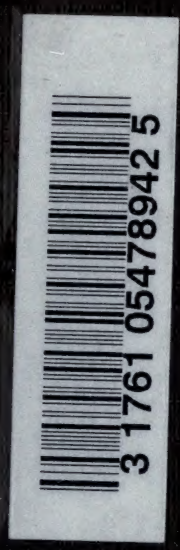




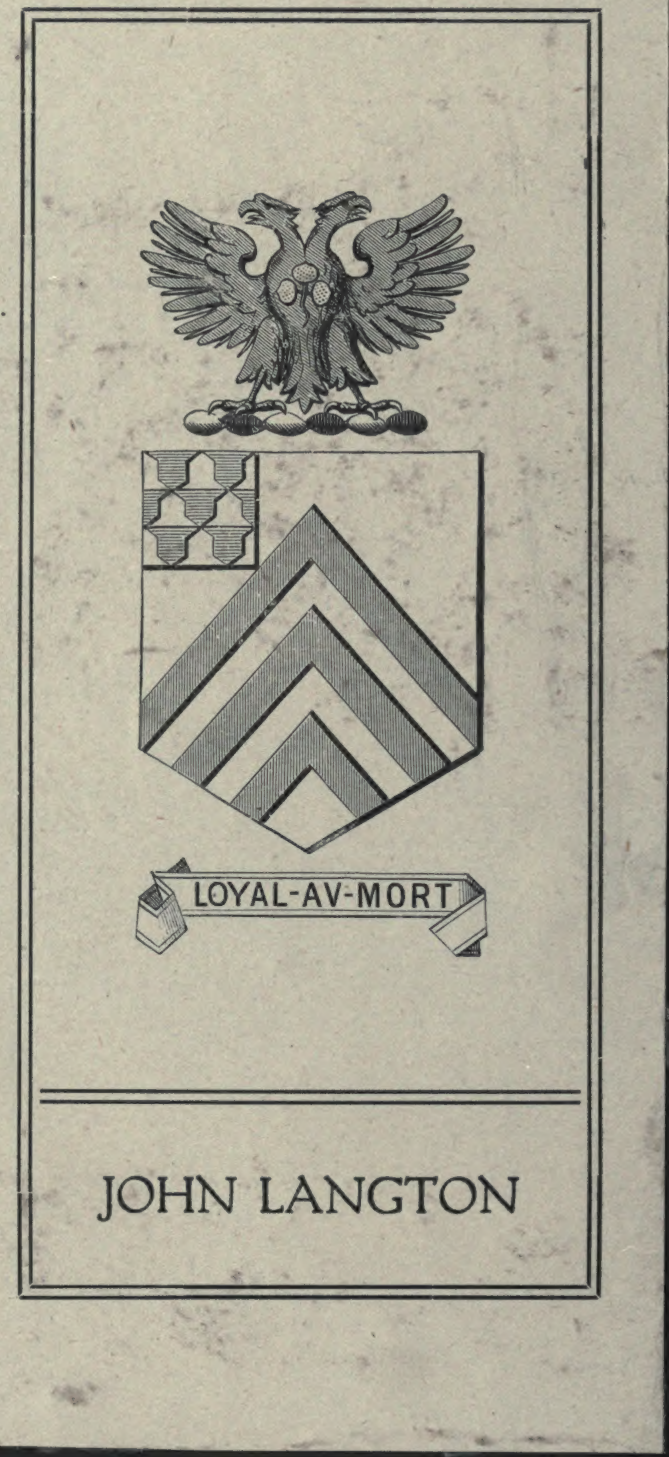

\begin{tabular}{|} 
From the \\
ESTATE OF JOHN LANGTON \\
to the \\
UNIVERSITY OF TORONTO \\
1920
\end{tabular}


Digitized by the Internet Archive in 2007 with funding from Microsoft Corporation 



\section{THE CALORIFIC POWER OF FUELS. \#}

FOUNDED ON

SCHEURER-KESTNER'S

POUVOIR CALORIFIQUE DES COMBUSTIBLES.

WITH THE ADDITION OF

A VERY FULL COLLECTION OF TABLES OF HEATS OF COMBUSTION OF FUELS, SOLID, LIQUID AND GASEOUS.

TO WHICH IS ALSO APPENDED

THE REPORT OF THE COMMITTEE ON BOILER TESTS

OF THE AMERICAN SOCIETY OF MECHANICAL ENGINEERS (DECEMBER, 189\%); TABLES

OF CONSTANTS USED.

BY

HERMAN POOLE, F.G.S.,

Member of the Society of Chemical Industry: the American Chemical Society: the American Society of Mechanical Engineers; etc.

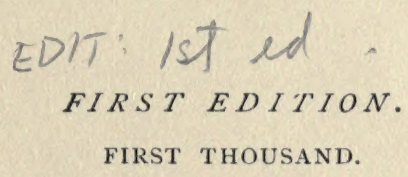

1) NEW YORK:

$\mathrm{JOHN}^{2}$ WILEY \& SONS.

LONDON: CHAPMAN \& HALL, Limited.

$$
\text { 3) } 1898
$$


Copyright, 1898 ,

BY

HERMAN POOLE.

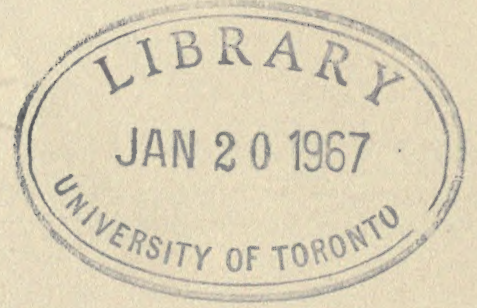


TO MY WIFE

THIS BOOK IS AFFECTIONATELY DEDICATED. 



\section{PREFACE.}

THE books on fuels hitherto published in English, contain only a few scattered facts regarding their calorific powers, how they are obtained, and the practical use made of them. Quite frequently these books are consulted for these facts, and the information they do contain is utilized to its fullest extent. It was thought that a book especially devoted to this subject containing all the reliable data might be of interest, and in furtherance of that idea this book is published.

The work commenced as a translation of M. Scheurer-Kestner's "Pouvoir Calorifique des Combustibles"; but changes became necessary to adapt it to American methods and data, and it was deemed advisable to simply use the skeleton of the work and fill it in, as considered best. Even this skeleton has hardly been preserved intact, as the arrangement of much of the material has been changed, many portions omitted, many new ones supplied, and in some of the original discussions the argument has been so changed as to point nearly opposite to that advocated by M. Scheurer-Kestner.

The work embraces only that portion of calorimetric determinations having a bearing on fuel values. A concise description is given of the leading calorimeters, those most commonly used being described more fully than the others, and some examples of working and calculations are added.

Coal being the principal fuel naturally receives more space than any of the others, and most of the examples and calculations are based on results from this fuel. The other fuels are 
discussed briefly, some space being given to the heats of formation of the different kinds of gas, and the advantages gained by their use. A short account of theoretical flame temperatures is given, with the methods of calculating and applying the same.

The Report of the Committee on Boiler Tests, submitted to the American Society of Mechanical Engineers, in December, 1897 , is published in full, as are also several of the appendices to the report. This report revises the old method of I 885 , and gives the most recent methods of testing boilers and reporting the same.

A set of tables of constants used in this and allied subjects is given, and finally a collection of calorimetric and analytic data on all the kinds of fuel used. It is believed that these tables are fuller and more complete than any previously published in any language, and in collating them all available books and periodicals have been freely used. In all instances where the author was known, he has been credited with his results. Of course in such a large amount some unreliable data may have crept in, but all possible pains have been taken to exclude any such. The list of periodicals, etc., consulted will be found following the table of contents.

For help in the work, and especially the tabular matter, the author is under obligations to many. Prominent among them are Profs. R. C. Carpenter, E. E. Slosson, W. O. Atwater, and D. S. Jacobus; and Messrs. William Kent, R. S. Hale, F. L. Slocum, W. B. Day, and C. E. Emery. The Astor Library and the Libraries of the American Society of Civil Engineers and the American Society of Mechanical Engineers were freely used, and much help obtained from the librarians. Most of the cuts are from Scheurer-Kestner's book; a few were taken from Lunge and Hurter's Alkali-Maker's Handbook; some from Groves and Thorpe's work on Fuels; a few from the Reports of the American Society of Mechanical Engineers; two from Dingler's Polytechnic Journal; one 
from the Scientific American Supplement; and one from Engineering News.

The work has been unavoidably delayed waiting for desired data, some of which came too late to be used.

The author knows well that the book is far from perfect or complete, but it is as near sa as could be made with the diverse kinds of material obtainable. Some errors, especially in the tables, may be found, which he hopes to correct in the future.

That it may be found of service and aid to others in their work on fuels is the sincere wish of the author.

HERMAN POOLE.

NEW YORK, Jan. I, I898. 



\section{CONTENTS.}

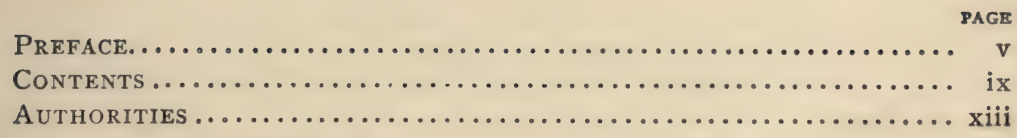

CHAPTER I.

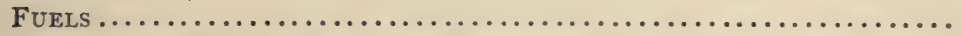
$\mathbf{I}$

Definitions. Fuels. Calorific Value. Heat of Combustion. Thermometers. Metastatic Thermometers.

\section{CHAPTER II.}

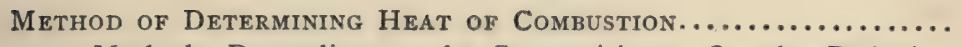

Methods Depending on the Composition. On the Reducing Power.

\section{CHAPTER III.}

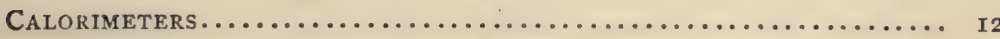

Installation. Evaluation in Water. Correction for Readings.

\section{CHAPTER IV.}

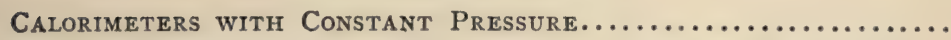

Calorimeters using Air or Oxygen. Favre and Silbermann's. Alexejew's. Fischer's. Thomsen's. Carpenter's. Schwackhöfer's. W. Thompson's. Barrus's. Hartley and Junker's.

\section{CHAPTER V.}

Calorimeters with Constant Volume........................

Relation of Constant Volume and Constant Pressure. Andrews'. Berthelot's. Description. Working. Calculation. 
CHAPTER VI.

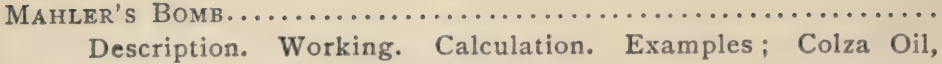
Coal, Gas, Coke. Atwater's. Kroeker's. Walther-Hempel. Witz's.

\section{CHAPTER VII.}

SOLID FUELS. .......................................

Coal. Lignite. Peat. Coke. Charcoal. Wood.

\section{CHAPTER VIII.}

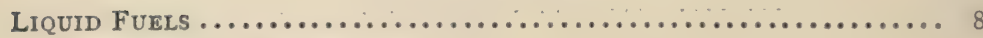

Shale Oils. Petroleum.

\section{CHAPTER IX.}

Gaseous Fuels

Heat of Combustion from Analysis. Coal Gas. Gas of Gasogenes. Producer or Air Gas. Water and Mixed Gas. Natural Gas.

\section{CHAPTER $\mathrm{X}$.}

Calorific Power of Coal burnt under a Steam-boiler......... Iog Distribution of Heat. Weight of Fuel. Sampling the Fuel. Analysis of the Coal. Analysis of the Cinders. Duration of the Test. The Water Evaporated. Temperature of the Steam. Moisture of Steam. Corrections for Quality of Steam. Quality of Superheated Steam.

\section{CHAPTER XI.}

Calorific Power of Coal burnt under a Steam-boller-Continued. Air Supplied and Waste Gases ................ I25

Volume of Air Necessary to Combustion. Volume of Waste gases by Analysis., Gas Sampler. Analysis of Gases. Calculation of Volume from Analysis. Calculation of Volume of Air Supplied. Calculation of Weight of Waste Gases from Analysis. Volume of Waste Gases by the Anemometer. Fletcher's Anemometer. Segur's Differential Gauge. Hirn's Method. Dasymeter. Econometer. Gas Composimeter. Temperature of Waste Gases. Pneumatic Pyrometer. Carbon in Smoke. 


\section{CHAPTER XII.}

Calorific Power of Coal burnt under a Steam-boiler-Continued. Calculation of the Heat Units................ I59 Heat of Aqueous Vapor. Heat of Waste Gases. Heat of the Temperature. Heat of the Hygroscopic and Combustion Water. Calories of the Combustible Gases. Calories due to Soot. Distribution of Calories-Loss.

Flame and Flame Temperatures........................ r6 68

Weight and Heat Units of Carbon Vapor................. I 73

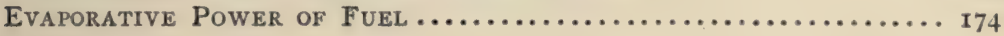

\section{APPENDIX.}

Report of the Committee on the Revision of the Society Code of 1885, Relative to a Standard Method of Conducting Steam-

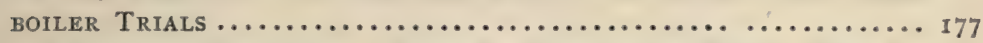

Report of Committee. Rules for Conducting Trial. Form for Report.

TABLES............................................... 8

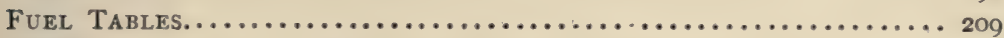

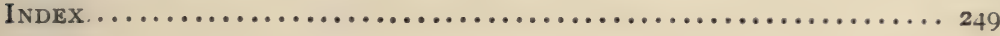





\section{ERRATA.}

Page 17. Table at bottom of page. All after and including the word "Mean" should be moved up one line.

102. Line 19, for kilogram read kilograms

106. In table, for Methane read Illuminants

I45. Line 4 blank space should read the actual

149. Line 5, first $i^{\prime}$ should read $i^{\prime \prime}$

163. Second line from bottom, after - 100) put ]

I8o. Last line, for 33.317 read 33,317

I88. Line 8 , add See page II9.

196. Number 56 , put 212 before "degrees"

197. Second foot-note, add See page ro.

207. Foot-note, after Deutschen add Chemische

213. Add foot-note: The determinations of Noyes, McTaggart and Craven considered water as vapor.

213. Column I2 on line with Noyes, McTaggart and Craven should read 7516

2r8. Column 4 on line with "Almy No. 7," for 83.66 read 83.63.

223. Column 6, on line with Dombrau, Austria, for 0.07 read 0.97 .

227. Last column, "R. Oriol " should be moved up one line.

229. First column, for Gangul read Gagul

Omit last line-" Saghalien."

Last column, for Alexeieff read Alexejew

233. First column, for Texas read Wyoming

238. First column, for Newcastle Western Co. read Newcastle Weston Co.

for Landen read Lander

Last column, for C. E. Slosson read E. E. Slosson

239. First column, 2d line add (distilled)

2ło. First column, last line, for Walled read Wallace

247. Column I2. for 1373 read 137 



\section{AUTHORITIES CONSULTED.}

The following list contains the names of the different publications consulted to obtain data, especially for the tables. Dates are not usually given, as in many cases the entire file was used since I 868 .

Alkali Reports, England.

American Engineer.

American Gas Light Journal.

American Manufacturer.

Annalen der Chemie und Physik.

Annales de Chimie et Physique.

Annales des Mines.

Australian Mining Standard.

Bayerisches Industrie und Gewerbeblätter.

Bell, Sir I. L., Chemical Phenomena of Iron-smelting.

Berichte der Deutscher Chemischer Gesellschaft.

Berthelot, Essai de Mécanique Chimique.

Berthier, Traité des Essais par la Voie sèche.

Bulletin No. 2I, U. S. Dept. Agriculture.

“ University of Wyoming.

“ de la Société Industrielle de Mulhouse.

" de la Société Chimique de Paris.

" de l'Association des Propriétaires d'Appareils à Vapeur du Nord de la France.

Chemical News.

Colliery Guardian.

Comptes Rendus de l'Académie des Sciences.

Crookes and Röhrig, Metallurgy.

Dingler's Polytechnisches Journal.

Dufrénoy, Traité de Mineralogie.

Electrical Engineering. 
xiv

Engineer.

Engineering.

Engineering and Mining Journal.

Engineering Mechanics.

Engineering News.

Groves and Thorpe, Chemical Technology, Vol. I.

Glückauf.

Ice and Refrigeration.

Iron Age.

Isherwood, B. M., Engineering Precedents.

" " Researches in Steam Engineering.

Jahrbuch der K. K. Berg-Akademie.

“ für Geologie.

Johnson, W. B., Report to Congress, U. S. A., I 844 .

Journal American Chemical Society.

“ Canadian Mining Institute.

“ Chemical Society.

" Franklin Institute.

$\because \quad$ Society of Chemical Industry.

“ Imperial Institute.

“ Iron and Steel Institute.

“ de l'Eclairage au Gaz.

“ des Usines à Gaz.

“ du Gaz et de l'Electricité.

“ für Gasbeleuchtung.

“ für Praktische Chemie.

“ für Angewandte Chemie.

“ of Gas Lighting.

Kent, William, Pocket-book.

Le Génie Civil.

Mémoires de la Société des Ingénieurs Civils.

Mineral Industry, Vol. I.

Mineral Resources, U. S. A., various volumes.

Mining Journal.

Morin and Tresca, Machines à Vapeur.

Oesterreichische Zeitschrift für Berg- und Hüttenwesen.

Peclet, Traité de la Chaleur.

Percy's Metallurgy, Fuels.

Philosophical Magazine.

Polytechnisches Centralblatt.

Progressive Age.

Proceedings: Alabama Industrial and Scientific Society. 
Proceedings: American Institute Mining Engineers.

"،

s6

“

Reports : British Alkali Commission.

American Society of Civil Engineers.

Institute of Mechanical Engineers.

Institution of Civil Engineers.

“ British Associątion of Gas Managers.

“ Bureau of Mines, Canada.

“ Department of Mines, New South Wales.

" Geological Survey, Ohio.

" Geological Survey, U. S.

“ South Lancashire and Cheshire Coal Association on Boilers and Smoke Prevention, I869.

Revista Minera.

Revue Scientifique et Industrielle.

"Universelle des Mines.

Sanitary Engineer.

Scheerer, Lehrbuch der Metallurgie.

Scheurer-Kestner, Pouvoir Calorifique des Combustibles.

Science.

Ser, Traité de Physique Industrielle.

Stahl und Eisen.

Stevens Indicator.

Thomsen, Thermo-chemie.

Transactions Newcastle Chemical Society.

Ure's Dictionary.

United States Census Bulletin, 1890.

Williams, C. W., Fuel, its Character and Economy.

Watt's Dictionary of Chemistry.

Witz, Traité théorique et pratique des moteurs à gaz.

Wurtz, Dictionnaire de Chimie.

Zeitschrift Physikalische Chemie.

“ des Vereines Deutscher Ingenieure.

Zeitung Berg- und Hüttenwesen. 



\title{
CALORIFIC POWER OF FUELS
}

\author{
CHAPTER I. \\ INTRODUCTORY.
}

\section{FUELS.}

FUELS are those substances containing carbon, or carbon and hydrogen, which are utilized for the heat they produce upon union with oxygen. The products of this union, called combustion, are carbonic acid or carbonic acid and water. Many fuels, such as wood, peat, crude petroleum, etc., exist naturally; others, such as coke, charcoal, coal-gas, etc., are formed artificially.

The fuel par excellence to-day is coal. Improvements in transportation allow deliveries at points more and more remote from the mines, and the increasing demand, aided by new and improved machinery, tends to lower the cost. New locations are still being discovered, and the old ones are being worked more thoroughly and completely. A large portion of this book will be devoted to coal, other fuels being treated incidentally; and such treatment is fitting, since it is the study of coal to which the energies of physicists and engineers are still principally devoted in their researches on the calorific power of fuel.

For convenience of discussion the fuels will be divided into three general heads:

Solid fuels-coal, lignite, peat, coke, charcoal, and wood. 
Liquid fuels-petroleum, shale oils, vegetable and animal oils.

Gaseous fuels-coal gas, producer gas, water gas, mixed gas, natural gas.

CALORIFIC POWER OR HEAT VALUE.

The quantity of heat generated by the combustion of a definite quantity of fuel in oxygen is called the calorific power, heat value, or heat of combustion.

The expression calorific power or heat value has a wider signification than heat of combustion. In the popular sense the former ones apply to the measure of an industrial yield as well as to the heat given off by the fuel during its complete combustion. The expression heat of combustion, more nearly correct from a scientific point of view, is applied, on the contrary, only to that quantity of heat generated by the substance when completely burnt; that is to say, when the carbon and hydrogen are completely changed to carbonic acid and water. The unit adopted for these quantities of heat is the Calorie and the British Thermal Unit.

The Calorie is the quantity of heat absorbed by the unit of weight of pure water when its temperature is increased one degree Centigrade. This unit is usually one gram or one kilogram. When it represents the atomic or molecular weight, it is called the atomic or molecular calorie, the gram being taken as the atomic unity.

The British Thermal Unit (B. T. U.) is the quantity of heat absorbed by one unit (usually one pound) when its temperature is increased one degree Fahrenheit. It is $\frac{1}{3.968}$ of a calorie.

A kilogram in burning generates $n$ calories with a kilogram as unit and the Centigrade scale; a pound generates $n$ calories with a pound as unit and the Centigrade scale (W. Kent's pound-calorie); or, whatever the weight taken, there will be generated the same number of calories. using the same unit of 
weight and the Centigrade scale. Hence to pass from the Centigrade scale to the Fahrenheit scale multiply by the factor I.8, that being the ratio of the two scales.

In this work calories referred to the kilogram (kilocalories) will be used, and the calorie will be the quantity of heat necessary to raise the temperature of that amount of pure water one degree Centigrade. We will omit consideration of the variations in specific heat of water; to consider these it would be necessary to state that the initial temperature was $0^{\circ} \mathrm{C}$. But, as remarked by Berthelot, " the calorie varies only to a very slight degree if we take the water at a slightly increased temperature-at $15^{\circ}$ or $20^{\circ}$, for example; so that we are accustomed to regard as constant the specific heat absorbed by the water for each degree comprised in this interval of temperature, thus simplifying the calculations." We may lessen this little error by referring the calorie to a litre of water instead of a kilogram, that is, by measuring the water instead of weighing it; the weight of a litre of water diminishing from its maximum density at $4^{\circ} \mathrm{C}$., while its specific heat gradually increases. The error of calculation is thus made less than the error of experiment.

\section{HEAT OF COMBUSTION.}

When the fuel contains hydrogen, its heat of combustion may be expressed in two ways. Hydrogen in burning produces water, and this water may be either condensed or in the state of vapor. The same number does not apply to both cases, since the vaporization of the water formed consumes heat, which is not given up to the calorimetric bath. We usually consider the heat of combustion, the result of the experiment made under ordinary conditions, or when the water is in the liquid state; this is the general acceptance of the term heat of combustion. Some authors, however, prefer to consider the water as vapor.

It is easy, however, to change from one system to the 
other. The heat of combustion of one kilogram of hydrogen being 34500 calories, ${ }^{*}$ and the water formed being liquid at $0^{\circ} \mathrm{C}$., a portion of the 34500 calories is used to vaporize the water in the case where it is gaseous or considered as such.

Experiment has shown that the heat of vaporization of water is expressed by the formula of Regnault,

$$
\begin{aligned}
& 606.5+0.305 t, \text { or } \\
& \text { 1091.7 }+0.305\left(t-32^{\circ}\right) \text { for Fahrenheit degrees, }
\end{aligned}
$$

in which $t$ represents the temperature of the water in the state of vapor. Now one kilogram of hydrogen produces nine kilograms of water. To keep these nine kilograms of water in vapor, at $100^{\circ} \mathrm{C}$. for example, there will be needed, by the above formula, 637 calories per kilogram of water, or nine times as much per kilogram of hydrogen, which is 5733 calories. These 5733 calories reduce to 5453 when the water is considered as being at $0^{\circ} \mathrm{C}$. instead of at $100^{\circ} \mathrm{C}$. Deducting 5453 calories from 34500 calories representing the heat of combustion of hydrogen, the water formed being condensed, we obtain 29047, which number represents the heat of combustion of hydrogen, the water being in the state of vapor at $0^{\circ}$. We will call it, in round numbers, 29 Ioot calories, as is done by several writers.

\section{THERMOMETERS.}

Before taking up the study of calorimeters, we must consider the calorimetric thermometer, which is a most important part of the apparatus employed. The reading of the thermometer and the corrections are quite delicate and also very important, the calculation of the heat of combustion depending principally on their accuracy.

In this work calorimetric questions relating to fuel only will be considered; hence a description of ordinary ther-

*62100 B. T. U.

+52380 B. T. U. 
mometers and their manufacture will not be needed. They are usually bought all finished, and should be obtained only from reliable dealers.

Favre and Silbermann employed a thermometer of their own design, divided into $\frac{1}{10}$ degrees and graduated from $32^{\circ}$ to $0^{\circ} \mathrm{C}$. Each degree occupied about 0.3 inch. By means of a cathetometer they read to $\frac{1}{100}$ of a degree. Their calorimetric bath of 2 litres capacity was subjected to at least $8^{\circ}$ elevation in temperature, and the quantity of substance necessary to use at times exceeded 2 grams. To lessen this amount of rise in temperature and also the time of combustion, they used longer thermometers, with scales reading to $\frac{1}{50} \sigma^{\circ}$ or even to $\frac{1}{1000}^{\circ}$. Scheurer-Kestner used a thermometer divided to $\frac{1}{50}^{\circ}$ with his Favre and Silbermann calorimeter. Since then they have been used generally. Such thermometers are difficult to work with, and require care in manipulation, and often a series of thermometers or at least two with scales in sequence are employed. If the initial temperature of a calorimetric bath is found a little above the highest graduation on the first thermometer, and if the rise in temperature of the bath amounts to two degrees, we must

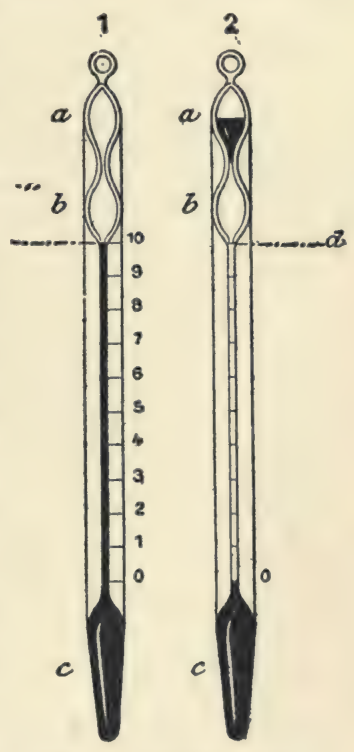

Fig. I.-Metastatic THERMOMETER. substitute the second one having for its lowest degree the highest of the first. Besides the trouble of substitution, it necessitates a correction for agreement of the degrees common to the two instruments. To obviate this difficulty the " metastatic" thermometer was invented by Walferdin and described in the Comptes Rendus de l'Académie des Sciences, I 840 , p. 292 , and 1842 , p. 63 . 
The metastatic thermometer is a differential thermometer with a variable scale. At will, a certain quantity of mercury flows into the bulb. By this means we raise or lower the degrees for which it may be used. Suppose an ordinary thermometer graduated from $0^{\circ}$ to $10^{\circ}$, and left open at the top at the 1oth degree. If we wish to use it between $12^{\circ}$ and $14^{\circ}$, heat it to $14^{\circ}$, and a portion of mercury corresponding to $4^{\circ}$ escapes. Now, instead of showing a difference of $10^{\circ}$ between $0^{\circ}$ and $10^{\circ}$, it will show this difference between $4^{\circ}$ and $8^{\circ}$, the original $0^{\circ}$ having descended to $-4^{\circ}$. It will be similar for temperatures of $10^{\circ}, 20^{\circ}$, or $30^{\circ}$, as desired. By. closing the thermometer at the top instead of leaving it open, and blowing a bulb in the upper portion as overflow, the conditions will remain the same. The thermometer has now become metastatic. These thermometers are made by Baudin of Paris, from whom full directions for use and corrections can be obtained.

With all thermometers it is essential that the glass of the bulb should be rather thin, or the thermometer will be " too slow." The slightest difference in temperature must be shown immediately by a movement of the mercurial column. To test for sensibility, read the height of the column and then place the hand on the bulb. If sufficiently sensitive the mercury will descend quickly from the expansion of the glass and afterwards rise. In thermometers divided to $\frac{1}{100}^{\circ}$ this movement should be immediate, and over several hundredths.

In ordinary calorimetric experiments the correction due to length of the mercury column flowing out of the bulb may be neglected for several reasons; the experiments should be made in a room where the temperature is nearly the same as that of the calorimetric bath, such correction would be of very little consequence for a slight change of temperature, and the experimenter should plunge the thermometer into the bath as deep as is necessary to take the reading at the level of the eye. 


\section{CHAPTER II.}

METHODS OF DETERMINING HEAT OF COMBUSTION.

THERE are two methods for determining tne heat of combustion of substances-one by calculation based on the chemical composition, and the other by actual combustion in a calorimeter. The first method may be considered under two heads: that in which the units are calculated directly from the composition, and that in which they are calculated from the quantity of oxygen consumed during combustion in a crucible.

\section{CALCULATION FROM CHEMICAL COMPOSITION.}

Dulong stated that the heat generated by a fuel during combustion was equal to the sum of the possible heats generated by its component elements, less that portion of the hydrogen which might form water with the oxygen of the fuel.

$\mathrm{H}$ is formula was

$$
x=8080 \mathrm{C}+34500\left(\mathrm{H}-\frac{\mathrm{O}}{8}\right)
$$

or expressed in B. T. U.'s,

$$
x=14500 \mathrm{C}+62100\left(\mathrm{H}-\frac{\mathrm{O}}{8}\right) \text {. }
$$

in which

$x=$ the heat of combustion sought;

$8080=$ the heat of combustion of carbon in calories;

$$
\begin{aligned}
& \mathbf{1} 4500=\text { " " " " } " \text { " } " \text { " } " \text { " B. T. U.; }
\end{aligned}
$$

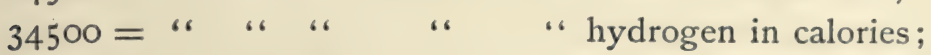

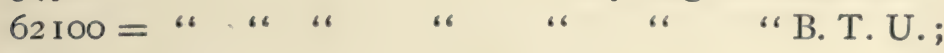



$\mathrm{H}-\frac{\mathrm{O}}{8}=$ the quantity of hydrogen less that supposed to form
water with the oxygen.

Other authors and experimenters have tried to interpret their results by a general formula with varying success. Many of them by working on a certain number of coals from a certain location work out a formula which applies to that set of coals, but not as well to another set. A few of them will be given. They all resemble Dulong's and are usually only modifications of his original one.

The Verein Deutscher Ingenieure adopted the following:

$$
x=8100 \mathrm{C}+29000\left(\mathrm{H}-\frac{\mathrm{O}}{8}\right)+2500 \mathrm{~S}-600 E,
$$

in which allowance is made for the heat of combustion of sulphur and the heat of the hygroscopic water. All the coefficients are round numbers and that for hydrogen, 29000, is the one in which the water is supposed to be as aqueous vapor, all the water being considered as passing off in that state. None of the other formulæ uses this coefficient. It gives rather low results. The question as to the advisability of reckoning the heat due to sulphur is a debatable one. In no case does it amount to more than a verv small per cent and can have but little effect on the total.

Balling gives as formula

$$
x=8080 \mathrm{C}+34462\left(\mathrm{H}-\frac{\mathrm{O}}{8}\right)-652(E+9 \mathrm{H})
$$

to represent the actual occurrences in a steam-boiler fire working under a pressure of steam corresponding to $300^{\circ} \mathrm{F}$.

Schwackhoefer made the following modification to allow for the correction due to hygroscopic water:

$$
x=8080 \mathrm{C}+34500\left(\mathrm{H}-\frac{\mathrm{O}}{8}\right)-637 E .
$$


Mahler formulated one based on the results of calorimetric determination of the heat of combustion of 44 different kinds of fuel. It is

$$
x=\frac{8 \mathrm{I} 40 \mathrm{C}+34500 \mathrm{H}-3000(\mathrm{O}+\mathrm{N})}{100} ;
$$

or simplified,

$$
x=111.4 \mathrm{C}+375 \mathrm{H}-3000 ;
$$

or in B. T. U.'s,

$$
x=200.5 \mathrm{C}+675 \mathrm{H}-5400 \text {. }
$$

With the coals he examined he found a very close agreement between the results calculated by this formula and those observed. A similar but not equally close concordance was found using the Dulong formula. With wood and lignites the difference amounted to 2 per cent. His formula applies also to other substances whose constituents are accurately known. Cellulose, the heat of combustion of which according to Berthelot is 4200 calories, by Mahler's formula is 4264 .

In summing up he says: "From a scientific point of view, in the present state of our knowledge on the subject, we cannot give a general formula depending strictly on the chemical composition which will give the calorific power of combustibles, substances so complex and varied."

Lord and Haas in a paper read before the American Institute of Mining Engineers, Feb. 1897, state that in a series of forty Pennsylvania and Ohio coals they found differences varying from +2.0 to - I. 8 per cent between the calculated and the observed results, and an average difference of -0.12 per cent.

In 1896 Bunte published some analyses and calorimetric tests of gas-cokes, showing a difference of from +0.04 to - I.2 per cent. 
Three elements enter into these cases, the analysis, the calculation, and the combustion; all may be erroneous. As the matter stands now the weight of error seems to be on the side of the analysis, as our methods of analysis, especially in water determinations, are not entirely satisfactory; yet it must be confessed that some of the most recent analyses give a basis trom which very close agreement can be calculated. With such fuels as coke, charcoal, or anthracite, having but little volatile matter, the results agree quite well, but with the bituminous coals, asphalts, mineral oils, etc., which are so very complex, the differences are greater. ${ }^{*}$ In these the actual proximate chemical constitution seems to make a difference. It may be safely stated, however, that for ordinary industrial uses, in absence of the possibility of a calorimetric test, and with coals having under 20 per cent of volatile matter, a fairly accurate approximation may be arrived at by calculation.

The great inducement that formerly existed in favor of calculated results exists no longer. I refer to the difficulty of making a calorimetric test. These can be made now by means of the modern apparatus, so simple and almost selfregulating that the time consumed is but a small fraction of that needed for an analysis, and the labor and care, hardly anything in comparison.

If possible, by all means have a calorimetric test. If not possible, use the best analysis available.

\section{CALCULATION FROM QUANTITY OF OXYGEN USED.}

This is the litharge reduction test. It depends on Welter's formula, which is based on the hypothesis that the heat of combustion is proportional to the quantity of oxygen consumed:

$$
N=m P,
$$

\footnotetext{
* Mahler's limit for Dulong's formula is $\mathrm{O}+\mathrm{N}>\mathbf{1 5}$.
} 
in which $N$ is the heat of combustion sought, $m$ is the coeffcient previously determined, and $P$ is the weight of oxygen necessary for the combustion of one kilogram of the substance.

Giving $P$ the value resulting from the use of the equivalents- 16 for oxygen to burn 6 of carbon, and 8 for oxygen to burn $\mathbf{I}$ of hydrogen-we have

$$
P=\frac{16}{6} \mathrm{C}+8 \mathrm{H}=8\left(\frac{\mathrm{C}}{3}+\mathrm{H}\right)
$$

and the general formula becomes

$$
\mathrm{N}=8 m\left(\frac{\mathrm{C}}{3}+\mathrm{H}\right)=26880\left(\frac{\mathrm{C}}{3}+\mathrm{H}\right) .
$$

To use this method the combustible is mixed with an excess of litharge and heated in a crucible. The button of lead formed shows the amount of oxygen consumed, and from this is deduced the heat by means of the formula. The heat should be increased very slowly. Mitchell substituted white lead for litharge and claimed to obtain uniform results.

This formula was recommended by Berthier, and has been used since by a few others. It is faulty, as was shown by some of Berthier's own determinations in which contradictory results were obtained. Dr. Ure showed that no uniform results could be obtained using the same materials. ScheurerKestner in 1892 showed that the formula not only gave erroneous results, but actually reversed the relation of combustibles. In one case cited the heats actually obtained by a calorimeter were 8813 and 8750 , while by the litharge test they were 7547 and 7977 . The results were not only low, but reversed the ratio.

This method is allowable only in cases where the crudest approximations are desired and where no analyses or calorimetric tests can possibly be made. 


\section{CHAPTER III.}

\section{CALORIMETRY.}

CALORIMETERS for rapid combustion are invariably composed of a combustion-chamber and a calorimetric bath, usually a cylinder, surrounding it and containing a known quantity of water, the elevation in temperature of which is measured. The combustion is made in oxygen, pure or diluted.

Combustion-chambers are either under a constant pressure, as in the calorimeters of Rumford, Favre and Silbermann, etc.; or with a constant volume, as in the calorimeters of Andrews, Berthelot, etc. With solids the difference of results obtained under constant volume and constant pressure is so small that we. shall not consider it. With gases, however, it is different, and we will state under which conditions the results have been obtained.

The first calorimetric experiments date from Lavoisier and Laplace. In I8I4 Count Rumford replaced the ice calorim. eter of Lavoisier by an apparatus in which the heat developed during the combustion was absorbed by water. It was some time after, I858, that Favre and Silbermann discovered the causes of the great errors of their predecessors, and pub. lished methods for correcting some while avoiding others. We owe to them, above all, the observation that, even when supplied with pure oxygen, combustion may be only partial, on account of the formation of combustible gases. They determined that this occurs generally, and gave a method of estimating the unburnt gases, so as to make allowances in the calculation. 
Carbon, which, before their time, had given only 7624 calories to Laplace, 7386 to Clément-Desormes, 79I 5 to Despretz, 7295 to Dulong, and 7678 to Andrews, yielded to F. \& S. 808I after correction for carbonic oxide in the waste gases. This number has since been increased to 8140 by the latest determinations of Berthelot. Berthelot and Vielle have shown that by using oxygen under pressure complete combustion can be attained.

\section{INSTALLATION OF APPARATUS.}

The apparatus should be placed in a room free from sudden changes in temperature and consequently protected from direct sunlight. If it is not entirely protected from solar radiation, the apparatus may be set up on the north side and shaded from the direct midday sun by a screen.

The calorimeter cylinder with its accessories, as well as the distilled water used, should remain in the room long enough to acquire its proper temperature. The cylinder should be protected as much as possible from radiation by envelopes which vary according to circumstances. Favre and Silbermann used a cylinder with a double wall. The external one was filled with water, and between this one and the cylinder proper swan's down was packed. The upper part of the cylinder also had a layer of thick paper covered with down on the under side.

Berthelot states that the down is more troublesome than useful, and that it may be omitted with advantage. The space between the cylinder and its envelope forms a layer of air which is an excellent non-conductor. In modern instruments the down is replaced by a thick layer of felt. Berthelot even omits this covering, stating that the great cause of loss of heat was not from radiation, but due to evaporation produced by the agitation of the water in contact with the air. $\mathrm{He}$ surrounds his cylinder with a layer of air inside of the envelope of water, and outside of all a layer of felt 0.8 inch thick. By this means external influence is much reduced. 


\section{EVALUATION OF THE CALORIMETER IN WATER.}

Before using a calorimeter its equivalent in water must be determined; that is, we must calculate to what quantity of water it corresponds in terms of specific heat. This is to be added to the weight of water employed and includes the combustion-chamber, cylinder, and the immersed pieces, thermometer, supports, etc.

Below is given an example showing the calculation of the value in water of a Favre and Silbermann's calorimeter:

Copper, Ir 45.651 grams at 0.09516 specific heat........ $=109.008$ grams. Platinum, 22.810 " "0.0324 " " $" \ldots \ldots \ldots .=0.706$ "

Value in water of the chamber and accessories $=109.7 \mathrm{I}_{4}$ " Thermometer, weight of glass immersed, $12 \mathrm{grams}$ at $0.198=2.400$ Mercury,

63 " $" 0.332=2.070$

Total equivalent of water............... $\overline{\mathrm{rr} 4.184}$ “

which added to the 2 kilograms of water in the bath makes a total of 2 II 4 . I 84 grams of water.

The calorimetric weight for the Berthelot bomb at the College of France in 1888 was 398.7 grams for bomb and accessories.

The water value of the calorimeter used by Lord and Haas at the Ohio State University, Columbus, O., was determined as 465 grams. Mahler's apparatus had a water equivalent of $48 \mathrm{I}$ grams. Still, it is better to determine this equivalent by actual experiment, as we are not sure of the specific heat of the metal of the bomb, which might, however, be determined by a sample taken from the original block of which it was made.

Several methods may be employed for this.

When we use the calorimetric bomb, we burn in the obus, using 2000 grams of water, a known quantity of a substance of fixed composition, and of which the heat of combustion is known, as sugar, or naphthalin. We then use less water and burn a smaller quantity of the substance. If I gram of substance was taken the first time, we may take 0.8 gram with 1800 grams of water the second time. We then have two 
equations, trom which we eliminate the heat of combustion of the substance and deduce thence the value in water of the cylinder, etc.

This method, suggested by Berthelot, may be replaced by the following, to which he gives the preference:

Pour into the calorimeter a certain quantity of warm water, at $60^{\circ} \mathrm{C}$. for instance. This water is previously contained in a bottle, and the temperature is measured by a thermometer placed inside. As control, operate first without the bomb in the cylinder and afterwards with it in place.

One test of this kind gave Berthelot a value of 354 calories for the bomb. The value deduced by calculation from specific heat was $355 \cdot 4$. Below is the detailed calculation giving the separate parts of the bomb.

\begin{tabular}{|c|c|c|c|c|c|c|}
\hline \multirow[b]{2}{*}{ Names of the Different Parts. } & \multicolumn{2}{|c|}{ Soft Steel. } & \multicolumn{2}{|c|}{ Platinum. } & \multicolumn{2}{|c|}{ Brass. } \\
\hline & $\begin{array}{l}\text { Weight } \\
\text { in } \\
\text { Grams. }\end{array}$ & $\begin{array}{l}\text { Value in } \\
\text { Water. }\end{array}$ & $\begin{array}{l}\text { Weight } \\
\text { in } \\
\text { Grams. }\end{array}$ & $\begin{array}{l}\text { Value in } \\
\text { Water. }\end{array}$ & $\begin{array}{l}\text { Weight } \\
\text { in } \\
\text { Grams. }\end{array}$ & $\begin{array}{l}\text { Value in } \\
\text { Water. }\end{array}$ \\
\hline 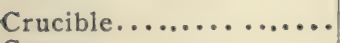 & I 709. 7 & $187.6 \mathrm{I}$ & 728.8 & 23.63 & & \\
\hline 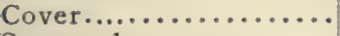 & 221.2 & 24.28 & $\mathbf{5 2 8} 8$ & I7.I5 & & \\
\hline Stop-cock............. & II.7 & I. 28 & $\ldots \ldots \ldots$ & $\ldots \ldots \ldots$ & 20.0 & I. 86 \\
\hline $\begin{array}{l}\text { Cone-screw and socket } \\
\text { of fire-carrier.......... }\end{array}$ & $\ldots \ldots \ldots$ & $\cdots \cdots$ & $\cdots$ & $\cdots$ & $3 \cdot 97$ & 0.37 \\
\hline 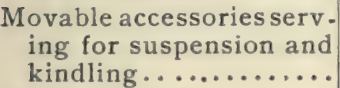 & $\ldots \ldots \ldots$ & $\ldots \ldots \ldots$ & 33.0 & I.07 & & \\
\hline Screw of bomb.......... & 802.7 & 88.08 & נט. & & & \\
\hline Movable foot of bomb... & $\ldots \ldots$ & $\cdots \cdots \cdots$ & $\cdots \cdots \cdots$ & $\cdots \cdots \cdots$ & 108.9 & 10.13 \\
\hline 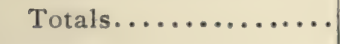 & $2745 \cdot 3$ & 301.24 & 1290.6 & 41.85 & 132.9 & 12.36 \\
\hline
\end{tabular}

RECAPITULATION.

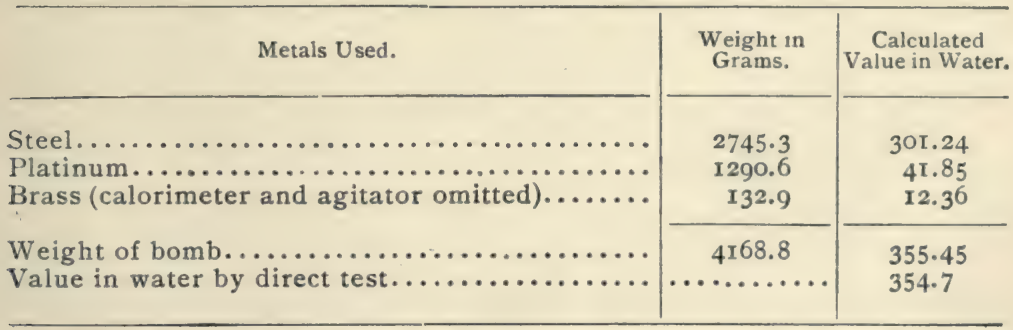




\section{CORRECTIONS FOR THE READINGS.}

The corrections to be applied to thermometric readings, besides those due to the thermometer itself, are of various kinds, and naturally vary with the kind of calorimeter used. Some, however, are common to all.

The correction relative to heating and cooling concerns all calorimeters. Favre and Silbermann made this correction with a coefficient previously determined, once for all, by a series of experiments. For example, the coefficient that they found for their calorimeter $( \pm 0.0020225)$ represents the influence of the external temperature through the envelopes and packings for one minute and one degree.

Instead of a coefficient of correction thus determined, use preferably a system of correction devised by Regnault and Pfaundler. This system is superior to the preceding, as it allows consideration of all external conditions at the time of the experiment. It is evident, for example, that the evaporation of a liquid may vary in such proportions that a fixed coefficient will not always represent it.

The system of Regnault and Pfaundler does not need previous experiments nor a determined coefficient. It rests on observation of the thermometer immersed in the bath a sew minutes before and after the experiment, or at the times when external influence is at its minimum or maximum. Knowing the value of these two kinds of influence, it is easy to calculate it for the whole duration of the test.

It is well to continue the observations before combustion for some five minutes. These five minutes should be preceded by at least ten minutes' immersion of the combustion chamber with agitator, so as to establish equilibrium of temperature between the cylinder and the water.

Suppose the initial correction corresponding to the first period to be zero-which is rare, it is true, but simplifies the 
demonstration-and that the observations have given the following data:

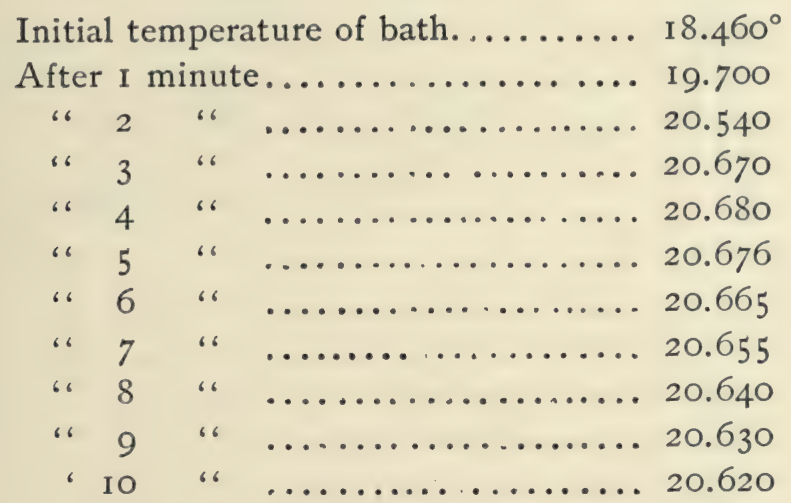

The combustion once commenced is continued till after the fourth minute and ends between the fourth and fifth minutes, but the equilibrium of temperature between the bath and the combustion-chamber is not established until the eighth minute, the time when the variation due to difference between them has become regular (0.010 ${ }^{\circ}$ per minute).

A table of corrections is formed as follows:

\begin{tabular}{|c|c|c|c|c|}
\hline & & I $8.460^{\circ}$ & & \\
\hline Ist $n$ & inute & $\ldots .19 .700$ & Mean $19.080^{\circ}$ & Difference $0.620^{\circ}$ \\
\hline $2 \mathrm{~d}$ & “6 & ... 20.540 & 20.120 & 1.660 \\
\hline $3 \mathrm{~d}$ & “ & $\ldots 20.670$ & 20.605 & 2.145 \\
\hline $4^{\text {th }}$ & “" & ... 20.680 & 20.675 & 2.215 \\
\hline $5^{\text {th }}$ & “ & ... 20.676 & 20.678 & 2.218 \\
\hline 6 th & “ & $\ldots 20.665$ & & \\
\hline 7 th & “ & $\ldots 20.655$ & & \\
\hline 8 th & ، & ... 20.640 & & \\
\hline $9^{\text {th }}$ & ، & ...2 20.630 & & \\
\hline oth & ، & ... 20.620 & & \\
\hline
\end{tabular}


The total elevation of temperature is

$$
20.676-18.460=2.216^{\circ}
$$

and the correction is

$$
\begin{aligned}
20.676-20.620 & =0.056^{\circ} \text { for five minutes, } \\
& \text { or } 0.0 \text { I I }^{\circ} \text { for one minute. }
\end{aligned}
$$

Then

$$
\begin{array}{r}
2.216: 0.01 \mathrm{I}=0.620: 0.0031 \\
2.216: 0.011=1.660: 0.0083 \\
2.216: 0.011=2.145: 0.0107 \\
2.216: 0.011=2.215: 0.0110 \\
2.216: 0.011=2.218: 0.0110 \\
\text { Total........ } 0.0441
\end{array}
$$

There is then $0.0441^{\circ}$ to be added to the difference, $2.216^{\circ}$, increasing it to $2.260^{\circ}$, which is the corrected difference of the bath temperature, from which the heat of combustion of the substance burnt in the calorimeter is calculated.

Regnault and Pfaundler's formula is

$$
\Delta t n=\Delta t o+K(t n-t o)
$$

in which

$\Delta t n=$ ascertained variation of temperature from the heating and cooling of the calorimeter for one minute;

$\Delta t_{0}=$ variation at the beginning;

$t n-t o=$ loss or gain during the total time of the test;

$n=$ number of minutes of test.

Using the above numbers,

$$
K=\frac{0.01 \mathrm{I}}{2.2 \mathrm{I} 6}=0.00496 \text {. }
$$


It will suffice, then, to find the total loss or gain to take the sum of all the gains or losses calculated by means of the coefficient $K$ during the whole time of the experiment.

Thus,

$$
\begin{aligned}
& 0.620 \times 0.00496=0.0031^{\circ}, \\
& 1.660 \times 0.00496=0.0083^{\circ},
\end{aligned}
$$

and so on. 
CHAPTER IV.

\section{CALORIMETERS WITH CONSTANT PRESSURE.}

THE first calorimeters were of constant pressure; that is, the combustion was carried on at the atmospheric pressure or very near it, and did not vary from the beginning to the end of the experiment. Hence the modifications in the volume of the gases before and after combustion exercised no influence on the observed results.

Rumford, in 1814 , was the first who tried to correct external influences. He employed a practical method which has often been used since, and consists in giving the calorimeter bath a temperature in the beginning of the test less than that of the room, and allowing it at the close to attain a temperature in the same proportion above that of the room. His calorimetric apparatus was composed of a copper boiler of several litres capacity, heated by an interior tube through which passed the gaseous products of the combustion. The combustible was burnt in a little burner placed under the boiler, and the air used circulated around the heater before passing to the burner, thus preventing any loss of caloric by radiation.

Dulong in 1838 used oxygen, and obtained much superior results. His calorimeter consisted of a rectangular copper box, 25 centimetres (about 10 inches) deep, 7.5 centimetres (2.9 inches) wide, and 10 centimetres ( 3.9 inches) long. It was closed at the upper part by a cover with a mercury seal. 
The oxygen passed into the calorimeter by a copper tube opening at one of the sides of the box near the bottom. The gases of combustion were drawn into a gas-holder. The apparatus was enclosed in another likewise rectangular, in which was put I I litres ( $9 \frac{2}{8}$ quarts) of water. This was the calorimetric cylinder. The water was kept in motion by an agitator.

The unit chosen by Dulong was one gram of water whose temperature was raised one degree. He corrected the temperature observed, same as Rumford, but he also noticed that this correction was correct only when the first period was equal to the second. The results obtained by Dulong in 1838 were not published till after his death, in 1843. For hydrogen and carbonic oxide they are but slightly different from the most modern determinations.

\section{CALORIMETER OF FAVRE AND SILBERMANN.}

In 1852 Favre and Silbermann published their first researches on the quantities of heat generated by chemical action and described their calorimeter.

All rapid-combustion calorimeters and all with constant pressure intended for solid bodies are copied more or less after that of Favre and Silbermann. The principle and mode of execution in their general lines are the same; the form in some details or the material employed for the combustion-chamber has been modified more or less; but the general apparatus and accessories, as well as the method, have remained as F. \& S. left them. We will describe, then, this calorimeter in its details, and outline the modifications made by other experimenters.

The calorimeter called Favre and Silbermann's is composed of three concentric copper cylinders (Fig. 2, $B, C, D$ ). Cylinder $B$ is the calorimeter cylinder; it is silver-plated and polished on the inner surface so as to lessen its emitting power; its capacity is a little over 2 litres ( $3 \frac{1}{2}$ pints), being 20 
centimetres (about 8 inches) high and 12 centimetres $\left(4 \frac{3}{4}\right.$ inches) in diameter. In the middle is placed the combustionchamber $A$ (Figs. 2 and 3).

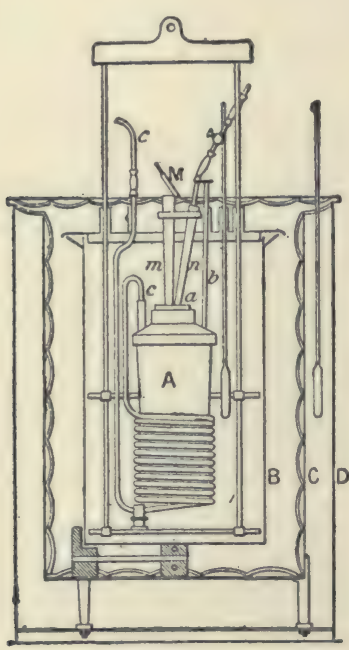

Fig. 2.

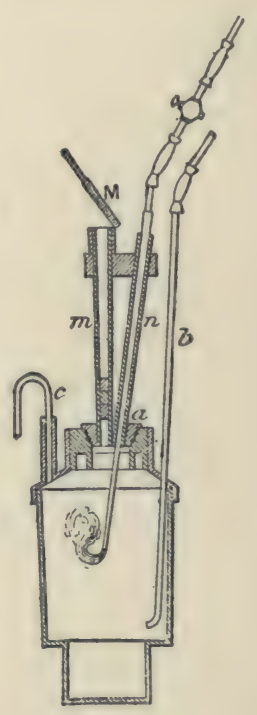

Fig. 3.

Favre and Silbermann Calorimeter.

The combustion-chamber is of burnished gilt copper, and is shown in Fig. 3. It is a slightly conical vessel, the large opening in which receives a stopper from which is suspended the burner made of a material suitable to that of the substance operated on. The stopper itself carries two tubes, $m$ and $n$, the first being an observation tube for the combustion, and is surmounted by a mirror. $M$, which allows examination during the burning. The mirror receives light by the tube $m$, which is closed by an athermanous system of quartz, alum, and glass. The other tube, $n$, carries the jet for the oxygen. Tube $b$ is closed, or removed during the test with coal, as it is of no use then. Tube $c$ serves as the exit for the waste gases of the combustion, which pass through the coil $c c$ (Fig. 2) before reaching the analytical apparatus. This coil 
is sufficient to cool the gas to the temperature of the bath. Experimenters should solder the oxygen-jet to the stopper so as to diminish the number of openings. It is also advantageous to solder the coil to the cover.

Certain fuels with very smoky flames require the addition of oxygen very near their surfaces. ScheurerKestner and Meunier-Dollfus employed the following arrangement (Fig. 4), $a$ being the platinum capsule; $c c^{\prime}$, the platinum tube, which at the part $c$ fits tight in the mouth of the oxygen-jet; $b, b, b$, platinum suspension-rods; $d$, fuel.

It is impossible to prevent the generation of more or less hydrocarbons and carbonic oxide. The weight of the hydrogen and carbon is determined by causing the gaseous products of combustion to pass through an organic analysis tube, after removing the water and carbonic acid. For this purpose the exit-tube $c$ (Fig. 3 ) is con-

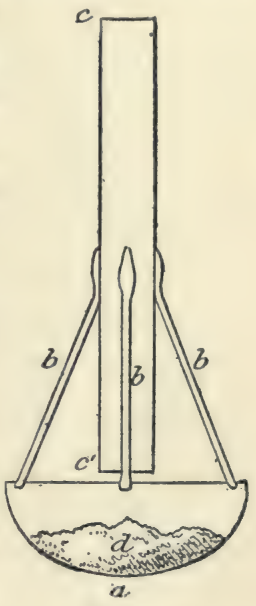

FIG. 4. nected by a caoutchouc tube with a Liebig apparatus, followed by a U-tube of soda-lime.

The gas-current being rather rapid, an absorption apparatus must be used, large and powerful enough to completely free the gas from the carbonic acid and water before it reaches the red-hot copper oxide. This is done by passing the gases through another U-tube smaller than the preceding, and whose weight should vary only a few milligrams. The gases thus freed pass to the tube of hot copper oxide, where the combustible gases are burnt to water and carbonic acid, which are collected and weighed as usual.

Scheurer-Kestner and Meunier-Dollfus employed a platinum combustion-tube, and prefer soda-lime as absorbent for the water after the conclusive experiments by Mulder.*

* Zeitschrift für analytische Chemie, I. 4 . 
The coal for the experiment must be in pieces; if in powder, the combustion is more difficult, unburnt gases escaping in considerable quantities, so that it is rare to obtain a complete combustion, and the cinders almost invariably contain small quantities of coke. To determine these, the capsule and tube are withdrawn from the combustion-chamber, dried, and weighed. The coke and the little soot on the sides of the capsule are burnt off by calcination in the air and a new weighing made, giving the weight of the carbon and cinder-elements which must be considered in the corrections. From half a gram to a gram of coal may be used.

When the combustion-chamber containing the weighed substance is put into the calorimeter all the parts of the apparatus are connected by caoutchouc joints and tested. A slow current of oxygen* from a gas-holder is passed through the apparatus. The combustible is ignited by a few milligrams of burning charcoal, the joint in the tube being broken for the moment, and immediately reconnected without stopping the flow of oxygen. The little glass $M$ allows inspection of the combustion, the intensity of which can be regulated by the flow of oxygen from the gas-holder. The temperature shown by the thermometer is recorded each minute to obtain the data necessary for the correction spoken of above (pages I6 et seq.).

To calculate the heat-units developed by the combustion the following elements are needed:

I. Weight of the combustible used;

2. Weight of the carbon remaining in the cinders unburnt or as black;

3. Weight of the cinders;

4. Weight of hydrogen escaped unburnt;

* To prepare the oxygen a copper flask of one litre capacity is used, in which is placed some chlorate of potash, which is then heated by a gas flame. The gaseous current is very regular, except towards the end, when it may become tumultuous. The addition of a small percentage of black oxide of manganese promotes the regularity of the gas generation. 
5. Weight of carbon escaped unburnt in the gaseous products;

6. Elevation of temperature of calorimeter bath:

7. Correction for heating and cooling caused by external influences on the calorimeter cylinder.

The combustion of the coal by this means is rarely complete; there remain variable quantities of coke mixed with the cinders formed. An uncertainty attends the calorimetric value according as the combustion was slow or rapid, since this small quantity of coke contains more or less hydrocarbons. These differences, however, apply within very close limits, so that no fear need be entertained of large errors therefrom. When a coal, in pieces, has been burnt, there remains in the capsule only a few milligrams of coke or unburnt carbon. From this we calculate the calorimetric value, using 8080 as coefficient (heat of combustion of charcoal according to Favre and Silbermann); and in using that coefficient the hydrogen which may exist in the coke is naturally neglected, but this cannot be prevented. The carbon and hydrogen of the combustible gases which escaped combustion are transformed into water and carbonic acid, and weighed as such. The hydrogen is calculated as in the free state (coefficient 34500 ) and the carbon as carbonic oxide (coefficient 2435).

It is evident that these are only approximations, since the hydrogen is not disengaged in a free state, but as a hydrocarbon; and its coefficient ( 34500 ) should be diminished by the heat of formation of this compound, or, in other words, by the heat of combustion of hydrogen and carbon. This correction, however, is not possible; for neither the composition nor state of molecular condensation of such hydrocarbon is known. Similarly for the carbon, and its heat of combination in the carbon compound. There are, then, some uncertainties, but not of much importance, in the determination of the heat of combustion of fuels-uncertainties which the use of the calorimetric bomb has entirely avoided. 
A complete test will now be described, giving all the corrections.

Suppose one gram of dried coal in fragments is used. After combustion in the calorimeter, weigh the capsule containing the cinders.

Cinders after combustion.............. . I Io gram. " " calcination in the air...... 0.100 "

Unburnt carbon remaining in cinders... 0.010 “ Then

Coal used, dried at $100^{\circ} \mathrm{C} \ldots \ldots \ldots \ldots . . . . .1 .000$ gram. Cinders........................ 0.100 "

Pure coal (cinders out)............. 0.900 "

Carbon not burnt during the experiment.. 0.010 “"

There was collected from the combustion of the hydrocarbons and the carbonic oxide O.IO gram of carbonic acid, corresponding to 0.006 of carbonic oxide (molecular ratio I I : 7); also 0.010 gram of water, corresponding to 0.00 I I gram hydrogen (molecular ratio $9: 1$ ).

Increase of temperature of the bath $\ldots \ldots \ldots \ldots \ldots \ldots \ldots \ldots \cdots \cdots \cdots+702^{\circ}$

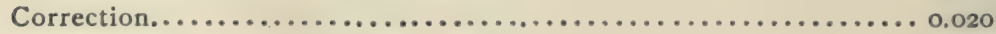

Total increase........................ $\overline{3.722^{\circ}}$

Calorimeter equiv, in water 2.114 kilos* and $3.722 \times 2.114=7.8683$

Unburnt carbon....................... $0.010 \times 8.080 \mathrm{cal} .=0.0808$

Carbonic oxide ........................... $006 \times 2.403 "=0.0144$

Hydrogen........................... $0.0011 \times 34.500 "=0.0383$

Total calories from 0.900 gram coal completely burnt $=\overline{8.0018}$

I gram pure coal $=8.89 \mathrm{I}$ calories,

I kilogram pure coal $=889$ calories, or

I pound " " $=16003.8 \mathrm{~B}$. T. U.

* 2000 grams of water + II 4 grams for value in water of calorimeter and accessories. 
In this example the corrections are not very important, since they do not exceed one-half per cent. These are the ordinary conditions when the coal used is in pieces. With pulverized coal, on the contrary, the quantity of unburnt carbon and of combustible gases increases considerably and renders results less certain. The opportunity we have to weigh the cinders of each test obviates pulverization of the coal to obtain an average sample of the cinders.

Favre and Silbermann's calorimeter has been modified by Berthelot in several particulars. ${ }^{*}$ He has happily modified the agitator and given it a coiled form, as shown in Fig. 5, a detailed description of which is given in his Essai de Mécanique Chimique, p. 145 .

This agitator has the advantage over the old one of more completely mixing the water, with less force, and without accelerating evaporation. Fig. 5 shows it placed in the middle of the calorimeter.

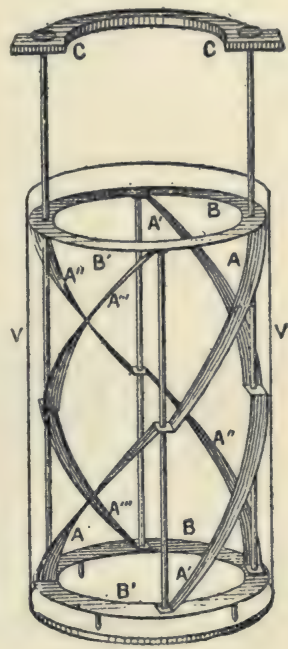

FIG. 5 . $\mathrm{He}$ has also replaced the gold-plated copper combustionchamber by the glass apparatus which Alexejew used for combustibles.

* The F. \& S. calorimeter with all accessories and an agitator (not mechanical) costs about 500 francs $(\$ 100.00)$; with mechanical agitator arranged for a laboratory turbine or dynamo the cost is about 600 francs ( $\$ 120.00)$. Berthelot's calorimetric bomb of platinum, enamelled inside and not double, costs no more, and is much preferable. A single operator can handle it, while the $\mathrm{F}$. \& S. apparatus requires two.

Nevertheless, the manner of working the F. \& S. calorimeter is described in detail, because its use is surrounded by conditions easily realized in all countries. The calorimetric bomb requires oxygen compressed to 25 atmospheres, which cannot be obtained everywhere. 


\section{ALEXEJEW'S CALORIMETER.}

The apparatus used by Alexejew was composed of a glass combustion-chamber $A$ (Fig. 6), in which he burnt the coal

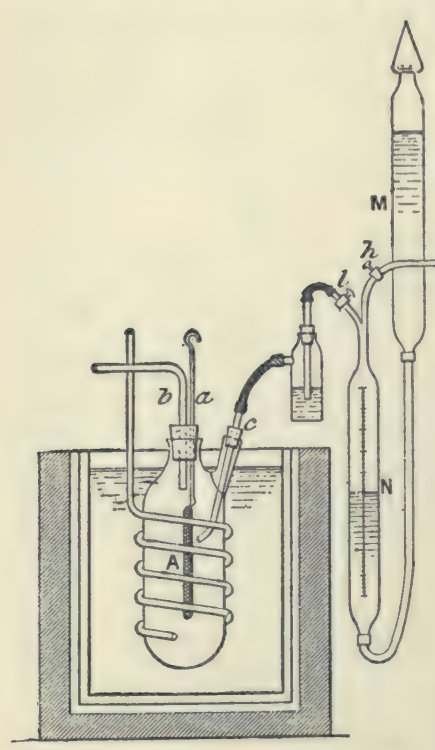

Fig. 6.-Aiexejew CalorimETER. previously reduced to fragments. These fragments were placed on a platinum grating in the centre of the chamber. The fuel was kindled by means of a platinum sponge placed over it, on which impinged a jet of hydrogen from the gasholder $M$, opening at $c$, correction for which is of course made in the calculation. The grating containing the fuel was suspended from the glass rod $a$. As soon as the combustion was started the current of hydrogen was cut off by the cock $l$, and the oxygen allowed to flow in through $b$, the waste gases passing out through the coil. If the combustion was interrupted, it was rekindled by the hydrogen and platinum sponge. The hydrogen used was calculated in grams and multiplied by 34500 . The number of calories thus obtained was deducted from that calculated from the rise in temperature of the bath. According to Alexejew, the importance of this correction never exceeded one-half per cent, and he never had to rekindle the fuel.

Alexejew did not determine the unburnt gases, as experience showed they never exceeded 0.35 per cent. It is impossible, however, to determine the hydrogen of the hydrocarbons if desired, as these would be mixed with the hydrogen used for kindling, part of which may escape combustion. The kindling with hydrogen might, however, be replaced by that with carbon, as in the F. \& S. apparatus. 
Burning the fuel on a grating renders it impossible to weigh the cinders, and this inconvenience is of more importance as the coal is used in pieces. The use of pastilles is not possible, as they splinter in burning.

The calorimeter contained 2500 grams (5.5 I I lbs.) of water, a quantity somewhat larger than that usually employed, and which is based on the sensibility of the thermometer. To attain the same degree of precision it was necessary to use larger samples of fuel or else have more delicate thermometers. The water was kept in motion by the coil-agitator.

\section{FISCHER'S CALORIMETER.}

Fischer made a combustion-chamber of silver 0.940 fine, so that it would be less easily attacked by sulphur, from which the gaseous products of coal are rarely free. He drew off the waste gases at the bottom of the apparatus (Fig. 7), thus avoiding the inconvenience of exit-tubes in the cover of the combustion-chamber. The coolling coil was replaced by a flattened pipe of a certain size. $A$ represents the combustion-chamber. The oxygen, purified by passing over potash and then dried, arrived by the tube $a$ fastened in the tube of the cover by a caoutchouc joint, and passed by means of the platinum tube $r$ into a crucible $\dot{z}$ of the same metal, containing one gram of the fuel. The crucible was covered by a grating, which became red-hot towards the end of the operation. This was intended to burn the

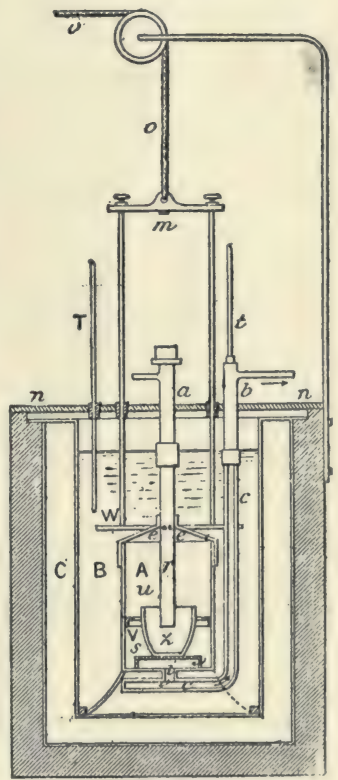

FIG. 7.-FISCHER'S CAI. ORIMETER. waste gases, and the black deposited at the beginning. The gases flowed out at $i$, and after having encircled the outside 
of the crucible escaped at $\dot{b}$. The thermometer $t$ showed whether the temperature of the gases was the same as that of the bath.

The calorimetric bath contained 1500 grams $(3.3 \mathrm{lbs}$.$) of$ water, and was protected against external influences by a wood casing, while the space $C$ was filled with glass wool; but this is not necessary. $n$ is a brass cover which may be dispensed with. The thermometer $T$ is the calorimetric thermometer; $m$ is an agitator moved by the string $o$. The value in water of the one used by Fischer was I 13.5 calories. The coal was dried in nitrogen. The carbonic acid and the unburnt carbon were determined.

\section{THOMSEN'S CALORIMETER.}

This calorimeter was designed especially for tests of gases and vapors. It is not adapted to tests of solid fuels. It

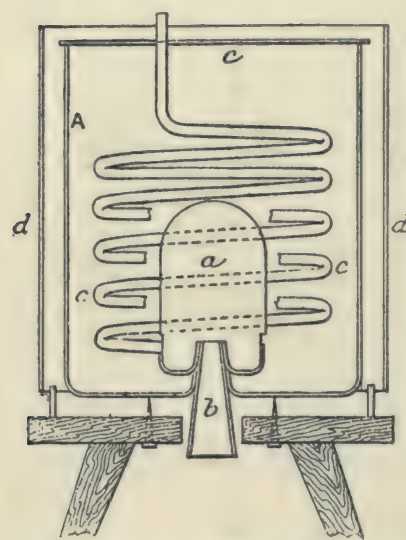

Fig. 8.-Thomsen CaloRIMETER. consisted (Fig. 8) of a calorimetric bath of thin brass, with a capacity of some 3 litres (I95 cubic inches), protected from radiation by a cylindrical ebonite envelope; and a platinum balloon of half a litre $(32.5$ cubic inches) capacity, in which the gases were burnt, being delivered through the opening at the bottom.

The waste gases passed off through a coil, and a mechanical agitator kept the water in circulation.

The dried gas was delivered with perfect regularity from a mercury gas-holder, sufficient air or oxygen being added to render it free-burning, and enough oxygen was supplied to insure perfect combustion. This he attained by always having 40 to 50 per cent in the 
waste gases. The gases passed off through a carbonic acid absorbing apparatus.

To reduce to the minimum, or entirely suppress, the correction for temperature he regulated his gas-flow so that the temperature was as much higher than the air at the close of the experiment as it was lower at the beginning. This he easily did by means of his hydrogen supply. If a liquid was tested, it was vaporized and burnt in a specially devised burner which allowed complete combustion of almost all compounds not having too high a boiling-point. If too high for heat vaporization, they were carried along by a current of air, oxygen, or hydrogen, as seemed best adapted.

The water of the calorimeter being weighed, the lower portion was closed with a rubber stopper and by means of an aspirator a pressure of 8 to 12 inches of water was put on the apparatus to test the joints. When ready, the temperature of the bath and the air was noted for some minutes, the gasholder reading taken, the burner placed in position, and the test commenced. The depression produced by the aspirator was about 0.4 inch during the whole test. The regularity of the working was shown by a gauge registering the pressure. When the temperature had reached the desired point the gas and electric current were shut off, the burner removed, and the opening closed again. The aspirator was used to draw dry air, freed from $\mathrm{CO}_{2}$, through the apparatus to insure removal of all waste gases. The apparatus was then allowed to rest, taking the temperature at short intervals for fifteen minutes. He then had all the data required.

\section{CARPENTER'S CALURIMETER.}

Prof. R. C. Carpenter devised a calorimeter especially for coal determinations, which is a modification or extension of Thomsen's. He has used it considerably in connection with work he has been engaged on, and the results credited to him in the tables at the end of the book were obtained with it. 
Fig. 9 is a sectional view of his apparatus. It consists of a combustion-cylinder, 15, with a removable bottom, I7,

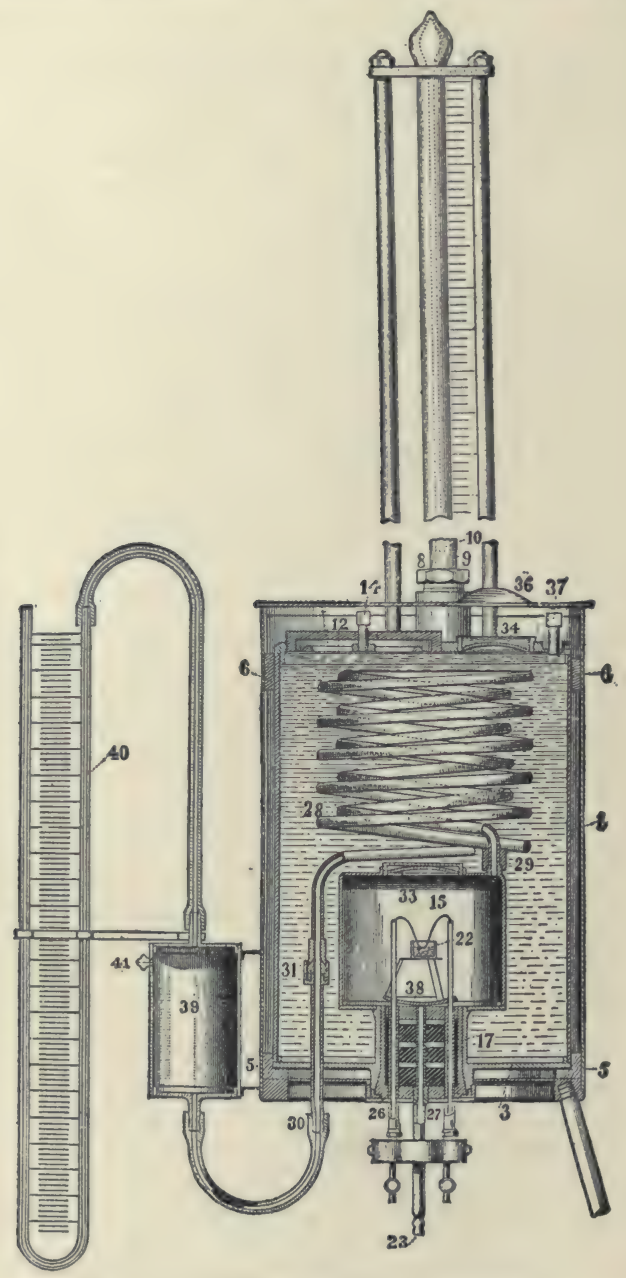

Fig. 9.-Carpenter Calorimeter.

through which passes the tube, 23 , to supply oxygen, and also the wires, 26 and 27 , to furnish electricity for the igniter. It also supports the asbestos combustion-dishes, 22, used for 
holding the fuel. At its top is a silver mirror, 38, to deflect the heat. The plug is made of alternate layers of asbestos and vulcanite. The products of combustion pass off through the spiral tube, 28, 29, 30, $3 \mathrm{I}$, which is connected with the small chamber, 39, attached to the outer case of the instrument. This chamber has a pressure-gauge, 40, and a small pinhole outlet, $4 \mathrm{I}$. Outside the chamber is the calorimetric bath, I, which is connected with an open glass gauge, 9, IO. Above the water is a diaphragm, I2, used to adjust the level.

The calorimeter has an outer nickel-plated case, polished on the inside. The bath holds about 5 pounds of water, and uses about 2 grams of coal at a time. It is thus considerably larger than the bomb, and the charge being larger the time consumed by the test is longer, being some ten minutes for each gram burnt. The entire outside dimensions of the case are $9 \frac{1}{2}$ inches high and 6 inches diameter.

In using the apparatus the coal is ground to a powder in a mill or mortar. The asbestos cup is heated to burn off all organic matter and weighed. The sample is then placed in it, and the whole weighed again. This gives the weight of the coal used. Place it in the combustion-chamber, raise the platinum igniting wire above the coal, make the connections with the battery, and as soon as the heat generated causes the water to rise in the glass tube turn on the oxygen, and by pulling down the wires kindle the coal. At this instant the reading on the glass scale must be taken.

By means of the glasses 33,34 , and 36 watch the progress of the combustion, and as soon as finished take the scale-reading and the time. The difference between this scale-reading and the one previously made is the "actual" scale-reading.

To correct for radiation, allow the apparatus to stand with the oxygen shut off for a length of time equal to that of the combustion, and take the scale-reading and the time. The 
difference between this and the "actual" reading is to be added to the " actual" for the " corrected" reading.

Now, by inspection of the calibration-curve previously prepared, at the point corresponding to the corrected scalereading will be found the $B$. T. U.'s for the quantity burnt. The ash is determined by weighing the asbestos cup after the combustion.

The following shows all the calculation needed:

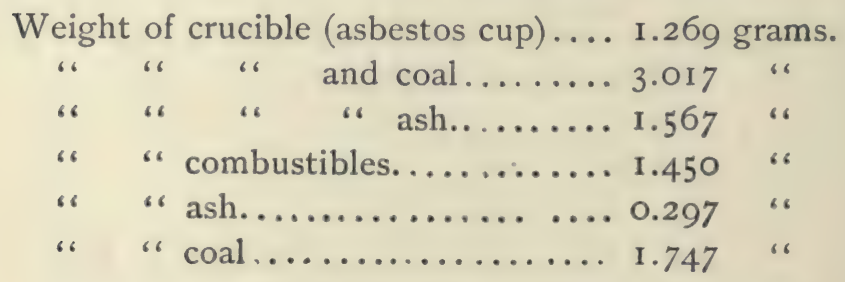

I.747 grams $\times 0.002205=0.003852$ pounds.

First scale-reading...... 3.90 inches; time 2 hrs. $55 \mathrm{~m}$. Second " " $\ldots . . .14 .70$ " " 34 " 20 " Third " " ...... 14.30 " " 3 " 45 “ "Actual" scale-reading. 14.70 - 3.90 = 10.80 inches. Radiation correction..... 14.70-14.30 $=.40$

Corrected reading.............. I I.20 "

On the calibration-sheet II.2 corresponds to 46.25 B. T. U.'s, and 46.25 B. T. U. $\div 0.003852=12000$ B. T. U. per pound.

All air must be removed from the water in the bath, the apparatus must work at a constant pressure, and the pressure for which it is calibrated. A pressure of 10 inches of water has been found satisfactory. Complete combustion is always attained in the asbestos cups.

It will be seen that the use of thermometers is obviated, and also all corrections but one. The apparatus is intended 
for ordinary every-day work, and will give good comparative results when used according to directions, which must be implicitly followed. The amount of calculation is reduced to a minimum, and there are no delicate parts requiring extra care and adjustment. For the purpose intended, it seems an advance over the others previously used, which could never give more faint approximations to correct results.

\section{SCHWACKHÖFER'S CALORIMETER.}

In 1884 Schwackhöfer published calorimetric researches on different kinds of coal, using a calorimeter in which he made

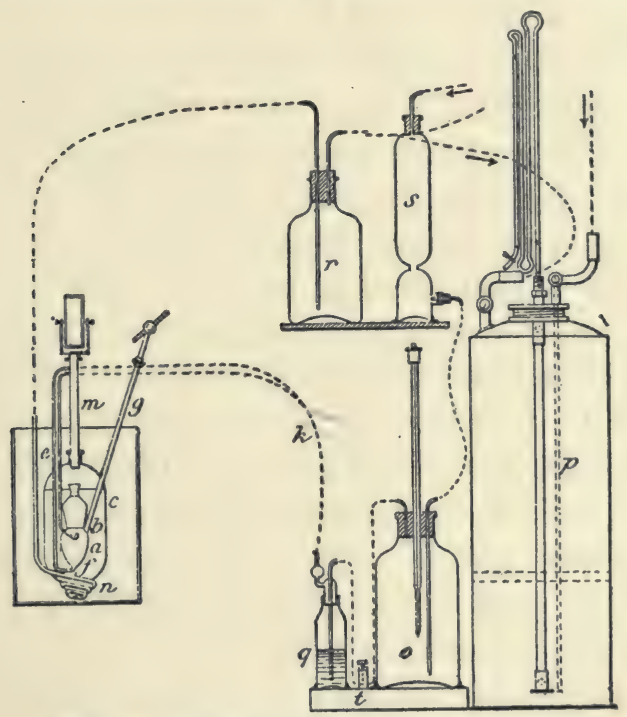

Fig. ro.-Schwackhöfer Calorimeter.

several modifications intended to render it specially applicable to such fuel.

He considered it advisable to use as much as five or six grams of coal, which is six times that generally used. $\mathrm{He}$ burnt at the same time and under definite conditions, shown 
in the sketch (Fig. IO), a certain quantity of sugar-charcoal, the combustion of which was intended to accelerate and complete that of the coal tested.

In the figure (Fig. IO) $a b$ represents the combustion-chamber, $c$ the calorimetric bath. Minor details of accessories, envelopes, regulators, etc., are omitted. The burner proper is of platinum and of two pieces, $a$ and $b$, superimposed, the coal being placed in the lower portion, the sugar-charcoal in the upper one. All pieces of the burner may be removed for the introduction of the coal and for cleaning. The two combustibles rest on perforated plates of platinum, in which the perforations, made by a special machine, are so small that light can hardly pass through, and from which the cinders can be completely removed; the holes in the upper one are slightly larger than those of the lower. The oxygen enters through three tubes, $e, f, g$. Tubes $g$ and $m$ pass outside the bath, and carry mirrors to allow inspection during the burning. The waste gases pass off at the bottom through a coil $n$, and are collected in $H$. This vessel is simply to detect smoking, he having found that it happened only when the pressure was diminished at the burner, and that it could be stopped by a reinstatement of the normal pressure. $p$ represents an aspirator, in which are collected the waste gases. Another one, not shown in the sketch, serves to contain the gas analyzed. Both are filled with water covered with a film of oil. The oxygen passes through a jar $s$ filled with soda-lime, a bottle $o$ furnished with a thermometer, a cock $t$ as regulator of the flow, and one or more wash-bottles $q$ containing sulphuric acid.

The calorimeter-chamber $c$ contains $5200 \mathrm{cc}$. (4.6 qts.) of water. 5 or 6 grams ( 77 to 92.5 grains) of coal were used, with 2 to 4 grams (3 I to 62 grains) of sugar-carbon of a known calorific value. The temperature of the bath rose about $10^{\circ}$ C., and the experiment generally lasted an hour.

The sugar-carbon was first kindled in the upper part of the burner, the under portion burning first. From this sparks 
were thrown to the coal, and it soon kindled. The oxygen flowed in by $g$ and $e$. When combustion was well under way and had reached the lower portions of the coal, $g$ was shut off and $f$ opened.

Schwackhöfer obtained complete combustion of the sugarcarbon and coal, with no formation of black, and no residue of coke.

The gaseous product of the combustion was generally of the following composition:

Carbonic acid........... 50 to 60 per cent;

Carbonic oxide .......... 1.2 to 0.3 " "

Oxygen.............. 10 to 15 " "

Nitrogen.. ......... 30 to 40 " " "

arising principally from the fact that to keep up the normal pressure the combustion-chamber was in communication with the open air. The cinders were weighed after each test.

This apparatus should give exact results, but its use is complicated. The long duration of the test requires important corrections for influence of external heat, and it needs several thermometers.

\section{W. THOMPSON'S CALORIMETER.}

W. Thompson devised a calorimeter in which the combustion is started by a jet of oxygen, but the waste gases instead of passing through a coil bubble up through the water of the calorimetric bath. In this apparatus the uncombined gases are naturally neglected. (See Fig. II.) It is an apparatus, as the inventor says, not intended for scientific researches, but for handy use of mechanics or " for popular use."

$a$ is a galvanized-iron gas-holder containing oxygen; $b$, a stop-cock regulating the flow of water to this holder; $d$, stopcock for gas; $e$, rubber tube; $f$, level-gauge; $g$, pressuregauge; $h$, bell-glass covering the platinum crucible $k$, in which the coal is burnt; $l$ is a support of earthenware suspended 
from the bell-glass by metal springs, and intended to insulate the crucible and prevent too quick cooling; $m$ is a glass jar containing 2000 grams ( $4.4 \mathrm{lbs}$.) of water, forming the calorimetric bath. Water cannot enter the bell $h$ while the cock $j$

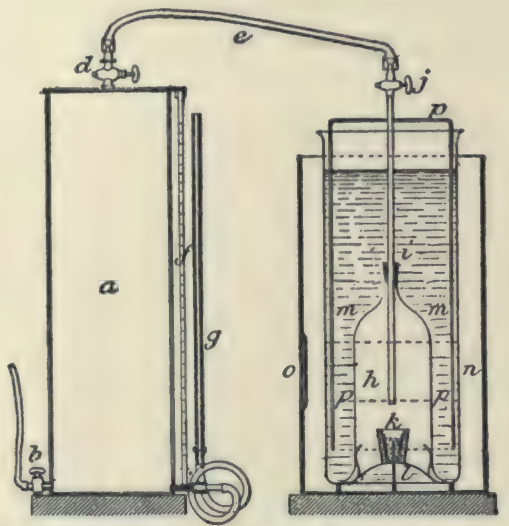

Fig. II.-W. Thompson CAlorimeter.

is closed, and it is opened only when the pressure in the gas-holder is sufficient; $n$ is a glass jar filled with water and surrounding the calorimetric jar, and $p$ is the agitator.

One gram of fuel is put into the crucible, and on this is placed a small cotton wick impregnated with bichromate of potash. This is lighted at the instant of putting into the jar, and its combustion aided by the oxygen kindles the fuel.

This is an imperfect apparatus, and will give in most cases only unsatisfactory results. Still it is in rather common use in the shops of England, where it serves principally as a comparative measure, the errors being considered constant.

\section{BARRUS'S CALORIMETER.}

The Barrus calorimeter is a modification of the one just mentioned. While it requires considerable care in using to get correct results, yet it is one of the simplest and most inexpensive. 
As described by Mr. Barrus, " it consists of a glass beaker (Fig. I2) 5 inches in diameter and II inches high, which can be obtained of most dealers in chemical apparatus. The combustion-chamber is of special form, and consists of a glass bell having a notched rib around the lower edge and a head just above the top, with a tube projecting a considerable distance above the upper end. The bell is $2 \frac{1}{2}$ inches inside diameter, $5 \frac{1}{2}$ inches high, and the tube above is $\frac{3}{8}$ inch inside diameter and extends beyond the bell a distance of 9 inches. The base consists of a circular plate of brass 4 inches in diameter, with three clips fastened on the upper, side for holding down the combustion-chamber. The base is perforated, and the under side has three pieces of cork attached, which serve as feet. To the centre

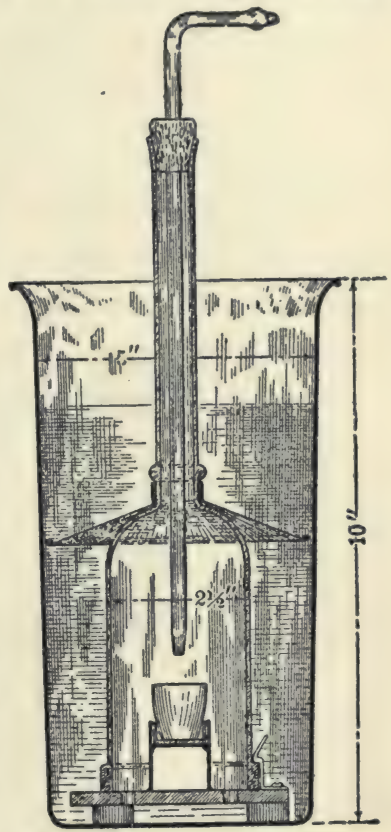

Fig. I2.-BARRUS CALORIMETER. of the upper side of the plate is attached a cup for holding the platinum crucible in which the coal is burned. To the upper end of the bell, beneath the head, a hood is attached made of wire gauze, which serves to intercept the rising bubbles of gas and retard their escape from the water. The top of the tube is fitted with a cork, and through this is inserted a small glass tube which carries the oxygen to the lower part of the combustion-chamber. This tube is movable up and down, and to some extent sideways, so as to direct the current of oxygen to any part of the crucible and to adjust it to a proper distance from the burning coal."

The method of working it can be easily seen from the description and cut. In burning very smoky coals he mixes 
them with a proportion of non-smoking coal of known calorific value, and when anthracite or coke is burnt he mixes it with a small portion of bituminous coal. In Mr. Barrus's hands very satisfactory results have been obtained.

\section{HARTLEY AND JUNKER'S CALORIMETER.}

Hartley's calorimeter is an apparatus of constant pressure and continued combustion. The gas measured by a meter is burnt in a Bunsen burner surrounded by a cylindrical copper

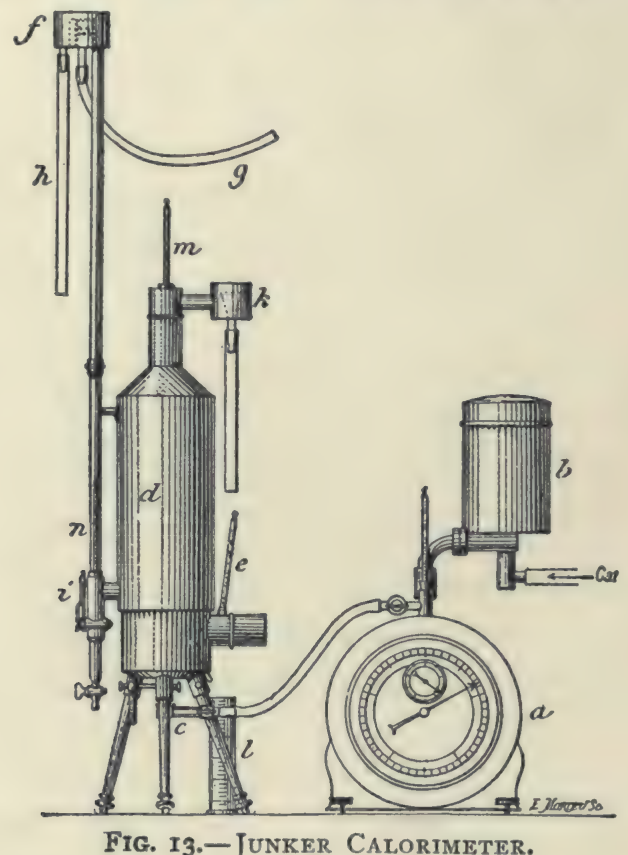

vessel filled with water, which is constantly renewed. The flow of liquid is such as to avoid much heating and time sufficient is used to increase the temperature so as to have a good thermometric observation. The volume or weight of the water is determined at such intervals and the thermometric readings taken often enough to obtain an average. 
Hugo Junker's modification of the apparatus rendered it more exact. It has been used for some time in Germany and in the United States. It is composed (Fig. I3) of a gas-meter $a$, preceded by a very sensitive regulator $b$. On leaving the meter the gas passes to a Bunsen burner $c$. The products of combustion give up their heat to a calorimetric tube $d$, through which regularly flows a stream of water. The temperature of the gases is regulated by means of a thermometer $e$. In order to keep the flow of water as regular as possible, it flows from the supply-tube $g$ into a small reservoir kept at a constant level governed by the tube $h$. The water passes through $i$ to the calorimeter and escapes at $k$, running into the glass in which it is measured or weighed. The graduated tube $l$ is to catch the condensed water from the interior of the calorimeter. The thermometer $m$ shows the heat of the escaping water, and $n$ that of the water entering the calorimeter.

To calculate the calories generated during the combustion proceed as follows:

Measure the quantity of water which runs through it in one minute, take the temperature of the two thermometers, and note the flow of gas. The heat of combustion per cubic metre of burnt gas is obtained by multiplying the volume of water flowing per minute by the difference of the two temperatures and dividing the product by the gas volume burnt per minute.

Thus:

Volume of water flowing per minute... $902.3 \mathrm{cc}$.

" " gas burnt per minute...... $2500.0 \mathrm{cc}$.

Temperature at inlet............. I $3.1^{\circ} \mathrm{C}$.

" " outlet............ $27.5^{\circ} \mathrm{C}$.

$$
Q=\frac{902.3 \times(27.5-13.1)}{2.5}=5196 \text { calories. }
$$


The gas tested has a value of 5196 calories per cubic metre.

Since the calorie is 3.968 times the B.T.U., and the cubic metre is 35.316 times the cubic foot, multiplying the calories per cubic metre by $\frac{3.968}{35.316}=0.11235$ will give B. T. U.'s per cubic foot.

Multiplying, then,

$$
5196 \times 0.11235=583.8 \text { B. T. U.'s per cubic foot. }
$$

The above example considered the volume of the water. It is sometimes advisable to consider the weight instead. The following example illustrates this:

Weight of water used during the test... 2000 grams.

Volume of gas burnt............. 7.23 litres.

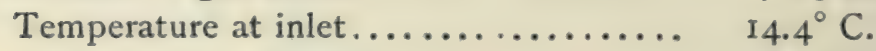

“ “ outlet.............. $36.5^{\circ} \mathrm{C}$.

Then

$$
Q=\frac{2000 \times(36.5-14.4)}{7.23}=6102 \text { calories per cubic metre, }
$$

and

$6102 \times 0.11235=685.6$ B. T. U. per cubic foot.

Two causes of error may occur. It is not certain that the combustion of the gas in the burner is regular; indications by gas-meters are not always very sure, the start being capricious. But these do not have much weight in its use for industrial purposes, for which it is chiefly designed. The results are very near those obtained by other methods. Stohmann, whose competence in such matters is universally recognized, says they give good results.

Bueb-Dessau, to prove the calorimeter, burnt hydrogen prepared by electrical decomposition, and obtained after corrections for thermometer and barometer 34I50 calories per 
kilogram-a difference of 350 calories from the usual number, 34500 , or only 9 thousandths.

Prof. Jacobus has determined that there is a constant error due to neglect of latent heat of moisture in products of combustion of -2 per cent in the determinations with this apparatus; otherwise it is very satisfactory.

\section{LEWIS THOMPSON'S CALORIMETER.}

Lewis Thompson's calorimeter has been used in England for some time. It gives only approximate results, but as the errors are of the same kind in each case, the results are comparable, and it has been found serviceable in industrial works where quick and comparative observations are required.

The apparatus (Fig. I4) is composed of a glass calorimeterbath $H$ containing water, a copper cylinder $E$ in which the

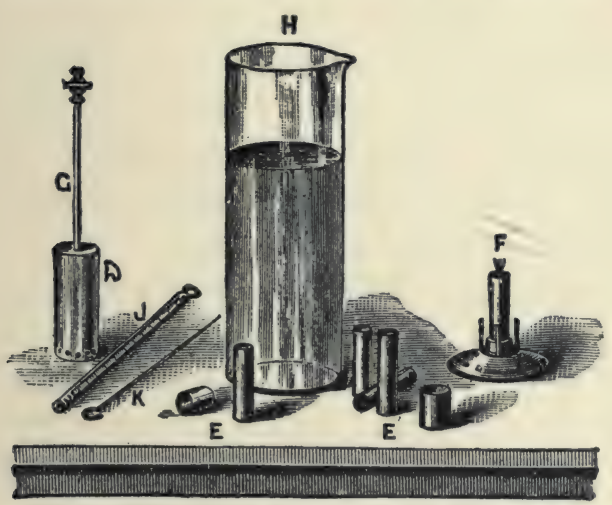

Fig. I4.-L. Thompson Calorimeter.

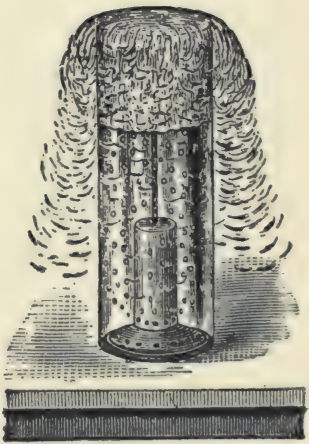

Fig. 15.-CAlorimeter in ACtion.

mixture of coal and potassa chlorate is placed, and surmounted by the nitrate of lead fuse $F$. Enclosing this cylinder is a bell $D$, having a tube $C$ carrying a stop-cock. The cock is closed before putting it in position in the water. $K$ is a cleaner for the tube $C$, and $J$ is a thermometer. 
The fuze is lighted, and the whole quickly put in the jar of water. The mixture of combustible and potassium chlorate soon ignites and burns, all the gases generated being forced out at the bottom of the bell through the perforations, and bubble up through the liquid. After the combustion is finished the temperature is taken and the heat-units calculated.

From 8 to 10 parts of oxidizing mixture is recommended for one of coal; but if the coal is very rich this must be increased to I I parts, calculated on the crude coal. With pure coal, cinders out, the extreme limits are II and I4 parts. It would probably increase the accuracy of the mothod, if the same quantity of oxidizing mixture was employed, whatever the kind of coal used, and to mix with it inert substances, as silica or ground porcelain, in quantity varying with the richness of the coal.

Scheurer-Kestner tested this apparatus very carefully, using a great variety of fuels whose heats had been previously ascertained by means of Favre and Silbermann's calorimeter. He found some 15 per cent deficit in the figures, and after correcting by this amount the results varied only a few per cent from those actually obtained. In thirty different kinds of coal tested the average was I. 8 per cent too low.

The use of this calorimeter requires some skill. Its imperfect insulation requires prompt reading and rapid combustion. Care must be taken to work at temperatures very close to that of the room, as the calorimetric bath is not protected. The proportions of the mixture used vary, not only with each kind of coal, but for each sample, on account of the proportions of cinders. Fat coals require more oxidizer than lean coals, as it is evident an increase in quantity of cinders should require a decrease in oxidizer. But in changing the proportions of oxidizer a certain difference in elevation of temperature is necessarily produced by the heat of solution of the salts left after the combustion. These various causes render its working rather delicate, and always uncertain. 


\section{CHAPTER V.}

\section{CALORIMETERS WITH CONSTANT VOLUME.}

THE results obtained with a calorimeter of constant volume are not exactly the same as those obtained with one of constant pressure; but for solid or liquid substances the difference is too small to consider, since the volume, as well as that of the water produced, is inconsiderable in relation to the volume of gas employed. As regards the correction for contraction and expansion of the gases, they also are inconsiderable.

In his Traité de Mécanique Berthelot has shown that the heat generated by a reaction between gases at constant pressure is equal to the heat of combination at constant volume at any temperature whatever, increased by the preceding product counting from absolute zero; and he gives the following formula for passing from one system to the other:

$$
Q T_{p}=Q T_{v}+0.5424\left(N-N^{\prime}\right)+0.002\left(N-N^{\prime}\right) t
$$

$Q T_{p}$ being the heat generated by the reaction at constant pressure, and at the temperature $T$ counting from ordinary zero; $Q T_{v}$, the heat generated by the reaction at same temperature and constant volume; $N$, the number of units of molecular volume occupied by the components, these being taken according to usage equal to 22.32 litres under normal pressure at $0^{\circ} ; N^{\prime}$, the corresponding number of units of molecular volume occupied by the product of the reaction.

As example, take the combustion of carbonic oxide at $15^{\circ}$. Then we have

$$
\mathrm{CO}+\mathrm{O}=\mathrm{CO}^{2} \text { generates at constant volume } 68 \text { calories. } *
$$


To pass from this to the heat given off under constant pressure, observe that $\mathrm{CO}$ occupies a unit of volume and $\mathrm{O}$ a half unit. Then

$$
\mathrm{N}=\mathrm{I} \frac{1}{2}
$$

$\mathrm{CO}_{3}$ occupies a unit of volume and

$$
\begin{array}{r}
N^{\prime}=\mathrm{I} . \\
\text { Hence } \quad \mathrm{N}-\mathrm{N}^{\prime}=\frac{1}{2} .
\end{array}
$$

At $0^{\circ}$ there would be, then, for the difference between the heat of combustion at constant pressure and that at constant volume,

$$
+0.542 \times \frac{1}{2}=+0.271 \text { calories. }
$$

At $+15^{\circ}$ add to this +0.015 , which increases the correction then to 0.286 . The heat of combustion of carbonic oxide at constant pressure and $15^{\circ}$ is then +68.29 calories.

With a solid or liquid, this volume in relation to those of the gases formed may be practically neglected, the same as with the water; all reduce then ta the contraction and expansion of the gases. Thus, for naphthalin, this correction does not exceed 8.8 in 9692 calories-less than o. I per cent.

In case of solids or liquids with unknown molecular weight, as with fuels generally, this difference may still be approximately calculated, as it is sufficient to know the volume of oxygen used in the combustion and that of the gases produced.

The first calorimeter of constant volume in date is that of Thomas Andrews, who in I 848 published results obtained with a closed calorimeter. The calorimeter was not applicable to solids or liquids; the combustion of the gases was conducted as in a eudiometer, but he did not take all the precautions necessary to be certain of complete combustion. 
Nevertheless, the results obtained for certain gases are remarkable, considering the elementary character of his apparatus and working. The combustion of solids, on the contrary, gave worthless results.

The calorimetric bomb of Berthelot and Vielle seems able to replace advantageously all the other calorimeters as much by its convenience as by its certainty of results.

Aimé Witz made certain changes in the bomb designed to facilitate its use, and devised his "calorimetric eudiometer," in which only gases can be burnt. The apparatus is more convenient than the bomb, but this convenience has been gained at a sacrifice of precision. It is more an instrument for practical use than a scientific calorimeter, but may be useful within narrow limits.

\section{ANDREWS' CALORIMETER.}

In 1848 Andrews published his labors on the heat of combustion of bodies, and notably on that disengaged $\mathrm{h}$. combustion of different gases. He used a calorimeter of constant volume, in which the combustion-chamber was a copper cylinder (Fig. 16) weighing I 70 grams (6 ounces), of 380 cubic centimetres (about $23 \frac{1}{2}$ cubic inches) capacity, and capable of resisting the pressure exerted by the combustion of the same volume of olefiant gas $\left(\mathrm{C}_{2} \mathrm{H}_{4}\right)$ with oxygen.

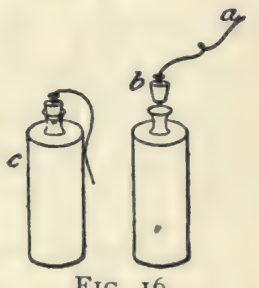

ANDREWS' CALORIMETER.

At the upper part, the cylinder had a small conical tube closed by means of a perfect-fitting stopper $b$. A silver wire $a$ was fixed in this stopper, and to this was soldered a very fine platinum wire for igniting the gases by a galvanic current. The mixture of gases was prepared as for eudiometric analysis.

The combustion-chamber was entirely submerged in a glass cylinder filled with water, of which the temperature is 
regulated so as to compensate approximately for the probable use, and thus avoid corrections for influence of external air. This cylinder was put into another, also of glass. A rotary motion imparted to the cylinder aided circulation in the liquid during combustion, which usually lasted thirty-five seconds.

Andrews also applied his calorimeter to combustion of solids, but judging from the low results he did not have perfect combustion. The results obtained with some of the gases, on the contrary, are quite reliable, notwithstanding the imperfections of the apparatus.

\section{CALORIMETRIC BOMB OF BERTHELOT AND VIELLE.}

Of all the calorimeters known to-day, the calorimetric bomb of Berthelot is that which offers the most advantages, as much from its ease of operation as from the precision of its results. Only one operator is needed; the combustion is perfect; the gaseous products need not be analyzed to determine the combustible substance; no weight save that of the substance used is needed; and it is as applicable to solids and liquids as to gases.

True, its use requires oxygen under high pressure; but this pressure ( 25 atmospheres) may be readily obtained with a compression-pump, which is easily procured; and at the present time oxygen may be bought sufficiently compressed for the purpose. Berthelot states that as much as 5 or even Io per cent of nitrogen is allowable, but that the latter limit must not be exceeded.

Mahler used compressed oxygen, and obtained good results with that bought in the Paris market. This gas is furnished in steel tubes and under 120 atmospheres pressure. The cylinders contain sufficient gas to make a large number of experiments before the pressure falls too low, i.e., below 25 atmospheres. 
Fig. I 7 shows the bomb adjusted ready to place in the calorimeter. Full details of the construction will be found in Berthelot and Vielle's treatise, Sur la force des métiers explosives, vol. I, p. 245.

Fig. 21 shows the arrangement adopted by Berthelot to burn solids. The cylinder (Fig. I8) is lined with platinum, and constructed so as to resist a pressure of 200 to 300 atmospheres. It is furnished with a tight-fitting head (Fig. I 7) fastened exteriorly by a piece of steel (Fig. I9), clamped on the external face of the bomb by a screw-

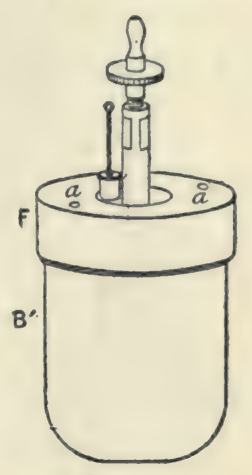

FIG. 17. clamp (Fig. 20), which does not form a part of the apparatus as immersed.

The sealing of the bomb results from the adherence of the margin of the head $B B$ (Fig. $2 \mathrm{I}$ ), and the interior of the cylinder, and also between the platinum of the head and the platinum of the cylinder. Berthelot makes the joint

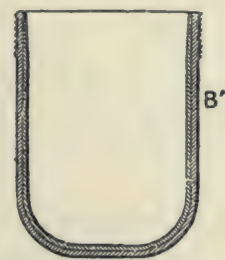

FIG. 18.

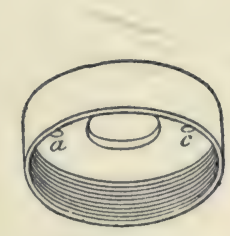

FIG. 19.

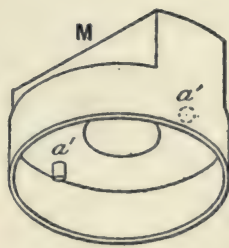

FIG. 20.

tight with a smearing of vaseline around the opening, being careful not to have a trace on the inside. If no bubbles escape on putting it into the calorimetric bath, the joints are tight.

The cover is pierced at the centre with a small hole, in which is fitted a tube formed of a hollow screw acting as a cock, and itself provided at the upper end with a circular head. The electric ignition is produced by a platinum wire 
fitting in an opening of the removable conical cover $E$. This is prepared (Fig. 2I) in advance, and is covered with a layer of gum lac applied in a strong alcoholic solution. When the

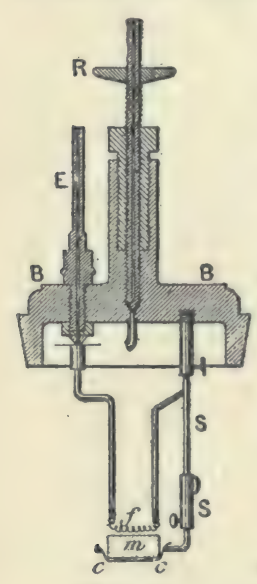

FIG. 21.

first coat is dry, a second one is put on and dried in a stove. Berthelot says that the combination of these two coatings, one elastic and soft, the other hard and brittle, resists very well the enormous pressure on the cone. This cone, lightly greased, is put into the conical opening in the bomb cover, and screwed up tight by means of a nut. It is well to protect the base of the cone by a film of mica.

An electric current passed through $E$ (Fig. 2I) reddens the spiral of very thin iron wire $f$ placed between the platinum wires and one of the supports $S S$ of the capsule $c c$ containing the substance $m$. This iron wire soon burns and kindles the combustible.

Fig. 22 gives a general and complete internal view.

The iron spiral is formed of an iron wire $\frac{1}{10}$ millimetre (0.004 inch) thick, rolled up on a spindle. The wire may be weighed, or by using the same length of wire always have the same weight.

The spiral is attached on one side to the cone, and on the other side by means of a platinum wire to the platinum supporting the fuel, taking care that the iron has no straight portions. The support of the capsule or platinum-foil is then fixed in the cover, by aid of the screw, arranging it so that the spiral is directly over the combustible used. The cover is put on, turning it gently to make the contact more perfect. The nut is tightened and the wire carefully screwed up, always using wooden tongs to prevent injuring the bomb.

The form of the bomb is such as permits filling the calorimeter with the smallest possible quantity of water-a neces- 
sary condition that the temperature, and consequently the precision, attain a high degree. For solids and also for coal Berthelot uses bombs containing 400 to 600 cubic centimetres (24 to 37 cubic inches), placed in a calorimeter of 2000 grams (4.4 lbs.) of water.

To determine the heat of combustion of coal, for instance,

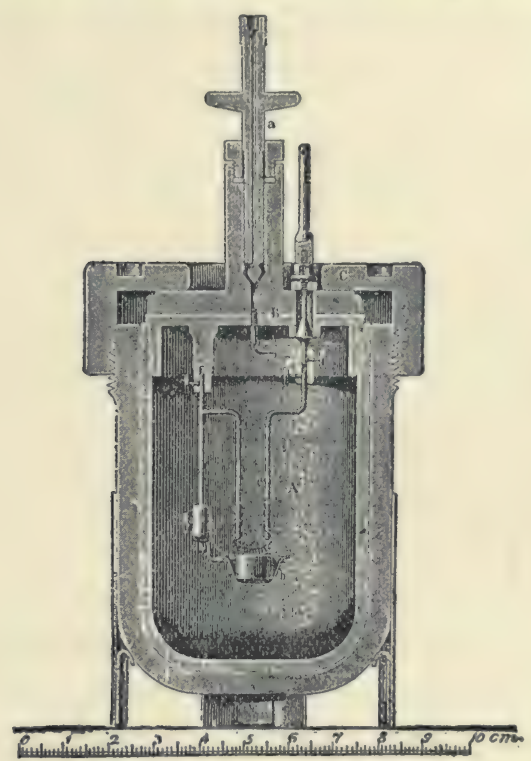

Fig. 22.-Berthelot Bomb.

it must be previously reduced to powder in order to have a sample whose cinder is known. As all kinds of coal do not burn completely in this state, they are formed into pastilles, * which are weighed and burnt. They are put on a platinum grating or foil, placed on the support SS (Fig. 2I), over

* We obtain very resisting pastilles or briquettes from fat coals by simple compression in a pastille or suppository mould such as used by druggists. With lean coals, or anthracite, the pastilles are too friable and burn incompletely. This is easily remedied by mixing with a small quantity of silicate of soda solution. Several of them should be made at a time, the cinders of some being determined to obtain a mean and the others burnt in the bomb. They may contain about 1 gram of pure coal. 
which and in contact with it is the iron spiral. At the instant of lighting a slight noise is made, and soon the thermometer begins to rise, showing that the combustion is proceeding.

Compressed oxygen may be introduced either by a pump drawing the gas from a holder or by using a compressed-gas cylinder. In both cases the gas is used without drying, if the combustible contains hydrogen in quantity enough to saturate the gases formed with water produced by its combustion. But if, on the contrary, the combustible has little or no hydrogen, like wood-charcoal for instance, it is not immaterial whether the oxygen be dry or not. In this case it is well to use the oxygen moist, or to put a little water in the bomb on the internal walls. By this means a correction for heat of vaporization of water formed by the combustion is obviated.

Oxygen compressed to 120 atmospheres is nearly dry. Berthelot observes: "The oxygen is, in short, actually or nearly dry, and if it contains aqueous vapor the tension is reduced to one fourth or one fifth on account of the change in volume of the gas during its passage through the bomb. It may be nearly nullified by the cold produced at the instant of filling the bomb. This admitted, we shall have to account in most combustions for the evaporation of the water produced in the bomb; and this is from 2 to 3.5 calories in a bomb of $\frac{4}{8}$ litre (about 0.6 pint), or 5 to 6 calories in a bomb of 600 to 700 cubic centimetres ( 37 to 43 cubic inches). These are rather small quantities, it is true; but while they can be neglected in industrial tests, they cannot in rigorously scientific investigations. This correction may, however, be neutralized by putting into the bomb 4 or $5 \mathrm{cc}$. of water, which should be considered in the calculations.

When oxygen not previously compressed is used and forced in by a pump, Berthelot recommends passing the gas through a large red-hot copper tube filled with oxide of the 
same metal, so as to burn any oil which may have been taken from the pump.

Operation.-At the laboratory of the College of France the successive operations are as follows:

I. Light the fire to heat the oxygen red-hot;

2. While the gas-holder is filling with oxygen, the fuel is dried;

3. Weigh the fuel;

4. Place the fuel in the bomb;

5. Grease the cover slightly; tighten with the screw;

6. Begin to compress the oxygen by forcing the air out with a few strokes of the piston; pump slowly to prevent heating the pump;

7. Close the stop-cock of the pump; break the connection with the bomb, extinguish the fire, and replace the bomb on its support so as to carry it to the calorimeter room;

8. Pour the water into the calorimetric bath.

The apparatus is allowed to come to equilibrium, and the readings of the thermometer taken for five minutes. The iron coil is then heated by the electric current from a small bichromate battery. It takes fire and kindles the combustible, which generally burns without smoke or producing any carbonic oxide, as Befthelot has shown.*

The water condensed from the combustion contains small quantities of nitric acid, showing imperfectly purified gas. This may be determined by titration, if accurate results are sought, and calculated 0.227 calories per gram of $\mathrm{HNO}_{3}$. . The correction will be very small. A correction for the iron used may be made at the rate of 1.65 calories per gram, this being the heat of formation of the magnetic oxide.

* With very fat coals it sometimes happens after a combustion that the platinum shows a black or brown mark, indicating a slight deposit of black or tar which has escaped combustion. Occasionally, also, a trace of tar is found at the bottom of the bomb. These may be prevented by using a grating or perforated plate instead of the foil. This detail must be attended to with a new coal. 
With substances containing nitrogen and sulphur, such as coal, the corrections are more complicated, as a larger quantity of nitric acid is formed and the sulphur forms sulphuric acid. If exactness is sought, it will not be sufficient to make a volumetric test: the sulphuric acid must be determined separately. Generally, however, this estimation may be dispensed with, if for technical purposes only. When, on the contrary, absolutely correct figures are desired, both acids must be considered. In the calculation the nitric acid is reckoned as 0.227 calorie per gram and the sulphuric acid as 1.44 calories per gram.

But these two corrections are really unimportant even with coal, as it contains usually only about I per cent of nitrogen or sulphur. One per cent of nitrogen represents $4 \frac{1}{2}$ per cent of $\mathrm{HNO}_{3}$, or 10 calories; one per cent of sulphur represents 3 per cent of $\mathrm{H}_{3} \mathrm{SO}_{4}$, or 43 calories,-both quitesmall compared with 7000 to 8000 calories.

Below will be found the details of a complete combustion taken from Berthelot's work.

\section{HEAT OF COMBUSTION OF CARBON.}

The wood charcoal, purified by chlorine at red heat to remove all traces of hydrogen (Favre and Silbermann's method), is dried at $120^{\circ}$ to $140^{\circ} \mathrm{C}$. $\left(248^{\circ}\right.$ to $284^{\circ} \mathrm{F}$.), then weighed in a closed tube after cooling in a sulphuric acid desiccator.

0.437 gram carbon; cinders, 0.0028 gram (0.66 per cent); real carbon, 0.4342 gram.

\section{Preliminary Period.}

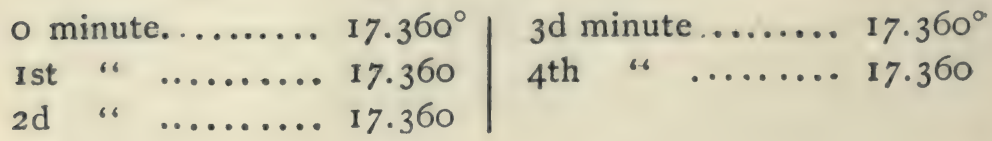


Combustion.

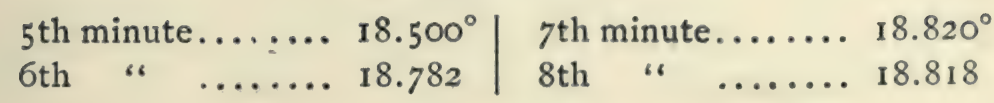

Subsequent Period.

$9^{\text {th minute } \ldots \ldots \ldots r .8} 18.810^{\circ} \mid$ I2 th minute $\ldots \ldots \ldots 18.785^{\circ}$ Ioth “ $\ldots \ldots \ldots 18.802$ I3th “ $\ldots \ldots \ldots 18.775$ IIth “ $\ldots \ldots \ldots$ I8.795 I4th “ $\ldots \ldots \ldots$ 18.768

Initial cooling per minute,

$$
\Delta t_{0}=0.00^{\circ}
$$

Final cooling per minute,

$$
\Delta t n=+0.008^{\circ} .
$$

Correction for cooling,

$$
\Delta t=+0.056^{\circ} .
$$

Variation of temperature, uncorrected,

$$
18.818^{\circ}-17.360^{\circ}=1.438^{\circ} .
$$

Value of corrected temperature,

$$
1.438^{\circ}+0.056^{\circ}=1.484^{\circ} .
$$

Value in water of the calorimeter (including oxygen),

$$
m=2398.4 \text {. }
$$

Weight of acid formed;

$$
\mathrm{HNO}_{3}=5 \mathrm{cc} \text {. of } \frac{1}{20} \text { normal } \mathrm{KHO}=0.0173 \text { gram. }
$$


Total heat observed, $q_{2}=3.5562$ calories. Heat of iron coil,

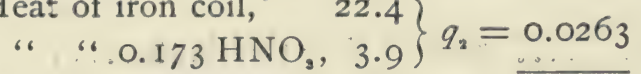

Real heat due to the carbon, $3 \cdot 5299$ or for one gram, $\frac{3.5299}{0.4342}=8.1296$ calories, or per kilogram, 8129.6 calories, or 1487 I.O B..T. U. per pound. 
CHAPTER VI.

\section{THE CALORIMETRIC BOMB ADAPTED TO INDUSTRIAL USE BY MAHLER.}

THE calorimetric bomb of Berthelot costs considerably more than can be paid by an industrial laboratory, owing to its large amount of platinum. Mahler replaced the interior platinum of the bomb by an enamel deposited on the steel. The description given by him in his paper before the Societe d.'Encouragement de Paris, in June, 1892, is as follows:

The apparatus is shown in Fig. 23. It consists essentially of a steel shell, $B$, capable of resisting 50 atmospheres

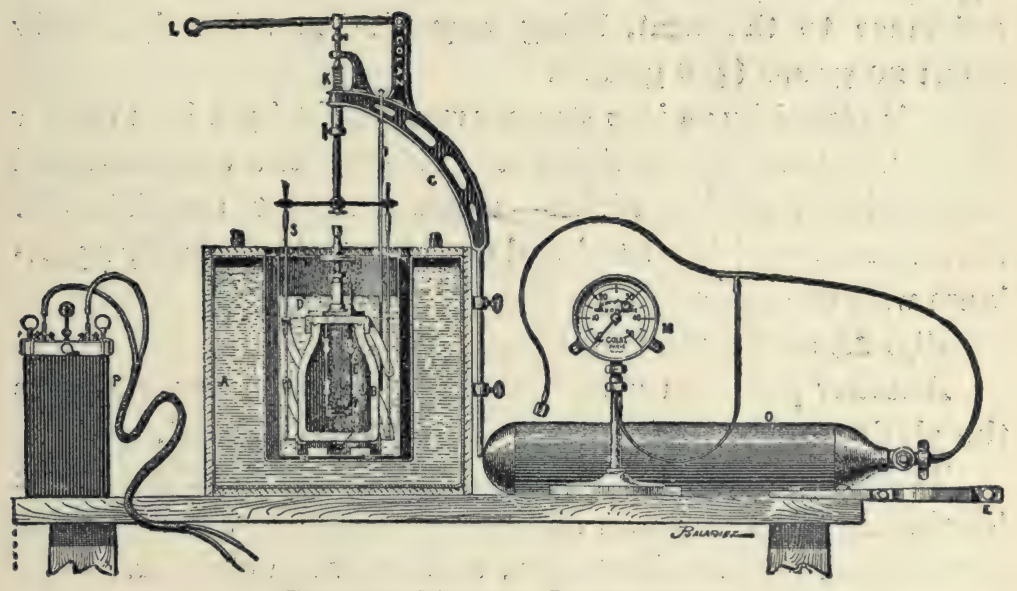

Fig. 23.-Mahler Calorimeter.

and 22 per cent elongation. This quality was carefully chosen, not only on account of the pressure it must stand, but also as it aids the enameling. The metal is very pure, containing but 
little phosphorus or sulphur. Tensile strength tests are the best criterion of quality.

It has a capacity of $654 \mathrm{cc}$. (40 cubic inches) at $15^{\circ} \mathrm{C}$. It is gauged with a balance showing $\frac{1}{50000}$. The total weight is about 4 kilograms $(8.8$ lbs.) with the accessories.* The metal of the walls is 8 millimetres (about 0.3 inch).

The capacity is greater than Berthelot's, and has the advantage of insuring perfect combustion of carbon in all cases, due to a certain excess of oxygen, even when the purity of this gas as bought is not quite satisfactory. Besides, it is designed to study all industrial gases, even those containing a large percentage of inert gas; hence it must be able to use a sufficiently large quantity to generate the required temperature. The contraction at the top aids in enameling.

The shell is nickeled on the outside, while internally it has a coating of white enamel, resisting corrosion and oxidizing action of the combustion. $t$ It does not, however, offer resistance to the heat, being very thin, and it weighs only about 20 grams (308 grains).

It is closed by an iron stopper made tight by a lead washer $(P$, Fig. 33) and clamped down. This carries a conical-seated stop-cock, $R$, of fine nickel-a metal almost unoxidizable. An electrode well insulated and reaching the interior by a platinum wire runs through the stopper.

Fig. 24 shows most of the details.

Another platinum wire, also fixed on the cover, supports the platinum disk or foil on which the fuel is placed.

The calorimeter, the non-conducting material, the support for the shell in the water, and the agitator differ in numerous details from those of Berthelot, and are much cheaper.

\footnotetext{
* Slight modifications have been made in the dimensions of the metal of the bombs made lately by Golaz.

+Prof. W. O. Atwater finds that the enamel chips off in time, and that after about 300 combustions it requires re-enameling. Hempel for coal determinations uses one without any inside enamel.
} 
The calorimeter is of thin brass, and is quite large on account of the size of the combustion-chamber. It contains 2200 grams $(4.85 \mathrm{lbs}$.) of water, thus eliminating the causes of error due to the loss of a few drops by evaporation.* The agitator of Berthelot is supplanted by a very simple and gentle cinematic combination called a drill movement, and which can be worked without fatigue. The source of electricity is a Trouvé bichromate pile $(P$, Fig. 23) of 10 volts and 2 amperes.

The oxygen used is that furnished by the Compagnie Continentale d'Oxygène. This company supplies oxygen free from $\mathrm{CO}_{2}$, but containing from 5 to 10 per cent of nitrogen. This means of supply simplifies the manipulation; it also obviates the introduction of grease, as happens with oxygen compressed by a pump in the laboratory. $\dagger$

The cylinders vary in size, and contain gas at a pressure of 120 atmospheres. The average content is about 1200 litres (about 40 cubic feet) compressed. They

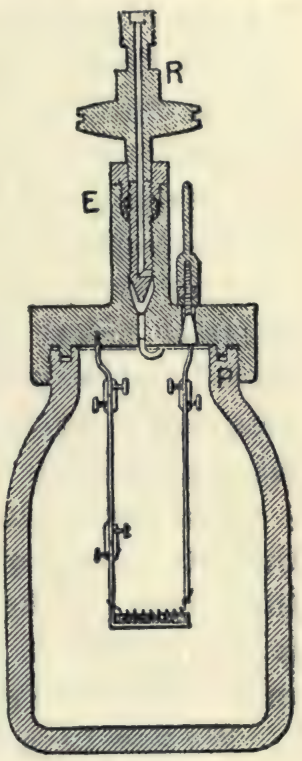

FIG. 24. have a uniform top, and hence the copper pipe connecting the bomb with the manometer and the cylinder, once adjusted, will fit all of them.

The method of working is very simple.

Weigh I gram of the substance to be tested in the capsule. Fasten a small weighed iron wire (English gauge 26 or 30) to the electrode and to the support of the capsule. Put the end in the bomb and fasten in the cover, which should be held in a vise. Put the conical stop-cock in connection with the oxygen cylinder, and open it carefully so as to allow suffi-

* The evaporation never exceeds a gram per hour.

+ This gas is also compressed by pumps at the works. 
cient oxygen to pass in for the required pressure. Close the cock of the oxygen cylinder, carefully close the conical cock, and break the connection between the bomb and the oxygen cylinder. The substance, especially if coal, must not be too fine, and the oxygen must flow in very slowly to avoid blowing any of it from the capsule.

The bomb thus prepared is placed in the calorimeter, and the thermometer and agitator adjusted. Pour in the previously weighed water, agitate a few minutes to restore equilibrium of temperature, and commence the observations.

The experimenter notes the temperature minute by minute for four or five minutes, and determines the rate of the thermometer before the combustion. Then he joins the electrodes, and the combustion begins immediately, almost instantaneously; but the transmission of heat to the calorimeter takes some time.

The temperature is taken one-half minute after kindling, then at the end of the minute, then at each minute to the time when the thermometer begins to lower regularly. This is the maximum. The observations are continued for a few minutes more to ascertain the rate of fall of temperature.

We now have all the elements needed for the calculation, and particularly for the single correction necessary to make under the circumstances. This is the correction for loss of heat before reaching the maximum temperature, which is quite small considering the short time and the large mass involved.

It is not necessary to use the corrections of Regnault and Pfaundler with this apparatus. Newton's law of cooling gives sufficiently accurate results, even in rigorous investigations. Special experiments made to determine the rate of cooling of the water in the calorimeter, when the apparatus was set up as usual, showed that the correction may be regarded as following a simple law, but between comparatively large limits, 
even under a variation of several hundred grams in amount of water used.

The law* is

I. The decrease in temperature observed after the maximum represents the loss of heat of the calorimeter before the maximum and for a certain minute, with the condition that the mean temperature of this minute does not differ more than one degree from the maximum.

2. If the temperature considered differs more than one degree but less than two degrees from the maximum, the number representing the rate of decrease dimminished by $0.005^{\circ}$ will be the correction.

The two preceding remarks suffice in all cases with Mahler's apparatus. The variation of heat in the first half-minute after kindling may also be corrected by the same law.

The agitator must be worked continually during the experiment, being careful of the thermometer.

When through, the conical valve is opened and then the bomb. Wash the inside with a little distilled water to collect the acids formed. The proportion of acids carried away by the escaping oxygen at the opening may be neglected. Determine the acids volumetrically.

When experimenting with substances low in hydrogen and incapable of furnishing sufficient water to form nitric acid, it is advisable to put a little water in the bomb, or hyponitric acid would be formed.

All the data being obtained, we proceed to the calculation of the calorific power $Q$.

Let $\Delta$ be the observed difference of temperature;

$a$, the correction for cooling;

$P$, the weight of water in the calorimeter;

$P^{\prime}$, the equivalent in water of the bomb and accessories;

\footnotetext{
* It is evident that the rule must be modified for apparatus notably dif-
} ferent from that used by Mahler. 


\section{$p$, the weight of the nitric acid, $\mathrm{HNO}_{3}$;}

$p^{\prime}$, the weight of the iron;

0.23 calorie, the heat of formation of I gram of nitric acid; and 1.6 calories, the heat of combustion of I gram of iron.

We then have

$$
Q=(\Delta+a)\left(P+P^{\prime}\right)-\left(0.23 p+1.6 p^{\prime}\right) .
$$

In testing coal in this manner the small amount of sulphuric acid formed will be reckoned as nitric acid without serious error, as it will be very small. The heat of the reaction is $\mathrm{I} .44$ calories per gram of $\mathrm{H}_{2} \mathrm{SO}_{4}$ formed.

The above details apply to liquids as well as solids. Heavy liquids, such as the heavy oils, tars, etc., are weighed directly into the capsule; but light, easily vaporized liquids must be placed in pointed glass bulbs. These are put into the capsule, and just before closing the bomb are broken to allow access of the oxygen to the liquid. An almost perfect combustion is obtained in operating with a great variety of materials, nothing but cinders remaining.

To determine the calorific power of gases the exact content of the bomb must be known. Fill it first with gas. Then work the air-pump to reduce the pressure to several millimetres of mercury, and then fill the bomb again with gas, under atmospheric pressure and at the laboratory temperature. The bomb may then be considered full of pure gas.

The method of working with gases is the same as with solids or liquids. The operator must not forget the need of preventing too great dilution with oxygen, as then the mixture will cease to be combustible. With illuminating gas 5 atmospheres of oxygen is sufficient, and with producer gas only one-half atmosphere, as shown by the mercury gauge, is needed.

The gases to be burnt are kept in gas-holders over water saturated with gas, or over salt water, according to circum- 
stances, and are saturated with aqueous vapor when they enter the bomb. From the calorific capacity of the different parts we obtain that of the whole, the glass and enamel being omitted.

Soft steel......3945 grams. $3945 \times 0.1097=432.76$

Brass........ 545 " $545 \times 0.093=50.68$

Mercury, plati-

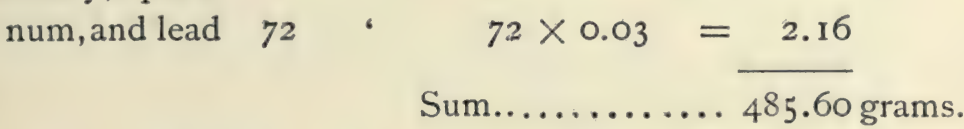

The coefficient 0.1097 is the one adopted by the College of France, from Berthelot and Vielle's experiments, for a steel of similar quality. We have given above (page 14) the calculations relative to the valuation in water. By direct method of mixing water of different temperatures Mahler found the equivalent to be 470 and 484 , and assumed the mean $48 \mathrm{I}$.

By the method of burning a body of known composition and heat of combustion he obtained with naphthalin 9688 calories-within $\frac{1}{2000}$ of that given by Berthelot (9692).

The equivalent in water may also be obtained by burning I gram of known composition and heat of combustion-naphthalin for instance.* We may also, after Berthelot, burn a substance of fixed composition at two trials with different weights of water in the calorimeter. Two equations are thus formed, from which the heat of combustion of the body used is eliminated, and the heat sought obtained.

In using naphthalin care must be taken to weigh it only after being gently fused in the capsule. It is so light that if not agglomerated some would be blown away by the oxygen. In practice the tests are made rapidly. The water equivalent once determined may be verified by combustion of cane-

* This practical method has the advantage of automatically eliminating causes of error. 
sugar $\left(\mathrm{C}_{12} \mathrm{H}_{11} \mathrm{O}_{11}\right)$, for which Berthelot and Vielle found $396 \mathrm{I} .7$ calories. (Use 2 grams for a combustion.)

\section{Examples of Calculations.}

Mahler gives several types of calculations from his notes, so as to show the different circumstances which may occur.

A. Colza Oil.-Elementary analysis showedCarbon.................... 77.182 per cent. Hydrogen .................. II.7II ، "

Oxygen and nitrogen............ II.107 ، “ 100.000 " "

Weight taken, I gram. Calorimeter contained 2200 grams water. Equivalent in water of bomb, etc., 48 I grams. Pressure of oxygen, 25 atmospheres.

The apparatus prepared as above was allowed to rest a few minutes to gain equilibrium of temperature. Then commenced noting the temperatures.

\section{Preliminary Period.}

o minute.......... $10.23^{\circ} \mid 3$ minutes.......... $10.24^{\circ}$ I “ $\ldots \ldots \ldots \ldots$ I0.23 4 “ “ $\ldots \ldots \ldots \ldots$. 0.25

2 minutes.......... 10.24 | 5 “ $\ldots \ldots \ldots \ldots$. 0.25

Rate of variation,

$$
a_{0}=\frac{10.25-10.23}{5}=0.004^{\circ} .
$$

The electrodes are connected and the combustion begins.

Combustion Period.

$5 \frac{1}{2}$ minutes .......... $10.80^{\circ} \mid 7$ minutes.. $13.79^{\circ}$

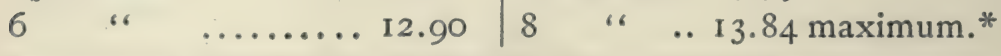

* Prof. Jacobus recommends plotting the temperatures and using, not the maximum, but the one at the instant the curve of cooling becomes a straight line. The difference is slight, but important in some cases. 
Period after Maximum.

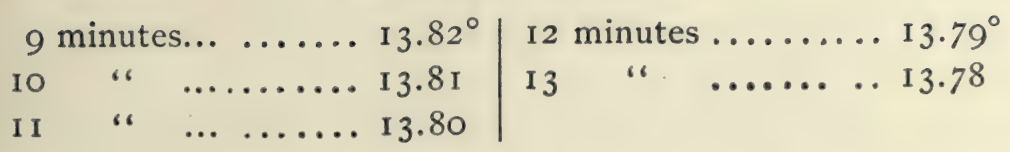

Rate of variation after maximum is

$$
a_{t}=\frac{13.84-13.78}{5}=0.012^{\circ}
$$

The thermometer observations now stopped.

The gross variation in temperature was

$$
13.84-10.25=3.59^{\circ} .
$$

The corrections are as follows:

The system lost during the minutes $(7,8)$ and $(6,7)$ a quantity of heat corresponding to $2 a_{t}$.

$$
2 a_{t}=0.012 \times 2=0.024^{\circ} \text {. }
$$

In the half-minute $\left(5 \frac{1}{2}, 6\right)$ it lost

$$
\frac{1}{2}\left(a_{t}-0.005\right)=0.0035^{\circ} \text {. }
$$

But during the half-minute $\left(5,5 \frac{1}{2}\right)$ it gained

$$
{ }_{2} a_{0}=\frac{0.004}{2}=0.002^{\circ} \text {. }
$$

Consequently, the loss for the minutes $(5,6)$ is

$$
0.0035-0.002=0.0015^{\circ} .
$$


So that the system had lost, before reaching the maximum temperature,

$$
0.024+0.0015=0.0255 \text {, }
$$

which must be added to the $3.59^{\circ}$ already found, making the variation in temperature $3.615^{\circ}$, neglecting the 4 th decimal.

The quantity of heat observed, then, is

$$
Q=(2200+48 \mathrm{I}) 3.6 \mathrm{I} 5=268 \mathrm{I} \times 3.615=9.6918 \text { calories. }
$$

From this number must be subtracted-

I. The heat of formation of the 0.13

$$
\text { gram of } \mathrm{HNO}_{3} \ldots \ldots \ldots \ldots . . .13 \times 0.23=0.0299
$$

2. The heat of combustion of 0.025

$$
\text { gram of iron wire.......... } 0.025 \times 1.6=0.04
$$

Total subtraction ............. 0.0699

The final result is, then,

$$
9.69 \text { I } 8-0.0699=9.6219 \text { calories, }
$$

\begin{tabular}{|c|c|c|c|c|c|}
\hline \multicolumn{2}{|c|}{ Preliminary Period. } & \multicolumn{2}{|c|}{ Combustion. } & \multicolumn{2}{|c|}{ After Combustion. } \\
\hline minutes. & degrees. & minutes. & degrees. & minutes. & degrees. \\
\hline 0 & 15.20 & $3 \frac{1}{2}$ & I6.60 & 7 & I8 32 \\
\hline I & I5.20 & 4 & 17.92 & 8 & I 8.30 \\
\hline 2 & I 5.20 & 5 & I8.32 & 9 & I 8.30 \\
\hline 3 & I5.20 & 6 & I 8.34 & Io & 18.30 \\
\hline \multicolumn{2}{|c|}{$a_{0}=0$} & \multicolumn{2}{|c|}{$\begin{array}{l}\text { maximum } \\
\text { oxygen pressure } 25 \\
\text { atmospheres }\end{array}$} & \multicolumn{2}{|c|}{$a t=\frac{18.34-18.26}{5}=0.016^{\circ}$} \\
\hline
\end{tabular}

or for I kilogram 962 I.9 calories, equivalent to I 73 I 9.4 B.T.U.

TECHNICAL EXAMINATION OF COAL.

The coal taken was a sample of Nixon's coal from South Wales. 
Difference of gross temperature ...... 3.140

Correction $(4,5)(5,6) 0.016 \times 2 \ldots .0 .032$

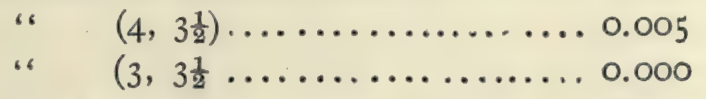

Corrected difference of temperature.... $3.177^{\circ}$

or $3.18^{\circ}$.

Heat disengaged...3. $18^{\circ}$.

$3.18 \times 2.681=$

Calories.

Iron wire.........0.025.

$0.025 \times 1.6=0.04$

Nitric acid

$0.15 \times 0.23=0.0345$

For one gram

or $845 \mathrm{I}$. I for I kilogram, equivalent to I $52 \mathrm{I} 2 \mathrm{~B}$. T. U.

\section{EXAMINATION OF A GAS.}

Illuminating gas was examined under the following conditions :*

Barometric pressure......... 76 I mm. (29.6 inches).

Tension of aqueous vapor..... 8 “ (0.3 I4 inch).

Temperature of laboratory ..... $18.5^{\circ} \mathrm{C} .\left(65.3^{\circ} \mathrm{F}\right.$. $)$.

Volume of bomb ............ $654+$ cc. $(39.9$ cubic inches).

". " " dry at $0^{\circ}$ and $760 \mathrm{~mm}$. 606 cc. (37 cubic inches).

The capsule was left in its usual place in the bomb to prevent specks of iron oxide from dropping on the enamel and injuring it. 


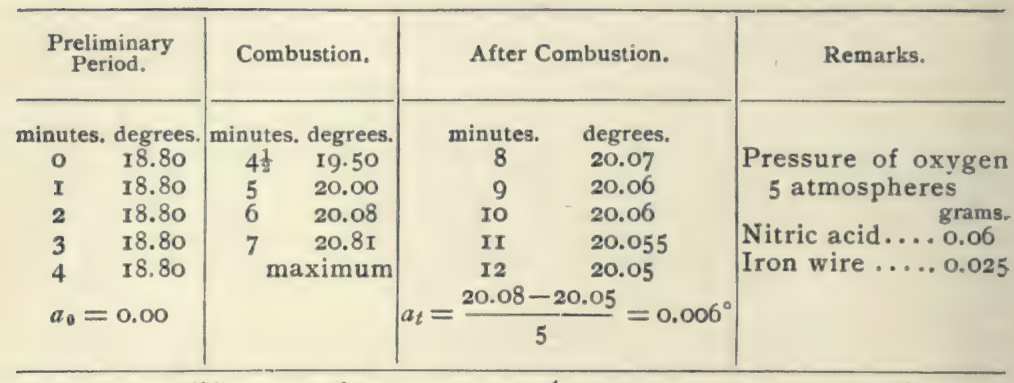

Gross difference of temperature, $4 \ldots \ldots \ldots \ldots \ldots \ldots \ldots, 28^{\circ}$

Correction as usual, $a \ldots \ldots \ldots \ldots \ldots \ldots \ldots \ldots \ldots \ldots \ldots$ or 5

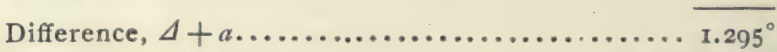

Quantity of heat observed, $1.295^{\circ} \ldots \ldots$ Calories. Calories. 3.47189

Heat of $\mathrm{HNO}_{3}$ formation................ $0.06 \times 0.23=0.0138$

Heat of iron-wire combustion........... $0.025 \times 1.6=0.04$

Heat of combustion of $606 \mathrm{cc}$ at $o$ and $760 \mathrm{~mm} \ldots \ldots \ldots \ldots \ldots .3 .41809$ or per cubic metre at $760 \mathrm{~mm}$. 5640 , or $633.6 \mathrm{~B}$. T. U. per cubic foot.

\section{COMBUSTION USING AN AUXILIARY SUBSTANCE.}

Sometimes an unconsumed residue is left while determining the heat of combustion of some difficultly burning substances, diamond or graphite for instance. In this case a combustible auxiliary is used to obtain complete burning of the sample. The most convenient to use is naphthalin $\left(\mathrm{C}_{10} \mathrm{H}_{8}\right)$, the heat of combustion of which is exactly known, 9692 calories.

Take petroleum coke, which is nearly allied to graphite. It is mixed with a little naphthalin which has been previously melted at a low heat and then cooled. After cooling the weight of the naphthalin is taken.

The coke analyzed as follows:

Carbon................... 97.855 per cent.

Hydrogen................ 0.489 " “ “

Oxygen................... 1.196 " "

Nitrogen................. 0.260 " "

Ash...................... 0.200 " "

100.000 "، 
The data obtained are as follows:

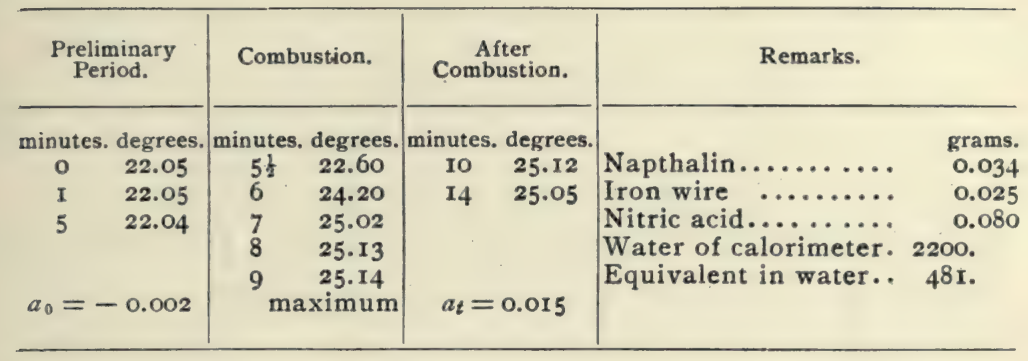

Difference of temperature............. 25.14-22.04 $=3.100^{\circ}$

Correction for minutes $(9,8),(8,7),(7,6) . . \quad 0.015 \times 3=0.045$

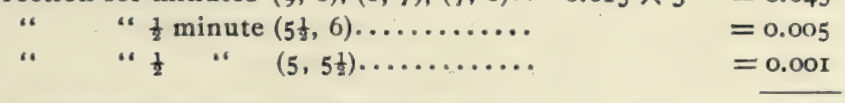

Corrected temperature difference............... $\overline{3.151^{\circ}}$

Then,

Total heat developed $3.15^{\circ} \ldots \ldots \ldots 3.15 \times 2.68 \mathrm{I}=\quad 8.445 \mathrm{I}$

From this subtract

Heat due to naphthalin.......... $0.034 \times 9692=0.3295$

" " " "iron wire............ $0.025 \times 1.6=0.04$

" " " $\mathrm{HNO}_{3} \ldots \ldots \ldots \ldots \ldots .0 .08 \times 0.23=0.0184$

Heat developed by the combustion of the coke......... $\frac{0.3879}{8.0572}$ or 8057.2 per kilogram, or 14503 B. T. U.

When the combustible tested contains hydrogen, it must be remembered that, while the gas in the bomb is dry at the beginning, it is saturated at the close of the experiment. In reality, the latent heat of vaporization of the small quantity of water necessary to be added is inconsiderable. The mean of several tests was 5 in 8500 calories observed, or only $\frac{1}{1700^{\circ}}$. Still, when we test gases, which cause less marked difference in temperature than solids or liquids, we must allow for this heat of vaporization to be exact.

It may be asked if any allowance will be made for the heat of the electric current at the moment of kindling. The 
heat developed by a current with intensity $I$ and electromotive force $E$ is

$$
C=\frac{E I}{4 \cdot 17} t
$$

$t$ being reckoned in seconds. If $t$ was appreciable, this should be considered at least in exact determinations. But, actually, $t$ is very small; the contact is hardly established before the iron is burnt and the contact broken.*

Mahler cites two successive tests made on the same coal with his bomb and with the bomb of the College of France, as furnishing proof of the accuracy of his method.

The following results were obtained:

Scheurer-Kestner
at the
College of France.

Coal (pure) from Bascoup, Belgium .... 8828

Mahler.

The calculations may be rendered simpler and the observation more rapid, still being exact enough for industrial uses.

Take the equation

$$
Q_{0}=(\Delta+a)\left(P+P^{\prime}\right)-\left(0.23 p+1.6 p^{\prime}\right), . .
$$

arranging the terms in order of the corrections

$$
Q_{0}=\Delta\left(P+P^{\prime}\right)+a(P+P)-\left(0.23 p+1.6 p^{\prime}\right) .
$$

It is clear that the calculation of the calorimetric operation.

* In exact researches this heat can be easily determined if wished. It will be sufficient to measure the electromotive force in volts. Then put an amperemeter in the line which connects the bomb and kindle the combustible as usual. The displacement of the needle shows the intensity of the current under the conditions of the test, and also the time during which the current was closed. The formula $\frac{E I}{4 \cdot 17} t$ will give the quantity of heat. sought. 
reduces to the determination of a maximum and to one multiplication if we have

$$
a\left(P+P^{\prime}\right)=0.23 p+1.6 p^{\prime} . . . . .
$$

Now from the tests made we readily see that whatever value $a$ may take, it increases with the quantity of heat generated in the bomb; it is a little greater when the external air is warmer than when it is cooler-a fact which may be attributed to the influence of evaporation on the cooling of the bath.*

On the other hand, the nitric acid appears to increase with the quantity of heat generated, and tends to offset the correction from $a$. In short, $p^{\prime}$ is, within certain limits, at the control of the observer, same as $P^{\prime}$. We consider it then . possible to arrange once for all so as to have the expression (3) sufficiently close for industrial purposes.

This can be done with Mahler's apparatus. Thus for oil of colza the multiplication $\Delta\left(P+P^{\prime}\right)$ gave 9625 calories, which is within $\frac{1}{3000}$ of the final number obtained after all corrections; with the Nixon's coal we found t at $\Delta\left(P+P^{\prime}\right)=$ 8418 calories, which differed $\frac{1}{250}$ from the correct number; with coal-gas the product $2681 \times$ I.28 $=3432$ calories, while the corrected result was 3418 , or $\frac{1}{240}$ difference.

\section{ATWATER'S CALORIMETER.}

Prof. Atwater has considerably modified the bomb, so that it seems to have some advantages for easy working. Fig. 25 gives a sectional view of it in the calorimeter. The steel used is the same as that used in the Hotchkiss guns,

* The rapidity of cooling in the apparatus employed by Mahler was, according to experiments, between $15^{\circ}$ and $20^{\circ} \mathrm{C}$.

$$
\frac{d \theta}{d t}=0.005\left(T-T_{0}\right) \text {, }
$$

$T_{0}$ being the temperature at which cooling ceases. 
and having an unusually high tenacity, seems álmirably fitted for the purpose. $A$ represents the bomb, $C$ the screw-cap, $B$ the cover, which is placed on the bomb cylinder and held down by the screw-cap. "The cover is provided with a neck into which fits a cylindrical screw $E$, holding another screw $H$. On the side of the neck is an aperture $G$, between the lower end of $D$ and the shoulder. In $D$ is a washer of lead, on which the lower edge of $E$ fits. By opening or closing the screw $F$ the narrow passage from $z$ is opened or closed. The opening is used for admitting oxygen at a high pressure through a narrow passage to charge the bomb. In $B$ is an aperture through which passes the platinum wire $H$, which is

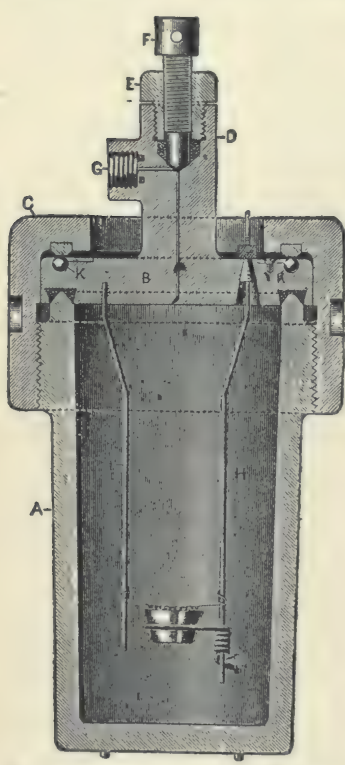

Fig. 25.-ATWATER BOMB. separated from the metal of the cover by insulating material. Hard vulcanized rubber serves very well for this purpose. Fastened to the lower side of the cover is another platinum rod, $I$, between which and $H$ an electrical connection is made with a very fine iron wire. A screw-ring holds the small platinum capsule, in which the substance to be burned is placed. At $K K$ are ball-bearings of hard steel to avoid friction in screwing the cap down."

" The large cylinders $N$ and $O$ are made of indurated fibre, and covered with plates of vulcanized rubber. A stirrer serves for equalizing the temperature of the different portions of water after the combustion is completed." *

The thermometer used is by Fuest of Berlin, graduated to $\frac{1}{100}$ degree, and can be read with a magnifying-glass to $\frac{1}{1000}$ degree.

* Prof. W. O. Atwater, in Bulletin No. 21, U. S. Dept. of Agriculture, 1895, pages 124 and 126. 
The apparatus has been used with success in making the very numerous determinations made by Atwater on the heats of combustion of food-products and other allied organic substances.

\section{KROEKER'S CALORIMETER.}

Kroeker has recently modified the bomb, making two inlet channels instead of one. By this means he has a current of oxygen gas passing in at one opening and waste gases passing out at the other. It can thus be used for the same purpose that a Junker calorimeter is used, and it is claimed with just as satisfactory results.

The cylinder (Fig. 26) is bored out of a piece of Martin steel, and has a closely-fitting screw-plug for cover, the depth of the screw joint being $25 \mathrm{~mm}$. The walls of the cylinder are Io mm. thick; external diameter, $72 \mathrm{~mm}$; internal diameter, 52 mm.; height, $120 \mathrm{~mm}$.; contents, $200 \mathrm{cc}$. It has four small legs on the under side, which support it and keep it entirely surrounded by the water of the bath. The entire inside surface is enameled, or preferably platinized. The fuel, in the form of compressed cylinders weighing one gram, is put into the carrier, ignited as usual, and the combustion gases collected and examined.

He also has a method of heating the calorimeter bomb in an oil-bath so as to expel all the water of combustion and hydration. He thus obtains data for cor-

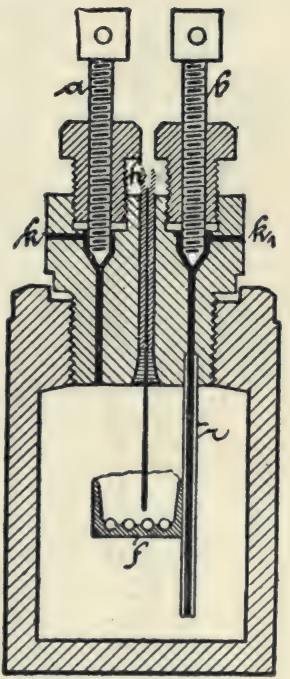

FiG. 26.-KROEKER Calorimeter. rections due to the usual method of determining the water, i.e., considering the water as condensed. 


\section{WALTHER-HEMPEL BOMB.}

Two modifications of the Berthelot bomb are known under this name. The larger one does not differ in enough points to make a special mention of it necessary; but the smaller one, the one intended for use in analysis, is worthy of description.

It consists of a small cylinder of $33 \mathrm{cc}$. capacity (Fig. 27), bored out of white cast iron and enameled inside. The walls are 2 millimetres thick, and it is strong enough to resist eight

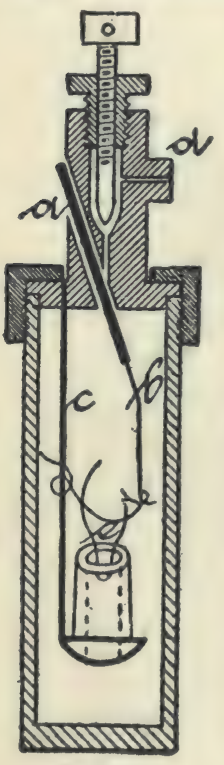

FIG. 27.

WALTHERtimes the pressure generally used. The cover is fastened on by means of a screw-clamp, and through it passes the slanting opening $a$, having the electric wire-carrier insulated by a caoutchouc sheath. To the wire at the end of this sheath is attached a platinum wire for kindling the combustible. On the opposite side of the cover is the oxygen tube $d$. The platinum wire $c$ is attached to the under side of the cover, and supports the combustiblecarrier and its little fire-clay cylinder $e$.

The fuel is made into small cylinders by compression, put into the fire-clay cylinder, and ignited by the electric spark. The products of combustion are collected and weighed or measured: the water partly in the bomb and partly by means of a calcium chloride tube; the nitric and sulphuric acids are HEMPEL Вомв. determined by titration with $\frac{1}{100}$ normal alkali, and afterwards separated if deemed necessary. It is claimed to be capable of use the same as a large one. A full description of it is given in the Berliner Bericht for January, 1897. 


\section{CHAPTER VII.}

\section{SOLID FUELS.}

COAL.

A MONG the first careful tests ever made, to determine the heat value of different kinds of coal, are those made in 1843 and 1844 by Prof. W. R. Johnson for the U. S. Navy. He analyzed and tested all the kinds obtained from the United States and England, which were then in use by the navy. At the time they were made the calorimetric determinations were not considered as of the importance they are now, and his tests were limited to determining the evaporative power of the coals. Mr. W. Kent reviewed them in the Engineering and Mining Journal, 1892, and showed that up to the time of the experiments nothing comparable with them had been attempted, and that in many respects they compare favorably with work done to-day.

In 1857 Morin and Tresca made numerous determinations of the calorific power of coal and wood, and in 1853 they published a work on "Fuels and their Calorific Power," in which they make many recommendations for more accurate work. They wrote: “It would be extremely important if experiments with the calorimeter could be made on most of the fuels, by methods similar to those used by Favre and Silbermann."

In 1868 such experiments were made by Scheurer-Kestner, and continued by him later with the aid of MeunierDollfus. They based their calculations on pure coal, i.e., with moisture and ash deducted. This method, which has been 
followed by many others, seems very logical, as it facilitates comparison of different fuels by reducing them to the same basis. Enormous errors due to comparison of values not comparable are thus obviated. Coal having 5 per cent impurity has been compared with coal having only I per cent, no account being made for the difference, and of course very erroneous and misleading deductions obtained.

It is a simple task for the engineer or the workman even, to determine approximately the proportions of moisture and ash as given on the grate. Knowing these proportions and the heat of combustion of the pure coal, they can render a statement of the practical working. If, on the contrary, the experimenter is limited in such way that he neglects the composition of the coal, it is impossible to make a conjecture as to its intrinsic or comparative value; still less can he judge of it as a steam generator.

In 1879 Bunte made some experiments at Munich, using a special apparatus devised by him for the occasion, which was part calorimeter and part boiler. The tests were published in Dingler's Polytechnisches Journal. Some of the results are included in the tables of this book.

Since then numerous tests have been made on nearly all the known coals. A collection of all available ones from which the desired data could be obtained will be found farther on.

The question as to the actual evaporative effect of each coal can be settled only by actual tests made on the boiler intended for use, as the same coal will give slightly different results with different kinds of boilers; also, and in a more marked degree, with different methods of firing and handling. The results in the tables cannot be taken, then, as absolute for all boilers under all circumstances, but they can be depended on for comparison of the different fuels with the same boiler and under proper conditions.

The manner in which a coal acts under heat in a closed 
vessel is a most important indication, taken in connection with its elementary composition. Gruner gave his opinion that the real value of a coal could be determined better from its proximate than from the ultimate composition. Speaking of the Loire coal, he says:

"The proximate analysis, which consists in distilling coal in a retort and incinerating the residue, allows direct valuation of the agglomerating power as well as the nature and proportion of the ash. Further, it is easy to show, especially with the aid of the work of Scheurer-Kestner and MeunierDollfus, that the calorific power varies with the proportion of fixed carbon left by distillation. This is true at least for all coal properly so called, but not always true for anthracite and lignite." *

Gruner formed the following table based on the quantity and nature of the coke furnished and the calorific power. $\mathrm{He}$ held, from the results of S.-K. and M.-D., that if the heat value of a coal increases with the proportion of fixed carbon

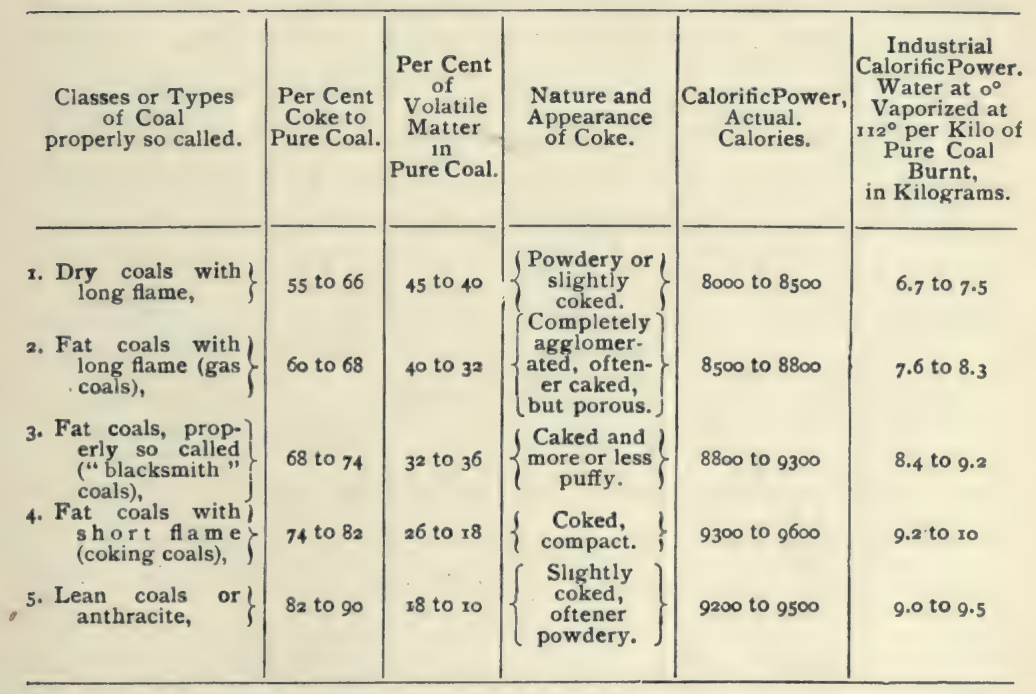

* Annales des Mines, r878, vol. rv. 
or coke formed, this increase is produced gradually by cutting off the lean coals and dividing the fat coals into three classes -gas, forge, and coking.

Bearing on the advisability of having proximate analyses, as well as ultimate analyses of coal, is the question recently brought up by Mr. Kent, regarding the ratio of hydrogen and carbon in coal. In discussing the results of Lord and Haas' determinations of Ohio and Pennsylvania coals, he thought he had discovered the ratio, that the fixed carbon is nearly equal to the total carbon minus five times the available hydrogen in bituminous coals, and minus three times the hydrogen in semi-bituminous ones. He gave a table showing results which support the hypothesis.

\section{LIGNITE.}

From an industrial standpoint lignite is of considerable importance. It occurs in most countries, and is used in a great many for domestic and manufacturing purposes.

As a fuel it is inferior to coal, being less distantly removed from woody fibre, and hence contains more hydrogen and, usually, considerable water. Most of the latter, however, dries out on exposure to the air. In some cases as much as 40 or 50 per cent of water is found in the freshly mined lignite, of which at times 20 per cent remains when air-dried. This greatly affects its value as fuel; still it is used in many of the Western States, and also in Europe. In some European localities, when thoroughly dried and compressed into blocks, especially in Italy and Austria, it is used as fuel for producing gas and for evaporating, with good results. In Austria it is burnt without any preparation, except drying in the air for heating saltpans.

The amount of ash varies exceedingly, being in some cases as low as 0.9 per cent, and in others as high as 58 per 
cent. It even varies in the same locality and in the same bed. In burning lignite there is considerable loss in the waste gases on account of the large quantity of air introduced, and also from the moisture carried off from the fuel.

Brix published the following results with dried lignite:

\begin{tabular}{|c|c|c|c|c|}
\hline \multirow{2}{*}{\multicolumn{2}{|c|}{ Lignite of Aussig, Bohemia ........ }} & \multicolumn{2}{|c|}{$\begin{array}{l}\text { Water Evap- } \\
\text { orated. }\end{array}$} & $\begin{array}{l}\text { Per cent } \\
\text { Ash. }\end{array}$ \\
\hline & & 5.8 & ounds & 15.0 \\
\hline & " Perleberg, " $\quad \ldots .$. .. & 5.6 & “ & 6.0 \\
\hline “" & " Goldfuchs n. Frankfort... & $5 \cdot 5$ & “ & 9.1 \\
\hline “ & "Rauen........... & $5 \cdot 4$ & “ & 6.3 \\
\hline
\end{tabular}

Bunte used two kinds of lignite in boiler-tests, and gives the following results:

\begin{tabular}{|c|c|c|c|}
\hline & \multirow{2}{*}{$\begin{array}{l}\text { Neusattel. } \\
42.8 \\
19.6\end{array}$} & \multirow[t]{2}{*}{$\begin{array}{l}\text { Chodan. } \\
49.2\end{array}$} \\
\hline & alories in steam $\ldots \ldots \ldots \ldots \ldots \ldots$ & & \\
\hline ، & " aqueous vapor........ & 9.2 & 8.7 \\
\hline “ & "ash $\ldots \ldots \ldots \ldots \ldots \ldots$ & 9.0 & 6.1 \\
\hline “ & unaccounted for......... & 19.4 & 15.0 \\
\hline
\end{tabular}

The grate used was a step grate (Treppen-Rost).

The lignite used on the railways in Italy contained I 5 per cent of water, and gave a yield of heat equal to one half its weight of coal.

Analogous to the lignites are certain shales or fossils carrying bitumen. They are sometimes termed boghead cannel, bituminous schist, etc. They are distilled in some localities for oil, but are not much used as fuel.

Bunte determined the heat of combustion of a sample from Australia, and analyzed one from Scotland.

Carbon. Hydrogen. $\mathrm{O}+\mathrm{N}$. Calories. $\begin{array}{llll}\text { Boghead shale, Australia. 83.17 } & \text { 10.04 } & 6.79 & 9134\end{array}$ Scotch Boghead ..... 81.54 II.62 6.84 
Scotch Boghead generally contains 18 to 24 per cent of ash. From its analysis as above, its heat of combustion should be near that of the other one given.

\section{PEAT.}

Peat is formed by the agglomeration of vegetable débris, and retains a large amount of water, which will not separate without heat. Its composition varies but little from that of wood, the principal difference being less oxygen and more carbon.

The composition may be represented by-

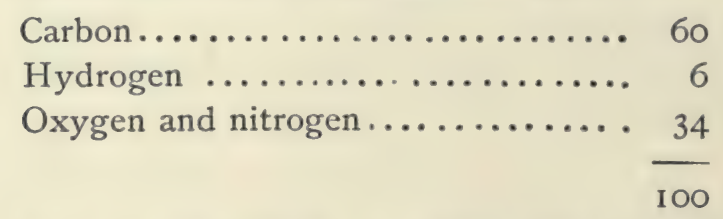

The heat of combustion is lower than that of coal or lignite, as might be expected. The quantity of hydrogen exceeds that necessary to form water with the oxygen.

It is usually dried before using, and when dry becomes quite porous. It carries, however, in this state some Io to I 5 per cent of water, which can be expelled only by artificial means. Large quantities of it are converted into charcoal in special kilns, and, where the large amount of ash is no objection, it makes a good fuel. It cannot be used for metallurgical purposes on account of its friability. From 30 to 40 per cent of its weight is left in the charcoal as carbon, but at the same time the ash increases to 15 to 25 per cent, and even more. This consists principally of phosphates and sulphates, with very little carbonates; hence it is not as apt to clinker as other fuel ashes.

Brix obtained with peat an evaporative power of 5.II pounds of water. The peat used was from Flatow, and contained I0.7 per cent of ash. Another, from Buchfeld-Neulangen, contained 1.2 per cent of ash, and gave 5.12 pounds 
evaporated. Noury, using a special grate, obtained from the Alsace peats 4 to 5 pounds evaporation (ashes deducted).

Bunte analyzed the gases produced by the combustion of peat on the hearth of a salt-pan, and found, carbonic acid I 3 , oxygen 6.4 , nitrogen 80.6 .

Karsten says that $2 \frac{1}{2}$ pounds of peat are equal to one of coal. In some experiments made, at St. Petersburg a firegrate of 32 square feet and 696 square feet of boiler heating surface was used. The peat was compact, hand-moulded into 4-inch balls, and dried till moisture did not exceed I4 per cent. 4. 26 pounds of coal were evaporated for I of peat.

Crookes and Rohrig, in their "Metallurgy," say: "One pound of dry turf will evaporate 6 pounds of water. Now in I pound of turf, as usually found, there are $\frac{8}{4}$ pound of dry turf and $\frac{1}{4}$ pound of water. The $\frac{3}{4}$ pound can evaporate $4 \frac{1}{2}$ pounds of water; but out of this it must first evaporate the $\frac{1}{4}$ pound of water contained in its mass, and hence the water boiled away by such turf reduces to $4 \frac{1}{4}$ pounds. The yield is here reduced 30 per cent, a proportion which makes all the difference between a good fuel and one almost unfit for use. When turf is dried in the air under cover it still retains $\frac{1}{10}$ of its weight of water, which reduces its calorific power I 2 per cent ; I pound of such turf evaporates $5 \frac{1}{3}$ pounds of water."

\section{COKE.}

Coke usually met with is from three sources: from gascoal, and made in gas-retorts; from gas or ordinary bituminous coal, and made in special ovens; from petroleum, and made by carrying the distillation of the residuum to a red heat.

Coke from gas-works is usually softer and more porous than the other kinds, burns more readily, but does not give as intense a heat. It has been used considerably for domestic heating, and in factories where a high heat is not needed but where a smokeless fuel is desirable. The oven coke is usually in large columnar masses of a close texture and quite 
hard. It has a dead gray-black color and is not susceptible of polish. It is principally used in furnaces requiring a blast, although limited quantities of it have been used in domestic heating, for which purpose it must be broken up much finer than its usual size. Petroleum coke is generally in large irregular lumps, perforated with cavities of greater or less size, the interior of which is usually quite smooth and shining. Its color is blacker than that of gas or oven coke, and its hardness intermediate. It is used principally for making electric carbons, although considerable quantities are used for fuel.

With the exception of gas-coke very little use is made of this fuel for steaming, the fire being too intense locally, and hence very apt to burn out the boiler directly over it. In all cases plenty of air is needed to keep up the combustion, which is also a drawback for steaming purposes. For metallurgical furnaces it is different. Here it is almost the ideal fuel, giving an intense reducing heat at just the part of the furnace where most needed. It has been used in iron furnaces for years, and is still the favorite fuel. It is superior to anthracite, as it has no tendency to splinter and crack with the heat, and bears its burden very well. Of course this does not apply to ordinary gas-coke, which crushes easily.

Coke is essentially carbon, and the mineral portions of the coal from which it is made. It contains small quantities of hydrogen and nitrogen, as may be seen from the tables. The percentage of these, however, is very low, so that the calculated and observed heat-units are usually within the limits of error, as is shown in the following table:

\begin{tabular}{|c|c|c|c|c|c|c|c|}
\hline Name. & c. & H. & N. & Loss. & $\begin{array}{l}\text { Calories } \\
\text { observed. }\end{array}$ & $\begin{array}{c}\text { Calories } \\
\text { calculated. }\end{array}$ & Authority. \\
\hline Saarbruck..... & 98.04 & 0.73 & $\ldots$ & I.23 & 8200 & 8229 & Bunte \\
\hline Petroleum coke & 98.05 & 0.50 & 0.25 & I. 20 & 8057 & $81_{5} \mathrm{I}$ & Mahler \\
\hline Graphite ....... & 98.98 & 0.02 & $\cdots$ & $\ldots$ & 7901 & 8054 & Berthelot \\
\hline
\end{tabular}




\section{WOOD CHARCOAL.}

Wood charcoal always contains quantities of hydrocarbons which have resisted the action of heat. That called forest charcoal, made by burning in heaps, is the most charged with them; that obtained from distillation of wood in retorts contains less.

The heat of combustion is very variable. According to Berthier* commercial wood charcoal contains ro per cent of volatile matters and 2 per cent of ash (carbon 80 to 90 , hydrogen 1.5-4).

Pure wood charcoal was first tested calorimetrically by Favre and Silbermann, and since then by several experimenters. To obtain it pure it was calcined strongly and treated with chlorine to remove all traces of hydrogen. In this state wood-charcoal produces under constant pressure 8080 calories, F. \& S., or 8100 S.-K. \& M.-D.; with constant volume Berthelot and Petit obtained 8I 37 calories.

Several years ago Berthier pointed out that half-burnt charcoal, charbon roux or Rothkohle, was superior in combustible content to that perfectly burnt. Sauvage has confirmed this, and gives the following results:

\begin{tabular}{|c|c|c|c|c|c|c|}
\hline $\begin{array}{l}\text { Ioo lbs. of wood } \\
\text { charred for...... }\end{array}$ & 3 hours. & 4 hours. & 5 hours. & $5 \frac{1}{2}$ hours. & $6 \frac{1}{2}$ hours. & $\begin{array}{l}\text { Mound } \\
\text { Charcoal. }\end{array}$ \\
\hline $\begin{array}{l}\text { Weighed ........ } \\
\text { roocu.ft.measured }\end{array}$ & $\begin{array}{l}65.4 \text { lbs. } \\
86 \mathrm{cu} . \mathrm{ft}\end{array}$ & $\begin{array}{l}53.0 \text { lbs. } \\
76 \mathrm{cu} . \mathrm{ft}\end{array}$ & $\begin{array}{l}47.0 \text { lbs. } \\
58 \mathrm{cu} . \mathrm{ft} .\end{array}$ & $\begin{array}{l}4 \mathrm{r} .5 \mathrm{lbs} . \\
55 \mathrm{cu} . \mathrm{ft} .\end{array}$ & $\begin{array}{l}39 . \text { I lbs. } \\
52 \mathrm{cu} . \mathrm{ft} .\end{array}$ & $\begin{array}{l}\text { I } 7.2 \mathrm{lbs} . \\
33 \mathrm{cu} . \mathrm{ft} .\end{array}$ \\
\hline
\end{tabular}

and

I cubic foot wood contained of combustible matter 908 parts.

\begin{tabular}{|c|c|c|c|c|c|c|c|c|}
\hline & “" & “" & 3 hours' 1 & eating & “، & “" & "6 & 883 \\
\hline I & “" & “‘ & 4 “ & $"$ & “6 & “" & “ & 904 \\
\hline & “" & "“ & " & "، & "6 & "6 & “" & I I 33 \\
\hline & "“ & “" & $5 \frac{1}{2}$ “ & “" & “ & “" & “" & IO9I \\
\hline & “” & "“ & $6 \frac{1}{2} “$ & “" & “ & “ & “، & I I 36 \\
\hline I & ““ & "“ & charcoal & “" & “6 & “ & “6 & 1069 \\
\hline
\end{tabular}

* Traité des essais par la voie sèche, vol. I, p. 286. 
So that the amount of combustible matter does not increase after 5 hours' heating, and a continuance of the heat diminishes it.

The principal use of charcoal is in iron furnaces, where it has been used for years, and produces the highest grades of iron, being free from sulphur and phosphorus. A small amount is used in private dwellings and hotels for heating and cooking. For boiler heating it has been used only experimentally.

Scheurer-Kestner and Meunier-Dollfus experimented with it in boiler-heating and found very little combustible gas in the products. Beech charcoal was used, and an evaporative effect of 7.62 pounds of water was obtained. The waste gases contained:

Carbonic acid............... I I. I6 per cent.

Carbonic oxide.............. 0.37 "

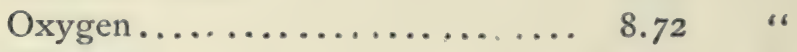

Nitrogen .................. 79.75 “

100.00

Brix, using wood and peat charcoal, obtained the following results :

Wood charcoal ........ 7.55 pounds evaporated.

Peat charcoal.........6. 6.85 " "

Schwackhöfer burnt charcoal from hard and soft wood in his calorimeter and obtained (constant volume) 7 I 40 calories for the soft charcoal and 707, I calories for the hard. The charcoal in both cases was the ordinary unpurified charcoal as sold.

\section{WOOD.}

Wood consists of a compact tissue more or less hard, formed of cellulose and a so-called incrusting substance. 
Wood contains, besides, small quantities of mineral matter and hygroscopic water varying from 15 to 30 per cent, according to dryness. Air-dried, it contains about 15 per cent of water, which it gives up easily on exposure to a heat of $100^{\circ} \mathrm{C}$.

The composition of wood may be represented by the following :

\begin{tabular}{ccccccc}
\multicolumn{8}{c}{ Carbon. Hydrogen. Oxygen. Ash. Water. } \\
Wood dried at $100^{\circ} \ldots \ldots$ & 49.5 & 6.0 & 43.5 & 1.0 & 0.0 \\
$"$ " & in the air.... & 29.6 & 4.8 & 34.8 & 0.8 & 29.0
\end{tabular}

Regarding wood from its ultimate composition, we may consider it as a hydrate of carbon, that is, as carbon united to water, the proportion of hydrogen and oxygen being nearly the same as in water. But regarded from its proximate composition, it is entirely different. What has been said of soft coal can be repeated for wood; that, those having a similar ultimate composition behave differently in distillation in a closed retort and produce very different proportions of carbon (as charcoal); hydrocarbons, liquid or gaseous; acid products, resin, and tar. It was supposed that the heat of combustion differed also, and this has been verified by experiments.

Berthelot and Vielle determined the heat of combustion of cellulose, and found 680 calories for the molecular weight of wood, or about 4200 calories per kilogram.

Hard wood gives less heat than soft wood. According to Gottlieb's experiments, pine-wood has a heat value of 5000 calories, while oak gave only 4620 calories. Mahler's experiments confirm a difference in favor of pine, but in less proportion.

Two determinations made by Mahler are (cinders and water deducted) :

\begin{tabular}{|c|c|}
\hline Carbon....$\ldots \ldots \ldots \ldots \ldots \ldots$ & $\begin{array}{l}\text { Fir. } \\
5 \text { I.08 }\end{array}$ \\
\hline 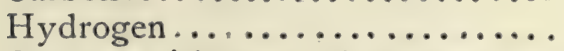 & 6.12 \\
\hline Oxygen with trace of nitrogen.... & 42.90 \\
\hline & 100.00 \\
\hline
\end{tabular}


Gottlieb obtained the following numbers, using a calorimeter of constant pressure, in which he burnt 2 grams of wood in the space of two or three minutes. The composition of the gas produced was not determined; he was satisfied that he had perfect combustion, and his figures do not appear very far from the truth. For cellulose he obtained 4I55. calories.

\begin{tabular}{|c|c|c|c|c|c|c|c|}
\hline Name. & c. & H. & N. & o. & Ash. & Calories. & B. T U. \\
\hline Oak....... & 50.16 & 6.02 & 0.09 & $43 \cdot 36$ & 0.37 & 4620 & 8316 \\
\hline Ash $\ldots . . . \ldots \ldots$ & $49 \cdot 18$ & 6.27 & 0.07 & $43.9 \mathrm{r}$ & 0.57 & 4711 & 8480 \\
\hline $\operatorname{Elm} \ldots \ldots \ldots \ldots$ & 48.99 & 6.20 & 0.06 & $44 \cdot 25$ & 0.50 & 4728 & 8510 \\
\hline Beech......... & 49.06 & 6.11 & 0.09 & $44 \cdot 17$ & 0.57 & 4774 & $859 \mathrm{I}$ \\
\hline Birch $\ldots . . . . . . .$. & 48.88 & 6.06 & 0.10 & 44.67 & 0.29 & $477 \mathrm{I}$ & 8586 \\
\hline Fir............. & 50.36 & $5 \cdot 92$ & 0.05 & $43 \cdot 39$ & 0.28 & 5035 & 9063 \\
\hline Pine.......... & $50.3 \mathrm{I}$ & 6.20 & 0.04 & 43.08 & 0.37 & 5085 & 9153 \\
\hline
\end{tabular}

Gottlieb's results are 69 calories less than Mahler's for oak and 207 more for fir.

In burning wood for steaming the fire is easily controlled; combustion is more complete; the products of combustion contain only very small quantities of unburnt gases; and the ashes are generally free from carbon. The countries using wood for this purpose are growing less in number yearly, on account of improvement in transportation and the discovery of new coal seams; petroleum oils for fuel have also become more common, especially in Russia, the United States, and Canada.

Morin and Tresca, in their tests, found that one pound of wood was equivalent to 0.368 pound of coal. ScheurerKestner's experiments in $187 \mathrm{I}$ show results more favorable for wood. The wood used was Vosges fir, which had been piled under cover for half a year. A cubic foot weighed 19.76 lbs. It was burnt in the same boiler used in his previous experiments, with the result that I pound of wood evaporated 4.4 pounds of water. The ratio was 0.490 , or nearly one half that of Ronchamp coal. 
Brix made a number of experiments in using wood for heating, and found that dry pine gave the best results -5 pounds per pound of fuel. Elm gave 4.6 pounds; birch, 4.6; oak, 4.56; ash, 4.63; and beech, 4.47.

Wood should be dry as possible, as otherwise it has to furnish heat to vaporize, not only the water formed from its hydrogen, but also that already existing as moisture. We have seen that this loss with coal is considerable, it is still greater with wood. Suppose the wood to be ordinary air-dried, containing 20 per cent of water. If this wood, when perfectly dry, could evaporate 5 pounds of water, it now has only $\frac{4}{5}$ of that power, or power to evaporate 4 pounds; but it already carries $\frac{1}{5}$ of its weight of water, which must be vaporized. Hence the available power is 4 pounds less $\frac{1}{5}$ pound $=$ $3 \frac{4}{5}$ pounds, or 76 per cent of its dry value. Hence the economy of using only dried, and even artificially dried, wood. 


\section{CHAPTER VIII.}

\section{LIQUID FUELS.}

\section{SHALE-OILS.-PETROLEUM.}

THE mineral oils comprehend the liquid hydrocarbons extracted from bituminous schist or coal and its congeners by distillation, as well as the oils which exist already formed in the earth, and called by the special name of petroleum.

While the former are seldom employed in heating, petroleum has become an important fuel in the countries which produce it. Its special qualities, light weight, and low price per calorie compared with other fuels insure a great future. The knowledge of its heat of combustion has become, then, of considerable interest.

Its ultimate percentage composition varies within rather close limits, yet it is of a very complex proximate composition. The industry of refining crude petroleum extracts from it some 50 per cent of refined oil for use in lamps, and having a density of $45^{\circ}$ to $47^{\circ}$ Beaumé, boiling-point $170^{\circ} \mathrm{C}$. $\left(328^{\circ} \mathrm{F}\right.$. $)$; ro per cent of naphtha with a lower density and boiling-point; and 20 per cent of paraffin oil of a higher density and boiling-point.

Crude petroleum contains a large number of hydrocarbons of the general formula $\mathrm{C}_{n} \mathrm{H}_{2 n+2}$, and running from $\mathrm{CH}_{4}$ to $\mathrm{C}_{10} \mathrm{H}_{34}$, with many isometric modifications. The industrial treatment modifies it profoundly. Hydrocarbons containing 95 per cent of carbon have been found in the products of distillation.*

\footnotetext{
* Wurtz, Dictionnaire de Chimie, Supplement.
} 
The first calorimetric experiments were published by Ste.Claire Deville in $\mathbf{1 8 6 8}$ or 1869 , using a large calorimeter especially constructed for the work. Mahler used the bomb. The liquids were burnt in the bomb under nearly the same conditions as solids, when they had no appreciable vapor tension. When they had considerable vapor tension (light oils, for instance) Berthelot placed them in a closed vessel, the bottom being platinum and the top formed by a pellicle of gun-cotton.

Heating by oil is quite recently introduced, but is already developed to a high degree in Russia and on this continent, and is gaining in other localities. The small volume occupied in comparison with its high calorific power renders it a formidable competitor with coal.

To burn petroleum, atomizers fed by steam or compressed air are used. They generally consist of a horizontal pipe under the boiler, fed with oil from an elevated reservoir placed at a presumably safe distance. The steam enters inside the oilpipe, and, mixing with the oil, throws it into a spray and produces a flame several feet long. At the Chicago Exposition 52 tubular boilers were exhibited heated by oil, developing a power of 25000 H.P., and yielding a total evaporation of 12000 cubic feet per hour. The oil used was the heavy portion of petroleum (the lighter ones having been distilled off for illumination), and it was fed under a pressure of one-fourth atmosphere. The result was an evaporation of about I5 pounds of water per pound of oil.

In 1889 Albert Hubner ran a whole battery of boilers with oil at his works in Moscow. He used Baku Nafta, or "Mazoute," which contained carbon 86.3, hydrogen 13.6, and oxygen O. I per cent. The density was 0.9 IO to 0.9I4.

At Petrolea and Oil City, Canada, the heavy residuum from the stills is used as fuel under boilers and stills. The burners used are very simple, and run without producing smoke. In the United States, the Standard Oil Company has 
pushed the sale of fuel-oil made of Ohio crude, and large quantities of it have been used; large quantities of a special grade are also made for use in enriching water gas.

The calorific power of petroleum residuum is, according to Sainte-Claire Deville, I 460 calories (20628 B. T. U.), the evaporation at 5 pounds pressure being 15 pounds. This compared with the heat of combustion shows a useful effect of over 86 per cent, while the entire absence of smoke, unburnt gases, ashes, and irregularity in air-supply add to its advantages still more.

Some experiments made at the Hecla Engineering Works, Preston, England, and lasting two days, used a marine boiler. The first day natural draft was used, the second a Körting blower. The oil was blast-furnace oil from Sheffield, and contained:

Per cent.

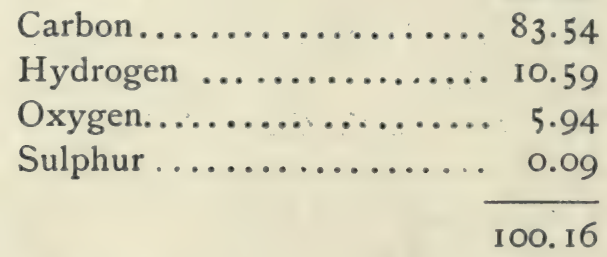

By Thompson's calorimeter its value was I6080 B. T. U. Equivalent to water at $212{ }^{\circ} \mathrm{F} \ldots \ldots \ldots .16 .66$ pounds.

The results were: First day, I4.97 lbs. ; second day, I4.2 I lbs.,-a yield of 89.87 and 85.25 per cent of the theoretical.

A series of tests made at South Lambeth with a Cornish boiler showed 20.8 lbs. evaporation; average of several days, I9.5 lbs. The same boiler with the best Aberdeen coal yielded 6.5 lbs., -an advantage of 3 to $I$ in favor of the oil.

The following analyses of the waste gases from boilers using oil show how perfect the combustion is, and that little if any excess of air is needed: 


\begin{tabular}{|c|c|c|}
\hline $\mathrm{CO}_{2} \ldots \ldots \ldots \ldots$ & 14.19 & I 8.08 \\
\hline $\mathrm{CO} \ldots \ldots \ldots \ldots$ & 5.20 & 0.34 \\
\hline $0 \ldots \ldots \ldots$ & 0.78 & 0.34 \\
\hline Hydrocarbons.... & 1.30 & None. \\
\hline$H \ldots \ldots \ldots \ldots$ & Not determined. & None. \\
\hline $\mathrm{N}, \ldots \ldots \ldots \ldots \ldots$ & 78.53 & 81.24 \\
\hline
\end{tabular}

To have the best results, the burner must be so regulated as to have a flame bordering on, but not quite, smoky. Thus sufficient and not too much air is obtained. The quantity of steam needed to atomize the oil at Moscow is 4 per cent of the water evaporated. The use of compressed air has been tried in some places with very satisfactory results: the atomizing is good, but the cost is higher, and the probable chemical effect of the steam is wanting.

Nothing but a bare mention need be made of animal and vegetable oils, as they are not used in the arts for heating purposes except, perhaps, on very exceptional occasions. The calorific power of all of them is high, as may be seen from Table I. 


\section{CHAPTER IX. \\ GASEOUS FUELS.}

THE heat of combustion of gaseous combustibles has been determined for a great many compounds, definite and pure. That of the industrial gases has been determined by different operators and in different ways, with more or less happy results. Its determination is often one of the greatest commercial interest, since it is used in domestic heating as well as in industrial appliances, where it is necessary to obtain definite, regular working. It serves also to furnish motive power to gas-engines, in which the heat of combustion is not without importance. Finally, it is well to know the heat produced in air or water-gas apparatus, if we wish to reach the best condition for their production and use.

For heating steam-boilers gas has given good results and a very high evaporative effect. It is easily regulated, and thus any required heat can be produced by simply turning a valve. No smoke is generated, no soot.or deposit of any kind produced in the flues, and no ashes to take out of the ash-pit. The fireplace needs repairing but seldom, and the boiler is heated eventy and regularly, there being no danger of burning out in strongly heated spots, as no such spots exist.

In metallurgical furnaces, gas possesses a decided advantage in its long, clean, easily managed, intense flame, and this advantage has been long recognized. A flame of 25 feet or more in length is easily produced, and it is practically uniform for its whole extent. Part of the heat usually lost up the chimney can be utilized to heat the air-supply, and no more is supplied than just enough for perfect combustion.

Using gas as fuel enables the metallurgist to use poor 
grades of coal, and all variations in quality may be eliminated, a uniform product being had by storing the gas in a holder, or by making proper arrangement of different generators so that an average will be obtained. In several cases where hand-fed coal fires have been tried against fires burning gas from the same coal, better results have been obtained, due to the possibility of more closely adjusted regulation. The tests made at Brieg may be cited. Here each boiler had I4I.25 square feet of heating-surface and steam-pressure 6 to 7 atmospheres.

No. I boiler was hand-fired; No. 2 was gas-fired. The evaporation in pounds per pound of fuel was :

$\begin{array}{lcccccc}\text { No. } 1 \ldots . . & 8.34 & 8.74 & 8.28 & 4.02 & 2.569 & 2.764 \\ \text { No. } 2 \ldots . . & 9.86 & 9.73 & 10.07 & 5.44 & 3.251 & 3.158 \\ \text { Increase... } & 18 \% & 12 \% & 20 \% & 35 \% & 25 \% & 14 \%\end{array}$

\section{HEAT OF COMBUSTION OF GASES FROM ANALYSIS.}

When the chemical composition of a gas is known exactly, its heat of combustion can be correctly calculated; but in absence of a correct analysis, the calorimeter must be used.

Knowing the proximate composition of a combustible gas, that is, the proportion of chemically defined components as well as their heats of combustion, it is sufficient to add the numbers obtained for each constituent gas. Take, for example, the analysis of illuminating gas of Manchester as given by Bunsen:

Hydrogen.................. 45.58

Marsh gas $\left(\mathrm{CH}_{4}\right) \ldots \ldots \ldots \ldots \ldots \ldots . \ldots . \ldots . \ldots 34.90$

- Carbonic oxide.............. 6.64

Ethylene $\left(\mathrm{C}_{2} \mathrm{H}_{4}\right) \ldots \ldots \ldots \ldots \ldots \ldots \ldots \ldots \ldots$

Butylene $\left(\mathrm{C}_{4} \mathrm{H}_{8}\right) \ldots \ldots \ldots \ldots \ldots \ldots, 2.38$

Sulphydric acid.............. 0.29

Nitrogen .................... 2.46

Carbonic acid.................. 3.67 
The calculation is as follows:

\begin{tabular}{|c|c|c|c|c|}
\hline Components. & $\begin{array}{l}\text { No.of Litres per } \\
\text { Cubic Metre. }\end{array}$ & $\mid \begin{array}{l}\text { Weight per Cubic } \\
\text { Metre at } 0^{\circ} \text { and } \\
70^{\circ} \text { mm. } \\
\text { Grams. }\end{array}$ & $\begin{array}{l}\text { Heat of } \\
\text { Combustion per } \\
\text { Cubic Metre. }\end{array}$ & $\begin{array}{l}\text { Calculated } \\
\text { Calories. }\end{array}$ \\
\hline $\begin{array}{l}\text { Hydrogen............ } \\
\text { Marsh gas, } \mathrm{CH}_{4} \ldots \ldots \ldots \\
\text { Olefiant gas, } \mathrm{C}_{2} \mathrm{H}_{4} \ldots \ldots \\
\text { Butylene, } \mathrm{C}_{4} \mathrm{H}_{8} \ldots \ldots \ldots \\
\text { Carbonic oxide } \ldots \ldots \ldots \ldots \\
\text { Sulphydric acid, } \mathrm{H}_{2} \mathrm{~S} \ldots\end{array}$ & $\begin{array}{l}455.8 \\
369 \\
40.8 \\
23.8 \\
66.4 \\
2.9\end{array}$ & $\begin{array}{r}89.61 \\
715.58 \\
1251.94 \\
2503.88 \\
1251.50 \\
2551.99\end{array}$ & $\begin{array}{r}3066 \\
9340 \\
14980 \\
29042 \\
3057 \\
\text { I } 1400\end{array}$ & $\begin{array}{r}1395 \\
3169 \\
611 \\
690 \\
201 \\
33\end{array}$ \\
\hline 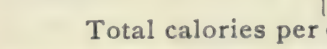 & & & & 6099 \\
\hline
\end{tabular}

City of Manchester gas, as analyzed by Bunsen, gives, then, with complete combustion, 6099 calories per cubic metre ( 685 B. T. U. per cubic foot).

If, however, only the actual ultimate composition of the gas is known or the total percentage of carbon, hydrogen, oxygen and nitrogen, then the calculated result will differ from the experimental one. This is because the heat units of the elements added together do not make those of the compound, as the heat of combination of the different constituent gases is not allowed for. If this factor is known, then it can be used as a correction and the correct heat determined.

This heat of combination of the elements to form the component gases will be seen in comparing the calculated and the actual heat of combustion of the following gases:

\begin{tabular}{|c|c|c|c|c|c|c|}
\hline Gases. & Formulæ. & Carbon. & $\begin{array}{l}\text { Hydro- } \\
\text { gen. }\end{array}$ & $\begin{array}{c}\text { Calculated } \\
\text { Heat. }\end{array}$ & $\begin{array}{c}\text { Actual } \\
\text { Heat }\end{array}$ & $\begin{array}{l}\text { Differ- } \\
\text { ence. }\end{array}$ \\
\hline Marsh gas... & $\mathrm{CH}_{4}$ & 75. & 25. & I 4685 & I3343 & +1342 \\
\hline Olefiant gas. & $\mathrm{C}_{2} \mathrm{H}_{4}$ & 85.7 & $14 \cdot 3$ & 11859 & 12182 & -323 \\
\hline Acetylene....... & $\mathrm{C}_{2} \mathrm{H}_{2}$ & .92 .3 & $7 \cdot 7$ & IOII 4 & I $2 \mathrm{I}_{42}$ & -2028 \\
\hline Benzene........ & $\mathrm{C}_{6} \mathrm{H}_{6}$ & 92.3 & $7 \cdot 7$ & IOII4 & $124 \mathrm{IO}$ & -2296 \\
\hline
\end{tabular}

It will also be seen, that although two gases may have the same percentage composition of the elements, yet the heat of combustion may be different owing to the action of the various physical forces at work in molecular condensation, etc. 
COAL GAS.

The heat of combustion of illuminating gas obtained from the distillation of coal in closed retorts is very variable. It depends not only on the nature of the fuel, but also on the rapidity of the distillation and the heat by which it is accom plished. The heat of combustion varies from 5200 to 6300 calories per cubic metre. It cannot be represented by any average number.

According to Witz, at the same gas-works and with the same fuel, yields may occur from 4719 to 5425 calories. According to Bueb-Dessau, the illuminating gas of the same city during the same day will sometimes vary 20 per cent. Dr. Birchmore reports the same result from his examinations of the gas of Brooklyn, N. Y.

We are not certain that the composition assigned to coal gas by analysis corresponds always to the gas as obtained by distillation; in Europe, especially, a portion of the heavy hydrocarbons is taken out for sale separately, and the deficiency supplied by cheaper oils.

From several experiments which he made, Bueb-Dessau* thought that the heat of combustion of illuminating gas was directly proportional to the candle power; but in addition to this being opposed to the theory of heat, the experiments of Aguitton show the contrary. He concluded from his determinations that each illuminating gas of different candle power has a definite heat of combustion which corresponds to the intensity of the light. His experiments were carried on with more than a hundred samples, rich and poor, the former kind from cannel coal, the latter from the end of the run carried to an extreme. He represents by the following formula the

* Bueb-Dessau cites the following among others:

\begin{tabular}{|c|c|}
\hline Gas of Dessau.............14. & $\begin{array}{l}\text { Heat-value. } \\
\qquad 4400 \text { calories }\end{array}$ \\
\hline Gas of Bremen............ 21.9 & 5977 \\
\hline Gas from cannel coal........ 26.0 & 6559 \\
\hline
\end{tabular}


relation between candle power and heat of combustion of a gas:

$$
c=i \times 352.6+2280 \text {, }
$$

in which $c$ represents the heat of combustion and $i$ the candle power. The formula seems to be applicable only between limits at which it has been verified-from 5 to 15 candles. Aguitton's determinations were made with the calorimetric bomb.

The following table gives a résumé of his observations:

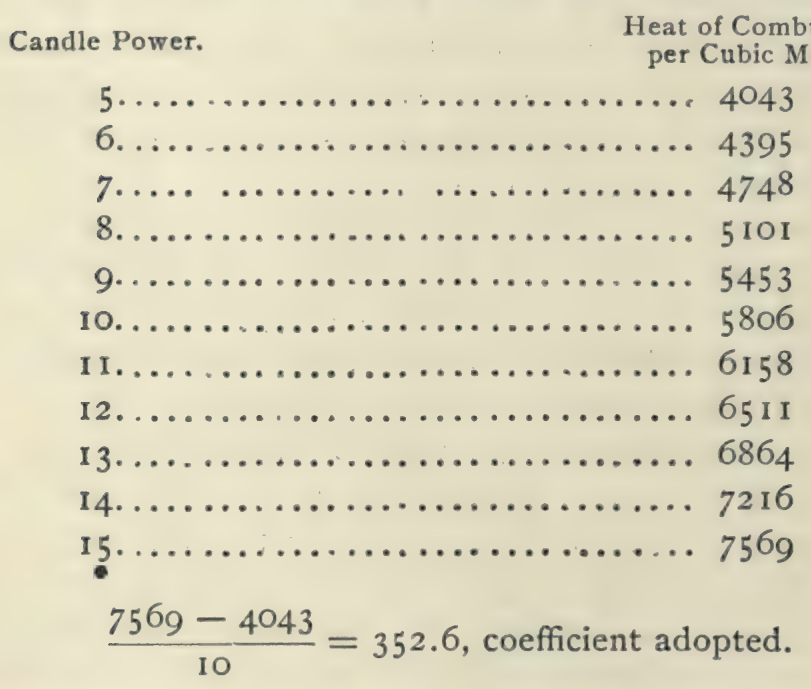

The three samples of illuminating gas, analyzed and burnt in the bomb by Mahler and given in the table below, call for the following observations: Gas from Niddrie cannel coal, the most calorific per cubic metre is the least calorific per kilogram, because the density is greater than that of the other two. The richest in hydrogen by volume (Lavillette) is the poorest in calorific power per cubic metre, while the poorest in hydrogen by weight is the richest in calories per cubic metre. These are due to the low density of hydrogen, which 
is less calorific by volume than the other hydrocarbons occurring in illuminating gas.

\begin{tabular}{|c|c|c|c|c|c|c|c|c|}
\hline \multirow[b]{2}{*}{ Name. } & \multirow[b]{2}{*}{ 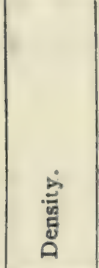 } & \multicolumn{5}{|c|}{ Analysis by Weight. } & \multicolumn{2}{|c|}{ Heat of Combustion } \\
\hline & & 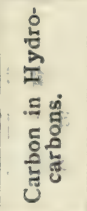 & 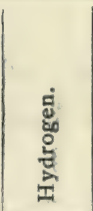 & 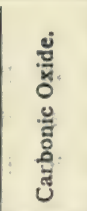 & 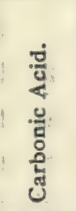 & 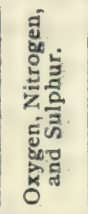 & 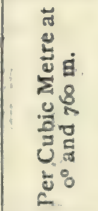 & 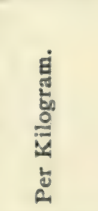 \\
\hline Niddrie cannel.. & 0.6367 & $43 \cdot 33$ & 13.50 & I6.84 & $9 \cdot 26$ & I 4.96 & 6365 & 7735 \\
\hline Commentry coal. & 0.4046 & $43 \cdot 74$ & 21.46 & 24.96 & 7.08 & $5 \cdot 75$ & 5834 & II IOO \\
\hline Lavillette gas... & 0.4033 & 42.25 & $2 \mathrm{I} \cdot 34$ & 21.23 & 6.83 & 8.33 & 5602 & I0764 \\
\hline
\end{tabular}

A cubic metre of hydrogen develops 309I calories in burning; a cubic metre of marsh gas develops 10038 calories; a cubic metre of olefiant gas, 15250 calories.

\section{GAS OF GASOGENES.}

The gasogenes, instead of transforming the fuel into carbonic acid and water in a single combustion, produce this change in two distinct burnings, the first being to make a combustible gas and the second to burn this gas with air.

In the first furnace, the coal, for example, is burnt in such a manner by feeding with an insufficient supply of air that a gaseous mixture is produced, containing principally carbonic oxide, besides nitrogen from the air. As the combustion has been well or poorly managed, it contains a less or greater quantity of carbonic acid, the production of which is avoided as much as possible. This is done by giving to the fuel only just enough air to form carbonic oxide, and not enough to form carbonic acid, even partially, and by making the bed of fuel quite deep.

The heat produced by this combustion is not used, and consequently an important part of the calories of the coal is lost. Gasogene gas is then lower in calories, and inferior to coal gas, as commonly made by distillation. 
One kilogram of carbon burnt to carbonic oxide disengages 2489 calories, while I kilogram of carbon burnt to carbonic acid generates 8137 calories. There is lost; then, in burning carbon to carbonic oxide in a gasogene about 30 per cent of the available calories.

At first sight this method of working seems irrational, but for obtaining high temperatures there are practical advantages, whose importance far exceeds the loss of heat in the gasogene. It permits much more elevated temperatures, and the recovery of a large portion of the heat, which in direct systems of heating in high temperature furnaces passes to the chimney as complete loss. There is actually an economy in the ordinary metallurgical methods even with this loss.

By means of gasogenes, we produce three kinds of gaseous fuel : the gas called producer or air gas, formed by the incomplete combustion of the fuel, with production of a mixed gas containing carbonic oxide and hydrogen compounds; the gas called water gas, from the decomposition of water by carbon at a high temperature, with production of carbonic oxide, hydrogen, and hydrogen compounds; 'and the gas called mixed gas, from the mixture of the two preceding ones by a process which combines the production of the two gases in the same furnace.

\section{PRODUCER OR AIR GAS.}

We have said that air gas results from incomplete combustion, and that its formation causes a loss of one third of the calories resulting from the complete combustion of the fuel. These gases contain, naturally, the nitrogen of the air used, to which must be added that of the air necessary to change the carbonic oxide and the hydrogen to carbonic acid and water.

The heat of combustion and the composition determined by different experimenters varies considerably, showing that they did not always work with average samples. 
The proportion of nitrogen in these gases reaches 56 to 60 per cent; that of carbonic oxide, 2 I to 32 per cent; that of of hydrogen, from traces to 17 per cent. The theoretical calculation for the combustion of carbon in air to a gas containing only carbonic oxide and nitrogen gives for the first 34.7 and for the second 65.3 per cent.

By adopting for the composition of air the round numbers 79 and 21 , and for the weight of oxygen 1.430 grams per litre, for carbon the atomic weight of 12 , and for oxygen 16 ,

$$
12: 16=1000 \text { grams : } 1333 \text { grams. }
$$

A kilogram of carbon needs, then, I $\frac{1}{8}$ kilograms of oxygen. A litre of oxygen weighing I.430 grams, I 333 grams would occupy 932 litres. These 932 litres will give with carbon a double volume, or 1864 litres carbonic oxide. Multiplying 932 litres by the coefficient 4.77 (see Table XIV), we obtain the volume of the air corresponding, or 4445 litres. The gases of combustion will be composed then of these 4445 litres of air and the 932 litres of increase in volume, or 5377 litres for I kilogram of carbon. The 4445 litres of air will contain (at 79 per cent) 3513 litres of nitrogen, or 65.3 per cent.*

The calculation is more complicated when we have fuel containing hydrogen, as one portion of the oxygen disappears by its combination with the hydrogen to form water. Take for example, a coal containing 90 per cent of carbon, 5 per cent of hydrogen, and 5 per cent of oxygen. Suppose I kilogram of this coal, under theoretical conditions, burnt in a gasogene, i.e., with perfect transformation of the carbon into carbonic oxide and no residues. This coal contains 900 grams carbon, 50 grams hydrogen, 50 grams oxygen. 900

* One pound of carbon requires I.333 lbs. of oxygen; I cubic foot of oxygen weighs $0.08926 \mathrm{lb}$; I. $333 \mathrm{lbs}$. measure I4.93 cu. ft. These would give 29.86 of CO. $14.93 \times 4.77=71.216$, and $71.216+14.93=86.146$, volume of gases of combustion. These contain $56.26 \mathrm{cu}$. $\mathrm{ft}$. of nitrogen. 
grams carbon produce 2100 grams carbonic oxide, requiring 1200 grams oxygen. I 200 grams oxygen occupy 839 litres. 50 grams hydrogen produce 450 grams water, and require 400 grams oxygen. These 400 grams oxygen occupy 279 litres. But the coal itself contains 50 grams oxygen, occupying 35 litres.

We have, then, $839+279-35=1083$ litres of oxygen required, and to calculate the amount of air needed multiply by 4.77 . This gives $5 \mathrm{I}_{3}$ litres of air needed for the incomplete combustion of I kilogram of carbon. These 5163 litres contain 4080 litres of nitrogen.

To obtain the total volume of gases produced by the incomplete combustion, we may add to the volume of the air introduced the volume due to the formation of carbonic oxide, and this is equal to the volume of the oxygen used, or 839 litres. We have, then, $5163+839=6002$ litres. But a quantity of oxygen has disappeared corresponding to the formation of the water, or $279-35=244$ litres ( 35 litres exists in the coal as above), and $6002-244=5758$ litres of gas produced by the incomplete combustion of I kilogram of coal.

Now, then, $5 \mathrm{I} 63$ litres of air contain 4079 litres of nitrogen, which would form $\frac{4079}{5758}$, or 70.8 per cent of the tota! gas. All these numbers are at $0^{\circ}$ and $760 \mathrm{~mm}$. pressure.*

Generally gasogenes contain less nitrogen, different causes producing diminution, among which are the use of a lower

* One pound of coal would be 6300 grains carbon, 350 grains oxygen, and 350 grains hydrogen; $0.90 \mathrm{lb}$. carbon produces 2.1 lbs. carbonic oxide, and needs I.2 lbs. oxygen; I. 2 lbs. oxygen occupies I3.44 cu. ft.; $0.050 \mathrm{lb}$. hydrogen produces $0.450 \mathrm{lb}$. water, and needs $0.4001 \mathrm{~b}$. oxygen, or $4.48 \mathrm{cu}$. $\mathrm{ft}$. The $0.05 \mathrm{lb}$. of oxygen in the coal occupies $0.56 \mathrm{cu}$. ft. Then $\mathrm{I} 3.44+$ $4.48-0.56=\mathrm{x} 7.36$ of oxygen required $\mathrm{I} 7.36 \times 4.77=82.8 \mathrm{I} \mathrm{cu} . \mathrm{ft}$. of air, containing $65.4 \mathrm{I}$ cu. ft. nitrogen. Total gases, $82.8 \mathrm{I}+\mathrm{r} 3.44-3.92=92.33$ total volume of gas, and

$$
\frac{65.41}{92.33}=70.8 \text { per cent. }
$$


hydrogen coal than we have taken, and the decomposition of the fuel in the body of the furnace with a certain quantity of aqueous vapor formed during the combustion, or from the moisture in the air supplied.

Mahler determined the heat of combustion of a sample of gas from the Follembray glass-house, and found its composi tion per volume, using coal from Béthune, to be:

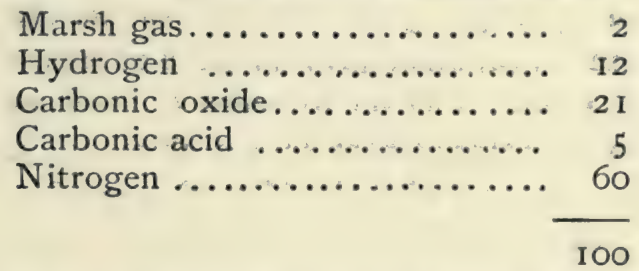

The heat of combustion calculated from its composition is:

Marsh gas.......... $0.02 \times 10038=200.8$

Hydrogen............ 0.12 $3091=370.9$

$\mathrm{CO} \ldots \ldots \ldots \ldots \ldots \ldots . .2 \mathrm{I} \times 3043=639.0$

1210.7

With the bomb he found 1212 calories.

\section{WATER GAS AND MIXED GAS.}

Water gas is produced when water is decomposed at high temperatures by fuels containing but little hydrogen, such as anthracite, charcoal, or coke. Mixed with hydrocarbon vapors, added to enrich it, or which may have been decomposed with the aqueous vapor, it serves for the illumination of a great number of cities, principally in America. But this is not its only use, as it is used for heating, and also for gasengines. Mixed with producer gas, it has become a powerful means of heating, especially where high temperatures are wanted.

Water gas contains but little nitrogen: this is its main distinction from producer gas, and that which gives it a special value from an economical heating point of view. 
We have previously stated (page 97) that during the combustion of carbon in a gasogene, there occurs a generation of nearly one third of the total heat were the fuel completely burnt. Besides this, the combustion produces a gas containing about one third its weight of combustible gas and two thirds inert gas (nitrogen), which is mixed with it.

These are important causes of two sources of loss in calories. In an air-gasogene one third of the calories is lost, since the gaseous products give up most of their sensible heat before being used. The 66 per cent of inert gas carries off an enormous quantity of heat to the chimney, and thence to the open air. It was with the idea of regaining or stopping these losses, or at least a large portion of them, that water gas originated.

Aqueous vapor and carbon, when submitted to a high temperature, produce carbonic oxide and hydrogen. Theoretically these are free from nitrogen; but there is always present a small percentage for various causes. In the air gasogene 12 kilogram of carbon and I6 kilograms of oxygen (atomic weights) unite to form 28 kilograms of carbonic oxide. On the other hand, 12 kilograms of carbon and 18 kilograms of water form 28 kilograms of carbonic oxide and 2 kilograms of hydrogen. Then I kilogram of carbon furnishes 2.5 kilograms of gas composed of carbonic oxide and hydrogen.

One kilogram of hydrogen has a caloric energy of 29042 calories. ${ }^{*}$ These calories represent also the quantity of heat necessary to decompose the water; in the case of the water gas gasogene they are formed by the carbon burnt. The I 2 kilograms of carbon will have to furnish, then, the calories necessary to decompose 18 kilograms of water; that is,

$2 \times 29042=58084$ calories.

* Water being considered as vapor. 
But 12 kilograms of carbon, in burning, generate only

$12 \times 2473=29676$ calories.

To decompose the water, then, there is a shortage of force of

$$
58084-29676=28408 \text { calories }
$$

for 2 kilograms of hydrogen, or 14204 calories for I kilogram. The heat must be furnished by an external source. In other terms, to gasify I kilogram of carbon there must be supplied

$$
14204 \div 6=2367 \text { calories. }
$$

As may be easily seen, this operation absorbs much heat, and the combustion of the water gas can give only the calories used at first in forming it. The heat necessary for the decomposition of the water is actually taken from that of the preparatory period of the air gasogene, which makes a loss of one third of the total calories. In burning the water gas made under these conditions we utilize a part of the heat which would have been lost by the air gasogene only.

The decomposition of water by carbon is not as simple as would appear from the equation

$$
\mathrm{H}_{2} \mathrm{O}+\mathrm{C}=\mathrm{CO}+\mathrm{H}_{2} \text {. }
$$

The lower portion of the fuel of the gasogene undergoes ordinary combustion on account of air being present; while in the upper portion the reaction takes place between the gaseous products formed in the lower portion and the heated carbon. The carbonic acid is then in contact with the heated carbon and is reduced to carbonic oxide:

$$
\mathrm{C}+\mathrm{CO}_{2}=2 \mathrm{CO} \text {. }
$$


Thus, the reaction with the water would be

$$
5 \mathrm{H}_{2} \mathrm{O}+{ }_{3} \mathrm{C}=2 \mathrm{CO}_{2}+\mathrm{CO}+10 \mathrm{H}
$$

carbonic acid being reduced to carbonic oxide in the final reaction, as in the case with the air gasogene.

Nine kilograms of aqueous vapor and 6 kilograms of carbon produce I kilogram of hydrogen and 14 kilograms of carbonic oxide, that is, a mixed gas is produced containing about one half its volume of each gas.

One cubic metre of hydrogen weighs 85.5 grams; one of carbonic oxide, I I 94 grams. Then the volumes occupied by each gas would be 11.69 for hydrogen and 11.13 for carbonic oxide, or 51.23 per cent of hydrogen and 48.77 per cent of carbonic oxide.

From the foregoing account, it will be seen that the intermittent flow is a cause of great loss of caloric in the working of the water gasogene; but when a gas is wanted solely for heating at high temperatures, it may be obtained by a mixed system working continuously. The gasogene is filled with a mixture of air and steam, the air being employed in the proper proportion to keep up the heat necessary, or, in other words, to furnish by the combustion of part of the carbon, the number of calories necessary to the gasification of the other part.

We have seen (page 103) that to gasify I kilogram of carbon 2367 calories were needed. To maintain the heat this quantity must be produced by the action of the air. Mixed gases are poorer than water gas, as they contain more nitrogen and carbonic oxide and less hydrogen. Theoretically, we should attain the result of furnishing the heat to the gasogene necessary to maintain the temperature by supplying the steam sufficiently superheated; a gas very poor in nitrogen would then be made. But the superheating of steam causes new losses of heat. 


\section{NATURAL GAS.}

Natural gas has been known for thousands of years in Asia, on the Caspian Sea, where it has long been a feature in religious services, but it is only recently that it has become of any use to man and played any part in the fuel world.

The natural gas output in the United States has attracted considerable attention since 1875 , and especially since 1880 . This gas always accompanies petroleum, although petroleum does not always accompany the gas. The wells are situated in various portions of New York, Pennsylvania, Ohio, Indiana, West Virginia, Kentucky, Tennessee, Colorado, California, and on the Canadian side also in numerous locations.

Natural gas is not of a constant or uniform composition, varying very much according to the locality from which it is taken. The individual constituent gases vary between wide limits, hydrogen at some places being almost wanting, while at others it is as high as 35 or 40 per cent. Marsh gas is in every case the principal constituent, but this runs down as low as 40 per cent in some analyses. Nitrogen is sometimes absent, and when present in large amounts, it is supposable that the gas analyzed was contaminated with atmospheric air.

The Ohio and Indiana fields yield gas of nearer a uniform composition than any of the others. The following table is typical:

\begin{tabular}{|c|c|c|c|c|c|c|}
\hline & \multicolumn{3}{|c|}{ Ohio. } & \multicolumn{3}{|c|}{ Indiana. } \\
\hline & Fostoria & Findlay. & St.Mary's & Muncie. & Anderson & Kokomo. \\
\hline Hydrogen............... & I. 89 & 1.64 & I.94 & 2.35 & 1.86 & $\mathrm{r} .42$ \\
\hline Marsh gas................ & 92.84 & 93.35 & 93.85 & 92.67 & 93.07 & 94.16 \\
\hline 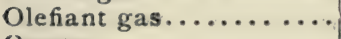 & 0.20 & 0.35 & 0.20 & 0.25 & 0.47 & 0.30 \\
\hline 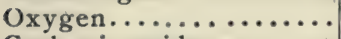 & 0.35 & 0.39 & 0.35 & 0.35 & 0.42 & 0.30 \\
\hline Carbonic oxide........... & 0.55 & $0.4 \mathrm{I}$ & 0.44 & 0.45 & 0.73 & 0.55 \\
\hline Carbonic acid $\ldots \ldots \ldots$ & 0.20 & 0.25 & 0.23 & 0.25 & 0.26 & 0.29 \\
\hline Nitrogen.............. & 3.82 & $3.4 \mathrm{I}$ & 2.98 & 3.53 & 3.02 & 2.80 \\
\hline Hydrogen sulphide ..... & 0.15 & 0.20 & $0.2 \mathrm{I}$ & 0.15 & 0.15 & 0.18 \\
\hline
\end{tabular}


In addition to difference in composition in different localities, the composition of the gas varies considerably from time to time in each well. This is shown by the following analyses made at different times within a period of three months from a well at Pittsburgh, Pa.:

\begin{tabular}{|c|c|c|c|c|c|c|}
\hline & $\mathbf{I}$ & 2 & 3 & 4 & 5 & 6 \\
\hline Hydrogen............. & 9.64 & I 4.45 & 20.02 & 26.16 & 29.03 & 35.92 \\
\hline 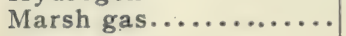 & 57.85 & 75.16 & 72.18 & 65.25 & 60.70 & 49.58 \\
\hline Olefiant gas............... & 0.80 & 0.60 & 0.70 & 0.80 & 0.98 & 0.60 \\
\hline Methane................ & 5.20 & 4.80 & 3.60 & $5 \cdot 50$ & 7.92 & I 2.30 \\
\hline Oxygen................ & 2. 10 & I. 20 & I. 10 & 0.80 & 0.78 & 0.80 \\
\hline Carbonic oxide.......... & I.OO & 0.30 & 1.00 & 0.80 & 0.58 & 0.40 \\
\hline Carbonic acid............ & 0.00 & 0.30 & 0.80 & 0.60 & 0.00 & 0.40 \\
\hline 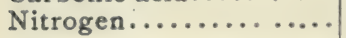 & $23.4 \mathrm{I}$ & 2.89 & 0.00 & 0.00 & 0.00 & 0.00 \\
\hline
\end{tabular}

The quantity of gas used daily in the town of Findlay, Ohio, in 1890 , was estimated by Professor Orton to be, for

Glass-furnaces ...... I0000000 cubic feet.

Iron mills.......... I0000000 " "

Other factories..... " 6000000 " "

Domestic use...... " 4000000 " "

Total per day .... 30000000 " “

In Indiana, large wells have been opened and used as in Ohio. In Pennsylvania, several of the large rolling-mills and glass-houses near Pittsburg were formerly supplied with millions of feet per day; but the supply, used solavishly, became exhausted. In Canada, at Fort Erie and Windsor are wells, the gas from which is piped across the river to Buffalo and Detroit respectively. All through the oil regions gas wells are to be found more or less, accompanying every well sunk.

From the composition of the gas, it will readily be seen that it is a valuable source of heat, the calorific power reaching 10000 calories or I $100 \mathrm{~B}$. T. U. per cubic foot. It is used for domestic purposes, steam, glass making, iron mills, brick burning, and numerous other ways, and until recently used wastefully in all. 
As compared with coal, 57.25 pounds of coal or 63 pounds of coke are about equal to Iooo cubic feet of the gas. The actual equivalent in steaming or furnace work varies with the furnace, and probably with the people using it. Equivalent values of 14000 to 25000 cubic feet per ton of coal are reported, and hardly any two users will give the same yield. It seems to be especially adapted to glass-making, giving a long, clean, ashless, smokeless flame, and hundreds of glasspots were set up in the neighborhood of the wells, especially in Ohio. Each pot consumes from 58000 to 61000 cubic feet per 24 hours in window-glass works and from 31000 to 49000 cubic feet in flint-glass works, the difference being of course due to difference in burners and men; the gas being the same.

In all cases where this gas is used the chief claim made, in addition to those of gases generally, has been cheapness, and it has been sold without any regard to its actual value. A comparison of its value with that of other gases is given by McMillin in the Report of the Ohio Geological Survey, vol. VI, page 544 , as follows :

IOOO feet natural gas will evaporate... 893 pounds of water.

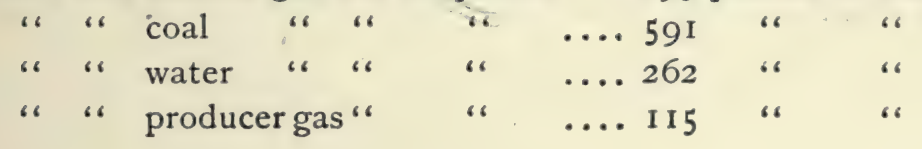

\section{OIL GAS.}

There are several processes for producing gas from oil, usually petroleum or its derivatives. Some of them decompose the oil by means of heat alone, while others use steam, or steam and air together. The most successful pure oil process is the Pintsch; this is used extensively in the large cities of Europe and America to obtain a gas for illuminating cars on railways. The gas is made by allowing the oil to fall drop by drop on a strongly heated surface. Complete decom- 
position occurs, and a gas of high candle-power is formed. This is collected, and after compression supplied to the consumers. It loses some 20 per cent of the illuminating power during compression. As a source of heat, its use is, so far, very limited. An analysis and heat test will be found in the tables.

The Archer gas process is somewhat similar to the Pintsch, but the products of decomposition are generated at a comparatively low temperature, and then superheated subsequently so as to make the gas permanent. This gas is used for metallurgical purposes, but its use for heating boilers is very limited.

The other gases made with steam or steam and air have been advertised or pushed as fuel gases for several years. Many plants have been established and failed. A few of the most prominent are mentioned in the tables.

\section{OTHER GASES.}

Gas has been obtained from destructive distillation of wood, rosin, fats, and other materials. They were used principally for illumination, and seldom if ever for heat. They are now made only in very exceptional cases. 
CHAPTER $\mathrm{X}$.

\title{
CALORIFIC POWER OF COAL BURNT UNDER A STEAM-BOILER.
}

\author{
FUEL USED AND WATER EVAPORATED.
}

\section{DISTRIBUTION OF THE HEAT PRODUCED.}

EXPERIMENTS in heating steam-boilers have to determine :

I. How much water is vaporized by a given quantity of coal, so as to compare it with other coals or fuels;

2. The evaporative power of the steam-boiler used;

3. A comparison of the various styles of grates or methods of heating applied to steam-boilers.

In this book we will consider only the first case, the others being outside of its scope.

The knowledge of the heat of combustion of coal and other fuels is closely connected with experiments in heating steam-boilers. It is not enough to know the proportion of water which the apparatus or the fuel tested will vaporize: we must also determine the number of calories lost. We must know, besides, the composition of the coal and its heat of combustion, to determine the proportion of calories used to that possible with perfect combustion.

The first work in this direction worth mentioning was probably that done by Peclet in 1833 , but his results were very crude, and are of no account now. The next were those made by Prof. Johnson, in 1842 and 1843 , for the U.S. Navy Department, to determine the steaming powers of the 
coals then in use. He analyzed and tested some thirty-five different coals, domestic and foreign. The tests were made with a specially built boiler, and careful and copious notes were taken all through. The chimney gases were analyzed, and an attempt made to determine their quantity. In I89 I $\mathrm{Mr}$. W. Kent * reviewed his work, and found that, with corrections for the constants employed by Johnson, the tests were comparable with those made at the present time. The figures given in the tables as Johnson's are with Kent's corrections.

The first experiments based on the knowledge of the composition and heat of combustion of coal were published in 1868 and 1869 in the Bulletin de la Société Industrielle de Mulhouse. Scheurer-Kestner remarks in the first part of this work, which he prosecuted later on with assistance of Meunier-Dollfus (loc. cit. p. I):

"It is necessary to analyze the great difference found between the theoretical heat of combustion (at that time no actual determinations had been made) and the practical yield.

"Several elements of the calculation aid in making this shortage. The principal ones are:

"The heat of combustion of the coal;

"The composition of the coal;

"The composition of the cinders as drawn from the ash-pit ;

"The quantity of water vaporized and the temperature of the steam produced;

"The volume of gases introduced under the grate, and their temperature when they leave the boiler to pass into the chimney;

"The composition of the gaseous products of combustion ;

\footnotetext{
* Engineering and Mining Journal, Oct. 189r.
} 
"The temperature of the cinders at the time of dumping; boiler."

"The loss of caloric by radiation from the setting of the

We must refer to mineral and organic as well as gas analysis to obtain the necessary elements for the distribution of the caloric produced by the combustion of the coal on a steam-boiler grate.

To avoid referring to them, we will consider the composition and heat of combustion of coal as known. (See tables.)

\section{WEIGHT OF FUEL.}

The coal used in the test should be kept under cover away from moisture and heat, so. that the hygroscopic water it contains shall vary as little as possible from the time of taking the sample. Weigh the coal in the gross, and then weigh portions of about 100 kilograms (220 lbs.) on a scale sensible to $\frac{1}{1000}$.

Where practicable, a box open at the top and holding 500 pounds of coal should be provided for each 25 square feet grate area, and in proportion for larger grates. It should be placed on the scales, and conveniently located for shoveling into the fire.

The exact time of weighing should be noted and the exact weight set down. The weight should be taken at the instant of closing the fire-door. The box should be completely emptied each time. The difference of weight at each firing will give the several quantities fired; the differences of time will give the intervals between firing; and the difference of time between successive charges will serve as a check on the record of the test. A chart or diagram should be made showing the regularity of the working, and it is well to keep the records in tabular form; weights in one column, time in another. 


\section{SAMPLING THE COAL.}

In all experiments for determining heat of combustion of fuels, the sampling must be done with the utmost care, espe.. cially if the laboratory and working test are to be made at the same time. Samples accurately representing the coal of the working test must be kept in the laboratory, and when coal is tested which contains foreign matter and considerable moisture, too much care cannot be taken to prevent errors.

The official method of the American Society of Mechanical Engineers is given in the Appendix, and answers the purpose very well. If very large quantities are to be sampled, remove a portion from each cart-load and then re-sample these as per directions above mentioned.

It is not always necessary to resort to these methods. When the coal comes from the same pit and level, experience has shown that a piece which seems to agree with the general character is usually sufficient. Care must be taken to avoid samples having too much hanging-wall or bed-rock. For twenty years the pure coal of Ronchamp taken from the same pit has given the same calorimetric test, when it contained from 10 to 20 per cent of ash. Lord and Haas* showed that the same was true of many American mines, especially in Ohio and Pennsylvania. This being true, we could consider that in sampling we did not sample the coal, but the impurities; and that a sample showing the average impurities would give all that was needed, as we would know what the coal was.

Care must be taken with regard to the moisture, and any coal showing much external moisture must be examined as near as possible to the original condition. For example, a coal containing io per cent of moisture in the pile may, after sampling, crushing, and resampling, lose all but 4 or 5 per cent. If the moisture was determined in this coal while in as

* Trans. Am. Inst. Min. Eng., Feb. 1897. 
large pieces as possible, this moisture would all be accounted for.

In spite of all precautions, samples do not always agree in mineral content with the mass. The difference seems to be due not only to the unequal distribution of the foreign mineral matter throughout the coal, but principally to the difference in specific gravity between the coal and this mineral, so that the purer the coal the more satisfactory the sampling.

Sometimes a coal is rich in foreign matter, and is contained in a tube open at one end. From this samples may be drawn showing differences of several per cents; as for example, I2.49 and 16.74 per cent obtained in two successive cases. The following experiment shows how this happens and how to prevent it : 30 grams of coal, finely pulverized, and containing 20 per cent of mineral, was put into a glass tube, which was closed with a cork and placed vertically, giving it slight taps to settle it down. In a short time most of the foreign material was at the bottom of the tube, the upper portion being nearly free. To avoid such an error the sample must be drawn only after thorough mixing, and without any shaking or jarring of the tube. It is well to use pastilles made up immediately after thorough mixing. A sample containing only 13 to 14 per cent of foreign matter has given from a tube, 12.20, I2.8I, I3.12, I 3.50, 14.42 per cent.

\section{ANALYSIS OF THE COAL.}

No attempt will be made to treat the methods of analyzing coal; still, as this usually accompanies a calorimetric determination, some hints may be useful. Scheurer-Kestner usually burns the coal in tubes of white glass placed on an iron gutter. The same tube may thus serve several times if asbestos cloth be placed between the tube and the iron and the cooling be properly regulated. His tubes are 70 to 75 centimetres (27 to 29 inches) long and I 5 to 20 millimetres 
( 0.6 to 0.8 inch) inside diameter. They are filled with copper oxide in small pieces, except at the front end, which has a small piece of metallic copper, and at the back, where the platinum boat containing the coal is placed. Usually half a gram is used for a test, the coal having been previously dried at $100^{\circ}$ to $105^{\circ} \mathrm{C}$. $\left(212^{\circ}\right.$ to $221^{\circ} \mathrm{F}$.).

Before putting in the sample the tube is heated to redness and thoroughly dried by means of a current of dry oxygen. The combustion is carried on so as to allow time enough for all the gas to be absorbed by the potash, during the first half of the time the bubbles passing through very slowly. There is no risk then of unburnt gases passing off. An iron or a platinum tube may be used in place of the glass one, but glass allows inspection at all times.

An analysis should show the carbon, hydrogen, oxygen, nitrogen, sulphur, ash, and moisture, and they should be so given that the carbon, hydrogen, oxygen, nitrogen, sulphur, and ash should equal 100 per cent, the moisture being determined separately, or if preferred all but ash and moisture may foot up 100, and those two be given separately. This latter method is the one which is followed by many of the European engineers, and will be found so in the tables given at the end of this book. If possible the approximate analysis should also be given.

In determining the moisture too much care cannot be taken to expel all of it. With many coals, and especially our Western ones, the ordinary heating to $110^{\circ} \mathrm{C}$. is not sufficient. Kent, Carpenter, Hale, and others have investigated this question, and find that a much higher temperature is needed, and must be employed. In some cases as high as $140^{\circ}$ to $150^{\circ} \mathrm{C}$. may be used with safety, and such temperatures are recommended by Carpenter, no appreciable amount of volatile matter being driven off. 


\section{ANALYSIS OF THE CINDERS.}

The cinders and ashes produced by the combustion of the coal are collected so as to weigh and sample them. After drying and determining the water the sample is put into a glass tube as with coal. As the quantity of hydrogen is usually very small, it need not be determined, and the calcination for the carbon can be performed in the open air. The following table contains the results of the tests made by Scheurer-Kestner and Meunier-Dollfus on steam-boiler cinders :

\begin{tabular}{|c|c|c|c|c|}
\hline. & 1 & 2 & 3 & 4 \\
\hline 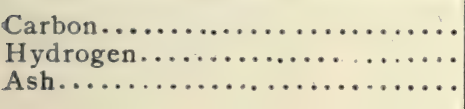 & $\begin{array}{r}9.20 \\
0.37 \\
89.95\end{array}$ & $\begin{array}{r}12.65 \\
0.29 \\
86.50\end{array}$ & $\begin{array}{r}6.73 \\
0.21 \\
92.64\end{array}$ & $\begin{array}{r}8.92 \\
0.27 \\
91.42\end{array}$ \\
\hline & 99.52 & 99.44 & 99.58 & $99.6 \mathrm{r}$ \\
\hline
\end{tabular}

The proportion of carbon in cinders may be as low as 7 per cent, but is usually higher, and Io to 12 per cent may be called good practice.

\section{DURATION OF THE TEST.}

A test should continue at least a whole day on account of certain irregularities and causes of error which are constant. The level of the water should be the same at the end of the test as at the beginning, since a slight difference in level means considerable water.

The condition of the combustion at the time of stopping cannot always be ascertained, and this produces a cause of uncertainty. Another cause is from the temperature of the water in the boiler, and especially in the economizer. On short runs these sources of error cause very faulty results. 


\section{THE WATER EVAPORATED.}

The feed-water is preferably held in a gauged reservoir, or else weighed, meters not being certain unless checked frequently. Use only cold water or water whose temperature will vary but little during the test, so as to avoid corrections of temperature and expansion. The temperature usually varies so little that no account of this variation need be taken. Pump to the boiler with as much regularity as possible, and keep accurate record.

To have the same level at the end as at the beginning, keep up the initial pressure and feed very carefully. The mean temperature of the feed-water is referred to $0^{\circ} \mathrm{C}$., considering that the specific heat is constant. Otherwise we may use Regnault's formula,

$$
Q=t-0.00002 t^{2}+0.0000003 t^{3}
$$

But when the temperature of the water varies no more than Io degrees, no appreciable error will be made by calling $t$ equal to the temperature.

\section{TEMPERATURE OF THE STEAM.}

We may measure the temperature of the steam directly by a thermometer in the boiler, or indirectly by observing the pressure. Both methods should be used. .

To take the temperature directly, the thermometer is placed in an iron tube closed at one end and reaching to the middle of the boiler. The tube should be filled with paraffin or some analogous substance. The temperature of the steam or the water may be taken as desired by changing the position of the thermometer in the tube. See Figure 39. Vertical maximum and minimum thermometers are very useful, preventing too hasty observations. 
To measure the temperature by pressure an air-thermometer is used. A registering manometer aids the work considerably, as observations should be taken regularly at frequent and equal intervals. The temperature is calculated by means of tables of vapor-tension.*

\section{MOISTURE IN THE STEAM.}

The percentage of moisture should be ascertained by means of a throttling or a separating calorimeter, directions for the use of which will be furnished by the makers. They should easily and completely separate the water in a manner convenient for measuring, or better, for weighing. It is advisable to use two or three at the same time, thus serving as checks for each other.

"The throttling steam-calorimeter was first described by Professor Peabody in the Transactions, $\nmid$ vol. x. page 327 , and its modifications by Mr. Barrus, vol. XI. page 790; vol. XVII. page 6I 7 ; and by Professor Carpenter, vol. XII. page 840 ; also the separating-calorimeter designed by Professor Carpenter, vol. XVII. page 608. These instruments are used to determine the moisture existing in a small sample of steam taken from the steam-pipe, and give results, when properly handled, which may be accepted as accurate within 0.5 per cent (this percentage being computed on the total quantity of the steam) for the sample taken. The possible error of 0.5 per cent is the aggregate of the probable error of careful observation, and of the errors due to inaccuracy of the pressuregauges and thermometers; to radiation; and, in the case of the throttling-calorimeter, to the possible inaccuracy of the figure 0.48 for the specific heat of superheated steam, which

* For full details regarding setting up an open-air manometer, see paper by Scheurer-Kestner and Meunier-Dollfus in the Bulletin de la Societé industrielle de Mulhouse, 1869, page 24r; also Trans. A.S.M.E., vol. vi. pages 281 and 282.

† Transactions A. S. M. E. 
is used in computing the results. It is, however, by no means certain that the sample represents the average quality of the steam in the pipe from which the sample is taken. The practical impossibility of obtaining an accurate sample, especially when the percentage of moisture exceeds two or three per cent, is shown in the two papers by Professor Jacobus in Transactions, ${ }^{*}$ vol. XVI. pages 448 , IOI 7 .

"In trials of the ordinary forms of horizontal shell and of water-tube boilers, in which there is a large disengaging surface, when the water-level is carried at least io inches below the level of the steam outlet, and when the water is not of a character to cause foaming, and when in the case of watertube boilers the steam outlet is placed in the rear of the mid. dle of the length of the water-drum, the maximum quantity of moisture in the steam rarely, if ever, exceeds two per cent; and in such cases a sample taken with the precautions specified in article xiII. of the Code may be considered to be an accurate average sample of the steam furnished by the boiler, and its percentage of moisture as determined by the throttling or separating calorimeter may be considered as accurate within one half of one per cent. For scientific research, and in all cases in which there is reason to suspect that the moisture may exceed two per cent, a steam-separator should be placed in the steam-pipe, as near to the steam outlet of the boiler as convenient, well covered with felting, all the steam made by the boiler passing through it, and all the moisture caught by it carefully weighed after being cooled. A convenient method of obtaining the weight of the drip from the separator is to discharge it through a trap into a barrel of cold water standing on a platform scale. A throttling or a separating calorimeter should be placed in the steam-pipe, just beyond the steam-separator, for the purpose of determining, by the sampling method, the small percentage of moisture which may still be in the steam after passing through the separator.

* Transactions A. S. M. E. 
"The formula for calculating the percentage of moisture when the throttling-calorimeter is used is the following:

$$
w=100 \times \frac{H-h-k(T-t)}{L},
$$

in which $w=$ percentage of moisture in the steam, $H=$ total heat and $L=$ latent heat per pound of steam at the pressure in the steam-pipe, $h=$ total heat per pound of steam at the pressure in the discharge side of the calorimeter, $k=$ specific heat of superheated steam, $T=$ temperature of the throttled and superheated steam in the calorimeter, and $t=$ temperature due to the pressure in the discharge side of the calorimeter, $=$ $212^{\circ}$ Fahr. at atmospheric pressure. Taking $k=0.48$ and $t=2 \mathrm{I} 2$, the formula reduces to

$$
w=100 \times \frac{H-1146.6-0.48(T-212)^{*}}{L} . "
$$

\section{CORRECTIONS FOR QUALITY OF STEAM. $†$}

Given the percentage of moisture or number of degrees of superheating, it is desirable to develop formulæ showing what we have termed " the factor of correction for quality of steam," or the factor by which the "apparent evaporation," determined by a boiler-test, is to be multiplied to obtain the "evaporation corrected for quality of steam." It has been customary to call the proportional weight of steam in a mixture of steam and water "the quality of the steam," and it is not desirable to change this designation. The same term applies when the steam is superheated by employing the "equivalent evaporation," or that obtained by adding to the actual evaporation the

* William Kent in the Report of the Committee on Boiler-tests, A. S. M. E., $\mathrm{r} 897$. 1897 .

†C. E. Emery in the Report of Committee on Boiler-tests, A. S. M. E., 
proportional weight of water which the thermal value of the superheating would evaporate into dry steam from and at the temperature due to the pressure. "The factor of correction for quality of steam " in a boiler-test differs from the "quality" itself, from the fact that the temperature of the feed-water is lower than that of the steam.

Let

$Q=$ quality of moist steam as described above;

$Q_{1}=$ the quality of superheated steam as described above;

$P=$ the proportion of moisture in the steam;

$k=$ the number of degrees of superheating;

$F=$ the factor of correction for the quality of the steam when the steam is moist.

$F_{1}=$ the factor of correction for the quality of the steam when the steam is superheated;

$H=$ the total heat of the steam due to the steam-pressure;

$L=$ the latent heat of the steam due to the steam-pressure;

$T=$ the temperature of the steam due to the steam-pressure;

$T_{1}=$ the total heat in the water at the temperature due to the steam-pressure; *

$J=$ the temperature of the feed.water;

$J_{1}=$ the total heat in the feed-water due to the temperature.*

Therefore, for moist steam,

$$
\begin{aligned}
& Q=\mathrm{I}-P, \\
& P=\mathrm{I}-Q,
\end{aligned}
$$

See also equation (6).

* Most tables of the properties of steam and of water are based on the total heat of steam and water above 32 degrees Fahr. For such tables the total heat in the water at a given temperature is equal approximately to the corresponding temperature minus 32 degrees. Exact values should, however, be taken from the tables. 
With both the condensing and throttling calorimeters the water and steam are withdrawn from the boiler at the temperature of the steam, and with a separator the water can only be accurately measured when under pressure, so that the difference between the steam and the moisture in the steam, as they leave the boiler, is simply that the former has received the latent heat due to the pressure, and the latter has not. There is, however, imparted to the water in the boiler not only the latent heat in the portion evaporated, but the sensible heat due to raising the temperature of all the water from that of the feed-water to that of the steam due to the pressure.

In equation (3) the proportional part $Q$ receives from the boiler both the sensible and the latent heat, or the total heat above the temperature of the feed $=Q\left(H-J_{1}\right)$ thermal units, and the part $P$ the difference in sensible heat between the temperatures of the steam and of the feed-water $=P\left(T_{1}-J_{1}\right)$ thermal units. If all the water were evaporated, each pound would receive the total heat in the steam above the temperature of the feed, or $H-J_{1}$. "The factor of correction for the quality of the steam," when there is no superheating, is therefore

$$
F=\frac{Q\left(H-J_{1}\right)+P\left(T_{1}-J_{1}\right)}{H-J_{1}}=Q+P\left(\frac{T-J_{1}}{H-J_{1}}\right) .
$$

The superheating of the steam requires 0.48 of a thermal unit for each degree the temperature of the steam is raised, so for $k$ degrees of superheating there will be $0.48 k$ thermal units per pound weight of steam, and the "factor of correction for the quality of the steam" with superheating.

$$
F_{1}=\frac{H-J_{1}+0.48 k}{H-J_{1}}=\mathrm{I}+\frac{0.48 k}{H-J} . . .
$$

See also equation (7). 
With the throttling-calorimeter the percentage of moisture $P$, or number of degrees of superheating, are determined as explained before.

Since the invention of the throttling-calorimeter the use of the original condensing, or so-ealled barrel, calorimeter is no longer warranted. Accurate results should, however, be obtained by condensing all the steam generated in the boiler, and this plan has been followed in certain cases. It has, therefore, been thought desirable to add other formulæ applicable to condensing-calorimeters. The following additional notation is required:

$W=$ the original weight of the water in calorimeter, or weight of circulating water for a surface condenser.

$w=$ the weight of water added to the calorimeter by blowing steam into the water, or of "water of condensation" with a surface condenser.

$t=$ total heat of water corresponding to initial temperature of water in calorimeter.

$t_{1}=$ total heat of water corresponding to final temperature in calorimeter.

Evidently, then:

$W\left(t_{1}-t\right)=$ the total thermal units withdrawn from the boiler and imparted to the water in calorimeter.

$\frac{W}{w}(t,-t)=$ the thermal units per pound of water withdrawn from the boiler and imparted to the water in calorimeter, from which should be deducted $T_{1}-t_{1}$ to obtain the number of thermal units per pound of water withdrawn from the boiler at the pressure due to the temperature $T$.

Since only the latent heat $L$ is imparted to the portion of the water evaporated, the quality $Q$, or proportional quantity evaporated, may be obtained by dividing the total thermal units per pound of water abstracted at the pressure due to the temperature $T$ by the latent heat $L$. Hence, as given in 
Appendix XVII., I 885 Code, with some differences in notation,

$$
Q \text { and } Q_{1}=\frac{\mathrm{I}}{L}\left[\frac{W}{w}\left(t_{1}-t\right)-\left(T_{1}-t_{1}\right)\right] . .
$$

The value $Q$ applies when the second term is less than unity. $P$ may be derived therefrom by substitution in equation (2) and $F$ from equation (4).

$Q_{4}$ applies when the second term of the above equation is greater than unity, which shows that the steam is superheated, and, as in this case, the heating value of the superheat has already been measured by heating the water of the calorimeter; the proportional thermal value of the same, in terms of the latent heat $L$, is represented directly by $Q_{1}-\mathrm{I}$, and we have as the factor of correction for the quality of the steam with superheating,

$$
F_{1}=\frac{H-J_{1}+L\left(Q_{1}-\mathrm{I}\right)}{H-J_{1}}=\mathrm{I}+\frac{L\left(Q_{1}-\mathrm{I}\right)}{H-J_{1}} .
$$

See also equation (5).

When the quality is greater than I, or equals $Q_{1}$, the number of degrees of superheating,

$$
k=\frac{L\left(Q_{1}-\mathrm{I}\right)}{0.48}-2.0833 L\left(Q_{1}-\mathrm{I}\right) . . .
$$

\section{THE QUALITY OF SUPERHEATED STEAM.*}

The quality of the superheated steam is determined from the number of degrees of superheating by using the following formula :

$$
Q=\frac{L+0.48(T-t)}{L}
$$
I897.

* G. H. Barrus in Report of Committee on Boiler-tests, A. S. M. E., 
in which $L$ is the latent heat in British thermal units in one pound of steam of the observed pressure; $T$ the observed temperature, and $t$ the normal temperature due to the pressure. This normal temperature should be determined by obtaining a reading of the thermometer when the fires are in a dead condition and the superheat has disappeared. This temperature being observed when the pressure as shown by the gauge is the average of the readings taken during the trial, observations being made by the same instrument, errors of gauge or thermometer are practically eliminated. 


\section{CHAPTER XI.}

\section{AIR SUPPLIED AND GASEOUS PRODUCTS OF COM- BUSTION.}

\section{VOLUME OF AIR NECESSARY TO COMBUSTION.}

Four elements are to be considered in calculating the theoretical volume of air for combustion: carbon, hydrogen, oxygen, sulphur. The last is sometimes wanting in coal, but not usually.

Carbon.-The atomic weights of carbon and oxygen are as 12 and 16 , and 2 atoms of oxygen are needed to form carbonic acid with I atom of carbon. Then

$$
\text { I2 }: 32=1: 2.666 \text {. }
$$

I kilogram of oxygen occupies 0.699 cubic metre (Table IV); I kilogram of carbon needs

$$
0.699 \times 2.666=1.863 \text { cubic metres of oxygen. }
$$

Hydrogen.-The atomic weights of hydrogen and oxygen being respectively $\mathrm{I}$ and $\mathrm{I} 6$, and water being formed of 2 atoms of hydrogen and I of oxygen, we have

$$
2: \mathrm{I} 6=\mathrm{I}: 8 \text {; }
$$

and as I kilogram of oxygen occupies 0.699 cubic metre, I kilogram of hydrogen requires

$8 \times 0.699=5.592$ cubic metres of oxygen 
Sulphur.-The atomic weights of sulphur and oxygen being as 32 to 16 , and sulphurous acid containing 1 atom of sulphur and 2 atoms of oxygen, we have

$$
32: 32=\text { I }: \text { I. }
$$

I kilogram of oxygen occupies 0.699 cubic metre; I kilogram of sulphur needs, then, to form sulphurous acid

$$
\text { I } \times 0.699=0.699 \text { cubic metre of oxygen. }
$$

As most fuels have some oxygen in their composition, we must deduct this at the rate of 0.699 cubic metre per kilogram.

Then multiplying these results by 4.77 (Table XIV) we obtain the number of cubic metres of air required.

A similar method of calculation will give

For one pound of carbon...... 29.86 cubic feet of oxygen.

$$
\text { “، “ “ “ “ " " }
$$

As an example, take a coal containing 90\% C, 5\% $\mathrm{H}, 3.5 \%$ $\mathrm{O}, 0.1 \% \mathrm{~N}$, and $0.5 \% \mathrm{~S}$.

$$
\begin{aligned}
& \text { C . ..... } 0.900 \times 1.863=1.677 \text { cubic metres. } \\
& \text { H...... } 0.040 \times 5.592=0.224 \\
& \text { S........ } 0.005 \times 0.699=0.003 \\
& \text { Total oxygen....... } \overline{1.904} \\
& 0 \ldots .035 \times 0.699=0.024 \\
& 1.880
\end{aligned}
$$

I. $880 \times 4.77=8.967$ cubic metres of air per kilogram of coal; or 143.98 cubic feet of air to the pound of coal.

This result of course is only approximate, as complete combustion is not attained with coal and solid fuels. With liquid fuels, and especially gases, however, the combustion is usually complete. 
Tables V and VI gives the coefficients to be employed in the calculations.

Table XIII gives the theoretical quantity of air required for the combustion of various fuels; the actual quantity used depends on the conditions of firing, fuel, etc, and is seldom less than twice the amount shown in the table, except perhaps with gases.

\section{VOLUME OF WASTE GASES BY ANALYSIS.}

For a long time efforts have been made to determine the quantity of air used by comparison of the analyses of the waste gases with those of the fuel used. Many analyses have been published, but the results showed so little regularity, and were so contradictory even, that it was impossible to form any conclusion further than that waste gases from coal may contain at the same time both combustible gas and an excess of air.

Peclet, in 1827 , published the first analyses, made with samples collected from a boiler-stack by means of an inverted flask containing water. Ebelmen, in 1844, published a memoir on the composition of gases from industrial furnaces. $\mathrm{He}$ analyzed the gases from a metallurgical furnace, the gas being collected by an aspirator. In 1847 Combes made a report on methods of burning or preventing smoke, giving analyses by Debette. In these the first attempts were made to obtain average samples, they being drawn at certain determined stages of the heat and the fuel.

In 1862 Commines de Marcilly published analyses of gases from locomotives, as well as from stationary boilers, but the author said the time of collection lasted only a few seconds. In 1866 Cailletet showed that, to obtain correct results, the gas should not be collected till somewhat cooled; otherwise, on account of dissociation, a larger proportion of combustible gas is found than when cooler.

But, on account of the defective methods of sampling 
used, no conclusion other than that stated above can be drawn from these analyses, and no possible idea can be deduced as to the actual composition of the gases as a whole. When we try to use laboratory methods of control in practical workings, the first necessity is to obtain correct samples for analysis, that is, average samples. In this respect all the above-quoted authors are deficient. The tests made by Scheurer-Kestner, published in 1868 , were the first to conform to this requirement. His samples were drawn by a system analogous in principle to that described for sampling coal.

It is not always necessary to resort to such a complicated operation in case of a permanent gas; samples taken from the general current by means of an ordinary aspirator or an oil-aspirator (page 132) will usually do if drawn at a sufficient distance from the fire. If the gases have passed through a long flue, especially one with several bends, they are sufficiently mixed, and may be considered as a homogeneous gas. We must remember, however, that as we recede from the fire the infiltration of air, if not prevented, becomes greater. In careful experiments, the method to be described of fractionating a large volume is preferable.

\section{GAS SAMPLER.}

In principle the apparatus consists of a falling-water aspirator, and a second mercury aspirator drawing a small fraction of the gases from the current of the first in a constant regular manner and keeping it in a mercury gas-holder, $A$ (Fig. 28), which is a strong glass flask of 3 litres capacity, holding about 40 kilograms (88 lbs.) of mercury. The gas-holder is connected by the tube $a$ with the tube $c$ for sampling the gas, the flask $A$ and its accessories acting as a Mariotte flask. It is closed at the top by a stopper hollowed out conically below and having holes for two tubes, $a$ and $b$. This hollowing is to permit filling without 
any air-bubbles. The tubes $a$ and $b$ have glass stop-cocks, but the one in $a$ may be omitted. The manometric tube $c$ shows the pressure. Tube $d$, like $c$, passes through a rubber stopper, closing the horizontal tubulature of the gas-holder.

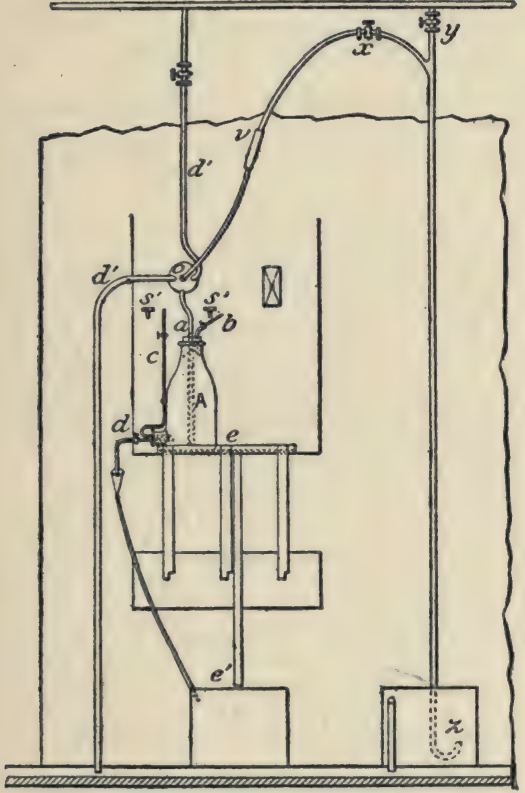

Fig. 28.-Gas SAMpler.

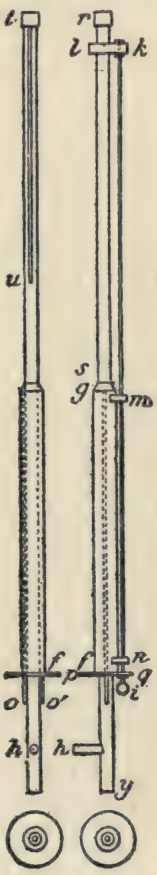

Fig. 29.-SAMPLeR TUbe.

This tube can be rotated in the stopper to the position shown, or to one $180^{\circ}$ from such position. The flask is graduated on the side into millimetres. Tube $a$ fits the hole of the stopper tightly, and can be moved up or down as desired to suit the quantity of gas in the flask. All joints are covered with paraffin, tube $a$ being greased to facilitate movement.

Fig. 29 shows the gas sampling tube. It consists of a platinum cylinder, $r s$, IO millimetres ( 0.4 inch) diameter and 700 millimetres $(27.5$ inches) long, having a longitudinal slot of several centimetres length. The end $r$ is closed with a 
platinum cap; the end $s$ is soldered to a copper tube, $s y$, passing into a Liebig condenser having two tubes, $o o^{\prime}$, for the water. In most cases the platinum tube may be replaced without trouble by one of copper, or even iron, the platinum being necessary only when the gases are drawn at a temperaperature high enough to cause oxidation of the other metals. With iron or copper a portion of the oxygen is removed in the passage through the tube.

The tube $r y$ is open at $y$, and has a side tube $h$. Aspiration is carried on through the opening in the platinum tube. A movable rod, $i k$, carrying a platinum scraper is attached to one end of the tube, and moves in the slot to clean it, as occasion requires, from soot, etc. The disk $p$ serves to hold the cement used in fastening it to the stack or chimney, and prevents ingress of external air. The rod $m n$ passes through a caoutchouc bearing fastened between the disks $p$ and $q$.

Fig. 28 represents a front view of the apparatus. Fig. 30 represents a side view in elevation. The tube $r y$ is introduced through an opening made for the purpose in the masonry, the part rs being exposed inside. The end $y$, is connected with a lead pipe, $v$, by a rubber tube; this pipe is soldered to another one, $y z$. On opening the cock $y$, water flows from a reservoir and empties at $z$. Suction in yrs should amount to several millimetres of mercury, and is regulated by the cocks $y$ and $x$ controlling the water-flow, and also by the length of $y z$. The gas drawn in by $y v x$ may be measured by collecting it at $z$, and should amount to 4 or 5 litres ( 25 to 30 cubic inches) per minute.

The gas-holder is supported by a piece of sheet iron with upturned edges forming a shelf. Any mercury spattered over or spilled is thus easily collected. The mercury tank is supported from the wall of the chimney in such position as to facilitate refilling the flask through a siphon. The tubes $d d^{\prime}$ serve to feed the condenser.

While the current is passing through yr a small quantity 
is drawn out by the tube $h$, and this should be so regulated by the cock $d$ that only from $\frac{1}{250}$ to $\frac{1}{500}$ is collected.

Whenever the level of the mercury lowers, it shows a

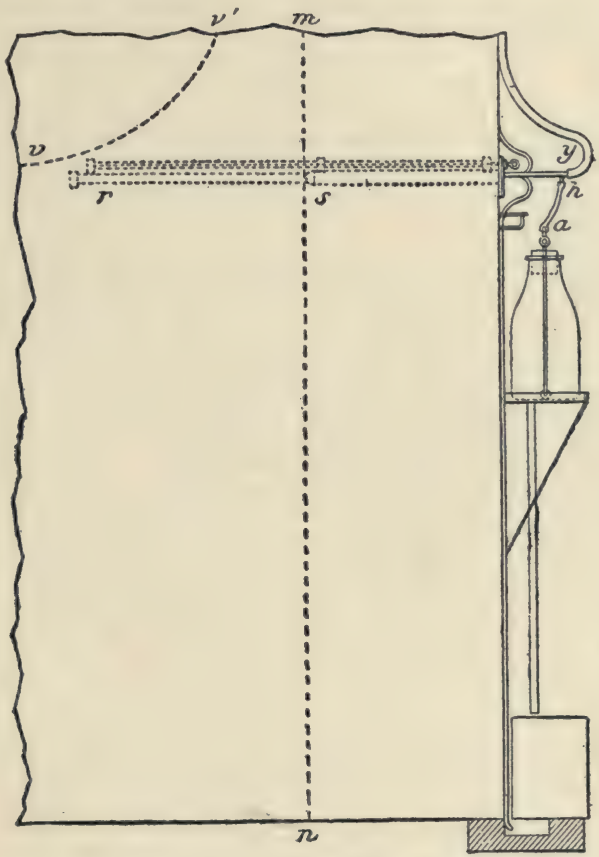

Fig. 30.-Gas Sampler.

clogging in the slot, and it should be cleaned by moving the rod. This always indicates when cleaning is necessary, and it sometimes keeps clean for hours.

When a sufficient sample has been obtained turn up the tube $d$, and then the gas-holder can be carried away.

The method recommended by the American Society of Mechanical Engineers is to have a "box or block of galvanized sheet iron equal in thickness to one course of brick," and secure in it a series of $\frac{1}{4}$-inch gas-pipes, all alike at the ends and of equal lengths, in such manner that the open ends may be evenly distributed over the area of the flue $A$ (Fig. 32 ), and their other open ends enclosed in the receiver $B$. 
If the flue-gases be drawn off from the receiver $B$ by

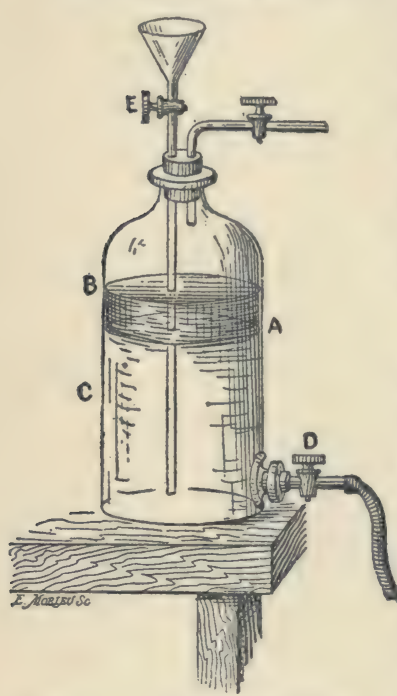

Fig. 31.-OIL Aspirator. four tubes, $C C$, into a mixing-box, $D$, beneath, a good mixture can be obtained. Two such samplers, one above the other, a foot apart, in the same flue will furnish samples of gases which show the same composition by analysis.

The oil gas holder (Fig. 3I) consists of a bottle tubulated at the bottom and connected with the supply of gas at the upper opening. It may contain some io litres (600 cubic inches), and is filled with water having on it a layer of Io centimetres ( 4 inches) of oil. The water running out from the tubulature at the bottom draws the gas in at the top. The stopper at the top has two openings, through one of which passes a funnel-tube, through which water may be poured to expel the gas when portions of it are needed. The gas then passes out by the same tube through which it was drawn into the bottle.

With all kinds of aspirators or gas holders especial care must be taken to prevent entrance of air into the flue after leaving the fire, since the correct analysis will show not only the quantity of unburnt gases, but also the excess of air, and any mixture of outside air will vitiate the result and cause faulty deductions as to the working of the fire; and consequently the waste calories.

To prevent this, all joints in the masonry must be examined and repaired if necessary. In case of dampers, which must be used, the bearings can be made in stuffing-boxes, as recommended by Burnet. Generally, the gas can be sampled before it arrives at a damper, as the course of the boiler-flue 
is usually sufficient to cause a thorough mixing of the gases. In case there are several dampers, the first one may be dispensed with for the time being.

When the gases are taken quite near the fire, they must be drawn very slowly in order to gradually cool them down and
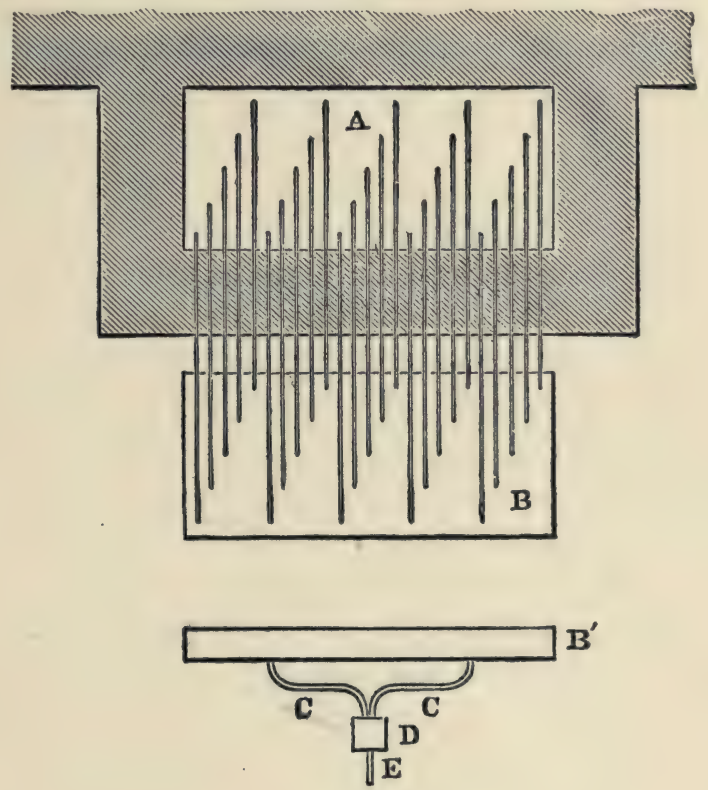

FIG. 32.

avoid dissociation. In this case a stoneware tube may be used for suction. If this precaution is neglected the gases collected may be entirely different from those passing off at the chimney. Metal tubes are inadmissible, since they abstract oxygen, and hence cause a change in composition.

$$
\text { ANALYSIS OF THE GASES. }
$$

The collected gases contain nitrogen, oxygen, carbonic acid, carbonic oxide, hydrocarbons, and occasionally free hydrogen. To determine all these a eudiometric method 
must be used; but usually only the oxygen, carbonic oxide, and carbonic acid are required. In normal combustion with sufficient air the quantity of hydrocarbons is very trifling, and need not be considered. This occurs usually with a supply of I 5 cubic metres of air per kilogram (240 cubic feet per pound) of coal, and should produce a waste gas containing io to 14 per cent of carbonic acid, in which case the unburnt hydrocarbons amount to less than I per cent.

The Orsat apparatus or its modifications may be used to determine the oxygen, carbonic acid, and carbonic oxide. By using Winckler's modification the hydrocarbons may be determined. For exact analyses of the gases the Hempel apparatus may be used. For general work, however, the Orsat apparatus or the Orsat-Muencke is the best and most easily transported and handled. Directions for using this apparatus need not be given here, as they can be found in all works on gas analysis, or can be had of the dealers.

The following table gives analyses made by ScheurerKestner of waste gases from Ronchamp coal. The gases for examination were collected by means of the apparatus described above (pp. 128 et seq.) and shows the average for a whole day's run.

\begin{tabular}{|c|c|c|c|c|c|c|c|c|c|}
\hline \multirow{3}{*}{ 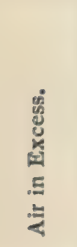 } & \multicolumn{6}{|c|}{ Percentage Composition of the Gases. } & \multirow{3}{*}{ 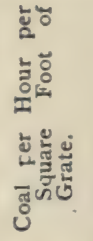 } & \multirow{3}{*}{ 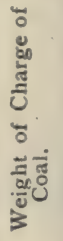 } & \multirow{3}{*}{ 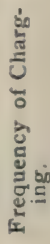 } \\
\hline & \multirow[b]{2}{*}{ 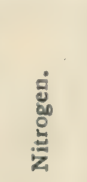 } & \multirow{2}{*}{ 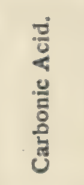 } & \multirow[b]{2}{*}{ 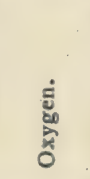 } & \multirow{2}{*}{ 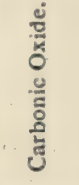 } & \multicolumn{2}{|c|}{ Hydrocarbons. } & & & \\
\hline & & & & & نू. & 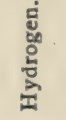 & & & \\
\hline 6.60 & 80.38 & 14.87 & I. $4 \mathrm{I}$ & 0.84 & I.15 & I. 35 & $\begin{array}{l}\text { Lbs. } \\
8.19\end{array}$ & $\begin{array}{l}\text { Lbs. } \\
15.4\end{array}$ & $5^{\prime}$ \\
\hline 10.47 & 80.60 & 14.16 & 2.18 & 0.97 & 0.98 & I.II & 9.625 & 30.8 & $8^{\prime}$ \\
\hline 13.32 & 80.66 & 14.63 & 2.80 & 0.86 & 0.49 & 0.56 & 9.625 & 15.4 & 4 \\
\hline 17.61 & 81.52 & I3.34 & 3.77 & 0.86 & 0.46 & 0.91 & 8.19 & 15.4 & $3^{\prime}$ \\
\hline 20.94 & 80.23 & I 3.43 & 4.42 & 0.24 & 0.32 & $1.4 \mathrm{I}$ & 8. 19 & 30.8 & Io' \\
\hline 26.18 & 80.34 & 12.89 & 5.53 & 0.24 & 0.28 & 0.96 & $4.7 I$ & 15.4 & $8^{\prime}$ \\
\hline 42.84 & 79.76 & 10.87 & 8.99 & 0.24 & 0.19 & o. I9 & I8.94 & 15.4 & $2^{\prime}$ \\
\hline 53.78 & 79.86 & 8.23 & II. 35 & 0.24 & 004 & 0.52 & $3.4 \mathrm{I}$ & 13.2 & $10^{\prime}$ \\
\hline
\end{tabular}


The following table gives some analyses by Bunte of gas samples from coal burnt in his experimental apparatus at Munich :

\begin{tabular}{|c|c|c|c|c|c|c|c|c|}
\hline \multirow{2}{*}{\multicolumn{3}{|c|}{ Coal from th }} & $\begin{array}{l}\text { Min. and } \\
\text { Max. } \\
\text { of Air. }\end{array}$ & $\mathrm{CO}$ & $\mathrm{CO}$ & $\mathrm{H}$ & $\mathrm{o}$ & $\mathrm{N}$ \\
\hline & & & & 10.26 & 0.53 & O.OI & 10.00 & 79.20 \\
\hline & & & ....... & 16.45 & 1.94 & I. 45 & I.52 & 78.64 \\
\hline & & o. & & 13.40 & 0.48 & 0.30 & 6.52 & 79.30 \\
\hline & & o. & & I1. 45 & 1.22 & 0.78 & 7.27 & 79.28 \\
\hline & & o. (grate more open). & …... & 8.15 & 0.10 & 0.01 & II.60 & 80.14 \\
\hline & & o. Do. & & 6.12 & 0.89 & 0.10 & 14.21 & 78.68 \\
\hline \multirow{2}{*}{\multicolumn{3}{|c|}{ Coal from Saarbruck: Kœnig.. }} & Min. & 15.12 & 1.09 & I.02 & 2.64 & 80.13 \\
\hline & & & Max. & 7.07 & 0.18 & 0.00 & 12.57 & 80.25 \\
\hline & \multirow[t]{2}{*}{ “. } & \multirow{2}{*}{ Trémosna: Bohemia } & Min. & I3.78 & 4.69 & 0.16 & I. IO & 80.27 \\
\hline & & & Max. & $7 \cdot 94$ & 0.03 & 0.09 & II.03 & 80.91 \\
\hline “ & “ & Hausham: Bavaria. & $\begin{array}{l}\text { Min. } \\
\text { Max. }\end{array}$ & $\begin{array}{r}10.48 \\
5.71\end{array}$ & $\begin{array}{l}0.07 \\
0.14\end{array}$ & $\begin{array}{l}0.19 \\
0.08\end{array}$ & $\begin{array}{r}9.28 \\
14.86\end{array}$ & $\begin{array}{l}79.98 \\
79.21\end{array}$ \\
\hline \multirow{2}{*}{ “ } & \multirow{2}{*}{ “ } & \multirow{2}{*}{ Miesbach: Bavaria. } & Min. & I1.46 & 0.07 & 0.07 & 8.66 & $79 \cdot 74$ \\
\hline & & & Max. & 542 & 0.03 & 0.02 & 15.00 & $79 \cdot 53$ \\
\hline “ & “" & Bohemia............ & Min. & 17.48 & I.2I & 0.06 & 3.13 & 79.12 \\
\hline \multirow[t]{2}{*}{ " } & \multirow[t]{2}{*}{ “ } & \multirow{2}{*}{$\begin{array}{l}\text { the Ruhr: General } \\
\text { Erbstolln......... }\end{array}$} & Min. & $\begin{array}{l}12.20 \\
16.45\end{array}$ & ז. 94 & $\begin{array}{l}0.30 \\
1.45\end{array}$ & $\begin{array}{l}7.07 \\
1.52\end{array}$ & 78.64 \\
\hline & & & Max. & 3. 95 & 0.06 & 0.00 & $16.4 \mathrm{I}$ & 79.58 \\
\hline \multirow[t]{2}{*}{ “ } & \multirow[t]{2}{*}{$\because$} & \multirow{2}{*}{$\begin{array}{l}\text { the Ruhr: Gelsen- } \\
\text { kirchen........... }\end{array}$} & Min. & 10.46 & O. I I & O. II & 8.58 & 80.74 \\
\hline & & & Max. & 5.44 & 0.12 & 0.10 & 14.15 & 80.19 \\
\hline \multirow[t]{2}{*}{ “" } & “ & Saarbruck: Saint- & Min. & 10.73 & 0.15 & 0.30 & $7 \cdot 36$ & 81.46 \\
\hline & & Ingbert............ & Max. & $7 \cdot 4^{8}$ & 0.07 & 0.10 & II.9I & 80.44 \\
\hline “ & “” & Saarbruck: Mittel- & Min. & 13.30 & $0.6 \mathrm{I}$ & 0.33 & $4 \cdot 13$ & 81.63 \\
\hline & & bexbach ........ & Max. & 8.44 & 0.19 & 0.16 & ro. 58 & 80.63 \\
\hline “ & " & Saarbruck : Heinitz & Min. & 14.62 & 207 & 1.00 & 2.07 & 80.24 \\
\hline ". & & & $\begin{array}{l}\text { Max. } \\
\text { Min. }\end{array}$ & 6.49 & 0.07 & 0.06 & 12.70 & 80.68 \\
\hline$\cdots$ & 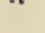 & Saarbruck: mixed & Max. & $\begin{array}{r}10.22 \\
8.21\end{array}$ & 0.22 & 0.07 & 8.57 & 80.92 \\
\hline " & “ & & Min. & 15.50 & 0.74 & 0.33 & $\begin{array}{l}10.04 \\
\text { I.67 }\end{array}$ & $8 \mathrm{r} .66$ \\
\hline & & & Max. & $8.4^{8}$ & 0.08 & 0.0 & 9.69 & $8 \mathrm{r} .68$ \\
\hline as $>$ & & “ & Min. & $9.6 \mathrm{I}$ & 0.16 & 0.08 & 9.47 & 80.68 \\
\hline & & & Max. & 7.00 & $0.1 \mathrm{I}$ & 0.05 & 12.70 & 80.14 \\
\hline “. & “" & Saxony. & Min. & 13.80 & 0.33 & 0.30 & $4 \cdot 36$ & $8 \mathrm{I} .2 \mathrm{I}$ \\
\hline & & & Max. & 7.60 & 0.16 & 0.09 & II. 53 & 80.62 \\
\hline " & •. & Silesia............. & Min. & II. 4 & O. 15 & 0.04 & $7 \cdot 45$ & $8 \mathrm{I} .22$ \\
\hline “ & “ & Bavaria : & $\begin{array}{l}\text { Max. } \\
\text { Min. }\end{array}$ & $\begin{array}{r}8.07 \\
3.06\end{array}$ & $\begin{array}{l}0.10 \\
x .46\end{array}$ & $\begin{array}{l}0.09 \\
0.70\end{array}$ & $\begin{array}{r}10.73 \\
2.03\end{array}$ & $\begin{array}{l}81.01 \\
80.86\end{array}$ \\
\hline & & - & Max. & 7.85 & 0.07 & 0.13 & 10.57 & 81.38 \\
\hline Lign & $e f_{r}$ & om Bohemia. . & Min. & $14.9 \mathrm{I}$ & 1.04 & 0.60 & 2.92 & 80.53 \\
\hline & & & Max. & 6.36 & 0.16 & 0.23 & I3. 15 & 80. 10 \\
\hline Coke & 11 & 1 Sad & Min. & I 4.87 & 0.13 & 0.09 & 4. I6 & 80.75 \\
\hline & & & & 8.01 & 0.03 & 0.00 & 10.87 & $8 \mathrm{I} .09$ \\
\hline
\end{tabular}

The data in the above table show that when air to the amount of 15 cubic metres and over per kilogram (200 cubic 
feet per pound) is used, corresponding to a maximum of 14 per cent of carbonic acid in the waste gases, the loss in hydrogen is very small. With 12 per cent of carbonic acid the hydrogen loss amounts to only a few thousandths.

\section{CALCULATION OF THE VOLUME FROM ANALYSIS.}

To calculate this volume, determine the weight of carbon in a unit of volume, and knowing the weight of carbon furnished by the coal, determine the volume corresponding to the unit of weight. The unit of volume for the gas is the cubic metre, and the unit of weight, the kilogram.

Carbon exists in the waste gases as carbonic acid, carbonic oxide, and hydrocarbons; when we do not know the composition of the hydrocarbons, we consider the carbon and hydrogen as free, and that the carbon is in the state of vapor.

To determine the weight of carbon contained in these different gases, reduce their volumes to kilograms, and by means of their molecular (or equivalent) weights and that of carbon make the calculation.

I litre of $\mathrm{CO}_{2}$ at $0^{\circ}$ and $760 \mathrm{~mm}$. weighs $\mathrm{I} .966$ grams.

I “ “

Molecular weight of carbon........... I2

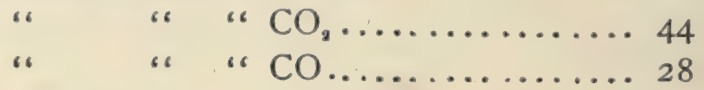

The weight of a volume $v$ of carbonic acid is $v \times 1.966$, and as 44 of carbonic acid contain 12 of carbon, then the weight of carbon would be as $44:$ I 2 or as I I : 3 . Then

$$
\frac{v \times 1.966 \times 3}{I I}=0.536 v .
$$


The weight of carbonic oxide of volume $v^{\prime}$ is $1.251 v^{\prime}$, and as 28 of carbonic oxide contains 12 of carbon, the ratio becomes $28: 12=7: 3$. We then have

$$
\frac{v^{\prime} \times 1.251 \times 3}{7}=0.536 v^{\prime} \text {. }
$$

The weight of a volume of carbon vapor is $v^{\prime \prime} \times 1.072$.

To calculate the weight of carbon in a cubic metre of gas: multiply the added volumes of $\mathrm{CO}_{2}$ and $\mathrm{CO}$ by the coefficient 0.536 . Multiply the volume of carbon vapor by 1.072, and add this product to that obtained above. The sum is the weight of carbon per cubic metre,

$$
C=0.536\left(v+v^{\prime}\right)+1.072 v^{\prime \prime} .
$$

If the gas contains, per cubic metre, 60 litres of carbonic acid, Io of carbonic oxide, and I of carbon vapor, we will have

$$
c=0.536(60+10)+1.072 \times 1=38.592 \text { grams carbon. }
$$

From the ratio of carbon of the coal consumed and that in the gas the volume of combustion gases is deduced.

To calculate this, subtract the carbon of the cinders from that of the original coal. If the coal contains $8 \mathrm{I}$ per cent carbon and leaves 6 per cent of cinders containing Io per cent of carbon, then the amount of carbon burnt will be

$$
8 \mathrm{I}-(0.10 \times 6.0)=8 \mathrm{I}-0.6=80.4 \text {. }
$$

We then have

$$
38.592: 1000=804: 20.830 \text { litres. }
$$

A kilogram of coal produces, then, 20.83 cubic metres of gas at $0^{\circ}$ and $760 \mathrm{~mm}$.

The general formula is

$$
V=\frac{C-c}{\left(v+v^{\prime}\right) 0.536+1.072 v^{\prime \prime}},
$$


in which

$V=$ volume of waste gases at $0^{\circ}$ and $760 \mathrm{~mm}$. in cubic metres;

$v=$ " " $\mathrm{CO}_{2}$ in litres per cubic metre of gases;

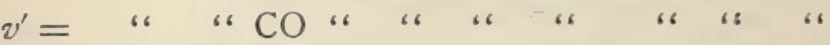

$v^{\prime \prime}=$ " " carbon vapor per cubic metre of gases ;

$C=$ weight of carbon in grams, contained in I kilogram of coal ;

$c=$ weight of carbon in grams, contained in cinders from I kilogram of coal.

Note.-The above calculation in English units would be as follows:

Weight of I cubic foot of carbonic acid.........

" "I " " " " " " " " "

$$
\begin{aligned}
& \frac{v \times 0.12274 \times 3}{I I}=0.0335 v . \\
& \frac{v^{\prime} \times 0.07811 \times 3}{7}=0.0335 v^{\prime} .
\end{aligned}
$$

$0.06693 v^{\prime \prime}=$ weight of carbon in vapor.

$$
C=0.0335\left(v+v^{\prime}\right)+0.06693 v^{\prime \prime} \text {. }
$$

Iooo cubic feet of gases having 60 cubic feet of $\mathrm{CO}_{2}$, Io cubic feet of $\mathrm{CO}$ and $\mathrm{I}$ cubic foot of $\mathrm{C}$ vapor would give

$$
C=0.0335(60+\mathrm{Io})+0.06693 \times \mathrm{I}=2.4 \mathrm{I} 2 \text { lbs. carbon. }
$$

I pound of coal has 80.4 per cent carbon; then

2.412: $1000=0.804: 333 \frac{1}{8}$ cubic feet of gases produced from I lb. of coal.

The general formula is

$$
V=\frac{C-c}{0.0335\left(v+v^{\prime}\right)+0.06693 v^{\prime \prime}},
$$

in which

$$
\begin{aligned}
& V=\text { volume in cubic feet of gases produced; } \\
& v=\text { " of } \mathrm{CO}_{2} \text { in cubic feet per rooo cubic feet; } \\
& v^{\prime}=\text { " "CO " " " " } \\
& v^{\prime \prime}=\text { “ " carbon vapor in cubic feet per rooo cubic feet; } \\
& C=\text { weight of carbon in coal in thousandths of a pound; } \\
& c=\text { " " " cinders per pound of coal in thousandths. }
\end{aligned}
$$




\section{CALCULATION OF VOLUME OF AIR SUPPLIED.}

The volume of combustion-gases just determined is less than that of the air supplied. Oxygen in forming carbonic acid produces a volume equal to itself; hence there is no change.

$$
\underset{2 \text { vols. }}{\mathrm{C}}+\underset{2 \text { vols. }}{\mathrm{O}_{2}}
$$

Oxygen in forming carbonic oxide produces twice the volume.

$$
\mathrm{C}+\underset{\text { I vol. }}{\mathrm{O}}=\underset{2 \text { vols. }}{\mathrm{CO}}
$$

Hence there is an increase in volume.

Carbon vapor and hydrogen as free gases or as hydrocarbons increase the volume but slightly. In forming sulphurous acid with sulphur there is no change of volume.

$$
\underset{2 \text { vols. }}{\mathrm{S}}+\underset{2 \text { vols. }}{\mathrm{O}_{2}}=\underset{2 \mathrm{O}_{2}}{\mathrm{~S}_{2}}
$$

Another slight cause of increase is setting free the nitrogen of the coal; but this is inappreciable. I per cent of nitrogen forms only O.I per cent of the entire volume of gases formed.

It might be said that, excepting the oxygen changing to water and disappearing by condensation, all the modifications of gaseous volume may be neglected, the increase being more than compensated by the loss due to oxygen. This elimination of oxygen must be allowed for, however.

A coal containing 4 per cent of hydrogen requires eight times such weight to form water, or 40 grams of hydrogen need 320 grams of oxygen. I litre of oxygen weighs 1.430 grams, then 320 grams measure $\frac{320}{1.430}=223.7$ litres $(7.9$ cubic feet). (Or I lb. of such coal would need 3.6 cubic feet of oxygen.)

These 223 litres must be added to the volume of the waste gases produced by the coal to obtain the original 
volume of air introduced. A coal containing 5 per cent of hydrogen would use 279 litres.

The volume of oxygen needed for various percentages of hydrogen is as follows:

$1 \%$ hydrogen uses of oxygen

$\begin{array}{llll}2 & \text { " } & \text { " } & \text { " } \\ 3 & \text { " } & \text { " } \\ 4 & \text { " } & \text { " }\end{array}$

Per kilo of coal. Per lb. of coal. 55.9 litres, 0.9 cubic feet.

$\begin{array}{lllll}\text { II } 2 & \text { " } & \text { I. “ } & \text { “ } \\ \text { I68 } & 2.7 & \text { " } \\ 223 & \text { " } & 3.6 & \text { " } & \text { " } \\ 279 & 4 & 4.5 & \text { " }\end{array}$

Calling $\mathrm{H}$ the per cent of hydrogen, the formula given above becomes

$$
\mathrm{V}^{\prime}=\frac{\mathrm{C}-c^{\prime}}{\left(v+v^{\prime}\right) 0.563+1.07 \mathrm{I} v^{\prime \prime}}+55.9 \mathrm{H},
$$

or

$$
\mathrm{V}^{\prime}=\frac{\mathrm{C}-c^{\prime}}{0.0335\left(v+v^{\prime}\right)+0.06693 v^{\prime \prime}}+0.9 \mathrm{H} .
$$

To make this applicable to normal air saturated with moisture at $0^{\circ} \mathrm{C}$. and $760 \mathrm{~mm}$. ( $32^{\circ} \mathrm{F}$. and 29.922 inches) containing 0.4 per cent of $\mathrm{CO}_{3}$, we must divide by 99.12, the composition of air being:

Nitrogen...................... 78.35

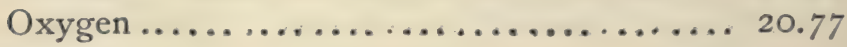

Water....................... 0.84$\}$

Carbonic acid.................. 0.04$\} 0.88$

$$
100.00
$$

And $100-0.88=99.12$. The formula then becomes

$$
\mathrm{V}^{\prime \prime}=\frac{\mathrm{C}-c^{\prime}}{\left(v+v^{\prime}\right) 0.567+1.0806 v^{\prime \prime}}+55.9 \mathrm{H},
$$

or

$$
\mathrm{V}^{\prime \prime}=\frac{\mathrm{C}-c^{\prime}}{0.0337\left(v+v^{\prime}\right)+0.06752 v^{\prime \prime}}+0.9 \mathrm{H} .
$$




\section{CALCULATION OF WEIGHT OF WASTE GASES FROM ANALYSIS. *}

Two methods of calculating from the analysis by volume of the dry chimney gases the number of pounds of dry chimney gases per pound of carbon, or the weight of air supplied per pound of carbon, have been given by different writers. These may be expressed in the shape of formulæ as follows:

(A) Pounds dry gas per pound $\mathrm{C}=\frac{\mathrm{r} \mathrm{ICO}_{2}+8 \mathrm{O}+7(\mathrm{O}+\mathrm{N})}{3\left(\mathrm{CO}_{3}+\mathrm{CO}\right)}$;

(B) Pounds air per pound

$$
\mathrm{C}=5.8 \frac{2\left(\mathrm{CO}_{2}+\mathrm{O}\right)+\mathrm{CO}}{\mathrm{CO}_{2}+\mathrm{CO}}
$$

Formula A may be derived from the method of computation given in Mr. R. S. Hale's paper on "Flue Gas Analyses," Transactions A. S. M. E., vol. Xvili. p. 901, and formula B from the method given in Peabody and Miller's Treatise on Steam-boilers. Both are based on the principle that the density, relatively to hydrogen, of an elementary gas $(\mathrm{O}$ and $\mathrm{N}$ ) is proportional to its atomic weight, and that of a compound gas $\left(\mathrm{CO}\right.$ and $\left.\mathrm{CO}_{2}\right)$ to one half its molecular weight. Both formulæ are very nearly accurate when pure carbon is the fuel burned; but formula B is inaccurate when the fuel contains hydrogen, for the reason that that portion of the oxygen of the air-supply which is required to burn the hydrogen is contained in the chimney gas as $\mathrm{H}_{2} \mathrm{O}$, and does not appear in the analysis of the dry gas.

The following calculations of a supposed case of combustion of hydrogenous fuel illustrates the accuracy of formula A and the inaccuracy of formula B: Assume that the coal has the following analysis: C, 66.50; H, 4.55; O, 8.40; N, I.00; water, 10.00; ash and sulphur, 9.55; total, 100. Assume 1897 .

* William Kent in Report of Committee on Boiler-tests, A. S. M. E., 
also that one tenth of the $\mathrm{C}$ is burned to $\mathrm{CO}$, and nine tenths to $\mathrm{CO}_{2}$; that the air supply is 20 per cent in excess of that required for this combustion; that the air contains one per cent by weight of moisture; and that the $S$ in the coal may be considered as part of the ash. We then have the following synthesis of results of the combustion of 100 pounds of coal:

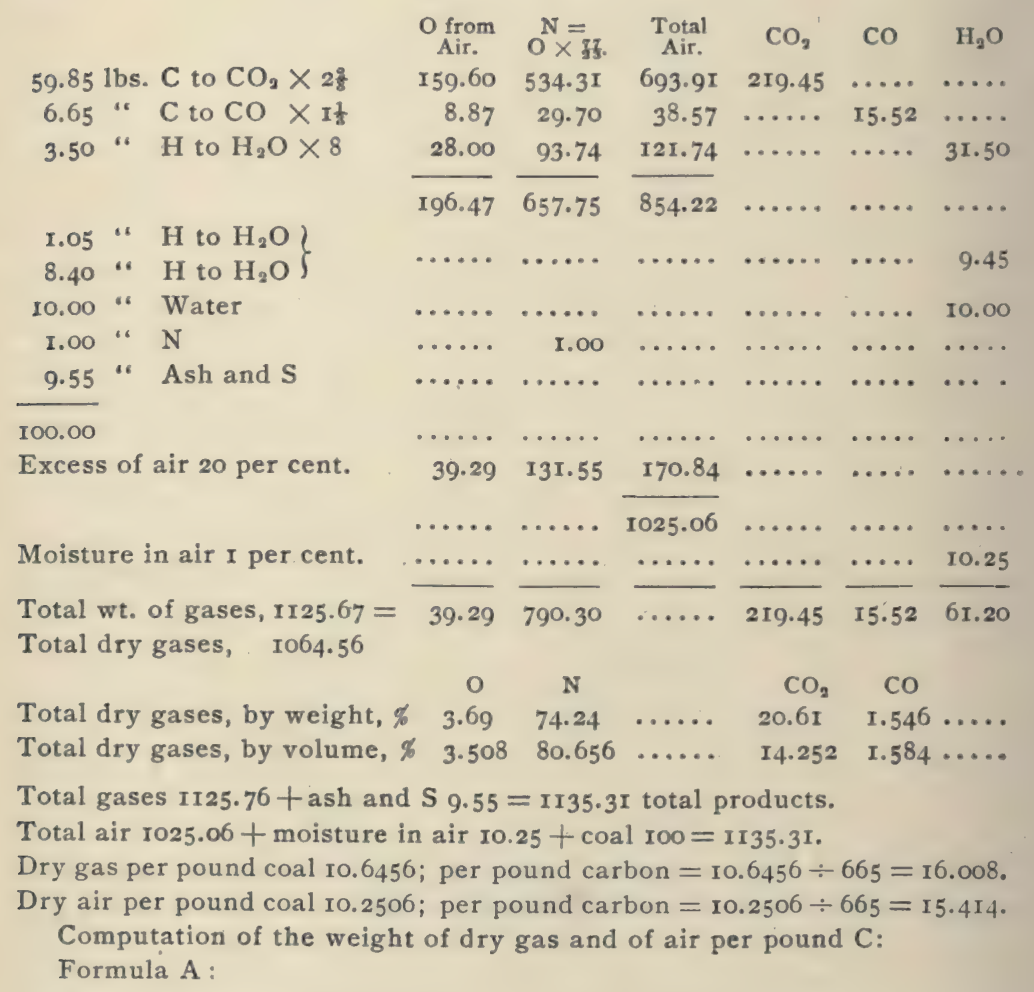

Dry gas per pound $C=\frac{14.252 \times 1 r+3.508 \times 8+82.240 \times 7}{3(14.252+1.584)}=16.008$ pounds. Formula B :

$$
\text { Air per pound } C=5.8 \frac{2(14.252+3.508)+r .584}{\mathbf{I} 4.252+1.584}=\mathrm{r} 3.589 \text { pounds. }
$$

The error in the last result is $15.414-13.589=1.825$ pounds. 
Prof. Jacobus recommends the use of the formula

Pounds of air per pound $\mathrm{C}=\frac{7 \mathrm{~N}}{3\left(\mathrm{CO}_{2}+\mathrm{CO}\right)} \div 0.77$

and in the case given above, where the actual quantity used was I 5.4I 4 per cent, his calculated one is I 5.434 per cent, practically the same, and as near as errors of analysis would allow a calculated result.

\section{VOLUME OF WASTE GASES BY THE ANEMOMETER.}

The fan-wheel anemometer is an instrument to measure the force or rapidity of a current of gas. It consists of a fan-wheel rotated by the moving gas, and which transmits such motion to an index showing the number of revolutions. Burnat used this apparatus to measure the quantity of air passing in under the grate of steam-boilers.

The coefficient to be used in calculating the flow is different for each machine, and must be determined by actual experiment. Burnat's formula,

$$
v=0.120+0.130 n
$$

means that the velocity is found by multiplying the number of revolutions per second by O.I3O and adding O.I2O to the product.

To obtain satisfactory results with the anemometer, it must be placed in the axis of a perfect cylinder at the depth of a metre, as the indications vary with the position in the flue. The formula needs correction for temperature, but the correction of the apparatus much exceeds this. Burnat compared his results with those obtained from a formula depending on the depression if under the grate (see page 147), and found differences of not more than 5 per cent. 
FLETCHER'S ANEMOMETER.

Fletcher's anemometer (Fig. 35) is used in England to ascertain the speed of flow in chimneys and flues. In its simplified form it is quite serviceable. It is based on the movement of a column of ether in a U-tube.

The ends of the glass tubes $a, b$ are placed in the flue a little less than one sixth of its diameter. The straight end $a$
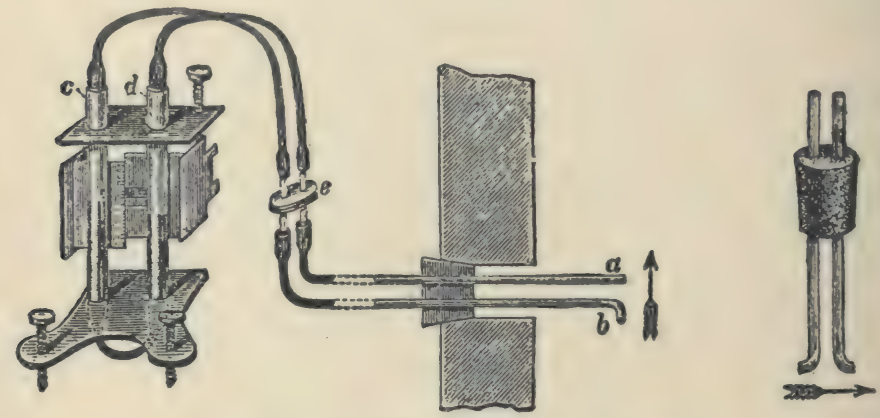

Fig. 33.-Fletcher's Anemometer.

should be parallel to the direction of the current, the end $b$ being at right angles to this. Hunter proposed bending both ends in opposite directions, to obviate the error caused if the tubes were not so placed. These tubes communicate with the ether tube $c d$. The draught across the tubes causes the ether to rise in $a$ by aspiration and to fall in $b$ by pressure. The difference of level is read, and then the tubes are turned around $180^{\circ}$, so as to reverse their positions, and the difference of level read again. The sum of the two differences is called the anemometer reading, and by means of tables the velocity of the current is ascertained.

The same trouble is common to all anemometer methods. The flue feeding the fire receives only the air passing in 
under the grate. Whatever passes in by the doors or

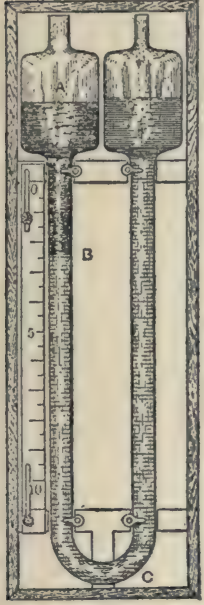

FIG. 34 . Segur Gauge. through cracks escapes accounting. On account of this it is certain that the calculations based on anemometer readings are lower than th al air supply.

\section{SEGUR'S DIFFERENTIAL GAUGE.}

This gauge (Fig. 34) consists of a U-tube of $\frac{1}{2}$-inch glass, surmounted by two chambers of $2 \frac{1}{2}$ inches diameter. Two non-miscible liquids of different colors, usually alcohol and paraffin oil, are put into the two arms, one occupying the portion $A B$, the other the portion $B C D$. The movement of the line of demarcation is proportional to the difference in area of the chambers and the tube adjoining. A movement of 2 inches in the column represents $\frac{1}{4}$-inch difference pressure or draft.

\section{HIRN'S METHOD.}

The apparatus used by Burnat as a check on his own calculations was devised by Hirn, and is based on the formula of the rate of flow of compressed gases from a reservoir, friction being neglected. The coefficient of reduction used is 0.9 , the one given by Dubuisson in his treatise on hydraulics.

The main difficulty consists in measuring the difference of pressure of the atmosphere in the ash pit and that outside, for the depression in the flues in some cases does not exceed a few millimetres of water. Hirn's apparatus removes this difficulty.

Burnat describes it as follows:

When making a test the doors of the ash pit are removed and replaced by a piece of sheet iron, $A$ (Fig. 37), which completely shuts out all access of air except through the opening in the middle, to which is fitted the pipe $C D$, I 3.8 inches 
diameter and 59 inches long. A tube leads from the front to the apparatus $E$, devised by Hirn, placed on a table or against the boiler-wall. This apparatus consists of a little gas holder whose upper surface is just one decimeter (3.9

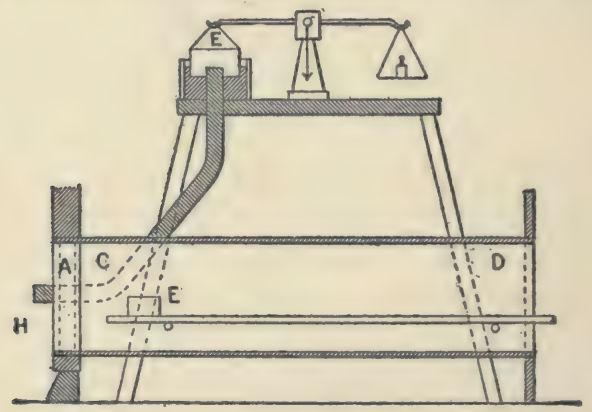

FIG. 35 .

inches) on a side. Inside this and above the water level the tube $A$ opens. The bell dips into a vessel of water and is suspended from a balance arm.

The balance being in equilibrium when the atmospheric pressure acts on both sides of the bell, if the interior is connected with the ash-pit the weight needed to restore equilibrium will give a measure of the difference in pressure. The weight of half a gram ( 7.7 grains) represents one-twentieth millimetre ( 0.002 inch) of water.

The formula adopted by Hirn is

$$
V=S \times 0.9 \sqrt{2 g \frac{h \times 0.76(1+0.0037 t)}{0.0013 B}},
$$

in which

$V=$ volume of air introduced under the grate in cubic metres;

$S=$ section in square metre of pipe-opening leading air to the ash-pit ;

$0.9=$ coefficient of reduction ; 
$h=$ difference of pressure expressed in height of water;

$B=$ barometric pressure in the room;

$t=$ temperature of the room;

$g=$ acceleration of gravity $=9.8088$ metres.

\section{VOLUME BY AUTOMATIC APPARATUS.}

\section{DASYMETER.}

Siegert and Durr * devised an apparatus called the Dasymeter, which has been introduced in several large works in Europe, where it gives satisfaction.

It consists of a balance enclosed in a cast-iron box with a glass side (Fig. 36). At one end of the beam is a very

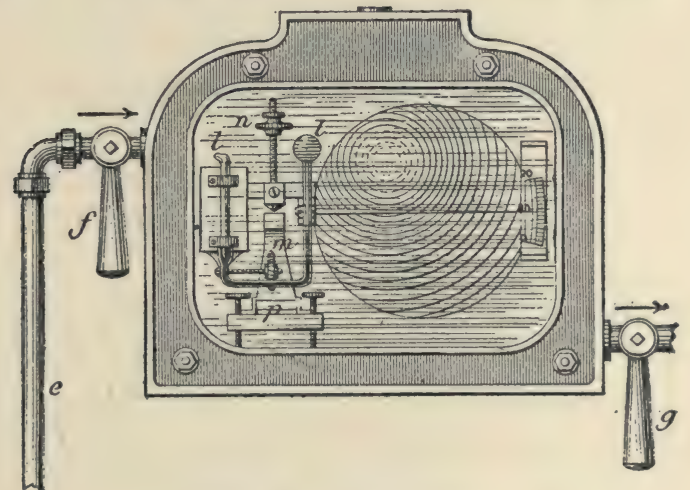

Fig. 36.-DASYMETER.

light glass balloon holding 2 to 3 litres, sealed by fusion. The other end carries a weight balancing the balloon. This weight is formed of a $\mathrm{U}$-tube, $l l$, containing mercury, and is open at one end; the other end is expanded into a bulb containing air, which is submitted to the variations of pressure and temperature through the mercury. If the pressure of the air increases or diminishes, the mercury rises or falls, and increases or diminishes the weight on the lever. Suppose an

* Oesterreichische Zeitschrift für B.- und H.-Wesen, Xvi. p. 291. 
increase of pressure and a lowering of temperature whicil would diminish the density of the air one half. A corresponding quantity of mercury passes into the arm of the tube, and the original compensating weight is diminished by that amount. A graduated index shows the variations of weight, and hence the variations of density in the gases. An ingenious arrangement allows regulation by rotating the $\mathrm{U}$-tube on the axis $p n$. The tube is turned slowly around till adjusted, thus changing the length of the lever-arm.

A difference of I per cent of carbonic acid causes a difference in weight of 20 milligrams. One litre of air at $0^{\circ}$ and 760 millimetres weighs 1294 milligrams; I litre of carbonic acid weighs 1967 milligrams; the difference is 673 milligrams. If the gas contains I per cent of $\mathrm{CO}_{2}$, each litre increases 6.73 milligrams in weight; and as the balloon contains 3 litres, it supports an external pressure of more than $3 \times 6.73=20.19$ milligrams (0.3 I I grains).

To prevent action of sulphurous acid the bearings are made of sapphire, onyx, bloodstone, etc., and metallic parts of phosphor-bronze.

To set up the dasymeter, connect pipe $e$ with the boilerflue before the damper; the tube $g$ leads to the chimney. By this means a current of gas passes through the box, and shows at any time the percentage of carbonic acid. Siegert gives the following results obtained with it, and the corresponding results by analysis:

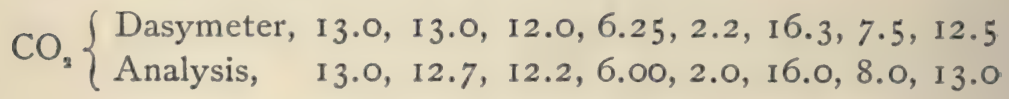

\section{ECONOMETER.}

H. Arndt has invented what he calls the "Econometer" (Fig. 37), which is on a similar principle.* It consists of a tight cast-iron shell, $N N$, containing a gas-balance. A pipe,

* Zeitschrift des Vereines Deutscher Ingenieure, xxxvir. p. 80 I. 
$v^{\prime}, 0.4$ inch in diameter leads to the inside of the flue before the damper; a second pipe, $v^{\prime \prime}$, communicates with the interior of the same flue beyond the damper. In the interior, the tube $i^{\prime}$ is connected to the upright pipe $f$, which leads the gas to bell $e^{\prime}$, and the tube $i^{\prime}$ to the tubulure $g . i^{\prime}$ and $i^{\prime \prime}$ are of rubber.

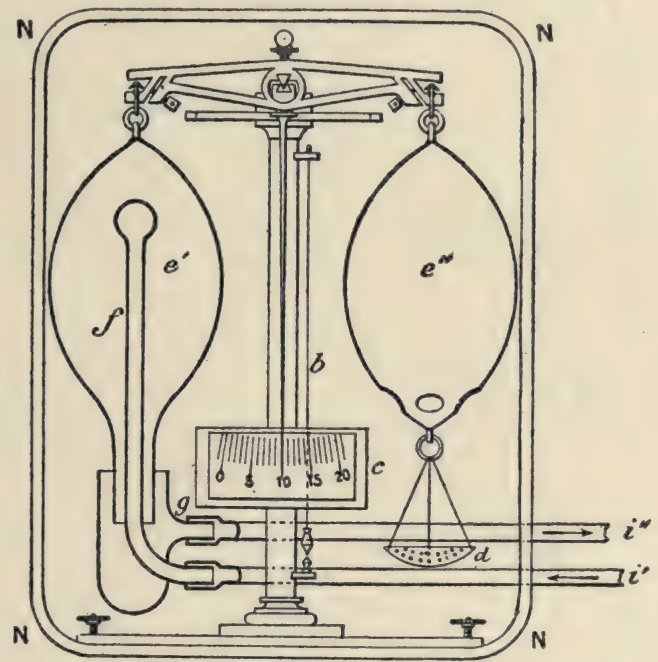

Fig. 37.-ECONOMETER.

The balance is very sensitive, the beam carrying at one end the gas-holder $e^{\prime}$, open below and containing about 30 cubic inches, and at the other end a second holder of similar size and weight as the first. Attached to the bottom of this one is a pan to hold the balancing weights.

The tube $f$ conducts the gas to the balloon $e^{\prime}$, which, open below, is freely movable in the cylinder $g$, by which it produces suction in the tube $i^{\prime \prime}$.

Carbonic acid being heavier than common air ( 1.96 to I.29) as well as the other associated gases, it follows that the density of the gases passing through the tubes depends on the carbonic acid content. The scale is divided so that each division shows one per cent of $\mathrm{CO}_{2}$ in the gases. 


\section{GAS-COMPOSIMETER.}

The gas-composimeter of Uehling is an apparatus for automatically and continuously determining the quantity of carbonic acid contained in waste gases.

It is based on the laws governing the flow of gas through small apertures.

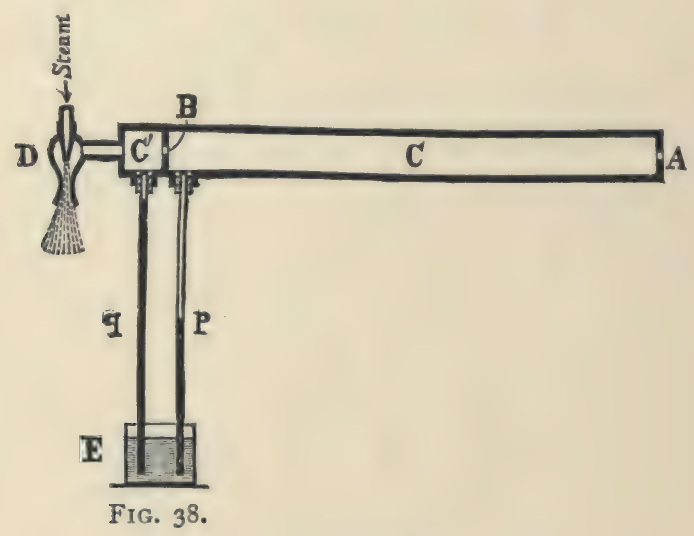

If two such apertures, $A$ and $B$ (Fig. 38 ), form respectively the inlet and outlet openings of chamber $C$, and a uniform suction is maintained in the chamber $C^{\prime}$ by the aspirator $D$, the action will be as follows:

Gas will be drawn through the aperture $B$ into the chamber $C^{\prime}$, creating suction in chamber $C$, which in turn causes gas to flow through the aperture $A$. The velocity with which the gas enters through $A$ depends on the suction in the chamber $C$, and the velocity at which it flows out through $B$ depends upon the excess of the suction in chamber $C^{\prime}$ over that existing in chamber $C$, that is, the effective suction in $C^{\prime}$. As the suction in $C$ increases, the effective suction must decrease, and hence the velocity of the gas entering at $A$ increases, while the velocity of the gas passing out through $B$ decreases, until the same quantity of gas enters at $A$ as passes 
out at $B_{4}$ As soon as this occurs no further change of suction takes place in the chamber $C$, providing the gas entering at $A$ and passing out at $B$ be maintained at the same temperature.

If from the constant stream of gas, while flowing through chamber $C$, one of its constituents is continuously removed by absorption, a reduction of volume will take place in chamber $C$ and cause an increase in suction, and consequently a decrease in the effective suction in $C^{\prime}$. Hence the velocity of the gas through $A$ will increase, and the velocity through $B$ will decrease, until the same quantity of gas enters at $A$ as is absorbed by the reagent, plus that which passes out at aperture $B$.

Thus every change in the volume of the constituents we are absorbing from the gas causes a corresponding change of suction in the chamber $C$.

The apparatus is connected with a regulator, a manometer, and automatic recording register.

\section{TEMPERATURE OF THE WASTE GASES.}

As in analyzing coal, cinders, and gases we must have average samples, so in treating of waste gases we need average temperatures. It is not enough to take the temperature occasionally with the thermometer; it varies too much from time to time, even if the readings are taken frequently. We must have some method of obtaining the average temperature of the gas current, and this can be accomplished by means of a heat reservoir introduced into the flue.

For this purpose one was devised by Scheurer-Kestner of a type which has been repeatedly copied and modified. It consists of an iron tube, $b b$ (Fig. 39), placed in the flue so that the upper end, covered with an insulating material, is let into the wall to about one half its thickness, the remainder hanging free in the flue. This tube is filled with paraffin, 
and in this is inserted the thermometer. The large mass of the paraffin is acted on by the mean temperature, but is uninfluenced by any slight momentary changes which may occur. A self-registering thermometer is very advantageous, but readings at intervals of half an hour are sufficient ordinarily. Of course the opening around the tube should be packed so as to prevent all possible ingress of cold external air.

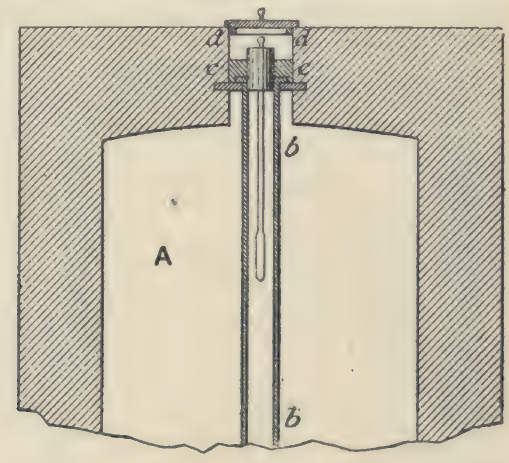

Fig. 39.-Flue Thermometer.

Occasionally mercury is used instead of paraffin. This renders the average of the heat more exactly, perhaps, but has the disadvantage of being much heavier and much more expensive. There are also many difficulties in handling it which do not obtain with paraffin. The paraffin should be well refined, and have a high melting-point.

\section{THE PNEUMATIC PYROMETER.}

Uehling's pneumatic pyrometer is based on a principle analogous to that of the gas-composimeter, and is now in use in many places, automatically measuring the temperatures of chimneys and furnaces for all temperatures up to $3000^{\circ} \mathrm{F}$., and registering the same on cards. The apparatus has been tested at the Stevens Institute of Technology, and the indications pronounced reliable. It cannot be safely used 
continuously for temperatures above $2500^{\circ}$, but at that temperature and lower it works well and satisfactorily for months without requiring any readjustment. The automatic register is very sensitive, and can be easily adjusted for a new range of temperatures at any time.

An explanation of the principle of its working is given in the inventor's own words:

"The Pneumatic Pyrometer is based on the laws governing the flow of air through small apertures.

"If two such apertures $A$ and $B$ (Fig. 38) respectively form the inlet and outlet openings of a chamber $C$, and a uniform suction is created in the chamber $C^{\prime}$ by the aspirator $D$, the action will be as follows:

"Air will be drawn through the aperture $B$ into the chamber $C^{\prime}$, creating suction in chamber $C$, which in turn causes air from the atmosphere to flow in through the aperture $A$. The velocity with which the air enters through $A$ depends on the suction in the chamber $C$, and the velocity at which it flows out through $B$ depends upon the excess of suction in $C^{\prime}$ over that existing in the chamber $C$, that is, the effective suction in $C^{\prime}$. As the suction in $C$ increases, the effective suction must decrease, and hence the velocity at which air flows in through the aperture $A$ increases, and the velocity at which air flows out through the aperture $B$ decreases, until the same quantity of air enters at $A$ as passes out at $B$. As soon as this occurs no further change of suction can take place in the chamber $C$.

"Air is very materially expanded by heat. Therefore the higher the temperature of the air the greater the volume, and the smaller will be the quantity of air drawn through a given aperture by the same suction. Now if the air as it passes through the aperture $A$ is heated, but again cooled to a lower fixed temperature before it passes through the aperture $B$, less air will enter through the aperture $A$ than is drawn out through the aperture $B$. Hence the suction in $C$ 
must increase and the effective suction in $C^{\prime}$ must decrease, and in consequence the velocity of the air through $A$ will increase and the velocity of the air through $B$ will decrease, until the same quantity of air again flows through beth apertures. Thus every change of temperature in the air entering through the aperture $A$ will cause a corresponding change of suction in the chamber $C$. If two manometer-tubes $p$ and $q$, Fig. 38 , communicate respectively with the chambers $C$ and $C^{\prime}$, the column in tube $q$ will indicate the constant suction in $C^{\prime}$ and the column in tube $p$ will indicate the suction in the chamber $C$, which suction is a true measure of the temperature of the air entering through the aperture $A$.

\section{DETERMINATION OF THE CARBON IN SMOKE.}

SOOT or black forms from quick cooling of the hydrocarbons, temporarily dissociated by high temperatures. Fuels having no hydrogen as hydrocarbons, never produce smoke; pure charcoal, coke, or graphite never smokes. Soft coal, on the contrary, produces more as the air-supply grows less.

Sainte-Claire Deville proved that a compound gas when heated sufficiently separates into its elements; a sudden cooling now will give a simple mixture instead of the original combination. A slow cooling, however, reproduces the original gas. Berthelot proved, on the other hand, that new compounds are formed on heating the hydrocarbons to high temperatures, a part of the carbon being deposited as soot. These two phenomena undoubtedly go on together in smoke production.*

If a metal tube be put in the gas current over a grate at a short distance from the fire, the hottest gases will be col-

* Bunte gives some analyses of smoke-black:

$\begin{array}{ccc}\text { r........ } & \text { C } & \text { H } \\ 2 \ldots \ldots \ldots \ldots & 97.2 & 2.8 \\ 3 \ldots \ldots \ldots \ldots & 97.3 & 2.7 \\ & 98.5 & 1.5\end{array}$


lected. Pass a stream of cold water through a pipe in this gas-current and a large quantity of black will be deposited. On stopping the water flow and inclining the tube a little the carbon disappears gradually, and when the temperature of the tube attains that of the gas, no black will be deposited. Cool it again, and more black forms immediately.

Combustion gases meet with surfaces relatively cold in the boiler sides or flues, or even in colder currents of gas or air passing in through the grate. This produces a quick cooling, and consequent formation of black.

Experiments made at Mulhouse in 1859 by Burnat showed an advantage gained in steaming by producing smoke, rather than introducing too great excess of air. The experiments showed that the loss in carbon was quite small, and these results have been confirmed by others since. E. R. Tatlock of Glasgow finds 60 per cent combustible matter in soot, and obtained 51.46 grains per cubic foot of furnace gases.

To determine the amount of carbon in smoke, ScheurerKestner used a glass organic analysis apparatus, the tube having in the middle loosely packed asbestos for about 8 inches, which was kept in place by platinum spirals. One end was drawn out to connect with the absorption apparatus, and the other end placed in the flue. After igniting and cooling the asbestos the small end is connected with an aspirator and the gas drawn slowly through. The carbon is all stopped by the asbestos, which becomes black for a short distance. When sufficiently collected, dry the tube at $100^{\circ}$ C., heat to redness, and pass a stream of oxygen through it, collecting the carbonic acid formed.

As an example Scheurer-Kestner gives the following:

Waste gases, reduced to $0^{\circ}$ and $760 \mathrm{~mm} .86$ litres. Time of sampling............... I hour. 
Composition of gas:

$\mathrm{CO}_{2} \ldots \ldots \ldots \ldots \ldots \ldots . . . .6$ per cent.

Excess of air........... 53.4

Nitrogen and residue........ 38 . I

$\mathrm{CO}_{2}$ from the combustion........... 0.070 gram.

Equivalent to carbon............... 0.019 "

By the analysis of the gases and that of the coal the quantity of air consumed was calculated. Knowing the volume of air used for the coal, its composition, and the proportion of carbon as black in the gases, the loss due to such formation was calculated.

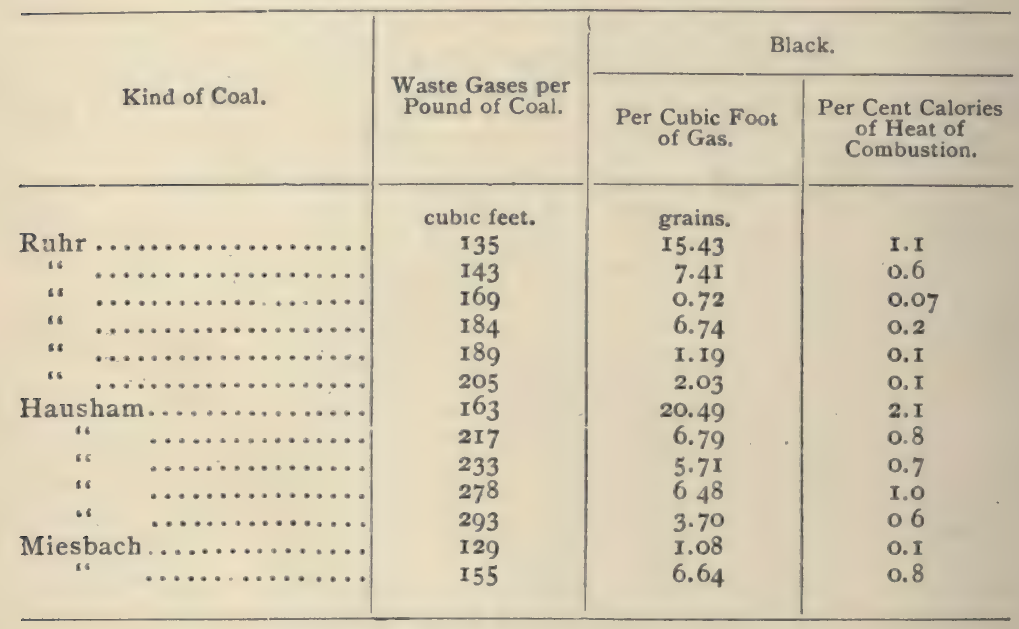

Under the most unfavorable conditions for feeding the air, the loss due to formation of black does not exceed 2 per cent, even with smoky coal. Ronchamp coal gave the following results:

Feeding 240 cubic feet of air per pound of coal gave a gas containing 8.5 per cent of carbonic acid, excess of air 53 per cent, and loss of carbon as black 0.485 per cent.

Feeding I 12 cubic feet of air per pound of coal gave a 
gas containing 14.8 per cent carbonic acid, 6.7 per cent excess of air, and 0.96 per cent of black.

Saarbruck coal supplied with 155 cubic feet of air per pound gave a gas having 12.8 per cent of carbonic acid, 28.5 per cent excess of air, and 2.03 per cent of black.

These show that in addition to being a sign of diminution in combustible gases, smoke cannot cause a notable saving in fuel if such saving is accompanied by increased waste gases. The sensible heat of a larger volume compensates easily for the advantages resulting from the more perfect combustion of the carbon.

Bunte publishes the following determinations of black:

Several methods have been devised for approximating to the actual quantity of carbon contained in smoke. One is based on the amount of soot deposited on a given surface placed in the chimney. The soot deposits on the upper surface away from the direct current. After being exposed for a few hours the deposit is brushed off and weighed. Another method is by using smoked glasses of different degrees of opacity and ascertaining what depth of color is necessary to make the smoke invisible. An improvement on this method is now being worked out by one of our manufacturers of optical goods, by means of which the glasses are held in a tube and so arranged as to gradually produce the effect, and in such way that it can be measured.

Another method is that devised by Ringelmann, by means of which the blackness of the smoke is compared with a set of ruled lines, so scaled in width of line and space as to produce six different gradations from smokeless through gray and gray-black to dead black. He recommends the preparation of cards 8 inches square, and have them suspended 50 feet from the observer, at which distance the individual lines become indistinct, and only a general tint is observable. The intensity of the smoke is then compared with the cards and recorded as agreeing with card No. I, 2 , or whatever it may be. 
The cards are shown in Fig. 40, reduced in size, the actual lines and spaces being as follows:
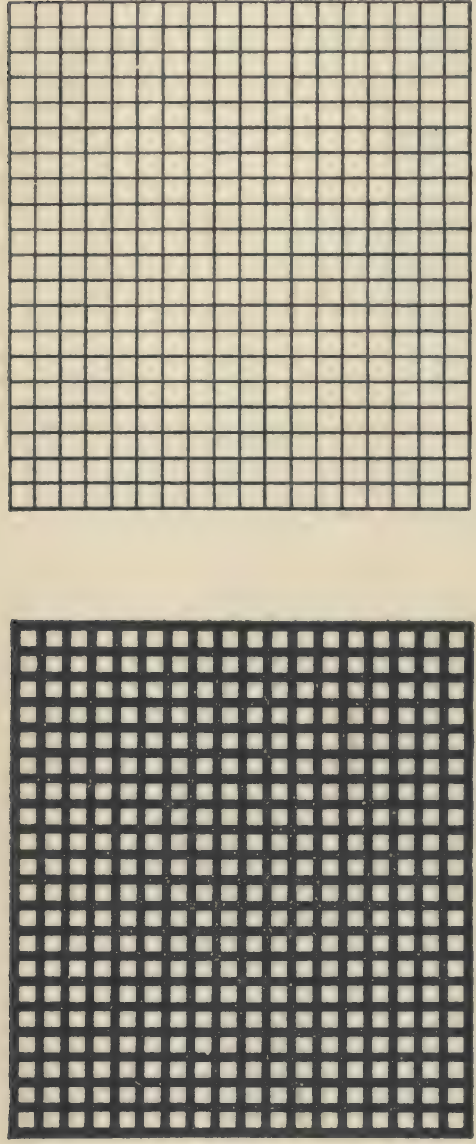
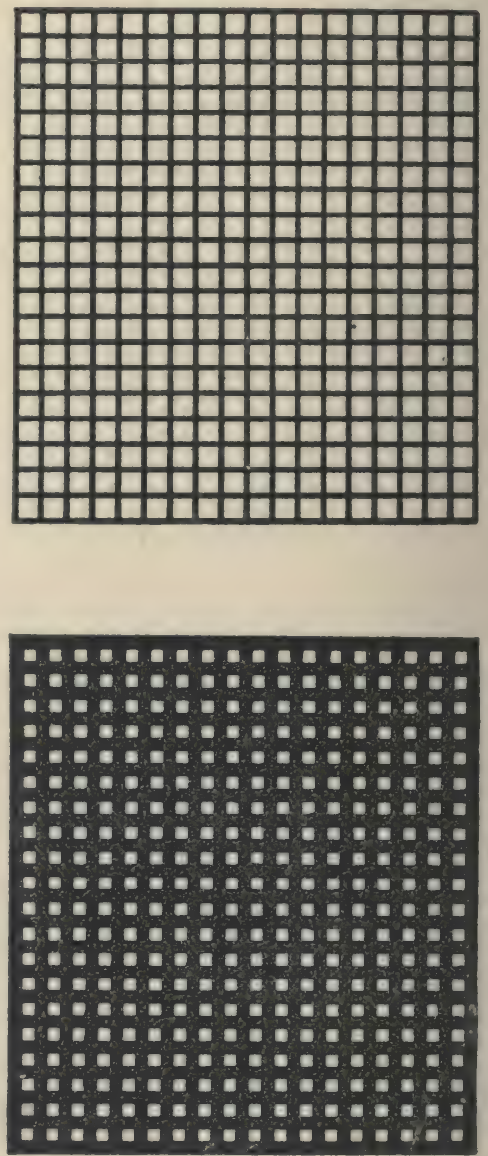

Fig. 40.-Ringelmann Smoke Scale.

Card o, all white.

Card I, black lines I $\mathrm{mm}$. thick, Io $\mathrm{mm}$. apart between centres, leaving spaces $9 \mathrm{~mm}$. square.

Card 2, lines $2.3 \mathrm{~mm}$. thick; spaces $7.7 \mathrm{~mm}$. sq.

Card 3, lines $3.7 \mathrm{~mm}$. thick; spaces $6.3 \mathrm{~mm}$. sq.

Card 4 , lines $5.5 \mathrm{~mm}$. thick; spaces $4.5 \mathrm{~mm}$. sq.

Card 5, all black. 
CHAPTER XII.

\section{CALCULATION OF THE HEAT UNITS.}

\section{HEAT OF THE AQUEOUS VAPOR.}

THE quantity of heat contained in a kilogram or pound of steam at any temperature is

$$
\begin{aligned}
Q & =606.5+0.305 t \text { calories, } \\
\text { or } \quad Q^{\prime} & =1091.7+0.305(t-32) \text { B. T. U., }
\end{aligned}
$$

allowing the specific heat of water to be constant. The number of heat units is considered the same as the temperature.

So that, allowing the average temperature of aqueous vapor to be $150^{\circ} \mathrm{C}$., each kilogram at $0^{\circ}$ has absorbed a quantity of heat equal to

$$
\begin{aligned}
& 606.5+0.305 \times 150=652.25 \text { calories } \\
& \text { or one pound has absorbed I I } 74 \text { B. T. U. }
\end{aligned}
$$

There is a correction to this, since we do not wish the units existing in the steam, but only those added to it from the fuel. We must then deduct that already existing in the water at its entrance to the boiler. If the feed-water be $20^{\circ}$ $\left(68^{\circ} \mathrm{F}\right.$.) the formula becomes

or

$$
\begin{aligned}
652.25-20 & =632.25 \text { calories, } \\
\text { I I } 74-(68-32) & =\text { I I } 38 \mathrm{~B} . \mathrm{T} . \mathrm{U} .
\end{aligned}
$$




\section{HEAT OF WASTE GASES.}

The heat carried to the chimney by the waste gases is from several sources:

I. Sensible heat shown by the temperature.

2. Heat of vaporization of the hygroscopic water and the water formed from the hydrogen of the coal.

3. Heat retained by the combustible gases or their heat of combustion.

4. Heat represented by soot or black of the smoke.

\section{SENSIBLE HEAT OF THE TEMPERATURE.}

The calculation of the water equivalent of the heat carried to the chimney as sensible heat requires the volume, temperature, composition, and specific heat of the constituents.

The specific heats of the usual constituents of waste gases are shown in Table VIII. The specific heats are supposed to be under constant pressure, so as to avoid useless calculations. The hydrocarbons or hydrogen will be omitted for the same reason. Calling $v, v^{\prime}, v^{\prime \prime}, v^{\prime \prime \prime}$ the volumes in cubic metres of the gases nitrogen, carbonic acid, carbonic oxide, and oxygen, we find their respective weights, by multiplying these volumes by the weight per cubic metre,

$$
\frac{1.256 v}{\mathrm{~N}}, \frac{\mathrm{I} .966 v^{\prime}}{\mathrm{CO}_{2}}, \frac{\mathrm{I.25 \textrm {I } v ^ { \prime \prime }}}{\mathrm{CO}}, \frac{\mathrm{I.430v^{ \prime \prime }}}{\mathrm{O}} \text {. }
$$

Multiplying these by the specific weights we obtain the value in water,

$$
\begin{aligned}
& \mathrm{C}=\mathrm{I} .256 v \times 0.244+1.966 v^{\prime} \times 0.217+1.251 v^{\prime \prime} \times 0.245+ \\
& \text { I. } 430 v^{\prime \prime \prime} \times 0.217 \text {. }
\end{aligned}
$$

The equivalent in water $c$ multiplied by the temperature on leaving the boiler gives calories,

$$
\mathrm{C}=c \times T \text {. }
$$


A correction of the same kind as that applied to the temperature of the feed-water must be applied. We do not wish the total calories, only those taken up from the coal. From the observed temperature $T$ we must deduct the original temperature $t$ before entering the fire. So that

$$
\mathrm{C}=c \times(T-t) .
$$

The general formula then becomes

$$
\begin{aligned}
\mathrm{C}=[\underbrace{[(\mathrm{I} .256 v) 0.244}_{\mathrm{N}} & +\underbrace{\left(1.966 v^{\prime}\right) 0.2 \mathrm{I} \eta}_{\mathrm{CO}_{2}}+\underbrace{\left(1.25 \mathrm{I} v^{\prime \prime}\right) 0.245}_{\mathrm{CO}} \\
& +\underbrace{\left.\left(\mathrm{I} .430 v^{\prime \prime \prime}\right) 0.2 \mathrm{I} 7\right]}_{\mathrm{O}}(T-t) .
\end{aligned}
$$

As an example, suppose the following composition:

Nitrogen ..... 8I.25 $\}=\{$ Air in excess..... 23.04 $(4.84 \times 4.76 \mathrm{I})$

Oxygen..............6. 4.84$\}$. 05 (81.25-4.84-23.04)

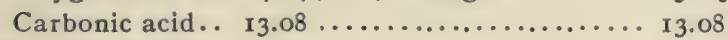

Carbonic oxide. $0.83 \ldots \ldots \ldots \ldots \ldots \ldots \ldots, 0.83$

$$
\overline{100.00} \quad \overline{100.00}
$$

and that the temperature $(T-t)$ is $130^{\circ}$. Then

$$
\begin{aligned}
& \text { Nitrogen....... I.256 X.8125 } \times 0.244=0.249 \\
& \text { Carbonic acid .... } 1.966 \times .1308 \times 0.217=0.055 \\
& \text { Carbonic oxide... I. } 251 \times .0083 \times 0.245=0.002 \\
& \text { Oxygen ........ } 1.430 \times .0484 \times 0.217=0.015 \\
& \text { I.0000 } 0.32 \mathrm{I}
\end{aligned}
$$

The value in water for I cubic metre is $0.32 \mathrm{I}$ kilogram, which at $130^{\circ}$ give

$$
0.321 \times 130=41.7 \text { calories. }
$$

If the volume of the gases was 8.938 cubic metres per kilogram of coal, the calories carried to the chimney would be

$$
\frac{8.938 \times 41.7}{100}=372 \text { calories. (669.6 B. T. U.) }
$$


The same result can be reached more quickly by taking the ratio of the specific heats to the volume (Table VIII).

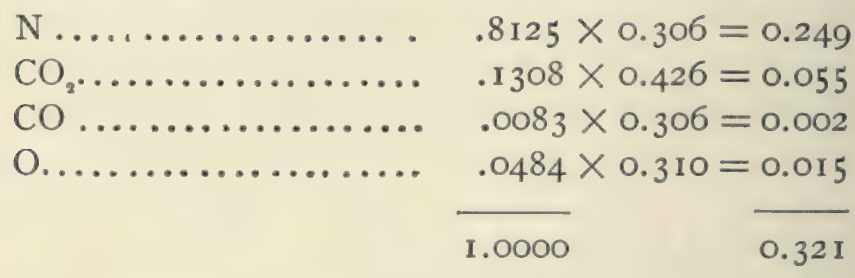

$0.321 \times 130 \times 8.938=372$ calories.

This may be still further simplified in practical work with the combustion under normal conditions. Base the calculation on the proportion of carbonic acid, using 0.306 as coefficient for the remaining gases. Then

$$
\begin{gathered}
\mathrm{C}=(0.426 v+0.306 R)(T-t) \\
v \mathrm{CO}_{2} \ldots \ldots \ldots \ldots \ldots \ldots . .1308 \times 0.426=0.055 \\
R N, \mathrm{CO}, \text { and } \mathrm{O} \ldots \ldots \ldots .0 .8692 \times 0.306=0.266
\end{gathered}
$$

0.32 I

By means of the coefficients in Table IX we can still further shorten the calculation. By this table we get directly

$$
0.321 \times 130 \times 8.938=372 \text { calories. }
$$

The loss of heat due to temperature of the waste gases varies according to the condition of the boiler, its surface for radiation, the grate surface, and the air supply. With the most advantageous cases, and moderate combustion, the gas temperature at the exit does not exceed $150^{\circ}\left(302^{\circ} \mathrm{F}\right.$.), and the loss, 5 or 6 per cent of the total heat of combustion. It may reach io per cent, and in some cases even more.

2. HEAT OF THE HYGROSCOPIC AND COMBUSTION WATER.

During combustion, coal furnishes a quantity of aqueous vapor from its hygroscopic water and its hydrogen; the latter 
is determined by multiplying the weight of hydrogen by 9 . This is added to the hygroscopic water, and the formula

$$
(606.5+0.305 t)-t^{\prime}
$$

applied; $t$ being the temperature of the vapor in the gases (equal to that of the gases), and $t^{\prime}$ being that of the external air. Besides this, however, we must consider the specific heat of the aqueous vapor, 0.475. Each kilogram still absorbs 0.475 multiplied by the number of degrees of temperature above $100^{\circ}$, and the formula becomes

$$
x\left[(606.5+0.305 t)-t^{\prime}+0.475(t-100)\right],
$$

$x$ being the quantity of water, in kilograms, furnished by the coal.

Suppose a coal contains I 5 grams per kilogram of hygroscopic water and 45 grams of hydrogen, as follows:

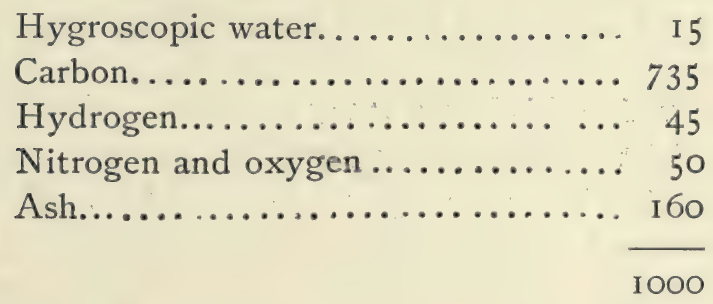

Hydrogen 45 produces $9 \times 45=405$ grams, to which add the I 5 grams of hygroscopic water, $405+I 5=420$ grams. The heat necessary to vaporize this, increased by that corresponding to the temperature of the gases passing up the chimney, represents the heat lost.

If the flue temperature is $145^{\circ}=t$, and the external air $17 \cdot 5^{\circ}=t^{\prime}$, we have

$$
\begin{aligned}
0.420[(606.5+0.305 \times 145) & -17.5+0.475(145-100) \\
& =274.9(494.8 \text { B T. U. }) .
\end{aligned}
$$


If the heat of combustion of the coal is 7000 calories, then the loss is

$$
\frac{274.9}{7000}=3.92 \text { per cent. }
$$

The loss due to these causes in an average coal (4-5 per cent hydrogen and I to 2 per cent moisture) is usually from 2 to 4 per cent.

\section{CAlories of the COMbustible Gases.}

Carbonic oxide is always present in variable quantities, often hydrocarbons and sometimes hydrogen. This refers to ordinary fuel and the usual methods of burning. The quantity of unburnt gases depends on the kind of fireplace used and the system of charging. Thick charges of fuel always increase the volume of unburnt gases; the smallest amount being obtained from small, equivalent charges, fed frequently and using 30 to 50 per cent more air than the theoretical quantity.

To determine this loss we may commence with the volume or the weight corresponding to I kilogram of coal burnt. The calculation is given on pages 137 and 138 . No account need be made of the temperature, the calculation of loss due this having been made on page 161 for all gases, and therefore for these gases.

The calorific coefficients of the unburnt gases, referred to a cubic metre at $0^{\circ}$ and $760 \mathrm{~mm}$. pressure, are

\begin{tabular}{|c|c|c|}
\hline \multirow{2}{*}{$\begin{array}{l}\text { Weight per cub. m. } \\
\text { in Kilograms. }\end{array}$} & \multicolumn{2}{|c|}{ Heat of Combustion. } \\
\hline & Per Kilo. & Per Cubic Metre. \\
\hline Hydrogen........... 0.089 & 34500 & $309 \mathrm{I}$ \\
\hline Carbonic oxide ....... I.25I & 2435 & 3043 \\
\hline Methane $\left(\mathrm{CH}_{4}\right) \ldots \ldots \ldots 0.715$ & I 3343 & 10038 \\
\hline Carbon vapor......... 1.073 & I I 328 & 12143 \\
\hline
\end{tabular}


The weight and heat of combustion of carbon vapor are given, as most of the time we do not know the molecular condensation of the hydrocarbons; usually the ultimate composition is all that is known. Hence the hydrogen and carbon must be given their heat values as though free. Fortunately they occur in only small percentages, and the error introduced by so doing is small.

Suppose a gas to analyze

Carbonic oxide ............... I.o

Carbonic acid................ I 3.0

Methane...................... I.0

Oxygen...................... 6.0

Nitrogen .................. 79.0

100.0

Assuming that the air has been fed at the rate of Io cubic metres per kilogram ( 160.5 cubic feet per pound), and that the coal has a heat value of 8000 calories (I4400 B. T. U.), we will have, for Io cubic metres,

Carbonic oxide........ o. I cubic metres.

Carbonic acid.......... I.3 " " “

Methane.............. 0.I " " "

Oxygen $\ldots \ldots \ldots \ldots \ldots \ldots$...... 0.6 ، ،

Nitrogen ........... 7.9 ، ،

Then

IO.O

$\mathrm{CH}_{4}$, O.I cub. m. @ 0.7I5 = 0.07I5 kilogram;

$\mathrm{CO}$, O.I " " (a) $\mathrm{I} .25 \mathrm{I}=0.125 \mathrm{I}$ "

and

$$
\begin{aligned}
& 0.0715 \times 13343=933.7 \text { calories; } \\
& 0.1251 \times 2435=\frac{305.0}{\text { " }} \\
& \text { Total.........1238.7 }
\end{aligned}
$$


The loss, then, is 1238.7 in 8000 , or 15.48 per cent.

If instead of knowing the proportion of the hydrocarbons we know only that of carbon and hydrogen, the heat values calculate separately. Then, instead of methane O.I, there would be carbon 0.05 , and hydrogen 0.2 . Then the calculation would be
$0.2 \times 0.089=0.0178$;
$0.0178 \times 34500=614.1$
$0.05 \times 1.073=0.0536$;
$0.0536 \times 8137=436.1$
O. I $\times 1.25 \mathrm{I}=0.125 \mathrm{I}$;
$0.1251 \times$
$2435=\underline{305.0}$

I 355.2 calories

The difference, $1355.2-1238.7=116.5$ calories, or 0.9 per cent of the calories lost, or $15.48 \times .009=0.138$ per cent of the total calories of the coal, which is small compared with other sources of error.

By employing Table VII we may dispense with reducing the volumes to weights, thus:

$$
\begin{aligned}
& \text { Hydrogen........ 0.2 } \mathrm{m}^{3} \times 309 \mathrm{I}=6 \mathrm{I} 8 \\
& \text { Carbon vapor...... 0.05 } \times 8722=436 \\
& \text { Carbonic oxide... 0.1 } \times 3043=\frac{304}{1358}
\end{aligned}
$$

The preceding is an exaggerated case; as usually, with ordinary working, the loss is from 2 to 7 per cent, rarely exceeding the latter. Either method of calculation may be used, then, without risk of causing an error of importance.

\section{CALORIES DUE TO THE SOOT.}

The soot in smoke consists of carbon with a trace of hydrogen. It can be calculated as all carbon without appreciable error and with the coefficient 8I37. Knowing the volume of gases produced by I kilogram and its content in black (page 154), calculate the number of calories. Under 
the most favorable conditions for smoke production the loss does not exceed I per cent, and is generally less than one half that amount.

\section{DISTRIBUTION OF CALORIES-LOSS.}

The difference between heat units accounted for and those possible is considered as resulting from radiation by surfaces not available for producing steam. The following is taken from Scheurer-Kestner's results with a three-tube steam boiler followed by a reheater. The first column gives results obtained with Ronchamp coal in $\mathrm{I} 868$, the second results with Nixon's Navigation Co.'s coal in I88I.

$$
\begin{aligned}
& \text { Ronchamp. Nixon. } \\
& \text { Calories in the steam........ } 58 \text { to } 67 \% \quad 74.5 \% \\
& \text { “ " " " waste gases.... } 3.8 \text { to } 7.7 \text { " } 5.42 \\
& \text { “. " “ " unburnt gases... } 2.4 \text { to } 9.7 \text { traces } \\
& \text { " " " "smoke........ } 0.3 \text { to } 0.75 \text { none } \\
& \text { " " " " aqueous vapor.. } 2.0 \text { to } 3.7 \quad 2.8 \mathrm{I} \\
& \text { “ not accounted for ..... } 19.4 \text { to } 24.7 \quad 17.27
\end{aligned}
$$

\begin{tabular}{|c|c|c|c|c|c|c|c|c|c|c|}
\hline Calories. & XII. & VIII. & VI. & VII. & II. & XI. & III. & IV. & $\mathrm{xx}$ & I. \\
\hline In the steam & 78.5 & 78.3 & 74.4 & 71.8 & 70.4 & 69.8 & 67.6 & 66.2 & 65.8 & 63.8 \\
\hline In the waste gases. & 6.5 & 14.0 & 13.8 & 13.3 & 13.6 & 18.0 & 16.2 & 22.5 & 18.0 & 9.4 \\
\hline In the combustible $\mathrm{g}$ & 0.0 & 1.7 & 2.4 & 0.8 & 0.0 & 1.2 & 1.2 & 0.0 & 1.6 & 12.7 \\
\hline Not accounted for........ & 15.0 & 5.8 & $9 \cdot 3$ & I4.0 & II.9 & I0.9 & 9.6 & II.O & I4.4 & 13.9 \\
\hline
\end{tabular}

On September 20, I895, Engineering published the results of some experiments made by Bryan Donkin with Nixon's coal on twenty different types of boilers. The following table contains some of them:

The calories in the steam

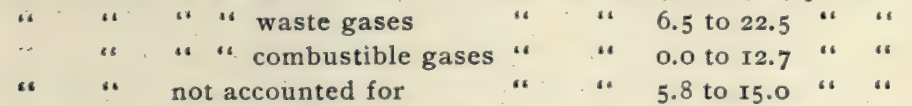

For the method of properly tabulating the heat balance, see section XXI of the Steam Boiler Code on page 193. 


\section{FLAME AND FLAME TEMPERATURES.}

Whenever the temperature is sufficiently high to raise a portion of the carbon, hydrogen, or other gaseous combustible to incandescence, flame is produced. The temperature at which this phenomenon occurs varies with the substance burnt. Usually it requires a red heat or higher, but in some cases a much lower temperature suffices: bor-methyl $\mathrm{B}\left(\mathrm{CH}_{3}\right)_{3}$ is an example, the flame temperature of which is not high enough to scorch the finger placed in it. It is not necessary that the flame should have solid particles in it, as flame is produced by hydrogen burning under pressure in oxygen; neither is incandescence alone sufficient, as the fire of pure carbon, magnesium, or iron glows but does not flame. Flame is hollow, the combustion occurring on the surface, and this may be easily demonstrated, by drawing off some of the interior unconsumed gases with a tube and burning them.

Bunsen's researches led to the conclusion that the temperature of burning carbonic oxide rapidly rose to $3000^{\circ} \mathrm{C}$., and remained stationary till one third of it was consumed; the temperature then fell to $2500^{\circ} \mathrm{C}$., at which more burnt; and finally fell to about $1200^{\circ} \mathrm{C}$., which temperature was maintained till all the remainder was consumed. Actually the last temperature is soon reached in practice. Berthelot confirms this, but is in doubt whether the loss of temperature is due to dissociation or to change in specific heat. Some hold that part of this loss of heat is caused by its absorption, due to the production of incandescence and its accompanying flame phenomena. A gas raised to incandescence gradually manifests each increment of heat till that point is reached, and beyond this no increase is noticed, all such further increase being consumed by the flame production.

The rate of propagation of flame varies with the pressure and with the material burning. The most rapid rate with coal gas is when it is mixed with 5 parts of air; with marsh 
gas, $8 \frac{1}{2}$ parts of air. It will be noticed that the proportion of oxygen is sensibly less than that required for perfect combustion.

The luminosity depends on the compression of the gases or the air. Hydrogen burning in oxygen at ordinary pressure gives a flame hardly visible at all; with a pressure of 20 atmospheres it becomes quite luminous. Arsenic in burning produces quite a luminous flame at ordinary air pressure; but hardly any in rarefied air. The same is true of carbonic oxide and other gases. The luminosity seems to be in direct proportion to the pressure.

Luminosity seems to be greater with those substances which on burning produce dense vapors. Hydrogen and chlorine produce a vapor twice as heavy as water and the luminosity is much stronger than with the oxygen-hydrogen flame. Carbon and sulphur also produce heavy vapors and much light. Phosphorus burning in oxygen produces the dense heavy phosphoric anhydride and this is accompanied with an almost blinding light.

The length of the flame ordinarily depends on the quantity of hydrogen, and consequently the hydrocarbons contained in, or generated from, the body consumed. With fuels containing high hydrocarbon percentages, flame of almost any desired length can be produced. This is especially the case with gases.

The theoretical temperature of combustion, and hence of the flame, may be calculated by dividing the heat units produced by the specific heats of the products formed. Of course, these theoretical temperatures are never reached in practice, but they serve as aids in determining the value of fuels for certain purposes.

A few typical examples of these calculations will be given.

I. Hydrogen.-Hydrogen burnt in oxygen produces 29000 heat units (water considered as vapor); the specific heat of the aqueous vapor produced is 0.475 . The hydrogen 
uses 8 times its weight of oxygen and generates 9 times the quantity of water.

Then

$$
\frac{29000}{9 \times 0.479}=6727^{\circ} \mathrm{C} \text {. }
$$

Bunsen and Sainte-Claire Deville showed that the highest temperature actually obtained is $2500^{\circ} \mathrm{C}$., which may be increased to $2850^{\circ} \mathrm{C}$. by a pressure of 10 atmospheres.

The presence of nitrogen modifies the result materially. The quantity of oxygen required, obtained from air, would introduce 26.78 parts of nitrogen, the specific heat of which is 0.244 . The equation would then be

$$
\frac{29000}{9 \times 0.479+26.78 \times 0.244}=2674^{\circ} \mathrm{C} \text {. }
$$

Bunsen's maximum temperature actually reached was $1800^{\circ} \mathrm{C}$.

2. Carbon.-Carbon burnt to carbonic oxide consumes I.33 parts of oxygen, forms 2.33 parts of carbonic oxide, and if burnt in air, introduces 4.46 parts of nitrogen. The specific heat of carbonic oxide is 0.245 and of nitrogen 0.244 , as before. The heat units generated are 2435 .

For combustion in oxygen the equation would be

$$
\frac{2435}{2.33 \times 0.245}=4265^{\circ} \mathrm{C} \text {. }
$$

In air it would be

$$
\frac{2435}{2.33 \times 0.245+4.46 \times 0.244}=1462^{\circ} \mathrm{C} \text {. }
$$

The latter temperature is about the same as that actually observed, and shows that but little dissociation occurs. Owing to the non-volatility of carbon no flame is produced, only an incandescence. The flame we ordinarily see on incandescent carbon is from the burning of carbonic oxide. Carbon burnt to carbon dioxide can be treated similarly; also carbonic oxide burnt to carbon dioxide. 
3. Marsh Gas.-This gas requires 4 times its weight of oxygen, and produces 2.25 parts of aqueous vapor and 2.75 parts of carbonic acid. If air is used, 13.39 parts of nitrogen are introduced. The heat of combustion is $\mathrm{I} 3343$ calories.

The equations are, then,

$$
\frac{13343}{2.25 \times 0.479+2.75 \times 0.217}=797 \mathrm{I}^{\circ} \mathrm{C} .
$$

for oxygen and

$$
\frac{\mathrm{I} 3343}{2.25 \times 0.479+2.75 \times 0.217+13.39 \times 0.244}=2245^{\circ} \mathrm{C} \text {, }
$$

for combustion in air.

Olefiant gas, acetylene, etc., can be calculated similarly. With a mixed gas, i.e., one containing several gases, account must be taken of each one separately. Producer gas will be given as an example.

4. Producer Gas.- - The producer gas taken will be assumed to have the following composition by volume:

Carbonic oxide.............. 21.0 per cent.

Hydrogen ................ II.5 " "

Marsh gas................. 2.0 " "

Carbonic acid............... 6.0 " " "

Nitrogen ............... 59.5 " "

$$
\text { I00.0 “ “ }
$$

First obtain the weight of the constituents. (See the tables.)

$$
\begin{aligned}
& 0.2 \mathrm{I} \times 1.2515=0.2628 \\
& 0.115 \times 0.0896=0.0103 \\
& 0.02 \times 0.7155=0.0143 \\
& 0.06 \times 1.9666=0.1360 \\
& 0.595 \times 1.2561=0.7474
\end{aligned}
$$

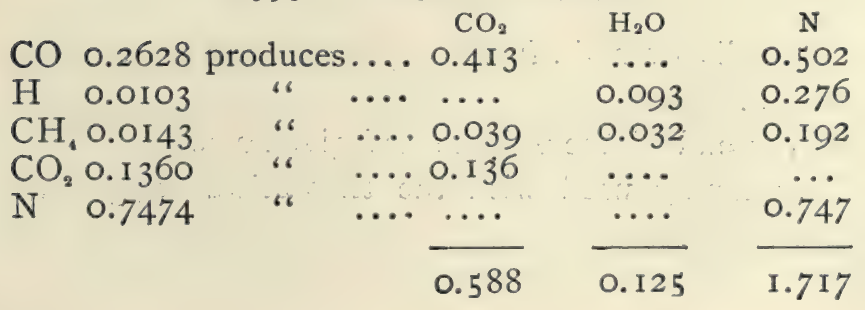


Then as the heat of combustion is 747.66 by volume or 874.6 by weight, we have for combustion in oxygen,

$\frac{874.6}{0.125 \times 0.479+0.588 \times 0.217+0.747 \times 0.244}=2350^{\circ} \mathrm{C}$, and for combustion in air,

$\frac{874.6}{0.125 \times 0.479+0.588 \times 0.217+1.717 \times 0.244}=1112^{\circ} \mathrm{C}$.

5. Petroleum Oil. - The oil may be assumed to contain

Carbon................. 85 per cent.

Hydrogen.

. I 15 " "

$$
\overline{100}
$$

C 0.85 produces $\ldots .$.

$$
\begin{aligned}
& \text { H o. } 15 \\
& \text { I. } 35 \mathrm{H}_{2} \mathrm{O} \\
& \text { 3.II } \mathrm{CO}_{2} \text { and } 7.588 \mathrm{~N} \\
& \overline{\mathrm{I} .35 \mathrm{H}_{2} \mathrm{O}} \\
& \text {.... " } 4.017 \text { " } \\
& \text { I. II } \mathrm{CO}_{2} \text { II. } 605 \mathrm{~N}
\end{aligned}
$$

The heat of combustion may be assumed at 10000 calories. Then for combustion in oxygen,

$$
\frac{10000}{1.35 \times 0.479+3.117 \times 0.217}=7558^{\circ} \mathrm{C} .,
$$

and for combustion in air,

$\frac{10000}{1.35 \times 0.479+3.117 \times 0.217+11.605 \times 0.244}=2400^{\circ} \mathrm{C}$.

Other oils or solid fuels may be calculated according to this model.

At the end of the volume are given a few of those fuels most commonly used with the theoretical oxygen and air flame temperatures. 
WEIGHT AND HEAT UNITS OF CARBON VAPOR.

Two volumes of carbonic oxide are produced from I volume of oxygen, and hence from I volume of carbon. I cubic metre of carbonic oxide weighs I25I grams. I cubic metre of oxygen weighs 1430 grams. I cubic metre of carbonic oxide contains, then, one-half a cubic metre of oxygen weighing 715 grams, and one-half a cubic metre of carbon vapor weighing 536 grams. Hence I cubic metre of carbon vapor weighs $2 \times 536=1072$ grams, and I kilogram measures I $: 1072=0.9328$ cubic metre.

Or

I cubic foot of carbonic oxide weighs 546.78 grains.

I “ " " oxygen weighs......624.85 “

One cubic foot $\mathrm{CO}$ then contains $\frac{1}{2}$ cubic foot of $\mathrm{O}$ and $\frac{1}{2}$ cubic foot of $\mathrm{C}$.

$$
546.78-312.425=234.355
$$

and

$$
2 \times 234.355=468.71 \text { grains, }
$$

weight of I cubic foot of carbon vapor.

One pound of carbon vapor measures 14.93 cubic feet.

If we wish the heat-units of carbon in vapor without the heat of vaporization, multiply the weight of a cubic metre by the heat of combustion of solid carbon. If from wood charcoal,

$$
8137 \times 1.072=8722(15699.6 \text { B. T. U.). }
$$

If from diamond,

$$
7859 \times 1.072=8424 \text { (14963.2 B. T. U.). }
$$

If carbon vapor with its heat of vaporization be wanted, take the heat of combustion of carbonic oxide which contains carbon as vapor and compare it with the heat of combustion of carbon, uniting with the same quantity of oxygen to form 
carbonic oxide. In doing so it is supposed that carbon in combining with two atoms of oxygen generates the same quantity of heat with one as with the other, only in the first case part of the heat is used in vaporizing the carbon. This heat is found by subtracting the heat of combustion of the solid carbon from that of the carbon supposed gaseous in carbonic oxide.

One kilogram of carbon unites with 1.333 kilograms of oxygen to form 2.333 kilograms of carbonic oxide. With diamond there is generated 2405 calories. The 2.333 kilograms of carbonic oxide in becoming carbonic acid generates $2.333 \times$ $2435=5680$ calories. Then I kilogram of carbon in passing from carbonic oxide to carbonic acid generates 5680 calories. We have seen, on the other hand, that I kilogram of diamond carbon generates 2405 calories in becoming carbonic oxide. The difference, then, $5680-2405=3275(5895$ B. T. U.) calories, represents the heat of vaporization of diamond carbon. With wood charcoal it becomes $5680-2489=3$ I 9 I $(5743.8$ B. T. U.).

The heat of combustion will be then $7859+3275=$ I I I 34 calories (2004I B. T. U.) for diamond, and 8I $37+319 \mathrm{I}=$ I 328 calories (20390 B. T. U.) for wood charcoal.

\section{EVAPORATIVE POWER OF FUEL.}

The evaporative power of a fuel represents the number of pounds of water at $212^{\circ} \mathrm{F}$. that can be evaporated or converted into steam by one pound of the fuel. Water at that temperature is sufficiently heated to vaporize, but needs an addition of force equivalent to that required for the vaporization. This quantity varies for the pressure of the barometer and the temperature of the water, but for the purposes of calculation is considered to be taken at 30 inches of mercury and $212^{\circ} \mathrm{F}$. Experiment has shown the equivalent to be 965.7 heatunits (B. T. U.). 
To find the theoretical evaporating power of a fuel, then; divide the number of thermal units it generates on combustion by 965.7. For instance, the heat of combustion of a sample of Illinois coal was determined by Prof. Carpenter to be 13200 . Its evaporative power would be

$$
\frac{13200}{965.7}=13.67 \text { pounds. }
$$

This means that under the proper conditions one pound of the coal in question would evaporate 13.67 pounds already heated to $2 \mathrm{I} 2^{\circ} \mathrm{F}$.

But this amount of duty is rarely realized. The boiler may not be well built, the setting may be faulty, and there are numerous other chemical or mechanical conditions which modify the yield. With these no rule can be established; each individual case must be allowed for specially. With ashes and moisture, chemical constituents of the coal, the case is different. A percentage allowance for these will usually suffice.

For instance, in the above coal there was 5.12 per cent of water and 15.2 per cent of ash. Then

$$
100-(15.2+5.12) \times 13.67=12.23 \text { pounds. }
$$

If deemed necessary, a further correction can be made for the water of the coal, which would reduce the evaporation by its own amount. This correction would become

$$
12.23-0.05=12.18 \text { pounds }
$$

as the quantity which should be evaporated with the coal as analyzed.

The quantity of ash produces an effect on the evaporative power aside from its proportional reduction in combustible. This is due to the fact that where a large percentage of ash occurs, the particles of carbon of the fuel are not burnt com- 
pletely, owing to being enclosed in the ash and consequently shut off from access of air. This is especially the case with those ashes which are easily fuzed by the heat of the fire. Ashes containing carbonates are much more easily fuzed than those containing phosphates or sulphates. On this account a chemical analysis of the ash is at times quite desirable.

Some difference in evaporation is noticed in using the different sizes of coal, more particularly with the fine sizes. With the proper arrangements for burning fires a good yield is obtained, but with the ordinary grates the yield is much lower. 


\section{APPENDIX.}

REPORT OF THE COMMITTEE ON THE REVISION OF THE SOCIETY CODE OF r885, RELATIVE TO A STANDARD METHOD OF CONDUCTING STEAM-BOILER TRIALS.

Presented to the New York meeting of the American Society of Mechanical Engineers, December, 1897, and forming a part of the Transactions, Volume XIX.

To the American Society of Mechanical Engineers.

Gentlemen: The undersigned Committee, to which was submitted the revision of the Society Code of 1885 , relative to a standard method of conducting steam-boiler trials, reports as follows:

The former Committee gave a full statement of the principles which governed it in the preparation of the Code of Rules at that time recommended. These principles covered the ground in an admirable manner, so far as the practice of boiler-testing had been perfected, and we are in unanimous accord with the sentiments which the report of that Committee expressed. During the interval of twelve years which has passed, methods and instruments have in some measure changed. Improvements have been made in the instruments for determining the moisture in steam. The throttling and separating form of calorimeters have displaced the barrel and other types of steam calorimeters referred to in the previous report. Attention has been devoted to the determination of the calorific value of coal, and a number of coal calorimeters 
have been brought out and successfully used for this purpose. It has come to be a practice with many experts to include in the table of results of boiler-tests the percentage of "efficiency," or proportion of the calorific value of the coal which is utilized by the boiler. Specifications and contracts are in some cases drawn up, providing for certain percentages of efficiency instead of a specified evaporation. The analysis of flue-gases is receiving more attention than formerly, not only in our educational institutions, but also in the regular practice of engineers who make a specialty of boiler-testing.

Your Committee submits a revised Code, termed the Code of 1897 . It is substantially the same as the 1885 Code, with such amendments as the experience of the last twelve years has shown to be desirable.

It is beyond the province of the Committee to recommend instruments of particular makers for obtaining the quality of the steam, the calorific value of the fuel, or any other data relating to the trial; but following the practice of the former Committee, individual members have submitted their views (with the approval of the full membership) in an "Appendix to the I 897 Code," signed by their initials. In this appendix are included some of the articles from the appendix to the former Code, which are thought to be of especial value.

In the matter of instruments for determining the calorific value of fuel, it seems desirable that the Committee should make a recommendation which is as specific as present knowledge and circumstances will warrant. It is agreed that some form of calorimeter in which the coal is burned in an atmosphere of oxygen gas is to be preferred, and it is generally held that the most perfect apparatus thus far brought out is the Bomb Calorimeter, originally designed by Berthelot, and modified by Mahler and Hempel. Several of these instruments are in use in this country, principally in the laboratories of engineering schools; but the apparatus is complicated 
and expensive, and it is not probable that many engineers will have the instrument as a part of their equipment for testing boilers. It is recommended, therefore, that samples of the coal used in testing boilers be sent for determinations of their heating value to a testing laboratory provided with one of these instruments, or with some instrument which shall be proven to be equally good.

Besides the amendments to the Code of 1885 , concerning the determination of "efficiency" and the use of improved steam calorimeters, directions are given for sampling the coal, for determining the heat of combustion from the chemical analysis of coal, and for working out a heat balance. Rules are laid down for finding the quantity of moisture in coal and for making allowance for it. The tabular form of presenting the results of the test is somewhat changed from that of the Code of 1885 , and alterations in the text of that Code are made wherever revision seems desirable.

The Committee approves the conclusions of the Committee of 1885 concerning the standard " unit of evaporation " contained in the following extract from the introduction to the Code of 1885 :

"It has gradually come to be the custom to reduce all results to the common standard of weight of water evaporated by the unit weight of fuel, the evaporation being considered to have taken place at mean atmospheric pressure, and at the temperature due that pressure, the feed-water being also assumed to have been supplied at that temperature. This is, in technical language, said to be the 'equivalent evaporation from and at the boiling-point ' (2 I 2 degrees Fahr.), and has now become so generally incorporated into the science and the practice of steam-engineering that your Committee would simply express their approval of the adoption, and recommend the permanent retention of this ' unit of evaporation,' viz., one pound of water at 212 degrees Fahr. evaporated into steam of the same temperature. This is equivalent to 
the utilization of 965.7 British thermal units per pound of water so evaporated."

The unit of commercial boiler horse-power adopted by the Committee of 1885 was the same as that used in the reports of the boiler-tests made at the Centennial Exhibition of 1876 . The Committee of 1885 reported in favor of this standard in language of which the following is an extract:

"Your Committee, after due consideration, has determined to accept the Centennial standard, and to recommend that in all standard trials the commercial horse-power be taken as an evaporation of 30 pounds of water per hour from a feed-water temperature of 100 degrees Fahr. into steam at 70 pounds gauge-pressure, which shall be considered to be equal to $34 \frac{1}{2}$ units of evaporation; that is, to $34 \frac{1}{2}$ pounds of water evaporated from a feed-water temperature of 212 degrees Fahr. into steam at the same temperature. This standard is equal to 33,305 thermal units per hour."

The present Committee accepts the same standard, but reverses the order of two clauses in the statement, and slightly modifies them to read as follows:

In all standard trials the commercial horse-power shall be taken as $34 \frac{1}{2}$ units of evaporation; that is, $34 \frac{1}{2}$ pounds of water evaporated from a feed-water temperature of $2 \mathrm{I} 2$ degrees Fahr. into steam at the same temperature. This standard is equivalent to 33,317 British thermal units per hour. It is also practically equivalent to an evaporation of 30 pounds of water from a feed-water temperature of 100 degrees $\mathrm{Fahr}$. into steam at 70 pounds gauge-pressure. *

* According to the tables in Porter's Treatise on the Richards Steamengine Indicator, an evaporation of 30 pounds of water from 100 degrees Fahr. into steam at 70 pounds pressure is equal to an evaporation of 34.488 pounds from and at 212 degrees; and an evaporation of $34 \frac{1}{2}$ pounds from and at 212 degrees Fahr. is equal to 30.010 pounds from Ioo degrees Fahr. into steam at 70 pounds pressure.

The "unit of evaporation" being equal to 965.7 thermal units, the commercial horse-power $=34.5 \times 965.7=33.317$ thermal units. 
The Committee also indorses the statement of the Committee of 1885 concerning the commercial rating of boilers, changing somewhat its wording, so as to read as follows :

"It is the opinion of this Committee that a boiler rated at any stated horse-power should develop that power when using the best coal ordinarily sold in the market where the boiler is located, fired by an ordinary fireman, with a draft at the smoke-box not exceeding $\frac{8}{8}$ inch of water column; and, further, that the boiler should develop at least one third more than its rated power when operated with the best system of firing and with the full draft available."

Respectfully submitted,

$\left.\begin{array}{l}\text { Chas. E. Emery,* } \\ \text { Wm. Kent, } \\ \text { Geo. H. Barrus, } \\ \text { Chas. T. Porter, } \\ \text { Robert H. Thurston, } \\ \text { Robert W. Hunt, } \\ \text { F. W. Dean, } \\ \text { J. S. CoOn, } \\ \text { Wm. B. Potter., }\end{array}\right\}$

\section{RULES FOR CONDUCTING BOILER-TRIALS,} CODE OF 1897 .

\section{Preliminaries to a Trial.}

I. Determine at the outset the specific object of the proposed trial, whether it be to ascertain the capacity of the

* The motion for the appointment of this Committee was made by Mr. Barrus in connection with the discussion of Mr. Dean's paper, No. DCL, on "The Efficiency of Boilers," etc. The President of the Society designated Mr. Kent, the chairman of the Committee of 1884 , to call the first meeting of the new Committee. At that meeting, on motion of Mr. Kent, Dr. Emery was selected as chairman, and he conducted the preliminary correspondence. The report in the form originally printed was prepared by a sub-committee consisting of Messrs. Emery, Porter, Barrus, and Kent. 
boiler, its efficiency as a steam-generator, its efficiency and its defects under usual working conditions, the economy of some particular kind of fuel, or the effect of changes of design, proportion, or operation; and prepare for the trial accordingly.

II. Examine the boiler, both outside and inside; ascertain the dimensions of grates, heating-surfaces, and all important parts; and make a full record, describing the same, and illustrating special features by sketches. The area of heating surface is to be computed from the outside diameter of all tubes, whether water-tubes or fire-tubes. This rule corresponds to the practice of many builders of different types of boilers, and is intended to make the practice of rating heatingsurface uniform. All surfaces below the mean water-level which have water on one side and products of combustion on the other are to be considered as water-heating surface, and all surfaces above the mean water-level which have steam on one side and products of combustion on the other are to be considered as superheating surface.

III. Notice the general condition of the boile- and its equipment, and record such facts in relation thereto as bear upon the objects in view.

If the object of the trial is to ascertain the maximum economy or capacity of the boiler as a steam-generator, the boiler and all its appurtenances should be put in first-class condition. Clean the heating-surface inside and outside, remove clinkers from the grates and from the sides of the furnace. Remove all dust, soot, and ashes from the chambers, smoke-connections, and flues. Close air-leaks in the masonry and poorly fitted cleaning-doors. See that the damper will open wide and close tight. Test for air-leaks by firing a few shovels of smoky fuel and immediately closing the damper, observing the escape of smoke through the crevices.

IV. Determine the character of the coal to be used. For tests of the efficiency or capacity of the boiler the coal should, 
if possible, be of some kind which is commercially regarded as a standard. For New England and that portion of the country east of the Allegheny Mountains, good anthracite egg coal, containing nơt over ro per cent of ash, and semibituminous Cumberland (Md.) and Pocahontas (Va.) coals are thus regarded. West of the Allegheny Mountains, Pocahontas (Va.) and New River (W. Va.) semi-bituminous, and Youghiogheny or Pittsburg bituminous coals are recognized as standards. * There is no special grade of coal mined in the Western States which is widely recognized as of superior quality or considered as a standard coal for boiler-testing. Big Muddy lump, an Illinois coal mined in Jackson County, IIl., is suggested as being of sufficiently high grade to answer the requirements in districts where it is more conveniently obtainable than the other coals mentioned above.

V. Establish the correctness of all apparatus used in the test for weighing and measuring. These are:

I, Scales for weighing coal, ashes, and water.

2. Tanks or water-meters for measuring water. Watermeters, as a rule, should only be used as a check on other measurements. For accurate work, the water should be weighed or measured in a tank.

3. Thermometers and pyrometers for taking temperatures of air, steam, feed-water, waste gases, etc.

4. Pressure-gauges, draft-gauges, etc.

The kind and location of the various pieces of testing apparatus must be left to the judgment of the person conducting the test, always keeping in mind the main object, i.e., to obtain authentic data.

VI. See that the boiler and chimney are thoroughly heated before the trial to their usual working temperature. If the

* These coals are selected because they are about the only coals which contain the essentials of excellence of quality, adaptability to various kinds of furnaces, grates, boilers, and methods of firing, and wide distribution and general accessibility in the markets. 
boiler is new and of a form provided with a brick setting, it should be in regular use at least a week before the trial, so as to dry and heat the walls. If it has been laid off and become cold, it should be worked before the trial until the walls are well heated.

VII. The boiler and connections should be proved to be free from leaks before beginning a test, and all water connections, including blow and extra feed-pipes, should be disconnected, stopped with blank flanges, or bled through special openings beyond the valves, except the particular pipe through which water is to be fed to the boiler during the trial. During the test the blow-off and feed-pipes should remain exposed.

If an injector is used, it should receive steam directly through a felted pipe from the boiler being tested.*

See that the steam-main is so arranged that water of condensation cannot run back into the boiler.

VIII. Starting and Stopping a Test.-A test should last at least ten.hours of continuous running. A longer test may be made when it is desired to ascertain the effect of widely varying conditions, or the performance of a boiler under the working conditions of a prolonged run. The conditions of the boiler and furnace in all respects should be, as nearly as possible, the same at the end as at the beginning of the test. The steam-pressure should be the same; the water-level the same; the fire upon the grates should be the same in quantity and condition; and the walls, flues, etc., should be of the same temperature. Two methods of obtaining the de-

* In feeding a boiler undergoing test with an injectọr taking steam from another boiler, or the main steam-pipe from several boilers, the evaporative results may be modified by a difference in the quality of the steam from such source compared with that supplied by the boiler being tested, and in some cases the connection to the injector may act as a drip for the main steam-pipe. If it is known that the steam from the main pipe is of the same quality as that furnished by the boiler undergoing the test, the steam may be taken from such main pipe. 
sired equality of conditions of the fire may be used, viz. : those which were called in the Code of 1885 "the standard method" and "the alternate method," the latter being employed where it is inconvenient to make use of the standard method.

IX. Standard Method.-Steam being raised to the working pressure, remove rapidly all the fire from the grate, close the damper, clean the ash-pit, and as quickly as possible start a new fire with weighed wood and coal, noting the time and the water-level while the water is in a quiescent state, just before lighting the fire.

At the end of the test remove the whole fire, which has been burned low, clean the grates and ash-pit, and note the water-level when the water is in a quiescent state, and record the time of hauling the fire. The water-level should be as nearly as possible the same as at the beginning of the test. If it is not the same, a correction should be made by computation, and not by operating the pump after the test is completed.

X. Alternate Method. - The boiler being thoroughly heated by a preliminary run, the fires are to be burned low and well cleaned. Note the amount of coal left on the grate as nearly as it can be estimated; note the pressure of steam and the water-level, and note this time as the time of starting the test. Fresh coal which has been weighed should now be fired. The ash-pits should be thoroughly cleaned at once after starting. Before the end of the test the fires should be burned low, just as before the start, and the fires cleaned in such a manner as to leave the bed of coal of the same depth, and in the same condition, on the grates as at the start. The water-level and steam-pressures should previously be brought as nearly as possible to the same point as at the start, and the time of ending of the test should be noted just before fresh coal is fired. If the water-level is not the same as at 
the start, a correction should be made by computation, and not by operating the pump after the test is completed.

XI. Uniformity of Conditions. - In all standard trials the conditions should be maintained uniformly constant. Arrangements should be made to dispose of the steam so that tine rate of evaporation may be kept the same from beginning to end. This may be accomplished in a single boiler by carrying the steam through a waste steam-pipe, the discharge from which can be regulated as desired. In a battery of boilers in which only one is tested the draught can be regulated on the remaining boilers, leaving the test-boiler to work under a constant rate of production.

Uniformity of conditions should prevail as to the pressure of steam, the height of water, the rate of evaporation, the thickness of fire, the times of firing and quantity of coal fired at one time, and as to the intervals between the times of cleaning the fires.

XII. Keeping the Records.-Take note of every event connected with the progress of the trial, however unimportant it may appear. Record the time of every occurrence and the time of taking every weight and every observation.

The coal should be weighed and delivered to the fireman in equal proportions, each sufficient for not more than one hour's run, and a fresh portion should not be delivered until the previous one has all been fired. The time required to consume each portion should be noted, the time being recorded at the instant of firing the last of each portion. It is desirable that at the same time the amount of water fed into the boiler should be accurately noted and recorded, including the height of the water in the boiler, and the average pressure of steam and temperature of feed during the time. By thus recording the amount of water evaporated by successive portions of coal, the test may be divided into several periods if desired, and the degree of uniformity of combustion, evaporation, and economy analyzed for each period. In addition 
to these records of the coal and the feed-water, half-hourly observations should be made of the temperature of the feedwater, of the flue gases, of the external air in the boiler-room, of the temperature of the furnace when a furnace-pyrometer is used, also of the pressure of steam, and of the readings of the instruments for determining the moisture in the steam. A log should be kept on properly prepared blanks containing columns for record of the various observations.

When the "standard method" of starting and stopping the test is used, the hourly rate of combustion and of evaporation and the horse-power may be computed from the records taken during the time when the fires are in active condition. This time is somewhat less than the actual time which elapses between the beginning and end of the run. This method of computation is necessary, owing to the loss of time due to kindling the fire at the beginning and burning it out at the end.

XIII. Quality of Steam.-The percentage of moisture in the steam should be determined by the use of either a throttling or a separating steam-calorimeter. The sampling-nozzle should be placed in the vertical steam-pipe rising from the boiler. It should be made of $\frac{1}{2}$-inch pipe, and should extend across the diameter of the steam-pipe to within half an inch of the opposite side, being closed at the end and perforated with not less than twenty $\frac{1}{8}$-inch holes equally distributed along and around its cylindrical surface, but none of these holes should be nearer than $\frac{1}{2}$ inch to the inner side of the steam-pipe. The calorimeter and the pipe leading to it should be well covered with felting. Whenever the indications of the throttling or separating calorimeter show that the percentage of moisture is irregular, or occasionally in excess of three per cent, the results should be checked by a steamseparator placed in the steam-pipe as close to the boiler as convenient, with a calorimeter in the steam-pipe just beyond the outlet from the separator. The drip from the separator 
should be caught and weighed, and the percentage of moisture computed therefrom added to that shown by the calorimeter.

Superheating should be determined by means of a thermometer placed in a mercury-well or oil-well inserted in the steam-pipe.

For calculations relating to quality of steam and corrections for quality of steam.

XIV. Sampling the Coal and Determining its Moisture.As each barrow-load or fresh portion of coal is taken from the coal-pile, a representative shovelful is selected from it and placed in a barrel or box in a cool place and kept until the end of the trial. The samples are then mixed and broken into pieces not exceeding one inch in diameter, and reduced by the process of repeated quartering and crushing until a final sample weighing about five pounds is obtained, and the size of the larger pieces are such that they will pass through a sieve with $\frac{1}{4}$-inch meshes. From this sample two onequart, air-tight glass preserving-jars, or other air-tight vessels which will prevent the escape of moisture from the sample, are to be promptly filled, and these samples are to be kept for subsequent determinations of moisture and of heating value, and for chemical analyses. During the process of quartering, when the sample has been reduced to about Ioo pounds, a quarter to a half of it may be taken for an approximate determination of moisture. This may be made by placing it in a shallow iron pan, not over three inches deep, carefully weighing it, and setting the pan in the hottest place that can be found on the brickwork of the boiler setting or flues, keeping it there for at least twelve hours, and then weighing it. The determination of moisture thus made is believed to be approximately accurate for anthracite and semi-bituminous coals, and also for Pittsburg or Youghiogheny coal; but it cannot be relied upon for coals mined west of Pittsburg, or for other coals containing inherent 
moisture. For these latter coals it is important that a more accurate method be adopted. The method recommended by the Committee for all accurate tests, whatever the character of the coal, is described as follows:

Take one of the samples contained in the glass jars, crush the whole of it by running it through an ordinary coffee-mill adjusted so as to produce somewhat coarse grains (less than $\frac{1}{16}$ inch), thoroughly mix the crushed sample, select from it a portion of from Io to 50 grams, weigh it in a balance which will easily show a variation as small as I part in I000, and dry it in an air or sand bath at a temperature between 240 and 280 degrees Fahr. for one hour. Weigh it and record the loss, then heat and weigh it again repeatedly, at intervals of an hour or less, until the minimum weight has been reached and the weight begins to increase by oxidation of a portion of the coal. The difference between the original and the minimum weight is taken as the moisture. This moisture should preferably be made on duplicate samples, and the results should agree within 0.3 to 0.4 of one per cent, the mean of the two determinations being taken as the correct result.

If the coal contains an appreciable amount of surface moisture, another portion of the IOO pounds sample should be weighed and spread out in a thin layer on a clean sheetiron plate, and exposed for a period of twenty-four hours to the atmosphere of the boiler-room, and by this means airdried. After being weighed again, the percentage which the weight shrinks during this drying may be termed the percentage of surface moisture.

XV. Treatment of Ashes and Refuse.-The ashes and refuse are to be weighed in a dry state. For elaborate trials a sample of the same should be procured for analysis. When it is desired to know accurately the amount of coal consumed, as distinguished from combustible, all lumps of unconsumed 
coal one-half inch or more in diameter are to be picked from the refuse and deducted from the weight of coal fired.

XVI. Calorific Tests and Analysis of Coal.-The quality of the fuel should be determined either by heat test or by analysis, or by both.

The rational method of determining the total heat of combustion is to burn the sample of coal in an atmosphere of oxygen-gas, the coal to be sampled as directed in Article XIV of this Code.

The chemical analysis of the coal should be made only by an expert chemist. The total heat of combustion computed from the results of the ultimate analysis should be obtained by the use of Dulong's formula (with constants modified by recent determinations), viz.,

$$
14600 \mathrm{C}+62000\left(\mathrm{H}-\frac{\mathrm{O}}{8}\right)
$$

in which $\mathrm{C}, \mathrm{H}$, and $\mathrm{O}$ refer to the proportion of carbon, hydrogen, and oxygen respectively, and determined by the ultimate analysis.*

It is recommended that the analysis and the heat test be each made by two independent laboratories, and the mean of the two results, if there is any difference, be adopted as the correct figures.

It is desirable that a proximate analysis should also be made to determine the relative proportions of volatile matter and fixed carbon in the coal.

XVII. Analysis of Flue-gases. - The analysis of the fluegases is an especially valuable method of determining the relative value of different methods of firing, or of different kinds of furnaces. In making these analyses great care should

* Favre and Silbermann give I4544 B. T. U. per pound carbon; Berthelot 14647 B. T. U. Favre and Silbermann give 62032 B. T. U. per pound hydrogen; Thomson, 6r8I6 B. T. U. 
be taken to procure average samples, since the composition is apt to vary at different points of the flue; and where complete determinations are desired, the analysis should be intrusted to an expert chemist. For approximate determinations the Orsat* or the Hempel $\dagger$ apparatus may be used by the engineer.

XVIII. Smoke Observations. - It is desirable to have a uniform system of determining and recording the quantity of smoke produced where bituminous coal is used. The system commonly employed is to express the degree of smokiness by means of percentages dependent upon the judgment of the observer. The Committee does not place much value upon a percentage method, because it depends so largely upon the personal element, but if this method is used, it is desirable that, so far as possible, a definition be given in explicit terms as to the basis and method employed in arriving at the percentage.

XIX. Miscellaneous.-In tests for purposes of scientific research, in which the determination of all the variables entering into the test is desired, certain observations should be made which are in general unnecessary for ordinary tests. These are the measurement of the air-supply, the determination of its contained moisture, the determination of the amount of heat lost by radiation, of the amount of infiltration of air through the setting, and (by condensation of all the steam made by the boiler) of the total heat imparted to the water.

As these determinations are not likely to be undertaken except by engineers of high scientific attainments, it is not deemed advisable to give directions for making them.

XX. Calculations of Efficiency.-Two methods of defining

* See R. S. Hale's paper on "Flue Gas Analysis," Transactions A. S. $M$. E., vol. xvill. p. gor.

tSee Hempel on "Gas Analysis." 
and calculating the efficiency of a boiler are recommended. They are:

I. Efficiency of the boiler $=\frac{\text { Heat absorbed per lb. combustible }}{\text { Heating value of I lb. combustible }}$

2. Efficiency of the boiler and grate

$$
=\frac{\text { Heat absorbed per lb. coal }}{\text { Heating value of } \mathrm{I} \text { lb. coal }}
$$

The first of these is sometimes called the efficiency based on combustible, and the second the efficiency based on coal. The first is recommended as a standard of comparison for all tests, and this is the one which is understood to be referred to when the word "efficiency" alone is used without qualification. The second, however, should be included in a report of a test, together with the first, whenever the object of the test is to determine the efficiency of the boiler and furnace together with the grate (or mechanical stoker), or to compare different furnaces, grates, fuels, or methods of firing.

The heat absorbed per pound of combustible (or per pound coal) is to be calculated by multiplying the equivalent evaporation from and at 212 degrees per pound combustible (or coal) by 965.7 .

In calculating the efficiency where the coal contains an appreciable amount of surface moisture, allowance is to be made for the heat lost in evaporating this moisture by adding to the heat absorbed by the boiler the heat of evaporation thus lost. The percentage of surface moisture used in this calculation is that which is found in the manner described in Article XIV of Code.

XXI. The Heat-balance.-An approximate "heat-balance," or statement of the distribution of the heating value of the coal among the several items of heat utilized and heat lost may be included in the report of a test when analyses of the fuel and of the chimney gases have been made. It should be reported in the following form: 
Heat balance, or Distribution of the Heating Value of the ComBUSTIBLE.

Total Heat Value of I lb. of Combustible.............. B. T. U.

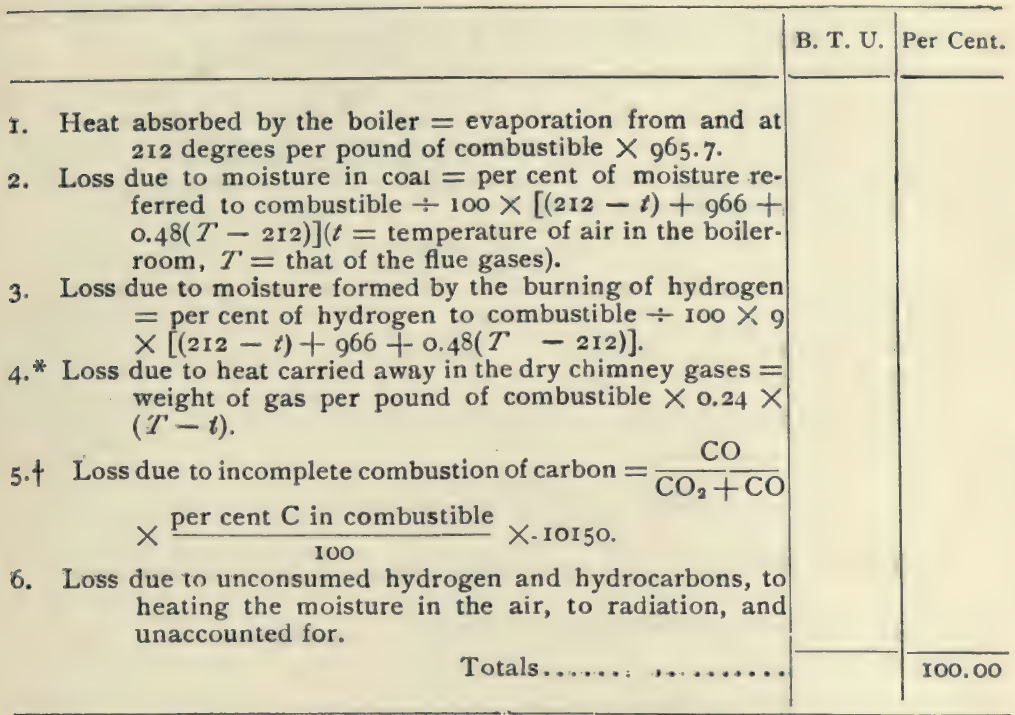

* The weight of gas per pound of carbon burned may be calculated from the gas analyses as follows :

Dry gas per pound carbon $=\frac{\mathrm{IICO}_{2}+8 \mathrm{O}+7(\mathrm{CO}+\mathrm{N})}{3\left(\mathrm{CO}_{2}+\mathrm{CO}\right)}$, in which $\mathrm{CO}_{2}, \mathrm{CO}, \mathrm{O}$, and $\mathrm{N}$ are the percentages by volume of the several gases. As the sampling and analyses of the gases in the present state of the art are liable to considerable errors, the result of this calculation is usually oniy an approximate one. The heat-balance itself is also only approximate for this reason, as well as for the fact that it is not possible to determine accurately the percentage of unburned hydrogen or hydrocarbons in the flue gases.

The weight of dry gas per pound of combustible is found by multıplying the dry gas per pound of carbon by the percentage of carbon in the combustible, and dividing by roo.

$+\mathrm{CO}_{2}$ and $\mathrm{CO}$ are respectively the percentage by volume of carbonic acid and carbonic oxide in the flue gases. The quantity ror $50=\mathrm{No}$. heat-units generated by burning to carbonic acid one pound of carbon contained in carbonic oxide.

XXII. Report of the Trial.-The data and results should be reported in the manner given in the following table, omitting lines where the tests have not been made as elaborately as provided for in such table. Additional lines may be added for data relating to the specific object of the test. The extra lines should be classified under the headings provided in the 
table, and numbered, as per preceding line, with sub letters, $a, b$, etc.

\section{Data and Results of Evaporative Trials.}

Made by of. boiler at. to determine.

Principal conditions governing the trial

Kind of fuel.

State of the weather

I. Date of trial .

2. Duration of trial. hours.

\section{Dimensions and Proportions.}

(A complete description of the boiler should be given on an annexed sheet.)

3. Grate surface........ width....... length..............

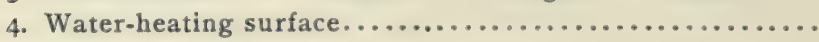
sq. ft.

5. Superheating surface.

6. Ratio of water heating surface to grate surface..........

7. Ratio of minimum draft area to grate surface.............

\section{Average Pressures.}

8. Steam-pressure by gauge........................ lbs.

9. Atmospheric pressure by barometer................. in.

10. Force of draft between damper and boiler............. "

II. Force of draft in furnace......................... "

12. Force of draft in ash-pit........................... "

\section{Average Temperatures.}

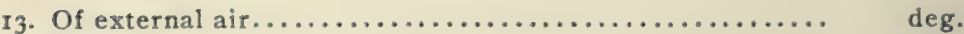

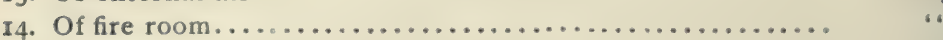

15. Of steam....................................... "

16. Of feed water entering heater..................... "

17. Of feed water entering economizer................ "

18. Of feed water entering boiler.....................

19. Of escaping gases from boiler .................... "

20. Of escaping gases from economizer................ 
Fuel.

21. Size and condition

22. Weight of wood used in lighting fire

lbs.

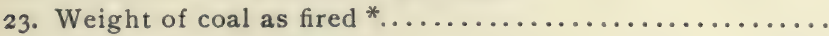

24. Percentage of moisture in coal $+\ldots \ldots \ldots \ldots \ldots \ldots \ldots \ldots$.

25. Total weight of dry coal consumed (Art. XIV, Code)......

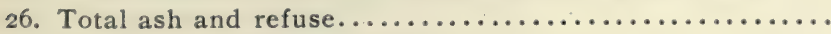

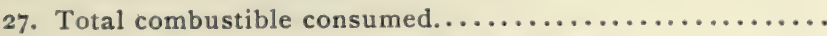

28. Percentage of ash and refuse in dry coal.

\section{Proximate Analysis of Coal.}

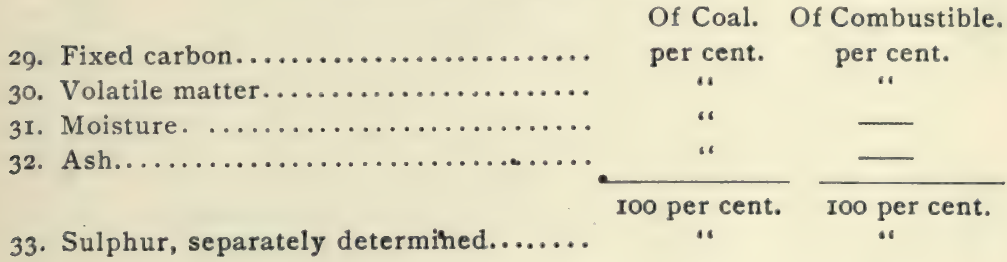

Ultimate Analysis of Dry Coal.

(Art. XVI, Code.)

34. Carbon (C)...

35. Hydrogen $(\mathrm{H})$.

per cent.

36. Oxygen $(\mathrm{O})$

.

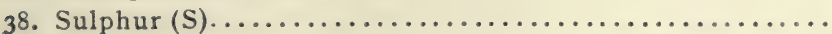

39. Moisture in sample of coal as received.

Analysis of Ash and Refuse.

40. Carbon

per cent.

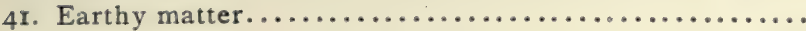

Fuel per Hour.

42. Dry coal consumed per hour....................... lbs.

43. Combustible consumed per hour..................... "

44. Dry coal per square foot of grate surface per hour........ "

45. Combustible per square foot of water heating surface per

hour

* Including equivalent of wood used in lighting the fire, not including unburnt coal withdrawn from furnace at end of test. One pound of wood is taken to be equal to 0.4 pound of coal.

+ This is the total moisture in the coal as found by drying it artificially, as described in Art. XIV of Code. 


\section{Calorific Value of Fuel.}

46. Calorific value by oxygen calorimeter, per pound of dry

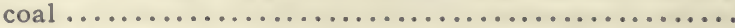

B. T. U.

16 66 6

16 40 , 6

16 ic is

49. Calorific value by analysis, per pound of combustible.....

\section{Quality of Steam.}

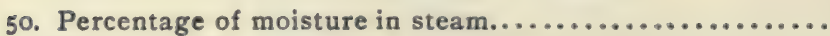

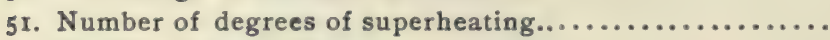

52. Quality of steam (dry steam $=$ unity) $\ldots \ldots \ldots \ldots \ldots \ldots \ldots$.

53. Factor of correction for quality of steam (page II9)......

\section{Water.}

54. Total weight of water fed to boiler....................

55. Water actually evaporated, corrected for quality of steam

56. Equivalent water evaporated into dry steam from and at degrees.

\section{Water per Hour.}

57. Water evaporated per hour, corrected for quality of steam

58. Equivalent evaporation per hour from and at 2 I 2 degrees.

59. Equivalent evaporation per hour from and at 212 degrees per square foot of water-heating surface.............

\section{Horse-power.}

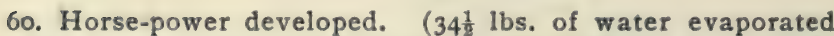
per hour intodry steam from and at 212 degrees, equals

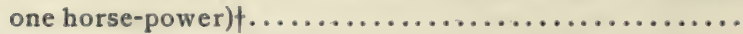

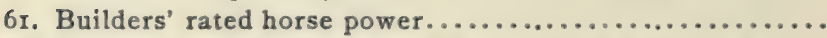

62. Percentage of builders' rated horse-power developed......

\section{Economic Results.}

63. Water apparently evaporated per $\mathrm{lb}$. of coal under actual

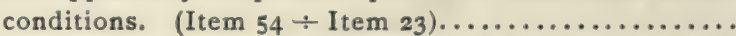

64. Equivalent evaporation from and at 212 degrees per lb. of

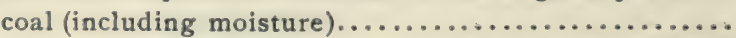

65. Equivalent evaporation from and at 212 degrees per $1 b$. of

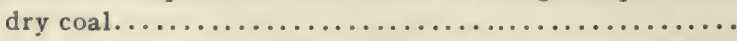

66. Equivalent evaporation from and at 212 degrees per lb. of

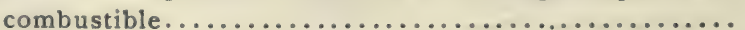

per cent. deg.

lbs.

6

is

H. P.

lbs.

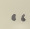

* See formula for calorific value under Article XVI of Code.

+ Held to be the equivalent of 30 lbs. of water per hour evaporated from 100 degrees Fahr. into dry steam at 70 lbs. gauge-pressure (See Introduction to Code.) 


\section{Efficiency.}

\section{(See Art. XX, Code.)}

67. Efficiency of the boiler; heat absorbed by the boiler per lb. of combustible divided by the heat-value of one lb. of combustible.*

68. Efficiency of boiler, including the grate; heat absorbed by the boiler, per lb. of dry coal fired, divided by the heat value of one lb. of dry coal. $\ldots . . . \ldots \ldots \ldots \ldots \ldots \ldots$.

\section{Cost of Evaporation.}

69. Cost of coal per ton of 2240 lbs. delivered in boiler-room... 70. Cost of fuel for evaporating rooo lbs. of water under ob-

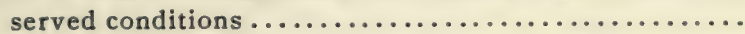

7r. Cost of fuel used for evaporating $\mathrm{r}, 000 \mathrm{lbs}$. of water from

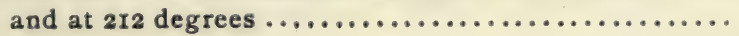

\section{Smoke Observations.}

72. Percentage of smoke as observed.

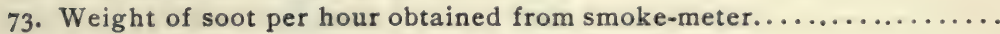

74. Volume of soot obtained from smoke-meter per hour ..............

*In all cases where the word "combustible" is used, it means the coal without moisture and ash, but including all other constituents. It is the same as what is called in Europe "coal dry and free from ash."

+ The heat value of the coal is to be determined either by an oxygen calorimeter or by calculation from ultimate analysis. When both methods are used the mean value is to be taken. 


\section{TABLE I.-HEAT OF COMBUSTION OF SUBSTANCES.}

\begin{tabular}{|c|c|c|c|}
\hline Crystallized carbon to $\mathrm{CO}_{2}$. . & $\begin{array}{c}\text { Calories. } \\
7859\end{array}$ & $\begin{array}{l}\text { B. T. U. } \\
\text { I41 } 46\end{array}$ & Berthelot \\
\hline " $"$ to $\mathrm{CO} .$. & 2405 & 4329 & " \\
\hline Amorphous carbon to $\mathrm{CO}_{2} .$. & 8137 & 14647 & “ \\
\hline " $\quad$ to $\mathrm{CO} .$. & 2489 & 4480 & “ \\
\hline Graphite to $\mathrm{CO}_{2} \ldots \ldots \ldots \ldots$. & 7901 & 14222 & " \\
\hline Petroleum coke to $\mathrm{CO}_{2} \ldots \ldots$ & 8017 & 14503 & Mahler \\
\hline Gas coke to $\mathrm{CO}_{2} \ldots \ldots \ldots \ldots$ & 8047 & 14485 & F. \& S. \\
\hline Carbon vapor to $\mathrm{CO}_{2} \ldots \ldots$ & 8722 & 15700 & $\left\{\begin{array}{l}\text { Calculated. } \\
\text { Page I73. }\end{array}\right.$ \\
\hline Coal (pure and dry) ........ & 7800 to 9000 & 14040 to 16200 & Various \\
\hline Lignite (pure and dry)....... & 6000 to 7000 & 10800 to 12600 & “ \\
\hline Beech chareoal............ & 7140 & 12852 & Schwackhöfer \\
\hline Soft charcoal............... & 7071 & 12723 & " \\
\hline Cellulose................ & 4200 & 7560 & Berthelot \\
\hline Soft resinous wood.......... & 5050 & 9090 & Gottlieb \\
\hline Hard woode................ & 4750 & 8550 & “" \\
\hline Peat....................... & 5940 & 10692 & Bainbridge \\
\hline Cane sugar................ & 3961 & 7130 & Berthelot \\
\hline Asphalt................. & 9532 & 17159 & Slosson \& Colburn \\
\hline Pitch..................... & 8400 & 15120 & Anon. \\
\hline Naphthalin............... & 9690 & 16842 & Berthelot \\
\hline Paraffin................... & 11000 & 19800 & Mahler \\
\hline Tallow.................... & 9500 & 17100 & Stohmann \\
\hline Sulphur................... & 2500 & 4500 & Berthelot \\
\hline Petroleum............... & 9600 to I 1000 & 17280 to 19800 & Various \\
\hline Schist-oil................. & 9000 to 10000 & 16200 to 18000 & " \\
\hline Heavy coal gas oil.......... & 8900 & 16020 & Ste-Claire Deville \\
\hline Cotton oil................ & 9500 & 17100 & Anon. \\
\hline Rape oil ................. & 9489 & I7080 & Stohmann \\
\hline Olive oil.................. & 9473 & 17051 & “ \\
\hline Sperm oil.................. & 10000 & 18000 & Gibson \\
\hline Hydrogen................. & 34500 & 62100 & Berthelot \\
\hline Carbonic oxide ............ & 2435 & 4383 & “ \\
\hline Marsh gas.................. & 13343 & 24017 & $"$ \\
\hline Olefiant gas................ & 12182 & 21898 & “ \\
\hline Acetylene................. & 12142 & 21856 & “ \\
\hline Carbon vapor (diamond)... & III 34 & 20041 & “ \\
\hline Coal gas ..................... & 4440 to 7370 & 7990 to 12266 & Various \\
\hline Petroleum gas............. & 10800 & $19+40$ & Anon. \\
\hline Air producer gas........... & 773 to 1370 & I39I to 2466 & Various \\
\hline Water gas................... & 2350 to 3032 & 4230 to $545^{8}$ & “ \\
\hline Mixed gas................ & Ior 5 to 1548 & 1827 to 2756 & $" 1$ \\
\hline
\end{tabular}


TABLE II.-THERMOMETER REDUCTION TABLES.

A. Centigrade to Fahrenheit.

\begin{tabular}{|c|c|c|c|c|c|c|c|}
\hline C. & F. & C. & $\begin{array}{l}\text { F. } \\
18\end{array}$ & C. & F. & C. & F. \\
\hline I & $\begin{array}{l}1.8 \\
3.6\end{array}$ & $\begin{array}{l}10 \\
20\end{array}$ & $\begin{array}{l}18 \\
36\end{array}$ & $\begin{array}{l}100 \\
200\end{array}$ & $\begin{array}{l}180 \\
360\end{array}$ & $\begin{array}{l}1000 \\
2000\end{array}$ & $\begin{array}{l}1800 \\
3600\end{array}$ \\
\hline 3 & 5.4 & 30 & 54 & 300 & 540 & 3000 & 5400 \\
\hline 4 & 7.2 & 40 & 72 & 400 & 720 & 4000 & 7200 \\
\hline 5 & 9.0 & 50 & 90 & 500 & 900 & 5000 & 9000 \\
\hline 6 & 10.8 & 60 & 108 & 600 & 1080 & 6000 & 10800 \\
\hline 7 & I2.6 & 70 & 126 & 700 & 1260 & 7000 & 12600 \\
\hline 8 & I4.4 & 80 & I 44 & 800 & 1440 & 8000 & 14400 \\
\hline 9 & 16.2 & 90 & 162 & 900 & 1620 & 9000 & 16200 \\
\hline
\end{tabular}

B. Fahrenheit to Centigrade.

$\begin{array}{cccccccc}\text { F. } & \text { C. } & \text { F. } & \text { C. } & \text { F. } & \text { C. } & \text { F. } & \text { C. } \\ \text { I } & \frac{5}{9} & \text { IO } & 5 \frac{5}{9} & 100 & 55 \frac{5}{9} & 1000 & 555 \frac{5}{9} \\ 2 & 1 \frac{1}{9} & 20 & 11 \frac{1}{9} & 200 & 111 \frac{7}{9} & 2000 & 1111 \frac{1}{9} \\ 3 & 1 \frac{8}{9} & 30 & 16 \frac{8}{9} & 300 & 166 \frac{8}{9} & 3000 & 1666 \frac{8}{9} \\ 4 & 2 \frac{2}{9} & 40 & 22 \frac{2}{9} & 400 & 222 \frac{8}{9} & 4000 & 2222 \frac{2}{9} \\ 5 & 2 \frac{7}{9} & 50 & 27 \frac{7}{9} & 500 & 277 \frac{7}{9} & 5000 & 2777 \frac{7}{9} \\ 6 & 3 \frac{8}{8} & 60 & 33 \frac{3}{9} & 600 & 333 \frac{8}{9} & 6000 & 3333 \frac{8}{9} \\ 7 & 3 \frac{8}{9} & 70 & 38 \frac{8}{9} & 700 & 388 \frac{8}{9} & 7000 & 3888 \frac{8}{9} \\ 8 & 4 \frac{4}{9} & 80 & 44 \frac{4}{9} & 800 & 444 \frac{4}{9} & 8000 & 4444 \frac{4}{9} \\ 9 & 5 & 90 & 50 & 900 & 500 & 9000 & 5000\end{array}$

Having given Centigrade degrees, obtain from Table A the corresponding equivalents, and to their sum add $32^{\circ}$.

Example: Find Fahrenheit degrees corresponding to $416^{\circ} \mathrm{C}$.

$$
720+18+10.8+32=780.8
$$

Having given Fahrenheit degrees, subtract $32^{\circ}$ and find the value in Table $B$ corresponding to the remainder.

Example: Find Centigrade degrees corresponding to $-16^{\circ} \mathrm{F}$.

$$
-\mathrm{r} 6-32=-48,-48^{\circ} \mathrm{F} .=-\left(22 \frac{2}{9}+4 \frac{4}{9}\right)=-26 \frac{6}{9} .
$$


TABLE III.-THEORETICAL FLAME TEMPERATURES.

\begin{tabular}{|c|c|c|c|c|}
\hline & \multicolumn{2}{|c|}{ In Oxygen. } & \multicolumn{2}{|c|}{ In Air. } \\
\hline & Centigrade. & Fahrenheit. & Centigrade. & Fahrenheit. \\
\hline $\mathrm{C}$ to $\mathrm{CO} . . \ldots \ldots \ldots \ldots \ldots \ldots \ldots$ & $4265^{\circ}$ & $7677^{\circ}$ & $1462^{\circ}$ & $2639^{\circ}$ \\
\hline $\mathrm{C}$ to $\mathrm{CO}_{2} \ldots \ldots \ldots \ldots \ldots \ldots \ldots$ & 10000 & 18000 & 2718 & 4892 \\
\hline $\mathrm{CO}$ to $\mathrm{CO}_{2} \ldots \ldots \ldots \ldots \ldots \ldots$ & 7010 & I261 8 & 3000 & 5400 \\
\hline 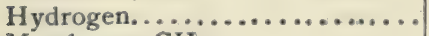 & 6727 & 12108 & 2674 & 4813 \\
\hline Marsh gas, $\mathrm{CH}_{4} \ldots \ldots \ldots \ldots \ldots$ & 7971 & 14348 & 2245 & 4036 \\
\hline Olefiant gas, $\mathrm{C}_{2} \mathrm{H}_{4} \ldots \ldots \ldots \ldots \ldots$ & 9659 & 17286 & 3000 & 5400 \\
\hline Acetylene, $\mathrm{C}_{2} \mathrm{H}_{2} \ldots \ldots \ldots \ldots \ldots$ & 11300 & 20340 & 3400 & 6120 \\
\hline Benzin, $\mathrm{C}_{6} \mathrm{H}_{6} \ldots \ldots \ldots \ldots \ldots \ldots$ & 9350 & 16830 & 2790 & 5022 \\
\hline 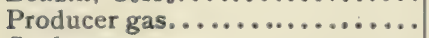 & 2500 & 4500 & 1200 & 2160 \\
\hline 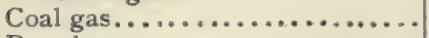 & 5400 & 9720 & 2700 & 4860 \\
\hline 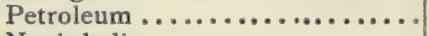 & 7558 & 13604 & 2400 & 4320 \\
\hline 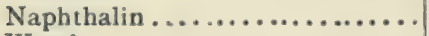 & 9444 & 17000 & 2730 & 4914 \\
\hline 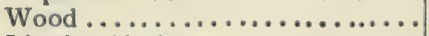 & 5800 & 10440 & 2280 & 4104 \\
\hline 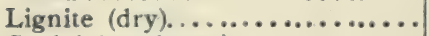 & 3000 & 5400 & 1200 & 2160 \\
\hline Coal (bituminous).............. & 3800 & 6840 & 1500 & 2700 \\
\hline Sulphur to $\mathrm{H}_{2} \mathrm{SO}_{4} \ldots \ldots \ldots \ldots \ldots$ & 2300 & 4140 & 1060 & I908 \\
\hline
\end{tabular}

TABLE IV.-WEIGHT AND VOLUME OF GASES.

\begin{tabular}{|c|c|c|c|c|}
\hline \multirow[b]{2}{*}{ Name. } & \multicolumn{2}{|c|}{ Weight. } & \multicolumn{2}{|c|}{ Volume. } \\
\hline & $\begin{array}{c}\text { Per Cubic } \\
\text { Metre in } \\
\text { Kilograms. }\end{array}$ & $\begin{array}{l}\text { Per Cubic } \\
\text { Foot in } \\
\text { Pounds. }\end{array}$ & $\begin{array}{c}\text { Per Kilogram } \\
\text { in Cubic } \\
\text { Metres. }\end{array}$ & $\begin{array}{l}\text { Per Pound } \\
\text { in } \\
\text { Cubic Feet, }\end{array}$ \\
\hline 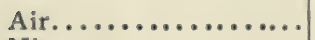 & I. 29318 & 0.08073 & 0.773 & $\mathrm{r} 2.385$ \\
\hline Nitrogen............. & I. $256 \mathrm{I} 6$ & 0.07845 & 0.796 & 12.763 \\
\hline Oxygen................ & I. 4298 & 0.08926 & 0.699 & II. 203 \\
\hline Hydrogen............. & $0.0896 \mathbf{r}$ & 0.00559 & II. I60 & 178.83 \\
\hline Carbonic acid.......... & I. 9666 & 0.12344 & 0.508 & 8.147 \\
\hline Carbonic oxide......... & I. 2515 & 0.07817 & 0.800 & I2.800 \\
\hline Carbon vapor........... & I. 0727 & 0.06696 & 0.932 & 14.930 \\
\hline Aqueous vapor......... & 0.8047 & 0.05022 & I. 242 & 19.912 \\
\hline Sulphurous acid......... & 2.8605 & 0.1787 & 0.349 & $5 \cdot 596$ \\
\hline Ethylene, $\mathrm{C}_{2} \mathrm{H}_{4} \ldots \ldots \ldots$ & 1.2519 & 0.07814 & 0.799 & 12.797 \\
\hline Methane, $\mathrm{CH}_{4} \ldots \ldots \ldots$ & 0.7155 & 0.04466 & I. 397 & 22.391 \\
\hline Acetylene, $\mathrm{C}_{2} \mathrm{H}_{2}, \ldots$. & I. Ig00 & 0.07428 & 0.840 & 13.456 \\
\hline Benzine, $\mathrm{C}_{6} \mathrm{H}_{6} \ldots \ldots \ldots$ & $3 \cdot 3333$ & 0.208 & 0.303 & 4.808 \\
\hline Ethane, $\mathrm{C}_{2} \mathrm{H}_{6} \ldots \ldots \ldots$ & 1.3415 & 0.08565 & 0.746 & I1. 950 \\
\hline
\end{tabular}


TABLE V.

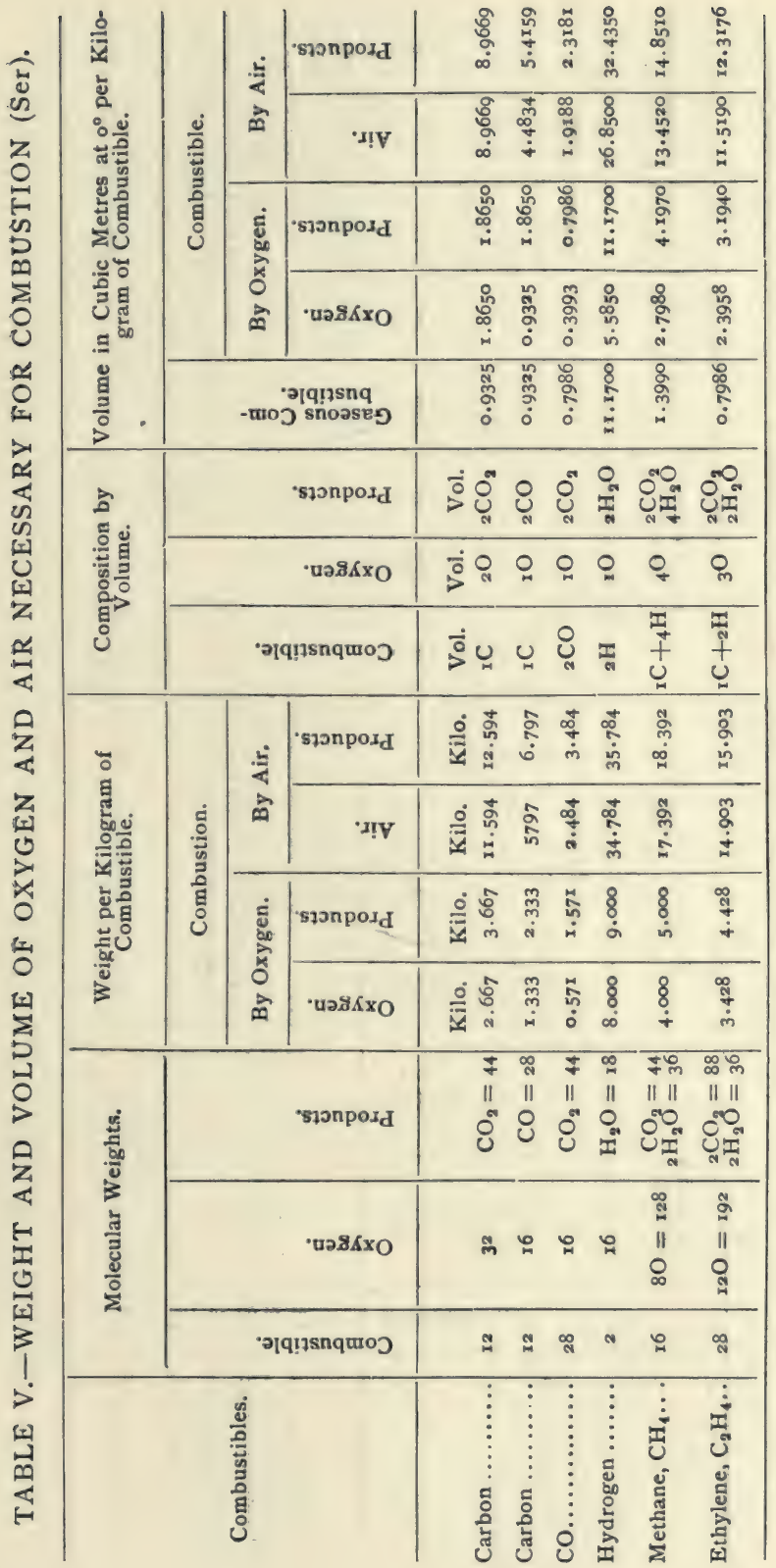




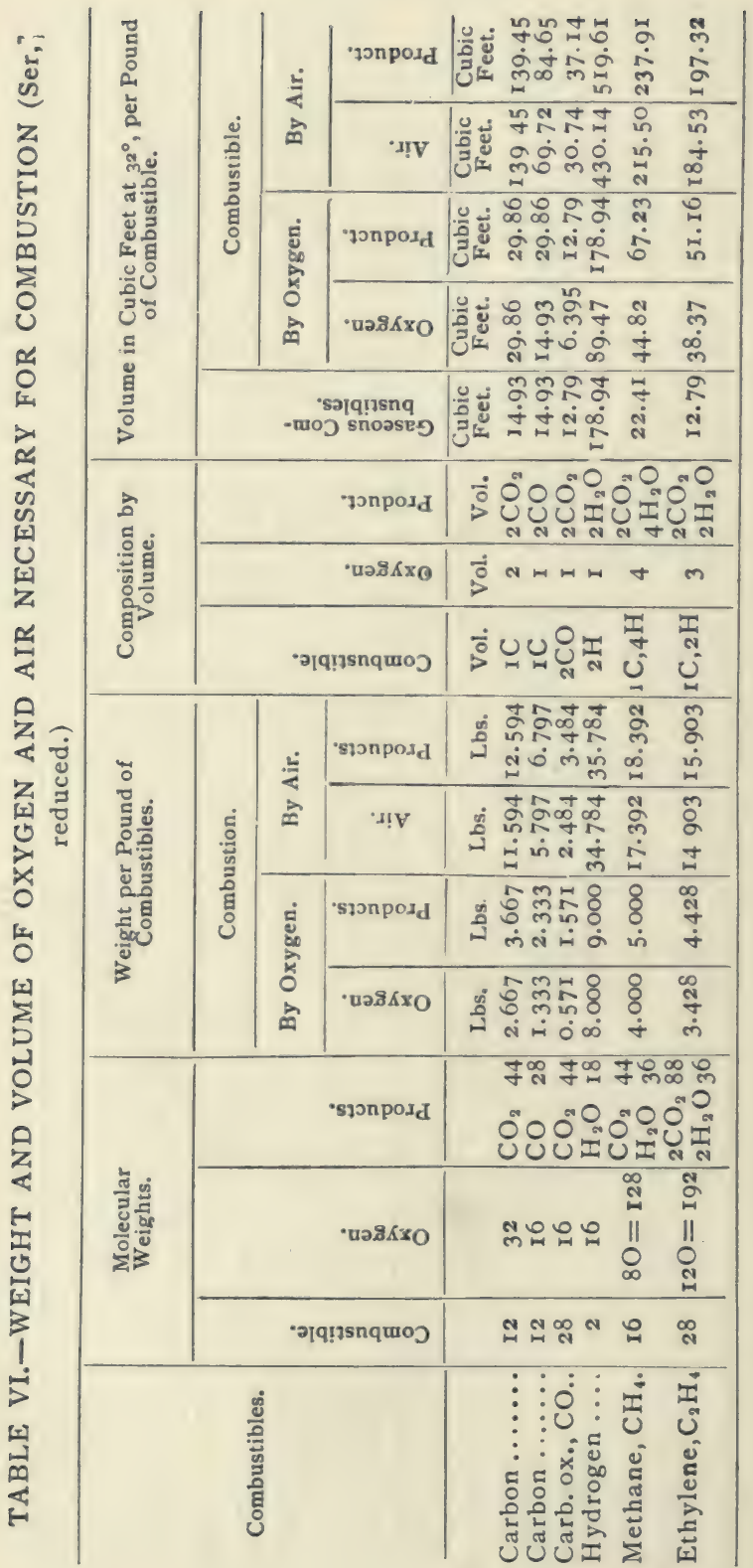




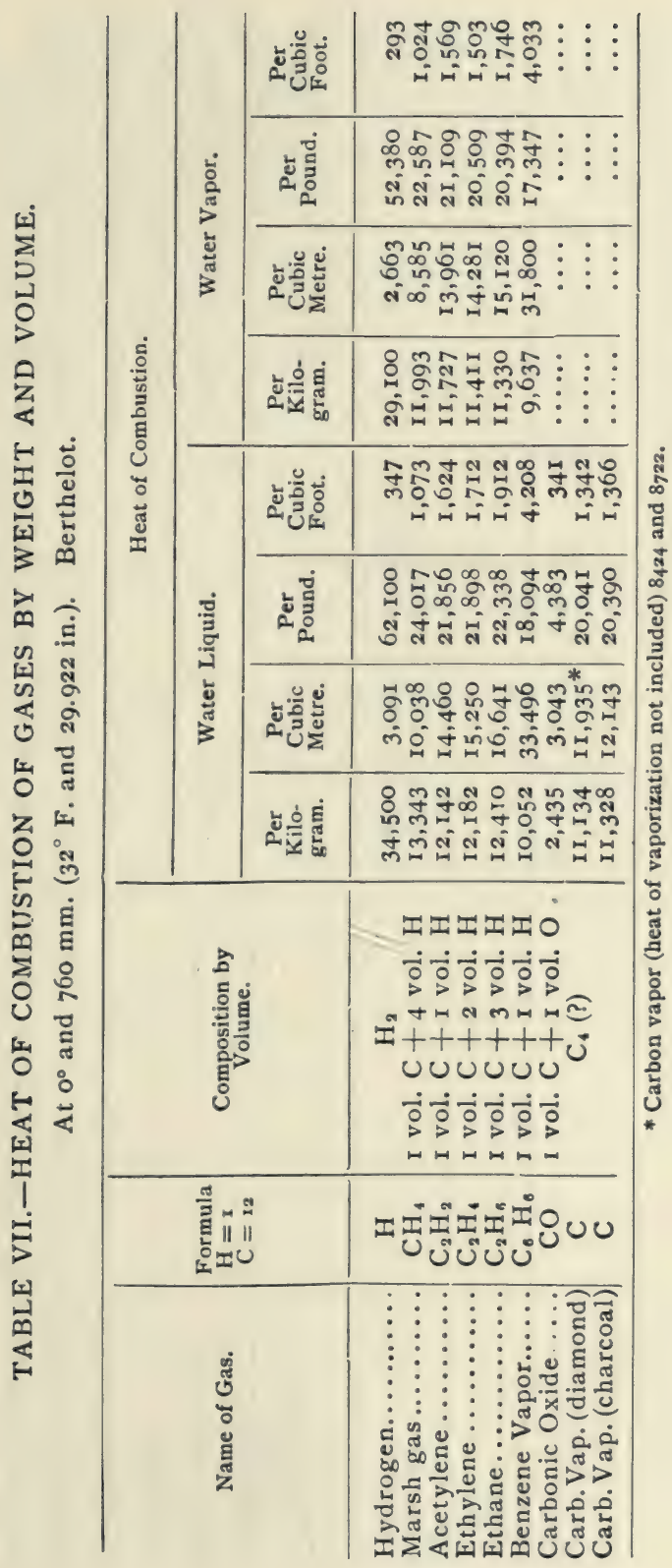




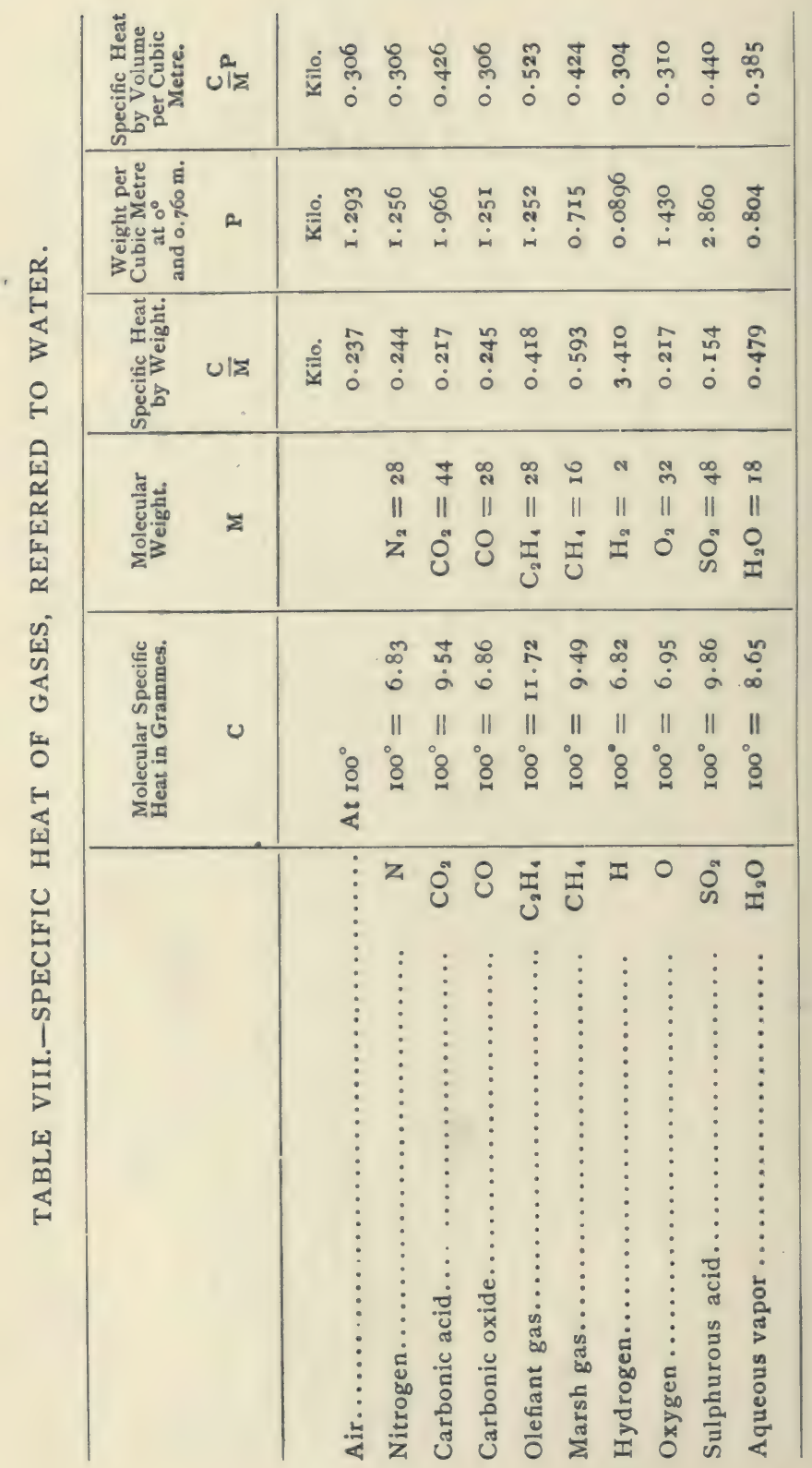


TABLE IX.-TABLE OF SPECIFIC HEAT OF GASEOUS PRODUCTS OF COMBUSTION REFERRED TO THE PROPORTION OF CARBONIC ACID.

\begin{tabular}{|c|c|c|c|c|c|c|c|c|c|}
\hline \multicolumn{4}{|c|}{$\begin{array}{l}\text { Proportion of } \\
\text { Carbonic Acid. }\end{array}$} & \multirow{2}{*}{$\begin{array}{c}\text { Specific } \\
\text { Heat. } \\
0.312\end{array}$} & \multicolumn{4}{|c|}{$\begin{array}{l}\text { Proportion of } \\
\text { Carbonic Acid. }\end{array}$} & \multirow{2}{*}{$\begin{array}{c}\text { Specific } \\
\text { Heat. } \\
0.319\end{array}$} \\
\hline 5 & per & cent & $\ldots$ & & I I & per & cent & t.... & \\
\hline 6 & “" & “ & $\ldots$ & 0.314 & 12 & ، & ، & $\ldots$ & 0.320 \\
\hline 7 & $" 6$ & "6 & $\ldots$ & 0.315 & I 3 & “ & “" & $\ldots$ & 0.321 \\
\hline 8 & ، & ، & $\ldots$ & 0.316 & I 4 & "6 & “6 & & 0.322 \\
\hline 9 & 66 & 66 & $\cdots$ & 0.317 & I 5 & $\because$ & “6 & $\cdots$ & 0.323 \\
\hline IO & 6 & " & $\ldots$ & 0.318 & & & & & \\
\hline
\end{tabular}

TABLE X.-HEAT OF VAPORIZATION OF WATER AT $0^{\circ}$ TO $230^{\circ} \mathrm{C}$.

\begin{tabular}{ccc}
\multicolumn{2}{c}{ Temperature. } & Heat of \\
Centigrade. & Fahrenheit. & Vaporization. \\
0 & 32 & 606.5 \\
100 & 212 & 537.0 \\
230 & 456 & 676.6
\end{tabular}

Latent heat of vaporization, 966 (Regnault).

TABLE XI.-SPECIFIC HEAT OF WATER (REGNAULT).

Temperature. Specific Heat. Temperature. Specific Heat.

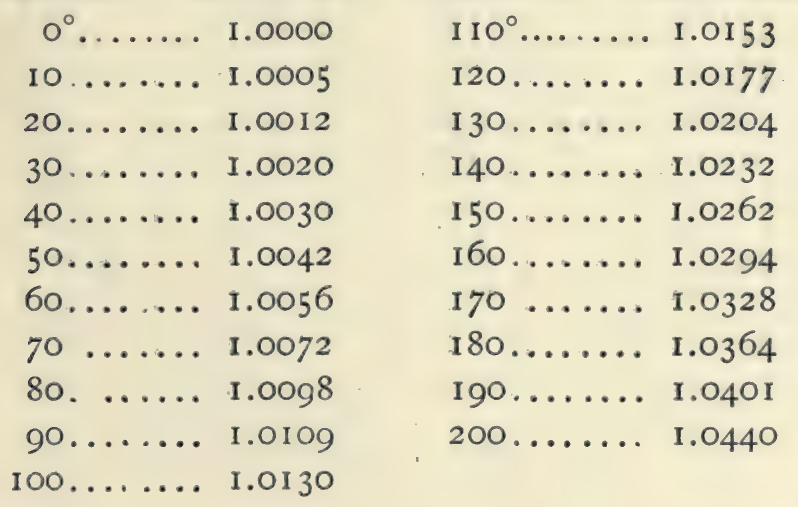


TABLE XII.-VOLUME OF OXYGEN TO FORM WATER WITH THE HYDROGEN OF COAL.

\begin{tabular}{|c|c|c|}
\hline Per Cent of Hydrogen. & $\begin{array}{l}\text { Oxygen in Litres per } \\
\text { Kilogram of Coal. }\end{array}$ & $\begin{array}{l}\text { Oxygen in Cubi } \\
\text { per Pound of }\end{array}$ \\
\hline$I \ldots \ldots \ldots$ & $\ldots .55 .9$ & .896 \\
\hline $2 \ldots \ldots \ldots$ & $\ldots$ II 2 & I. 792 \\
\hline $3 \ldots \ldots \ldots$ & $\ldots$ I68 & 2.699 \\
\hline $4 \ldots \ldots \ldots$ & $\ldots .223$ & 3.585 \\
\hline $5 \ldots \ldots \ldots$ & ... 279 & $4 \cdot 48 \mathrm{I}$ \\
\hline $6 \ldots \ldots \ldots$ & $\ldots .335$ & $5 \cdot 397$ \\
\hline $7 \ldots \ldots \ldots$ & $\ldots .39 \mathrm{I}$ & 6.283 \\
\hline $8 \ldots \ldots \ldots$ & $\ldots 446$ & 7.170 \\
\hline $9 \ldots \ldots \ldots$ & $\ldots .502$ & 8.096 \\
\hline
\end{tabular}

TABLE XIII.-QUANTITY OF AIR REQUIRED FOR PERFECT COMBUSTION OF FUELS.

\begin{tabular}{|c|c|c|c|c|c|c|}
\hline \multirow{2}{*}{ Fuel. } & \multicolumn{4}{|c|}{ Composition. } & \multicolumn{2}{|c|}{ Air per- } \\
\hline & Carbon. & Hydrogen. & Oxygen. & Nitrogen. & Kilogram. & Pound. \\
\hline Coke.............. & 98.0 & 0.5 & $\ldots \ldots$ & $\ldots \ldots \ldots$ & $\begin{array}{c}\text { cu. metres } \\
\text { Io.09 }\end{array}$ & $\begin{array}{l}\text { cu. feet } \\
162.06\end{array}$ \\
\hline Coal, anthracite.... & 95.4 & 2.2 & 1. 8 & 0.5 & $9.0 \mathrm{I}$ & $\mathrm{I} 44.60$ \\
\hline bituminous . & 87.0 & 5.0 & 4.0 & $\ldots \ldots \ldots$ & 8.93 & 143.40 \\
\hline coking........ & 85.0 & 5.0 & 6.0 & $\ldots \ldots \ldots$ & 8.68 & $I 39 \cdot 4 I$ \\
\hline cannel...... & 84.0 & 6.0 & 8.0 & $\ldots \ldots \ldots$ & 8.79 & 141.07 \\
\hline smithy...... & 77.0 & 5.0 & 15.0 & $\ldots \ldots \ldots$ & 7.67 & 123.15 \\
\hline Charcoal.......... & 90.0 & 2.0 & $\ldots \ldots$ & $\ldots \ldots \ldots$ & 8.53 & 133.90 \\
\hline Lignite ......... & 71.0 & 5.0 & 19.0 & $\ldots \ldots \ldots$ & 7.02 & II 2.43 \\
\hline Peat, dry.......... & 58.0 & 6.0 & 30.0 & $\ldots \ldots \ldots$ & $5 \cdot 75$ & $92 \cdot 36$ \\
\hline Wood, dry ......... & 50.0 & 6.0 & 42.0 & I. 0 & $4 \cdot 57$ & 73.36 \\
\hline Petroleum.......... & 85.0 & 14.0 & I.O & $\ldots \ldots \ldots$ & 10.76 & 172.86 \\
\hline Natural gas....... & 68.7 & 22.5 & I. 0 & 6.2 & 14.20 & 227.93 \\
\hline Coal gas .......... & 58.0 & 23.7 & 1.4 & 3.8 & $14.5 \mathrm{I}$ & 233.06 \\
\hline Water gas.......... & 34.0 & $5 \cdot 9$ & 43.0 & 3.4 & 3.16 & 50.70 \\
\hline Producer gas ...... & 1.0 & 5.0 & 21.0 & 69.0 & .72 & II. 56 \\
\hline
\end{tabular}


TABLE XIV.-RELATION BY WEIGHT AND VOLUME OF THE COMPONENTS OF AIR.

Air contains by volume :

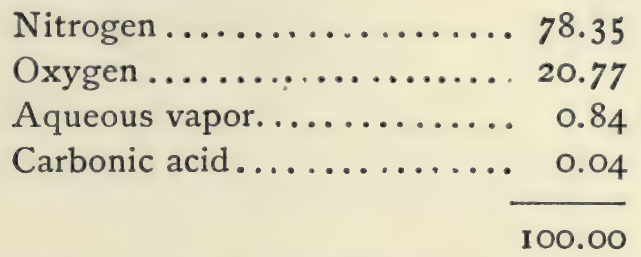

Deducting the carbonic acid and aqueous vapor, we have: Nitrogen....By volume: $79.04 \quad$ By weight: 76.83 Oxygen...." " $\frac{20.96}{100.00}$ " $\frac{23.17}{100.00}$

Ratio of nitrogen to oxygen:

$$
\text { By volume, } \frac{\mathrm{N}}{\mathrm{O}}=3.77 \text { I. By weight, } \frac{\mathrm{N}}{\mathrm{O}}=3.32 \text {. }
$$

Ratio of air to oxygen :

By volume, $\frac{\mathrm{Air}}{\mathrm{O}}=4.771$. By weight, $\frac{\mathrm{Air}}{\mathrm{O}}=4.315$.

Ratio of air to nitrogen:

$$
\text { By volume, } \frac{A i r}{N}=1.265 \text {. By weight, } \frac{A i r}{N}=1.302 \text {. }
$$

TABLE XV.-IGNITION POINT OF GASES (Mayer and Münch).*

Marsh gas, $\mathrm{CH}_{4} \ldots \ldots \ldots \ldots 667^{\circ} \mathrm{C}$.

Ethane, $\mathrm{C}_{2} \mathrm{H}_{6} \ldots \ldots \ldots \ldots \ldots 6 \mathrm{I} 6$

Propane, $\mathrm{C}_{\mathrm{a}} \mathrm{H}_{1} \ldots \ldots \ldots \ldots \ldots . \ldots \ldots+547$

Acetylene, $\mathrm{C}_{2} \mathrm{H}_{2} \ldots \ldots \ldots \ldots, 580$

Propylene, $\mathrm{C}_{3} \mathrm{H}_{0} \ldots \ldots \ldots \ldots .504$

* Berichte der deutscher Gesellschaft xxvi, 2421 . 



\section{FUEL TABLES.}

These tables contain all the available information covering the data required which have been published to date. They contain analyses of the fuels, and the heat units as determined by the authors, whose names are given. In some cases it has been necessary to recalculate the results as published by the experimenters to conform with the standard adopted. This applies especially to the coals and solid fuels, the data for which are given based on pure dry coal, i.e., on the combustible present. If the actual test of the sample as given is desired, it will be easy to make the necessary deductions. Some of the cokes and some of the natural gases have been calculated, the calculated results being within the limits of experimental error in these cases. 


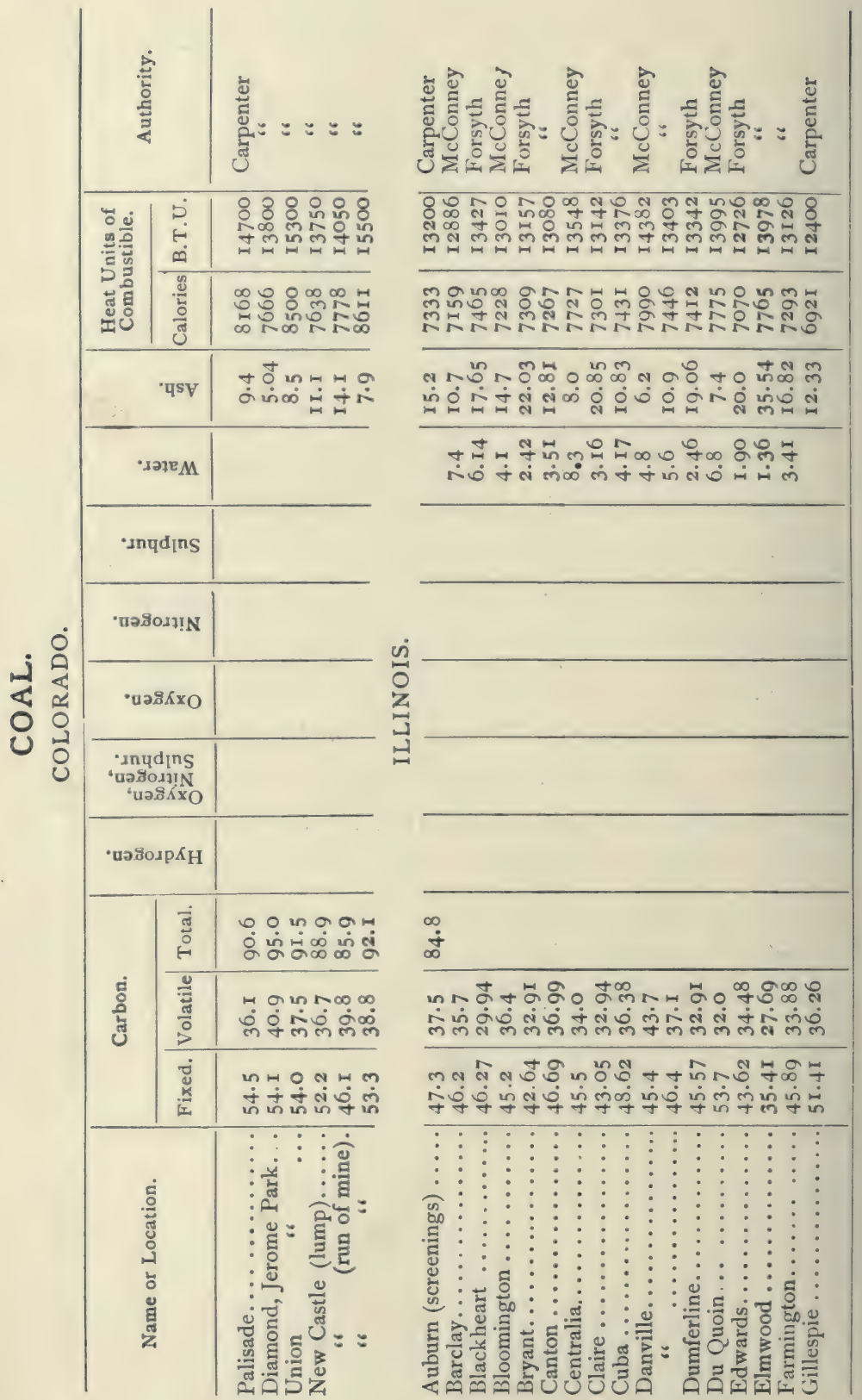




\begin{tabular}{|c|c|c|}
\hline \multicolumn{2}{|c|}{ 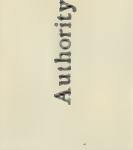 } & 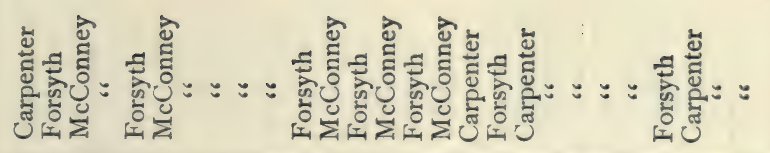 \\
\hline \multirow{2}{*}{ 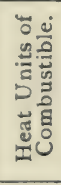 } & 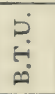 & 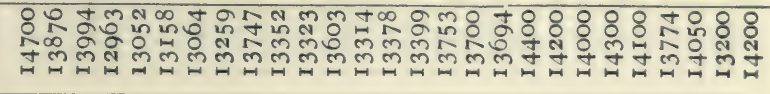 \\
\hline & ปू. & 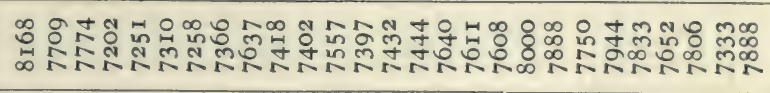 \\
\hline \multicolumn{2}{|c|}{ - पs } & 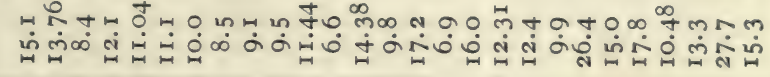 \\
\hline \multicolumn{2}{|c|}{ מכוכג } & 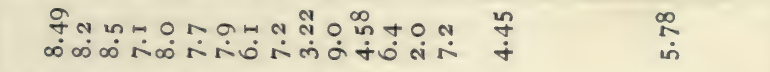 \\
\hline \multicolumn{2}{|c|}{ - Inugdins } & \\
\hline \multicolumn{2}{|c|}{ 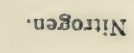 } & \\
\hline \multicolumn{2}{|c|}{ - } & \\
\hline \multicolumn{2}{|c|}{ 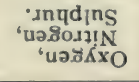 } & \\
\hline \multicolumn{2}{|c|}{ 'uәภำ $\kappa_{H}$} & \\
\hline \multirow{3}{*}{ 范 } & 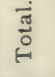 & \\
\hline & $\stackrel{\frac{0}{\pi}}{\frac{\pi}{2}}$ & 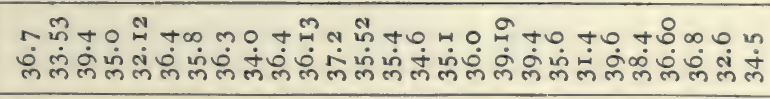 \\
\hline & 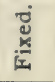 & 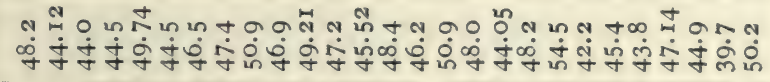 \\
\hline \multicolumn{2}{|c|}{ 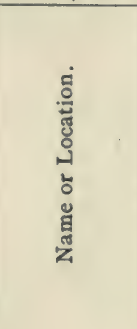 } & 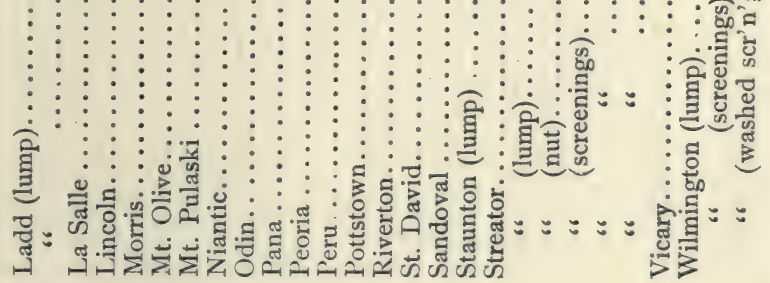 \\
\hline
\end{tabular}




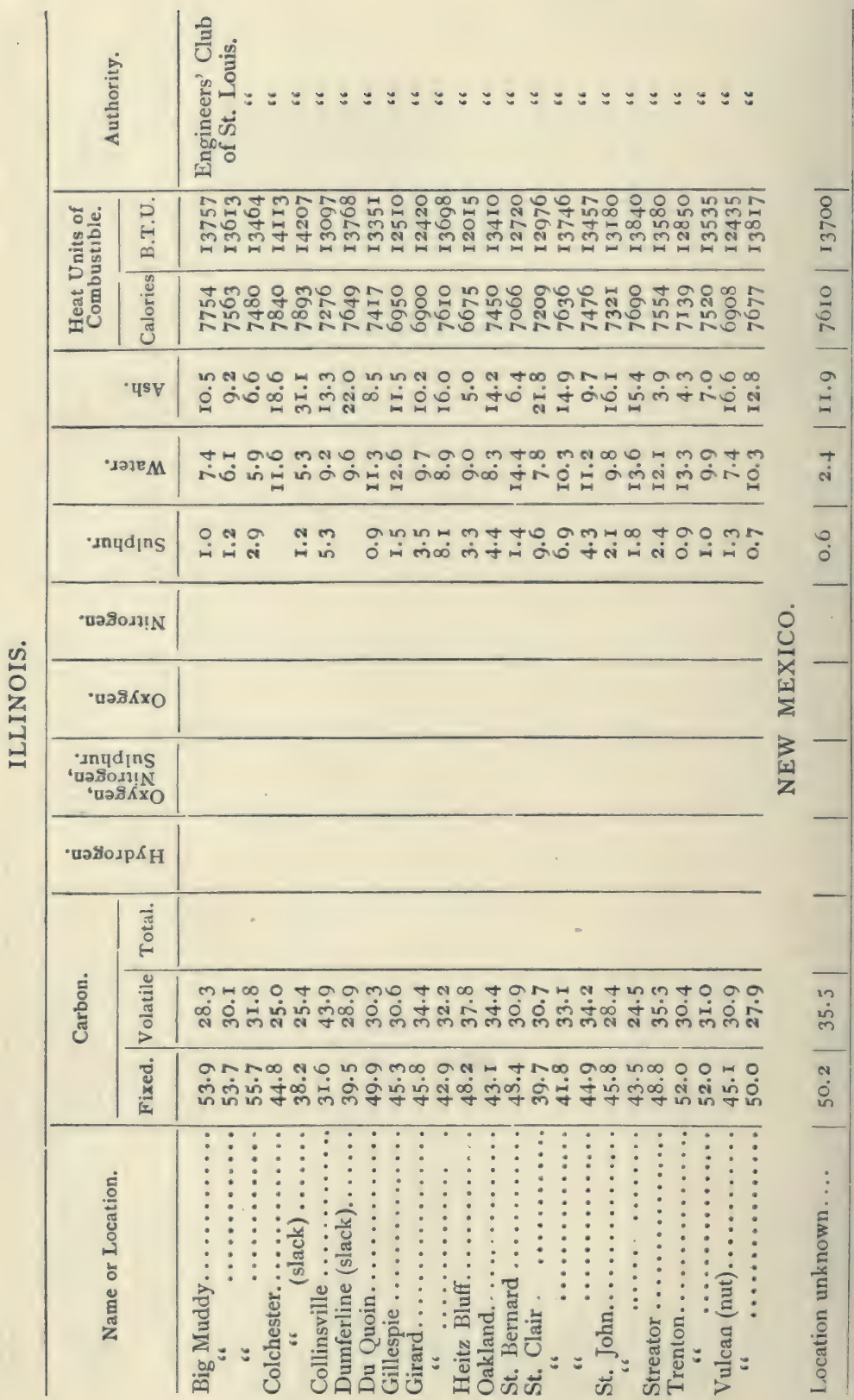


COAL.

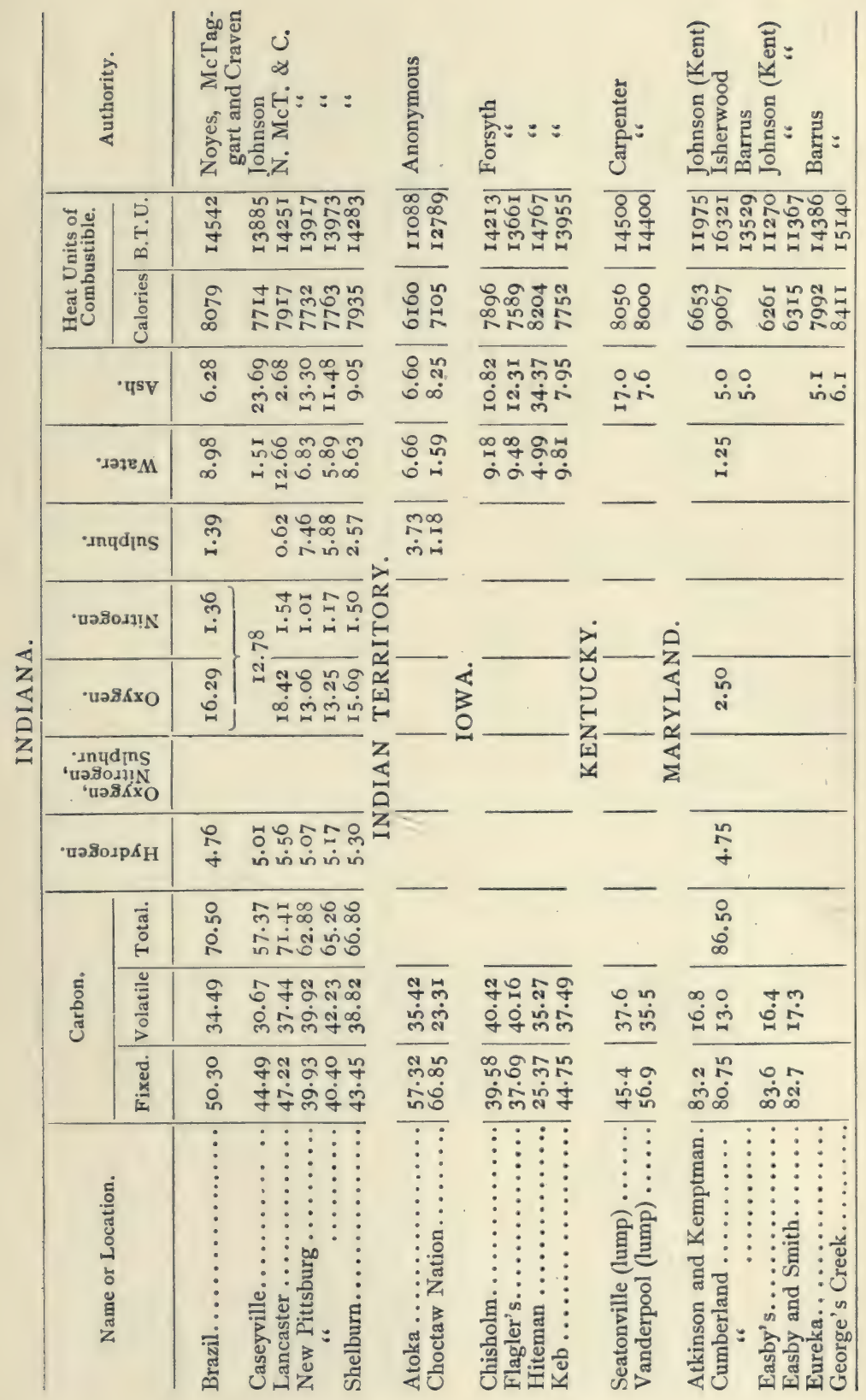




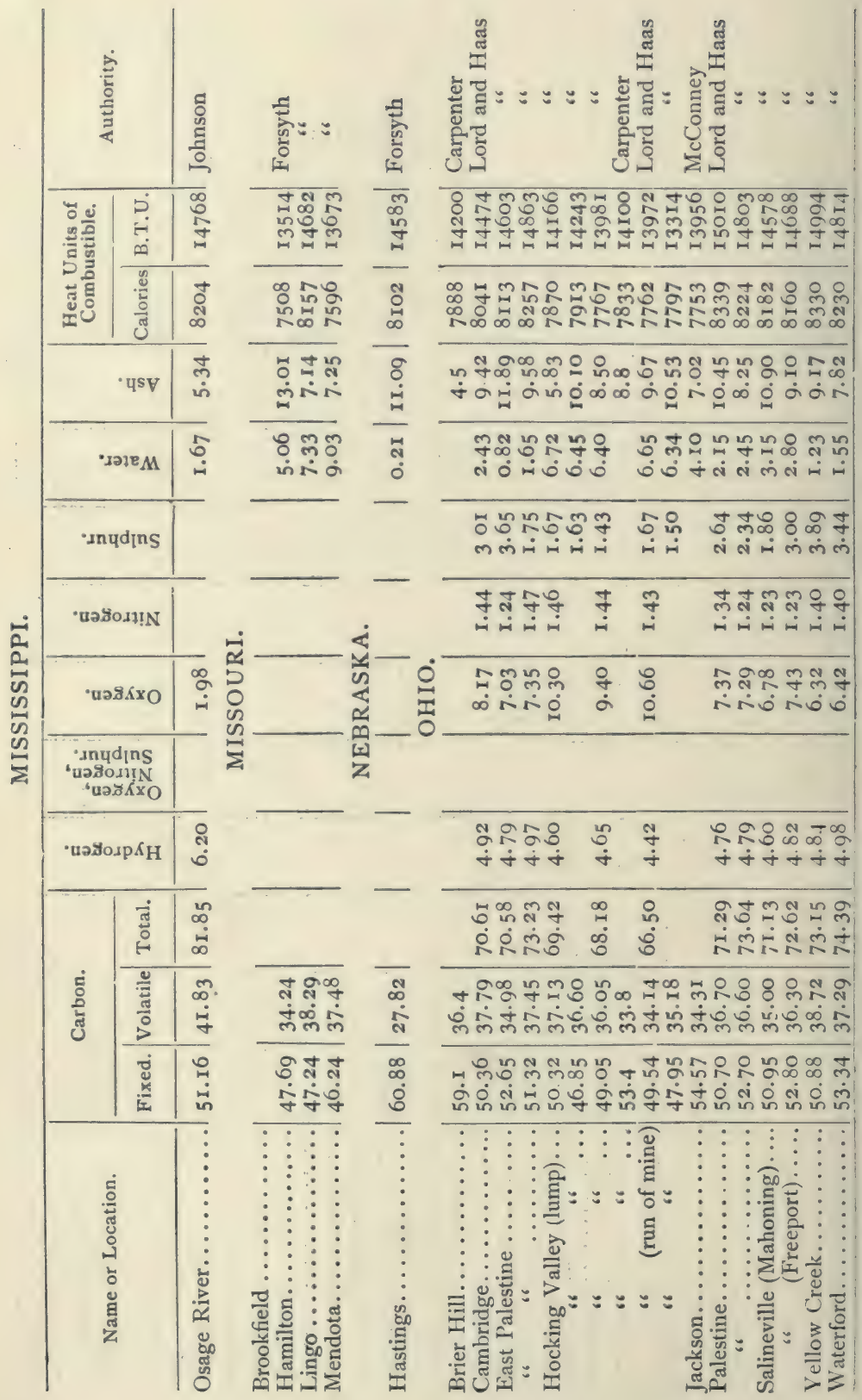


COAL.

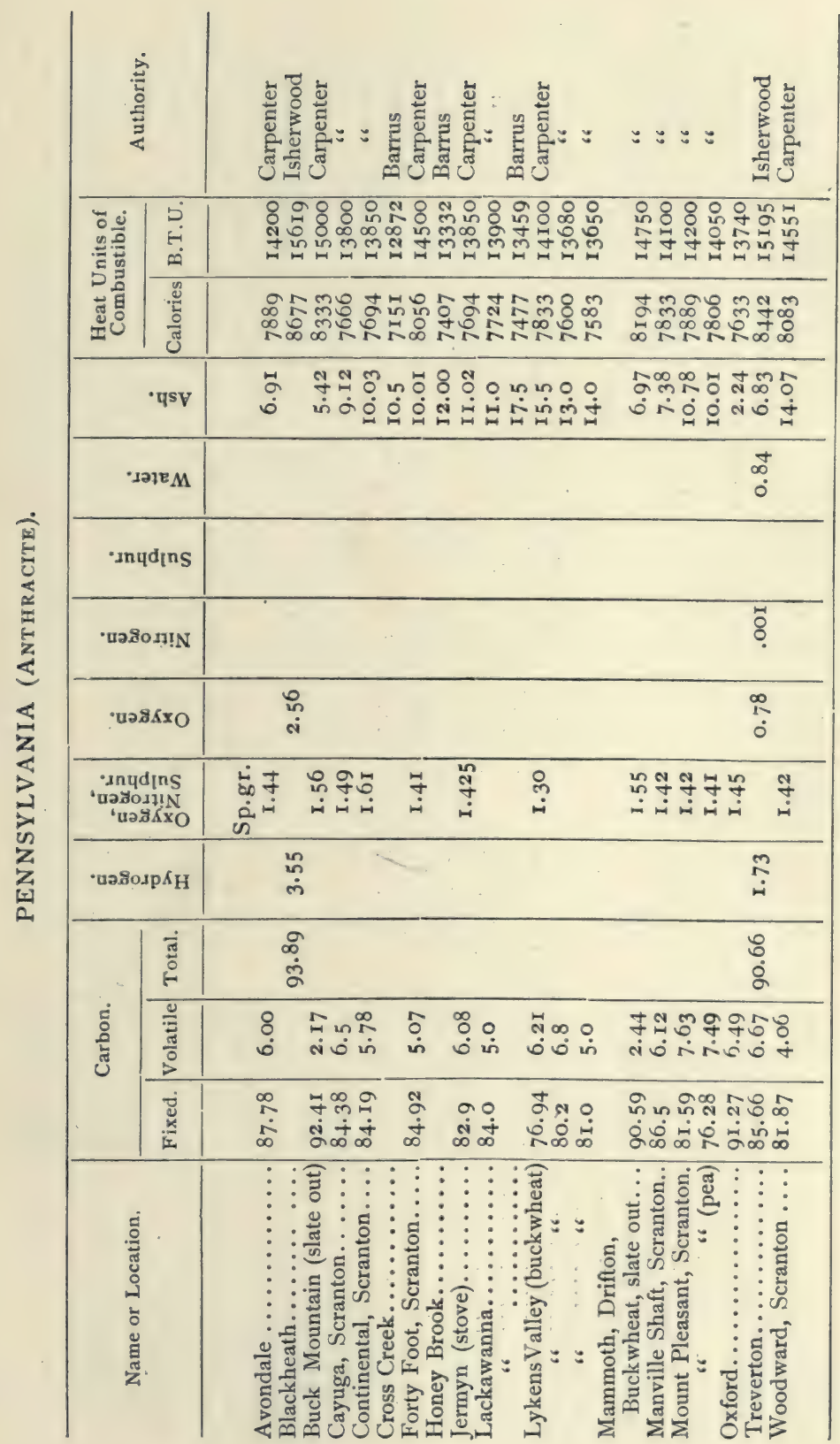




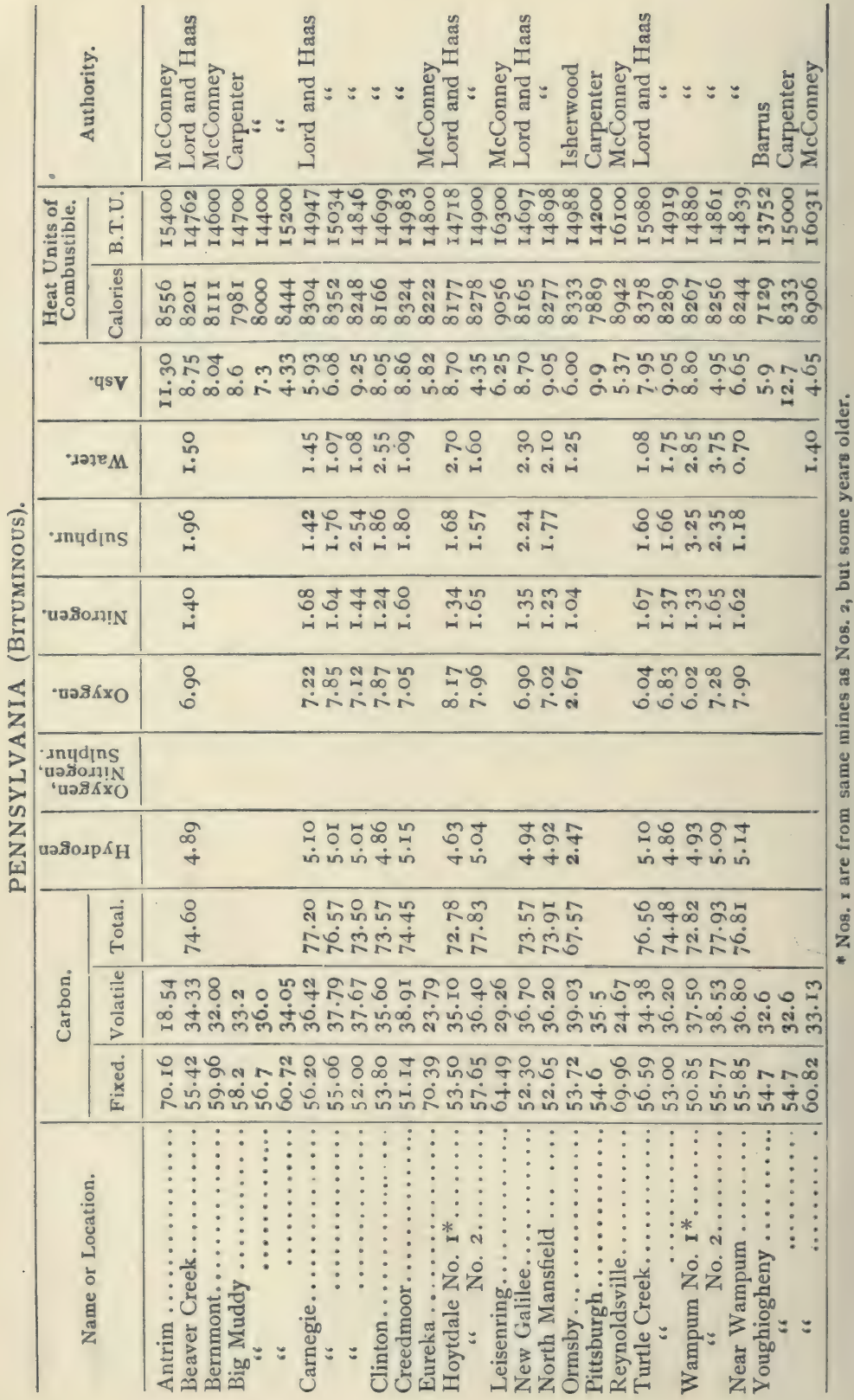


COAL.

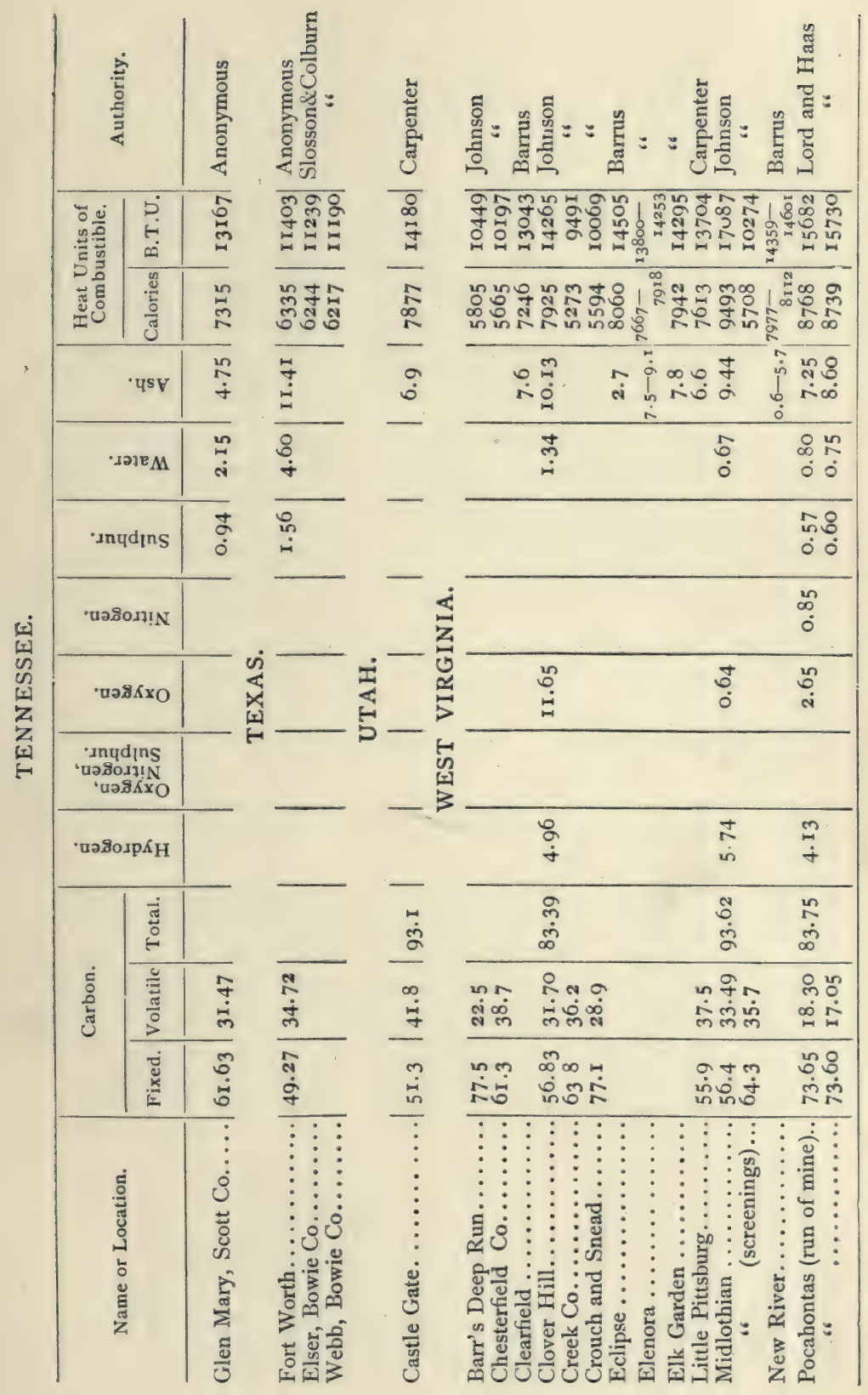




\begin{tabular}{|c|c|c|}
\hline \multicolumn{2}{|c|}{ 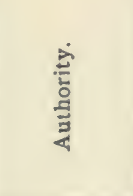 } & 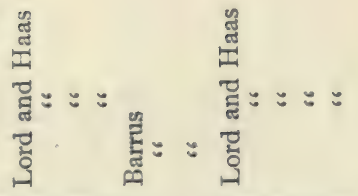 \\
\hline \multirow{2}{*}{ 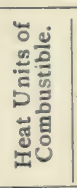 } & $\stackrel{\vec{P}}{\leftrightarrow}$ & \multirow{2}{*}{ 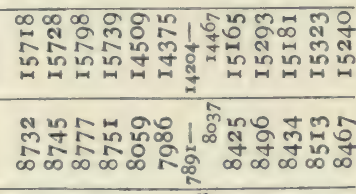 } \\
\hline & 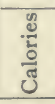 & \\
\hline \multicolumn{2}{|r|}{ पs } & 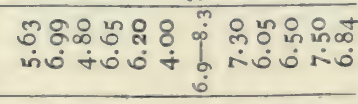 \\
\hline \multicolumn{2}{|c|}{$\cdot{ }^{\cdot}$} & 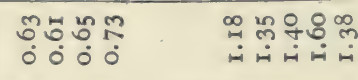 \\
\hline \multicolumn{2}{|c|}{-Inydins } & 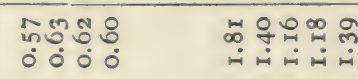 \\
\hline \multicolumn{2}{|c|}{ 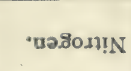 } & $\begin{array}{cc}n & n \\
\infty & \infty \\
0 & 0\end{array}$ \\
\hline \multicolumn{2}{|c|}{ 'บว $8 \mathrm{x} \times \mathrm{O}$} & $\begin{array}{ll}\stackrel{\infty}{o} & \infty \\
\text { तi } & \stackrel{1}{*}\end{array}$ \\
\hline \multicolumn{2}{|c|}{ 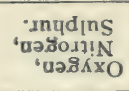 } & \\
\hline \multicolumn{2}{|c|}{ 'นวภัภр $\AA_{H}$} & $\begin{array}{ll}\infty & \stackrel{\text { d }}{\infty} \\
\stackrel{+}{+} & +\end{array}$ \\
\hline \multirow{3}{*}{ 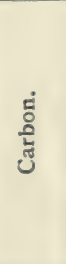 } & 悹 & $\begin{array}{l}\stackrel{0}{+} \underset{+}{\dot{n}} \\
\dot{n} \\
\infty\end{array}$ \\
\hline & $\frac{0}{\pi}$ & 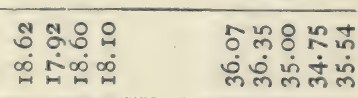 \\
\hline & 它 & 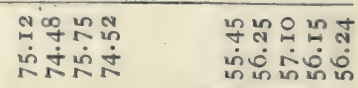 \\
\hline \multicolumn{2}{|c|}{ 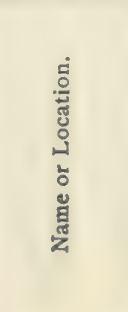 } & 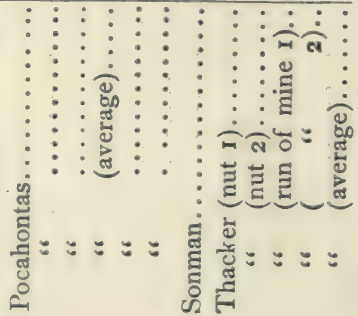 \\
\hline
\end{tabular}

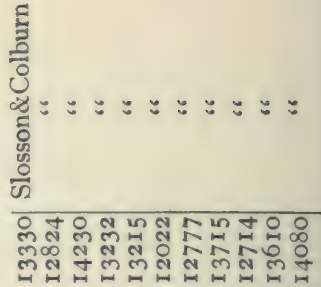

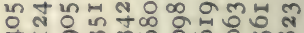

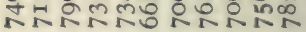

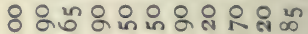
ó ம்

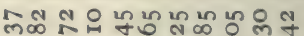
ர்

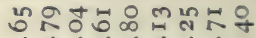

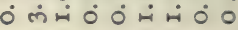

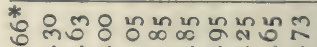

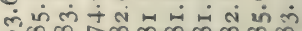
$\infty \omega \infty \pi \infty \infty \infty \infty \infty \infty \infty \infty \infty)$ $\infty$ ณ

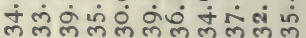

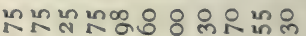

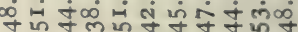

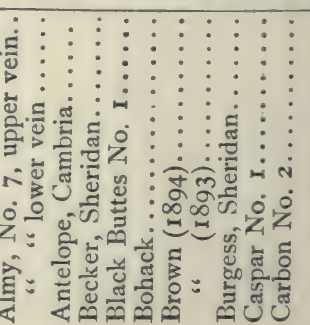




\begin{tabular}{|c|c|c|}
\hline \multicolumn{2}{|c|}{ 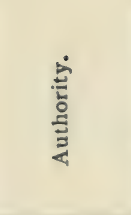 } & 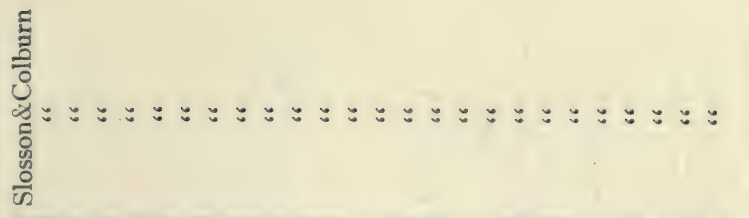 \\
\hline \multirow{2}{*}{ 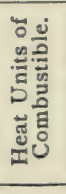 } & $\underset{:}{\stackrel{\leftrightarrow}{\leftrightarrow}}$ & 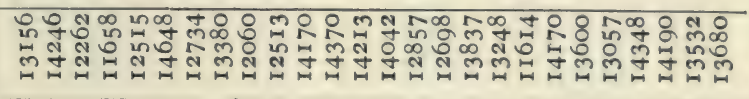 \\
\hline & iั้ & 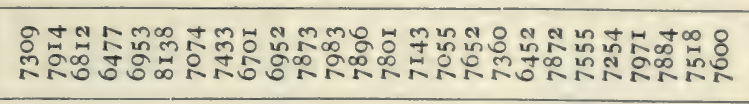 \\
\hline & पs & 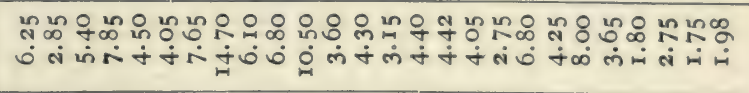 \\
\hline \multicolumn{2}{|c|}{$\cdot{ }^{-}$} & 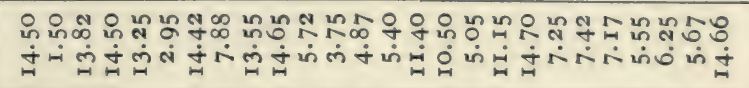 \\
\hline \multicolumn{2}{|c|}{ 'mudins } & 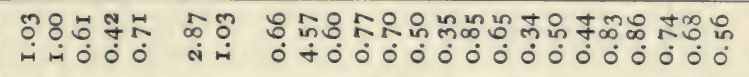 \\
\hline \multicolumn{2}{|c|}{ 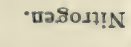 } & \\
\hline \multicolumn{2}{|c|}{ 'บขรณ $x_{0}$} & \\
\hline \multicolumn{2}{|c|}{ 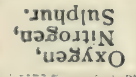 } & \\
\hline \multicolumn{2}{|c|}{ 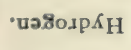 } & \\
\hline \multirow{3}{*}{ 㐫 } & ङึं & 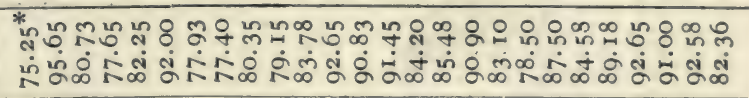 \\
\hline & 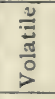 & 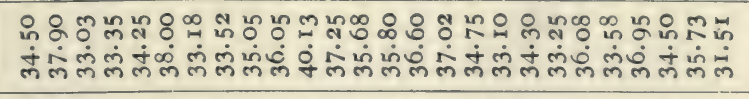 \\
\hline & 递 & 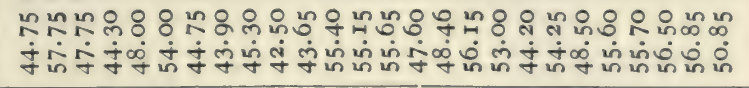 \\
\hline \multicolumn{2}{|c|}{ 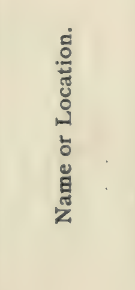 } & 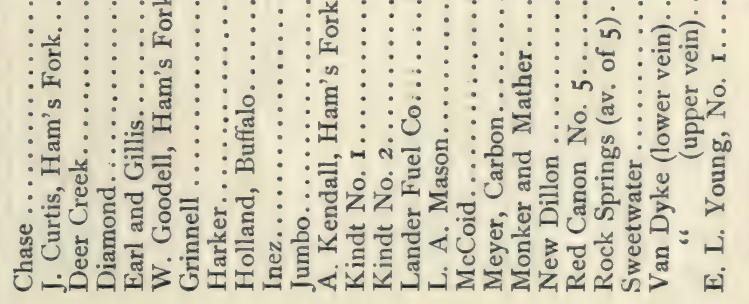 \\
\hline
\end{tabular}




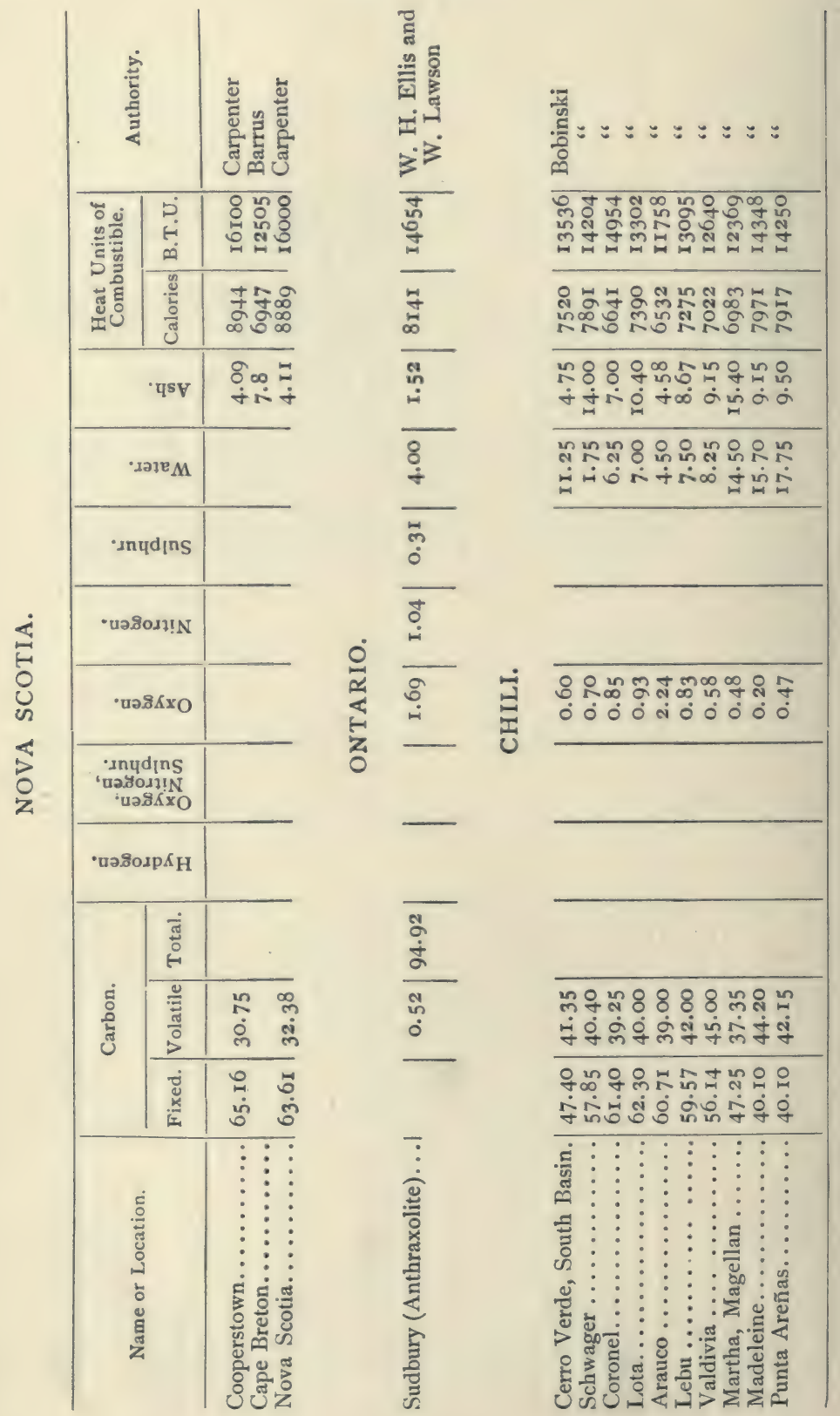


COAL.

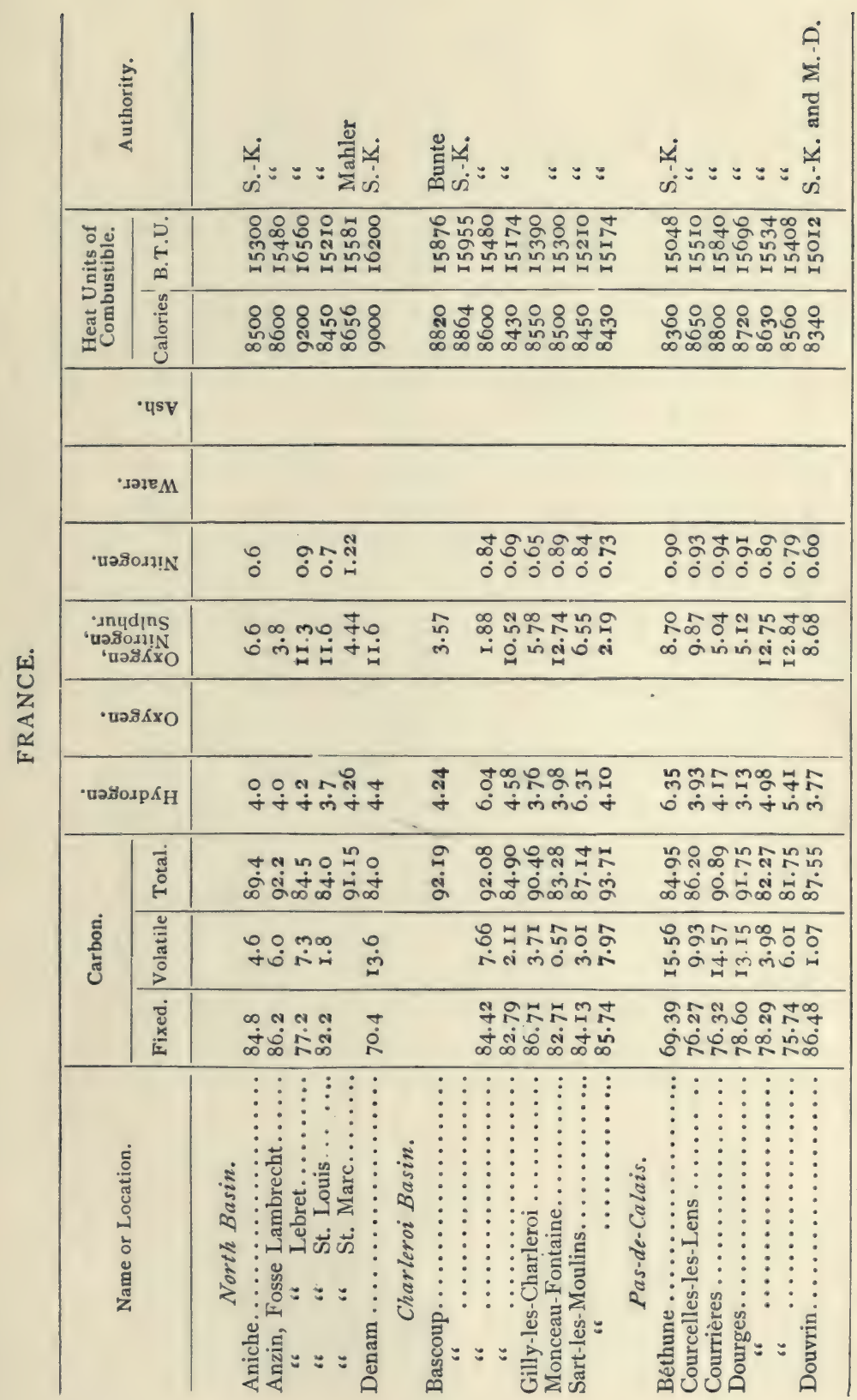




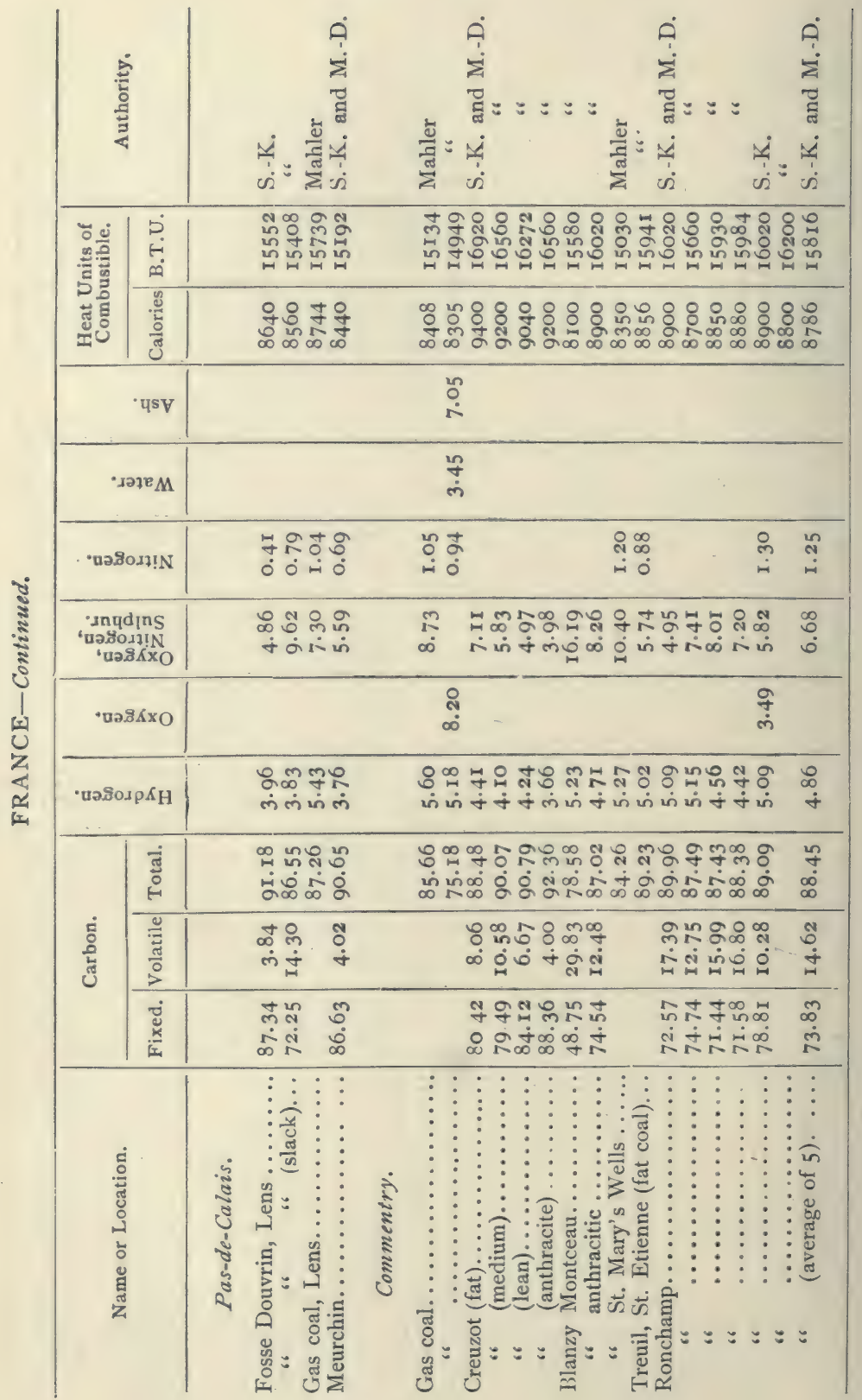


COAL.

\begin{tabular}{|c|c|c|c|c|}
\hline 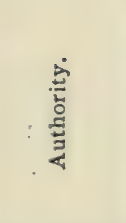 & 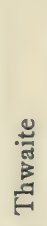 & 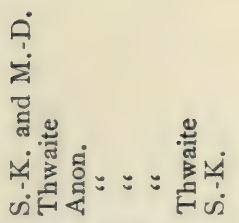 & 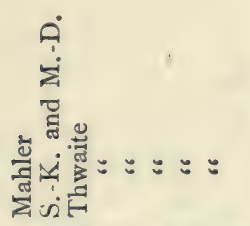 & 总 \\
\hline$\stackrel{\leftrightarrow}{\dot{\infty}}$ & $\begin{array}{l}\delta_{0} \\
\vdots \\
\end{array}$ & 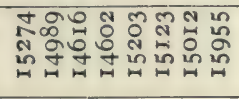 & 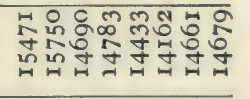 & 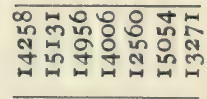 \\
\hline نु & $\stackrel{\infty}{N}$ & 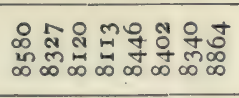 & 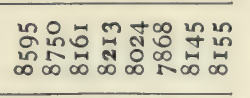 & 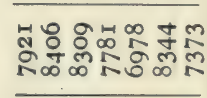 \\
\hline$\cdot$. ISY & $\stackrel{\text { Q }}{\text { i }}$ & 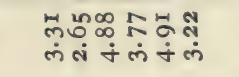 & 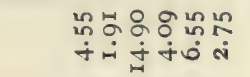 & \\
\hline${ }^{-1 ә \jmath \varepsilon_{M}}$ & $\stackrel{\circ}{\dot{q}}$ & ్ㅜ용 & 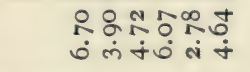 & $\stackrel{\circ}{\dddot{7}}$ \\
\hline -mydins & $\stackrel{\circ}{\circ}$ & 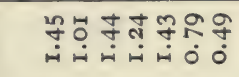 & 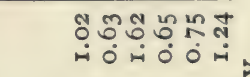 & 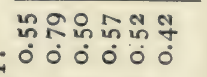 \\
\hline 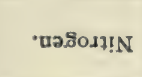 & $\stackrel{\circ}{\text { in }}$ & 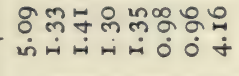 & & 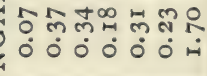 \\
\hline ' แә $8<\times O$ & 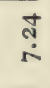 & 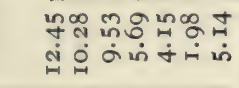 & 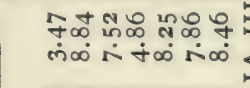 & \\
\hline - uəภిం $\lrcorner \kappa_{H}$ & $\stackrel{\circ}{\circ}$ & 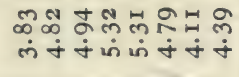 & 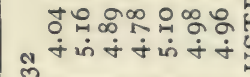 & 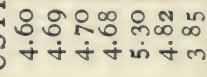 \\
\hline స్ & חू & 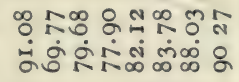 & 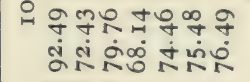 & 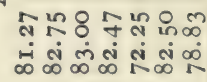 \\
\hline ֻँّ & ஷे & 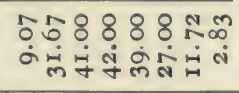 & 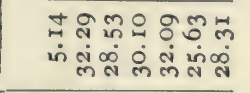 & \\
\hline 崖 & $\begin{array}{l}\infty \\
\infty \\
\text { ஸ் }\end{array}$ & 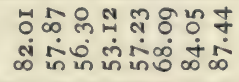 & 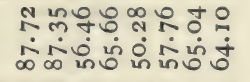 & \\
\hline 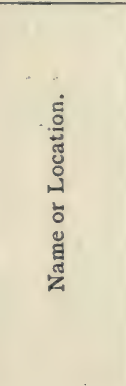 & 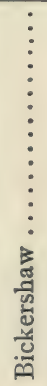 & 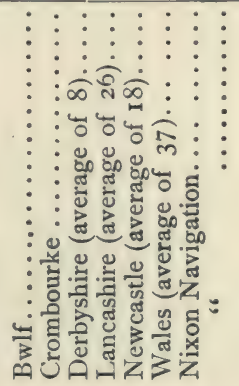 & 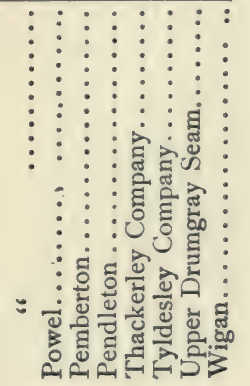 & 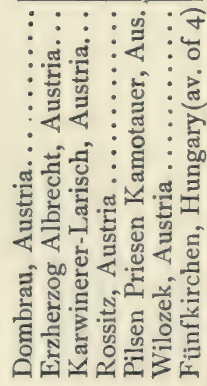 \\
\hline
\end{tabular}




\begin{tabular}{|c|c|c|c|}
\hline 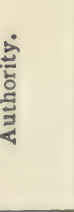 & 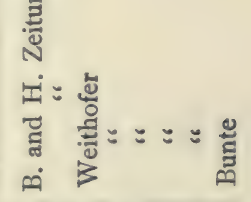 & 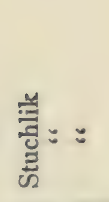 & 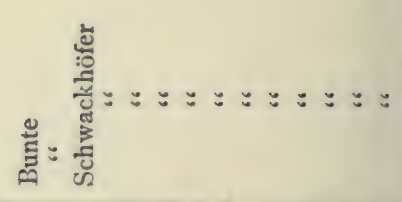 \\
\hline$\underset{⿱ ㇒ 㠯}{\stackrel{S}{:}}$ & 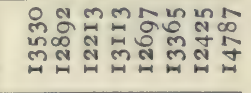 & 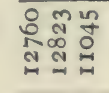 & 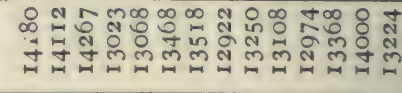 \\
\hline 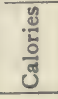 & 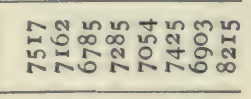 & 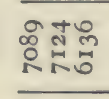 & 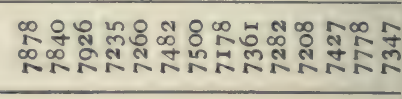 \\
\hline - usv & 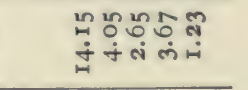 & \multicolumn{2}{|l|}{ 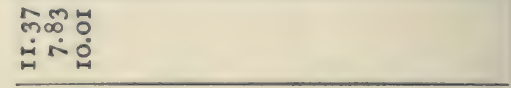 } \\
\hline${ }^{1 \supset \jmath} \mathbb{E}_{M}$ & 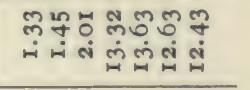 & \multicolumn{2}{|l|}{ 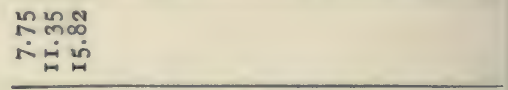 } \\
\hline nudins & $\stackrel{\text { N }}{\stackrel{2}{+}}$ & & 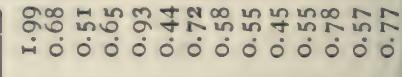 \\
\hline มింn! & मูं & & 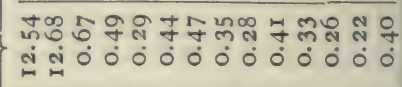 \\
\hline 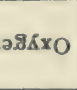 & 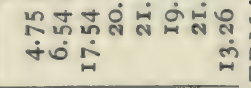 & & 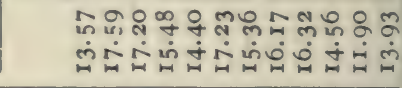 \\
\hline ภింدp $\kappa_{H}$ & 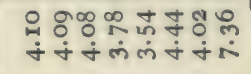 & $\begin{array}{l}\text { भें山ू } \\
\dot{+} \dot{q} \dot{m}\end{array}$ & 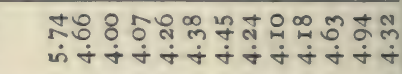 \\
\hline ฮัँ & 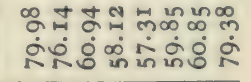 & 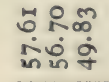 & 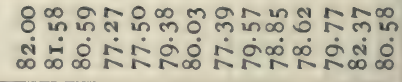 \\
\hline$\stackrel{0}{\frac{\pi}{\pi}}$ & 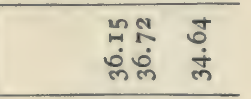 & & \\
\hline 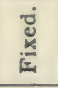 & $\begin{array}{l}\infty 80 \\
\infty \\
0 \\
0 \\
0\end{array}$ & & \\
\hline & 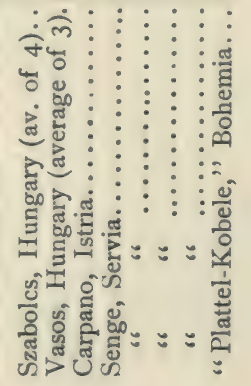 & 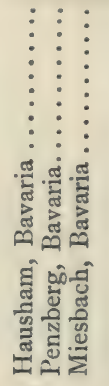 & 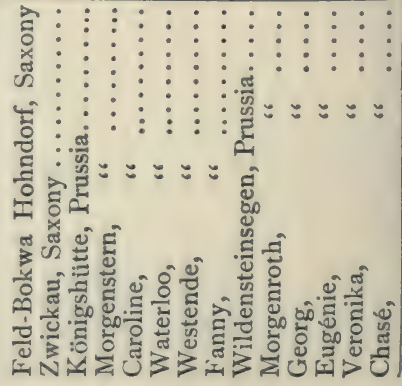 \\
\hline
\end{tabular}


COAL.

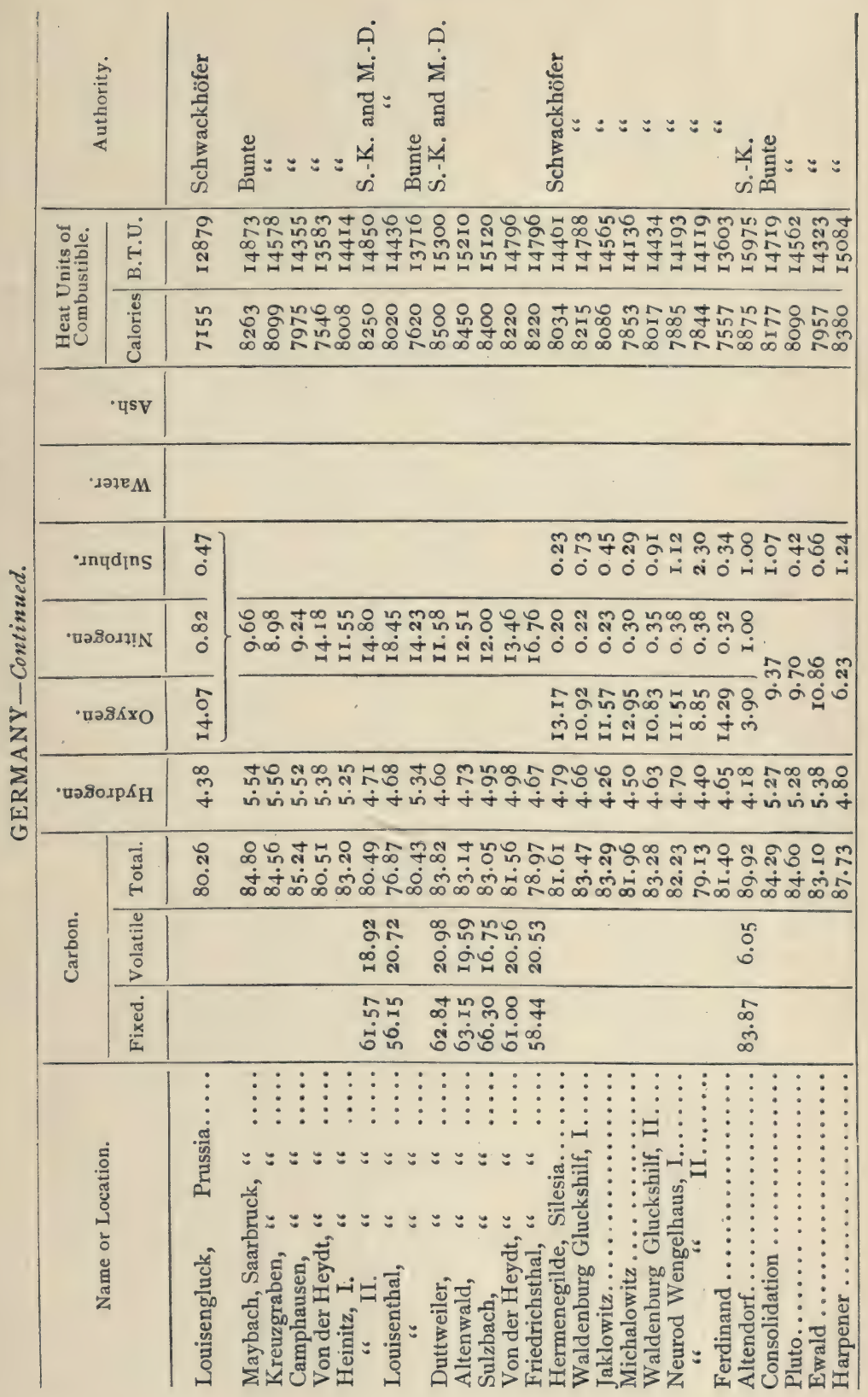




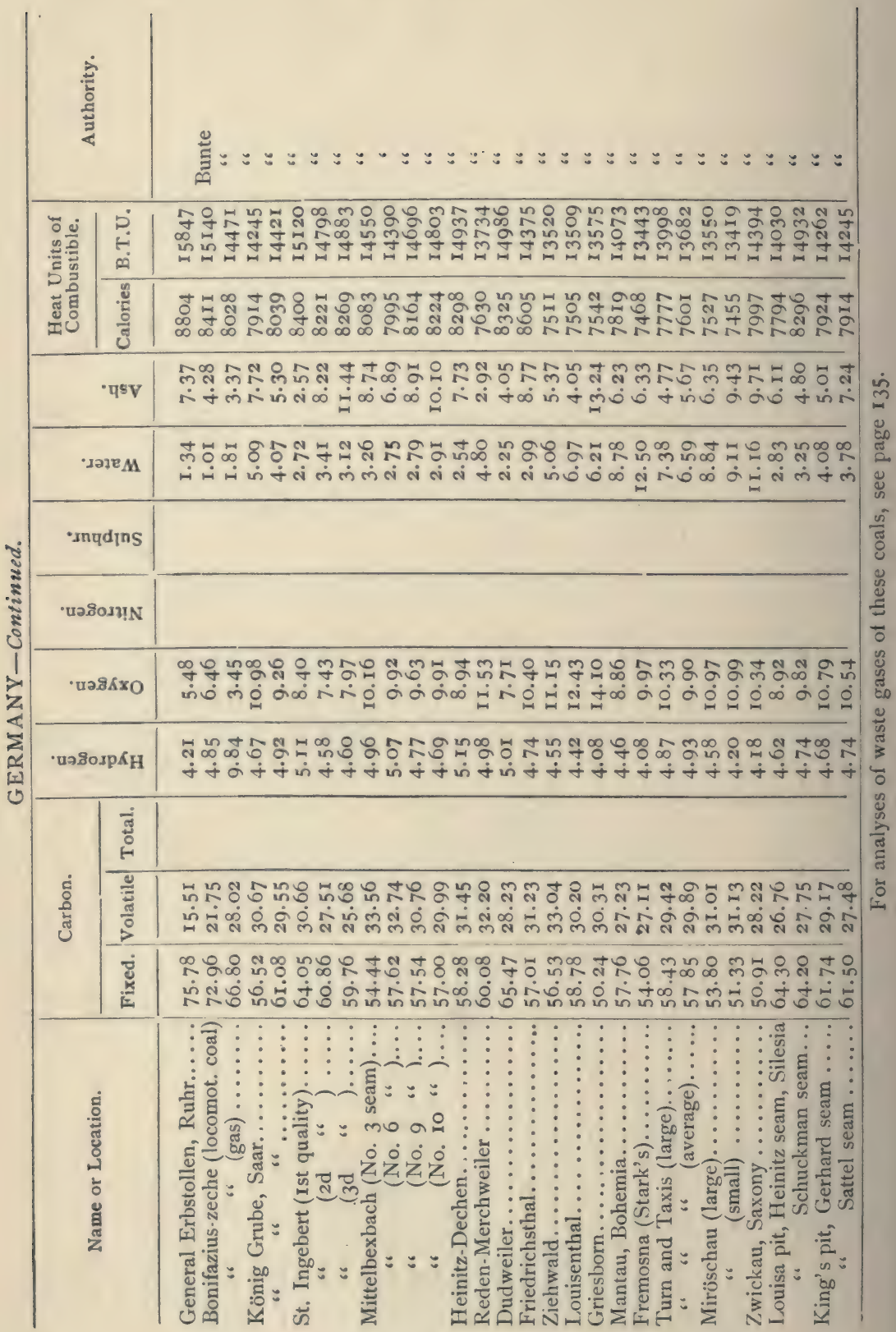


COAL.

\begin{tabular}{|c|c|c|c|}
\hline \multicolumn{2}{|c|}{ 离 } & $\begin{array}{l}\overline{0} \\
\dot{\delta} \\
\dot{\sim}\end{array}$ & 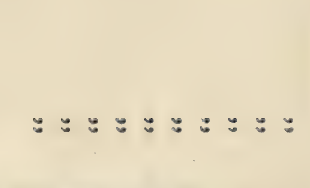 \\
\hline \multirow{2}{*}{ 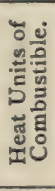 } & $\stackrel{\leftrightarrow:}{\leftrightarrow}$ & 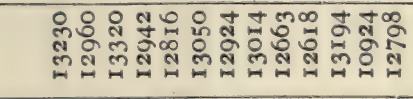 & 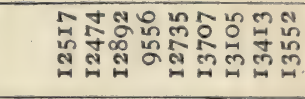 \\
\hline & हु & 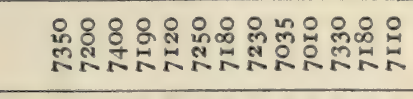 & 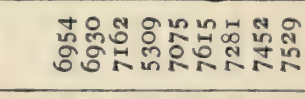 \\
\hline \multicolumn{2}{|c|}{$\cdot \varphi s \mathrm{~s}$} & 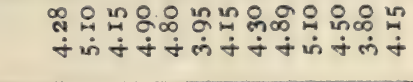 & 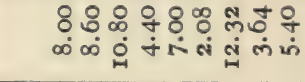 \\
\hline \multicolumn{2}{|c|}{ - дәэе } & & \\
\hline \multicolumn{2}{|c|}{-Inydins } & & \\
\hline \multicolumn{2}{|c|}{ 'บอภิอนท! } & & \\
\hline \multicolumn{2}{|c|}{ แอภ $\mathrm{x} \times \mathrm{O}$} & & \\
\hline \multicolumn{2}{|c|}{ 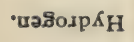 } & & \\
\hline \multirow{3}{*}{ 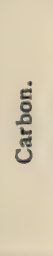 } & लें & & \\
\hline & $\stackrel{0}{\frac{0}{\pi}}$ & @ mo & 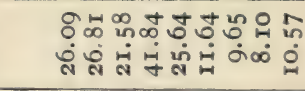 \\
\hline & 岕 & 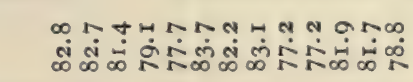 & 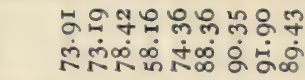 \\
\hline \multicolumn{2}{|c|}{ 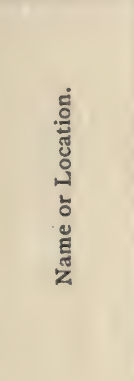 } & 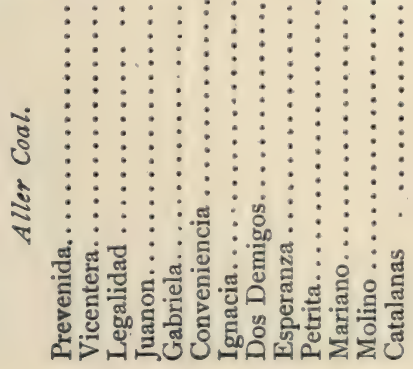 & 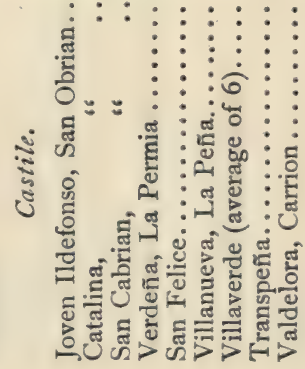 \\
\hline
\end{tabular}


FUEL TABLES.

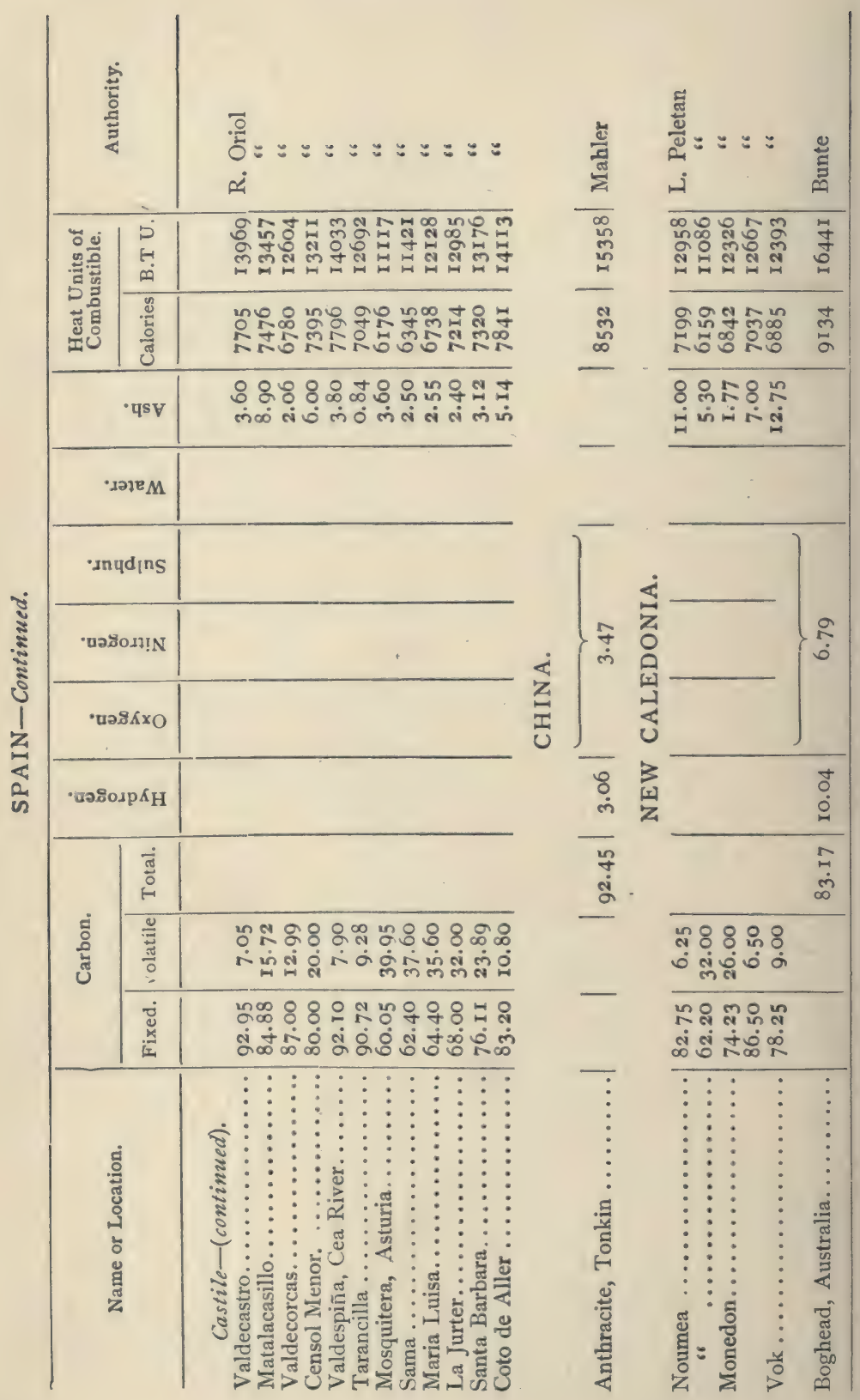


COAL.

\begin{tabular}{|c|c|c|c|c|}
\hline \multicolumn{2}{|c|}{ 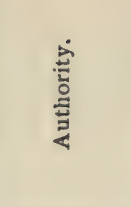 } & 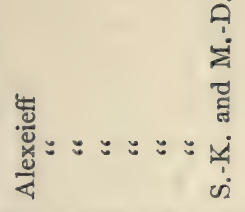 & 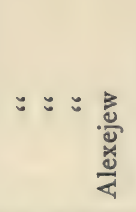 & 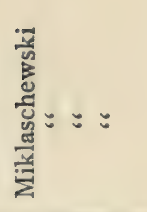 \\
\hline \multirow{2}{*}{ 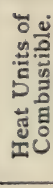 } & Pُ & 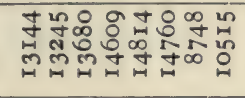 & 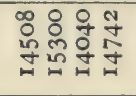 & 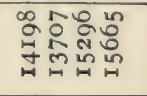 \\
\hline & 总 & 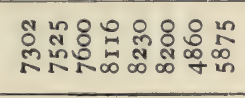 & 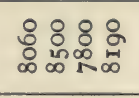 & $\begin{array}{l}\infty \\
\infty \\
\infty \\
\infty \\
\infty \\
1\end{array}$ \\
\hline & - पs & & & 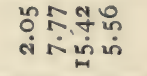 \\
\hline \multicolumn{2}{|c|}{$\cdot{ }^{-1 \partial \jmath e_{M}}$} & & & 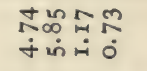 \\
\hline \multicolumn{2}{|c|}{ - Inqdins } & & & 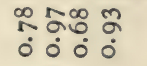 \\
\hline \multicolumn{2}{|c|}{ "นวรింมไ! } & 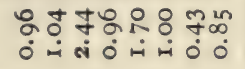 & 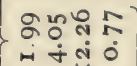 & \\
\hline \multicolumn{2}{|c|}{. } & 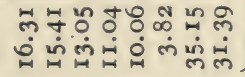 & 少 & \\
\hline \multicolumn{2}{|c|}{ - } & 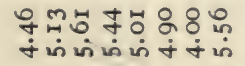 & $\begin{array}{l}\text { బூ융ㅇㅇ } \\
\dot{\sim} \dot{+} \text { in }\end{array}$ & 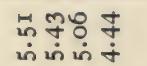 \\
\hline \multirow{3}{*}{ نี } & 范 & 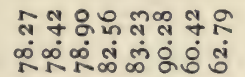 & 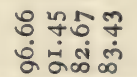 & 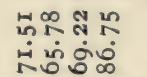 \\
\hline & 퓽 & & ํํำ & 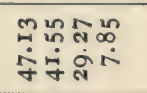 \\
\hline & 芯 & & 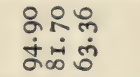 & \\
\hline \multicolumn{2}{|c|}{ 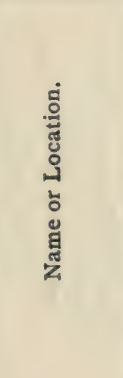 } & 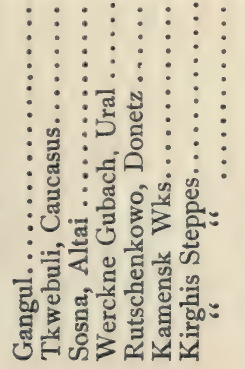 & 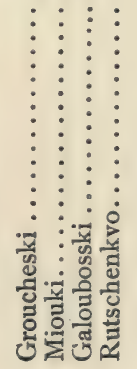 & 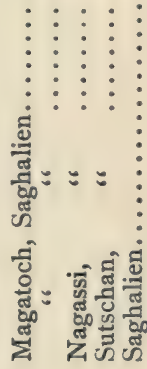 \\
\hline
\end{tabular}




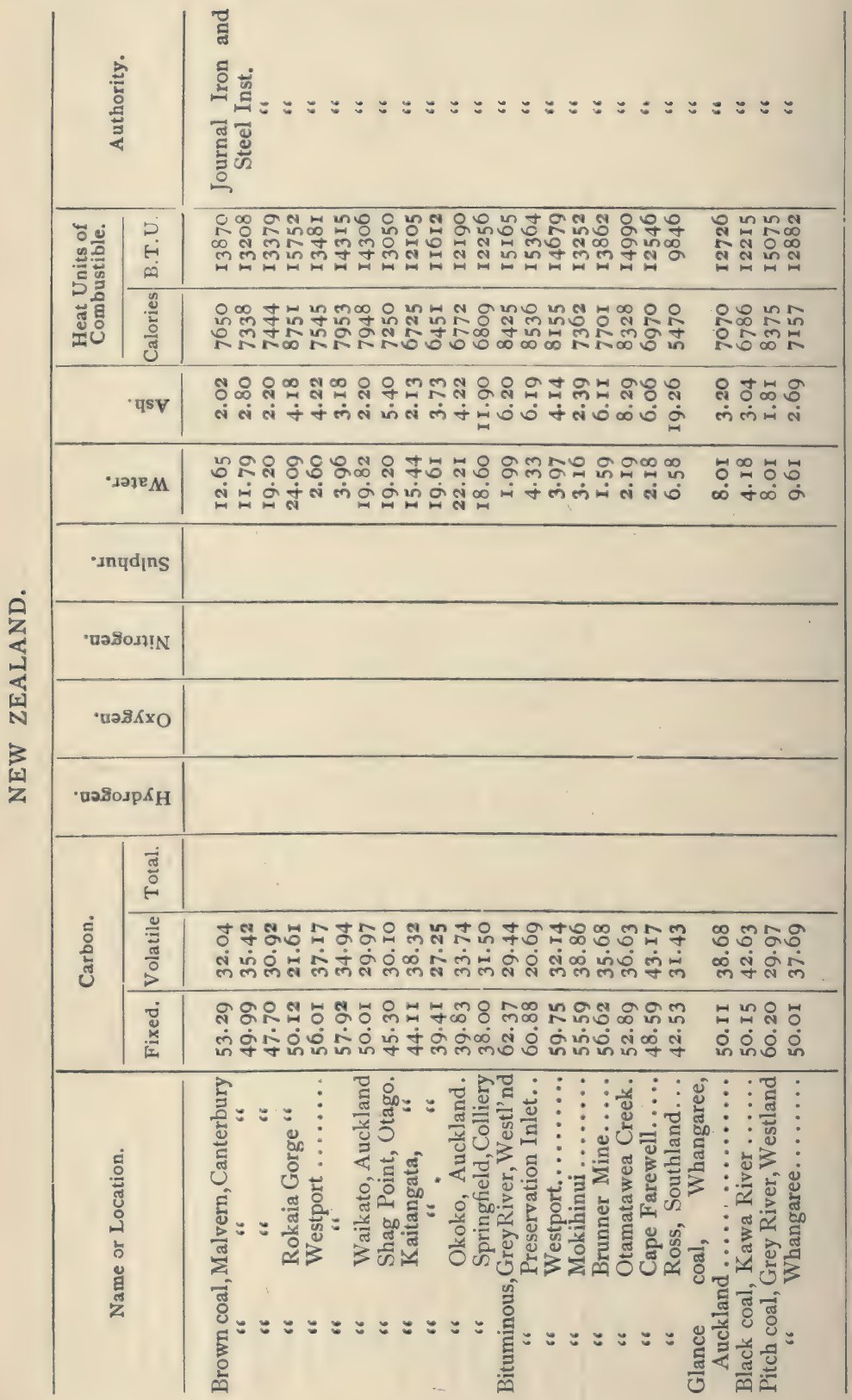



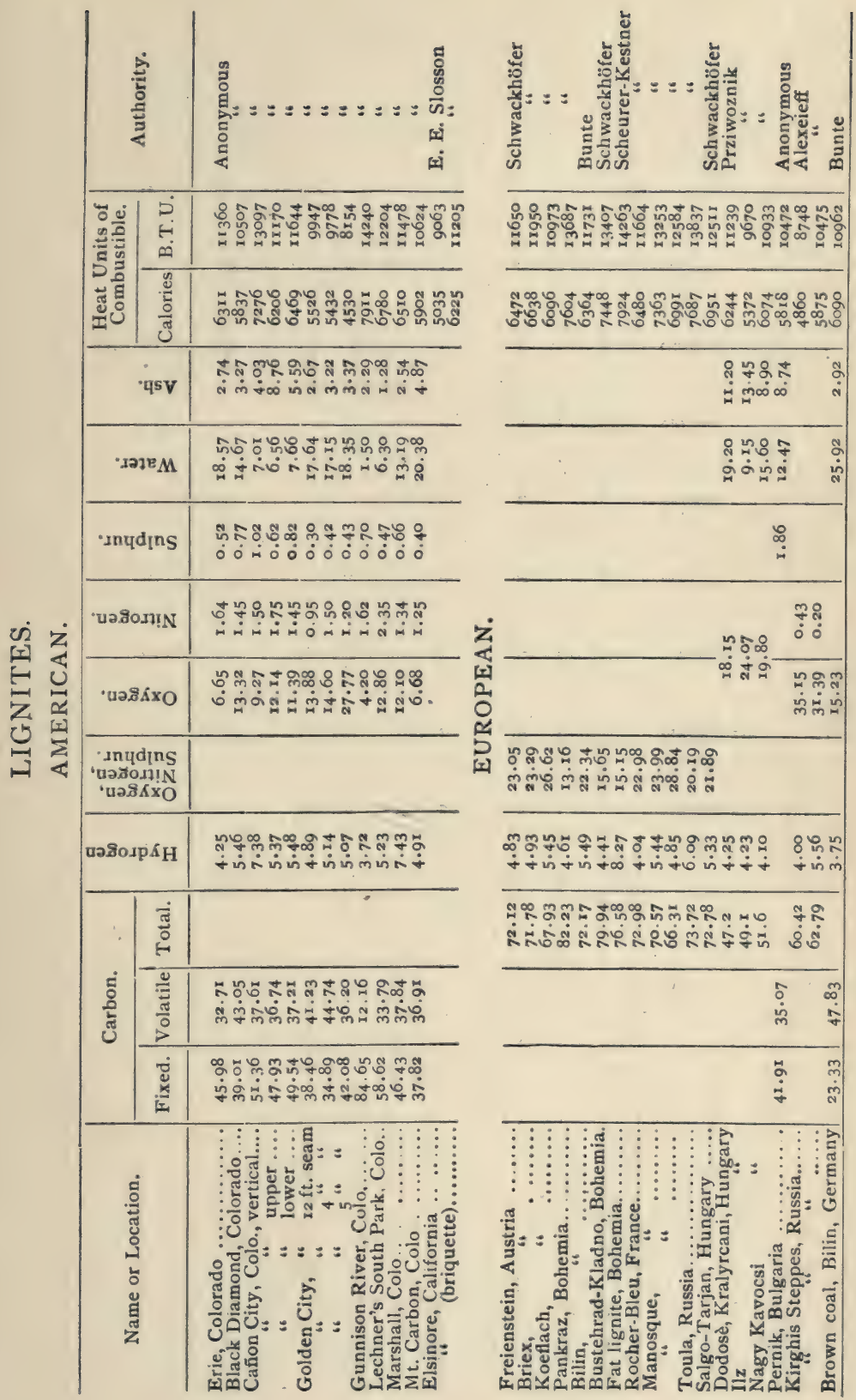

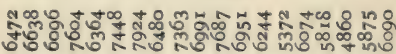

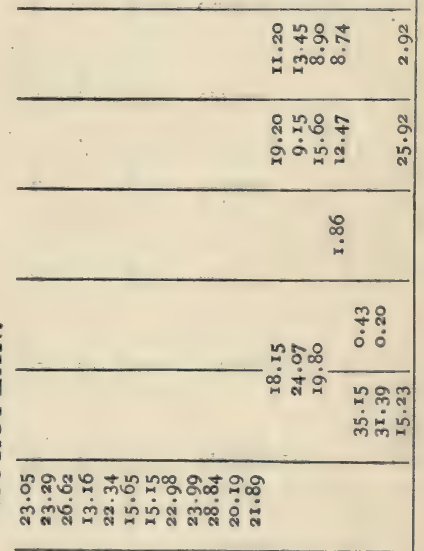

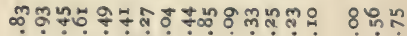

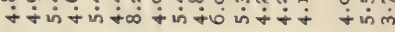

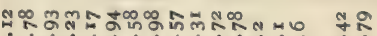

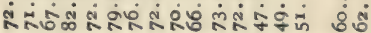

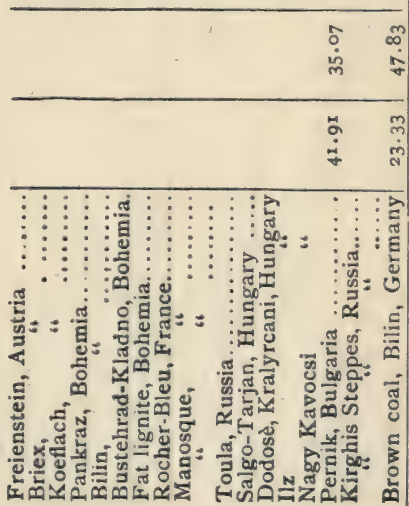


FUEL TABLES.

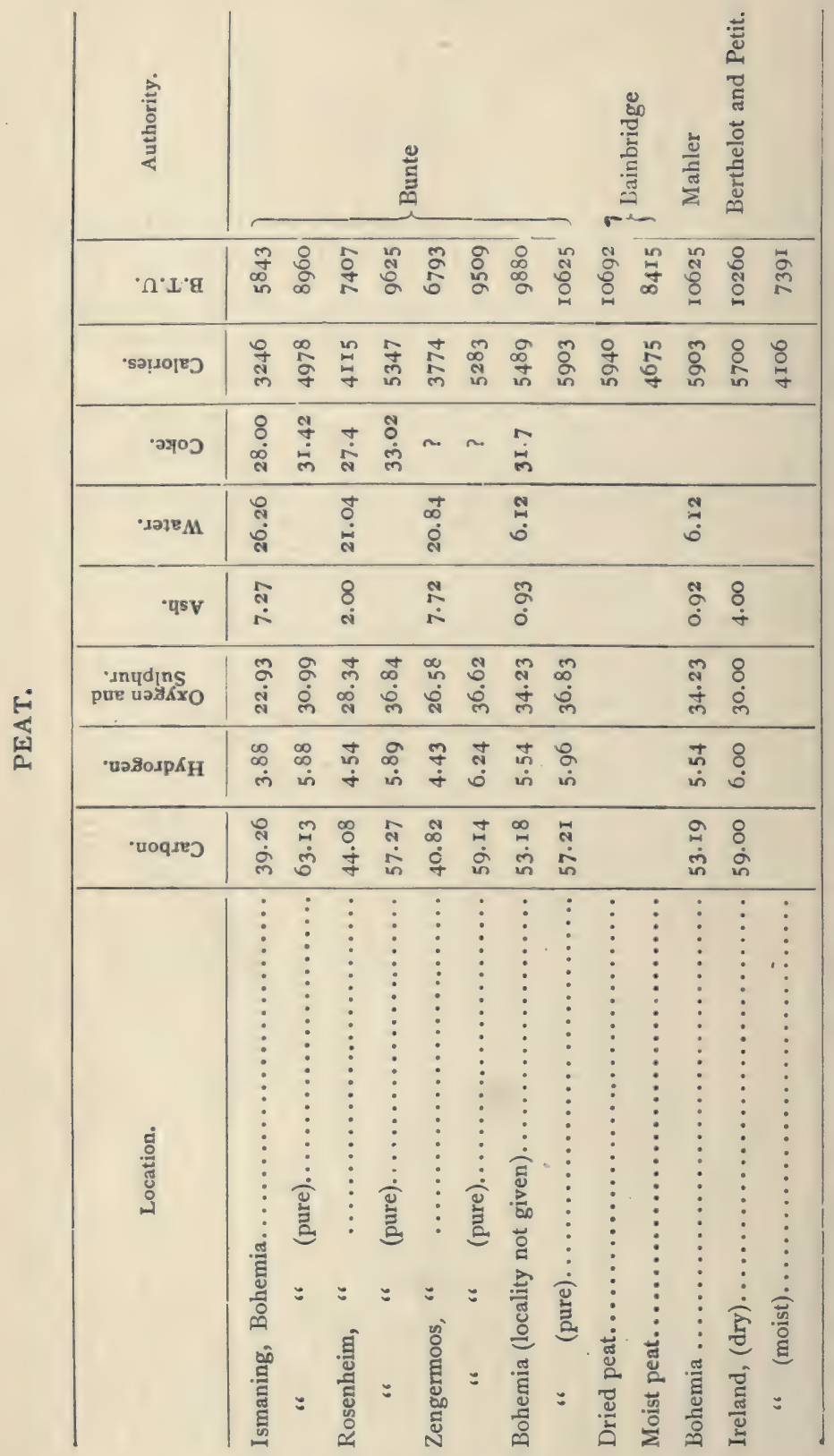


WOOD.

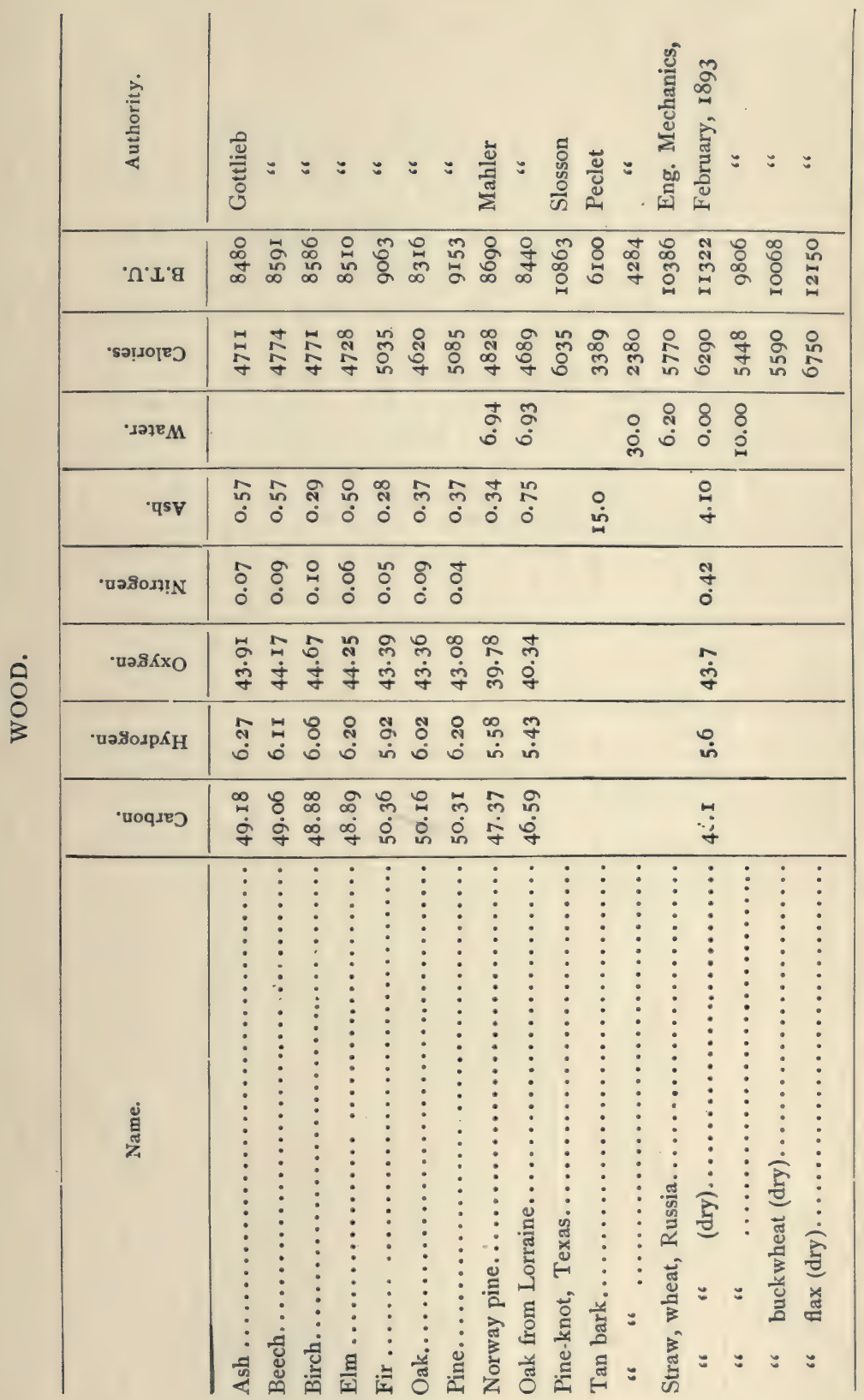




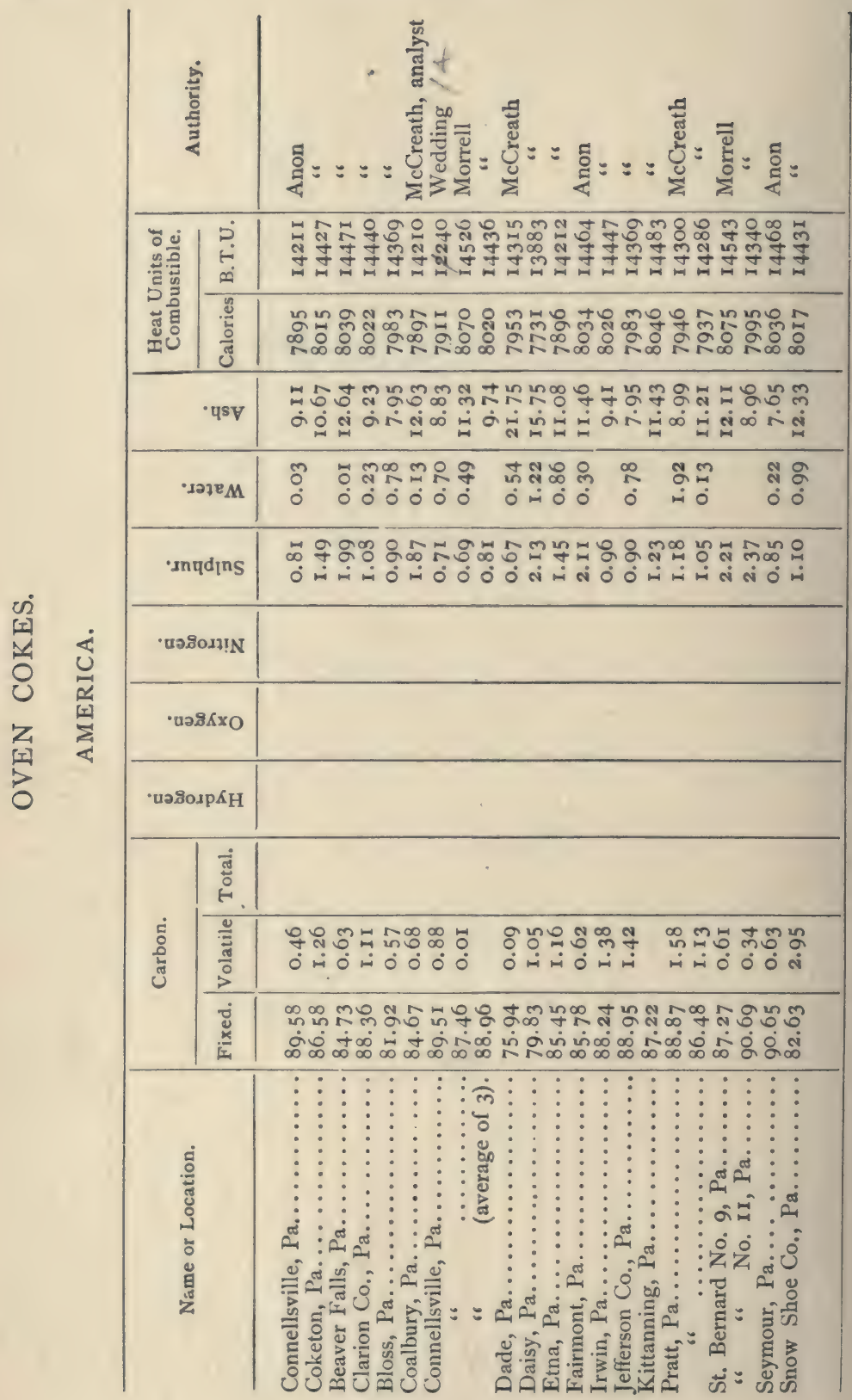


OVEN COKES.

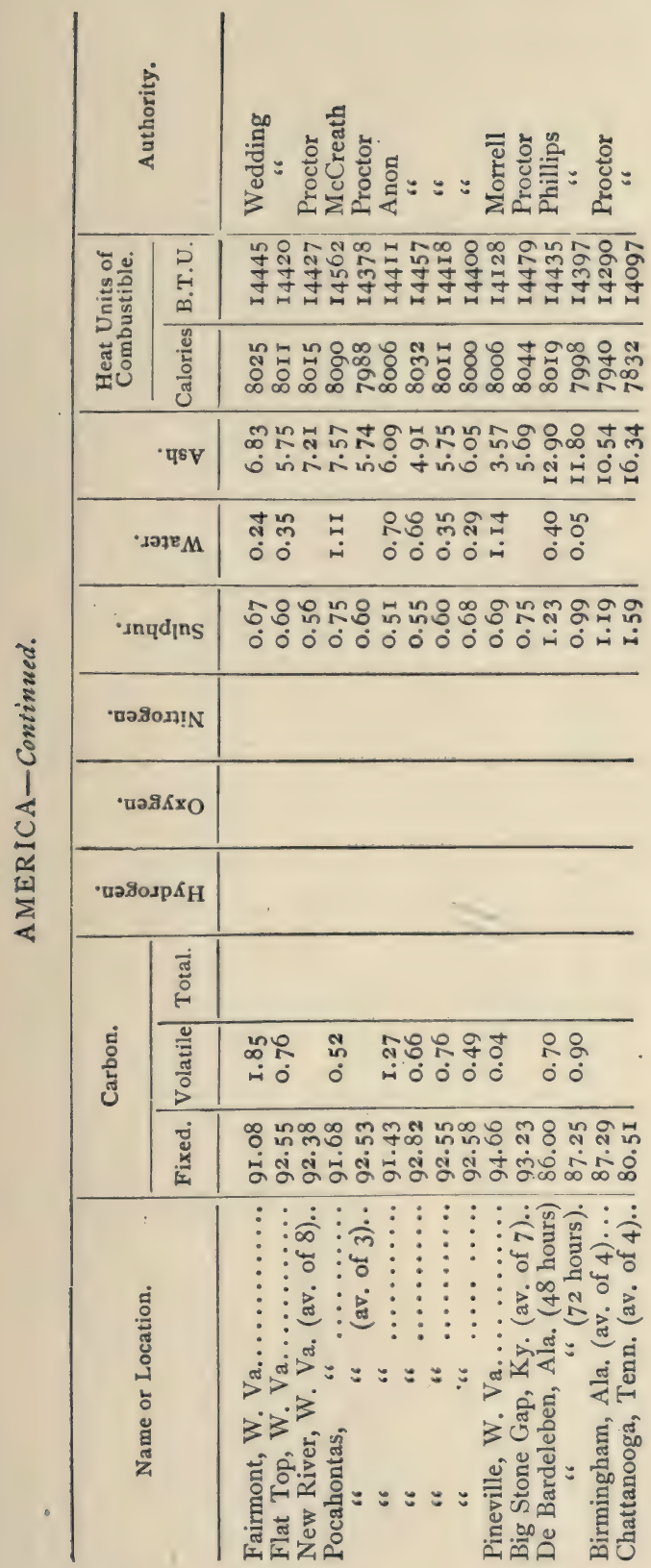

苛: :

กํㅇㅇㅇㅇ윻

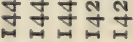

융형유유

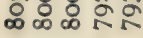

영여 용

ம் $\dot{\text { मे }}$

กั กั ำ

ख্

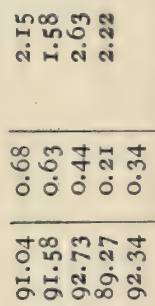

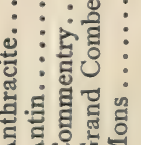


FUEL TABLES.

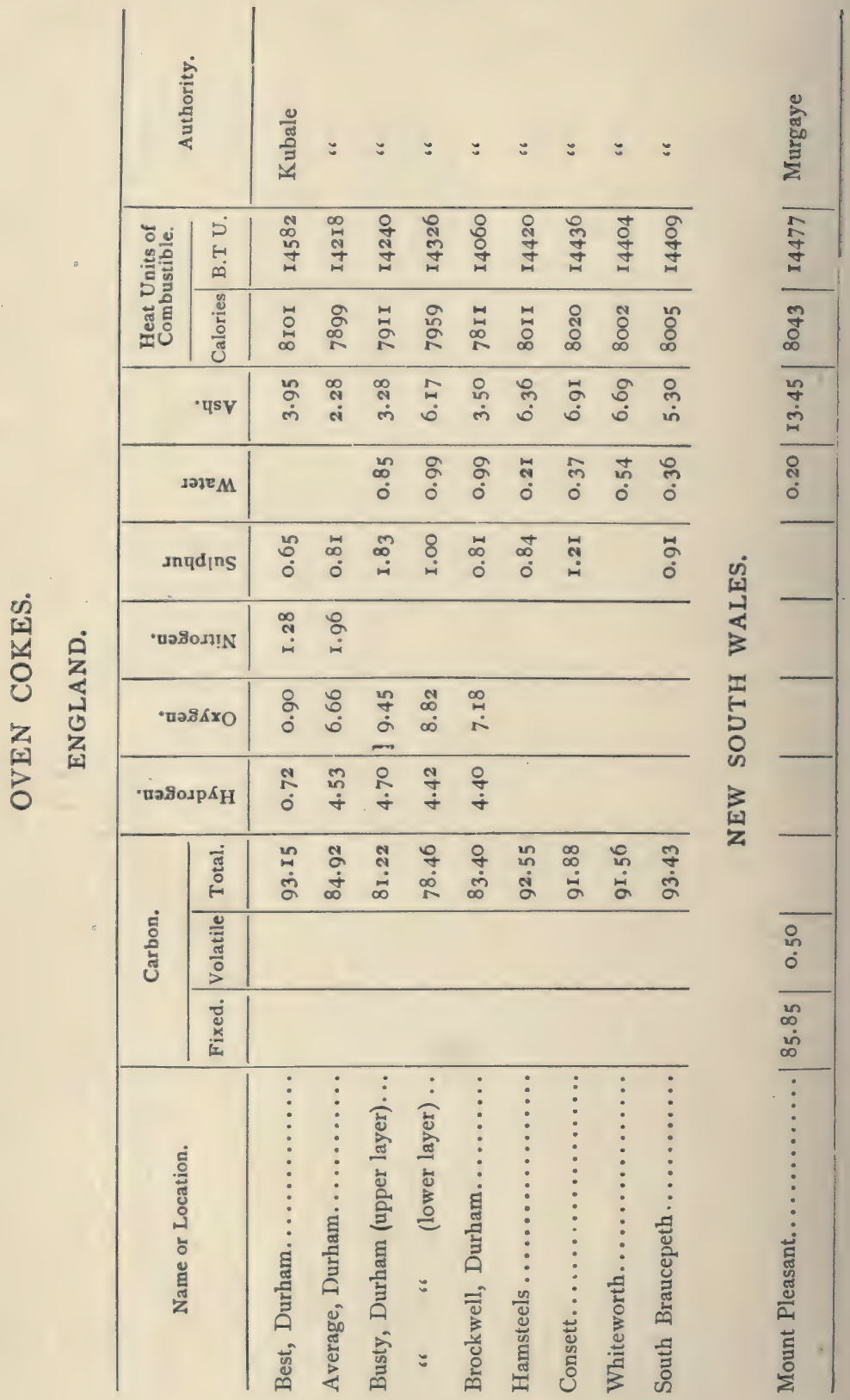


GAS COKES.

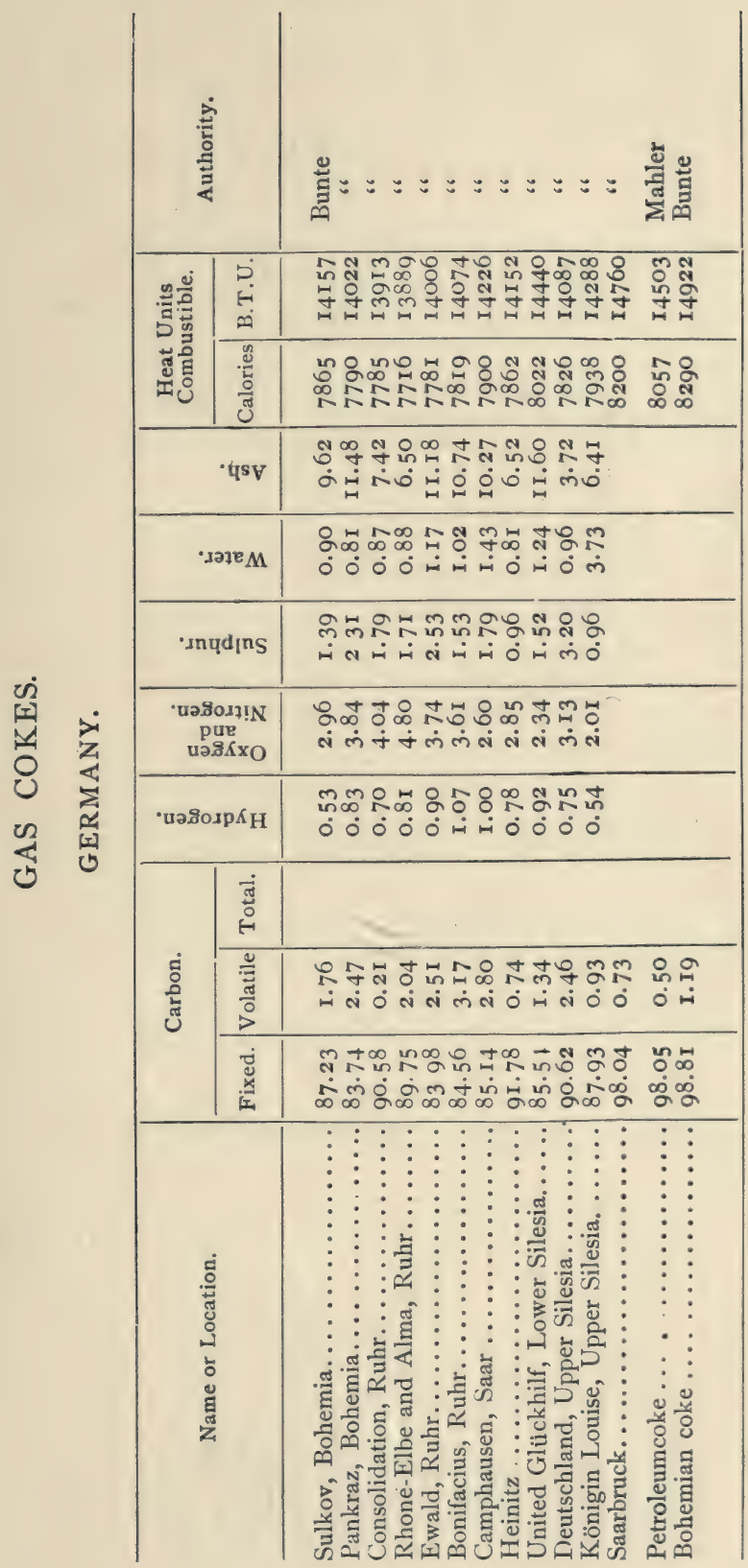




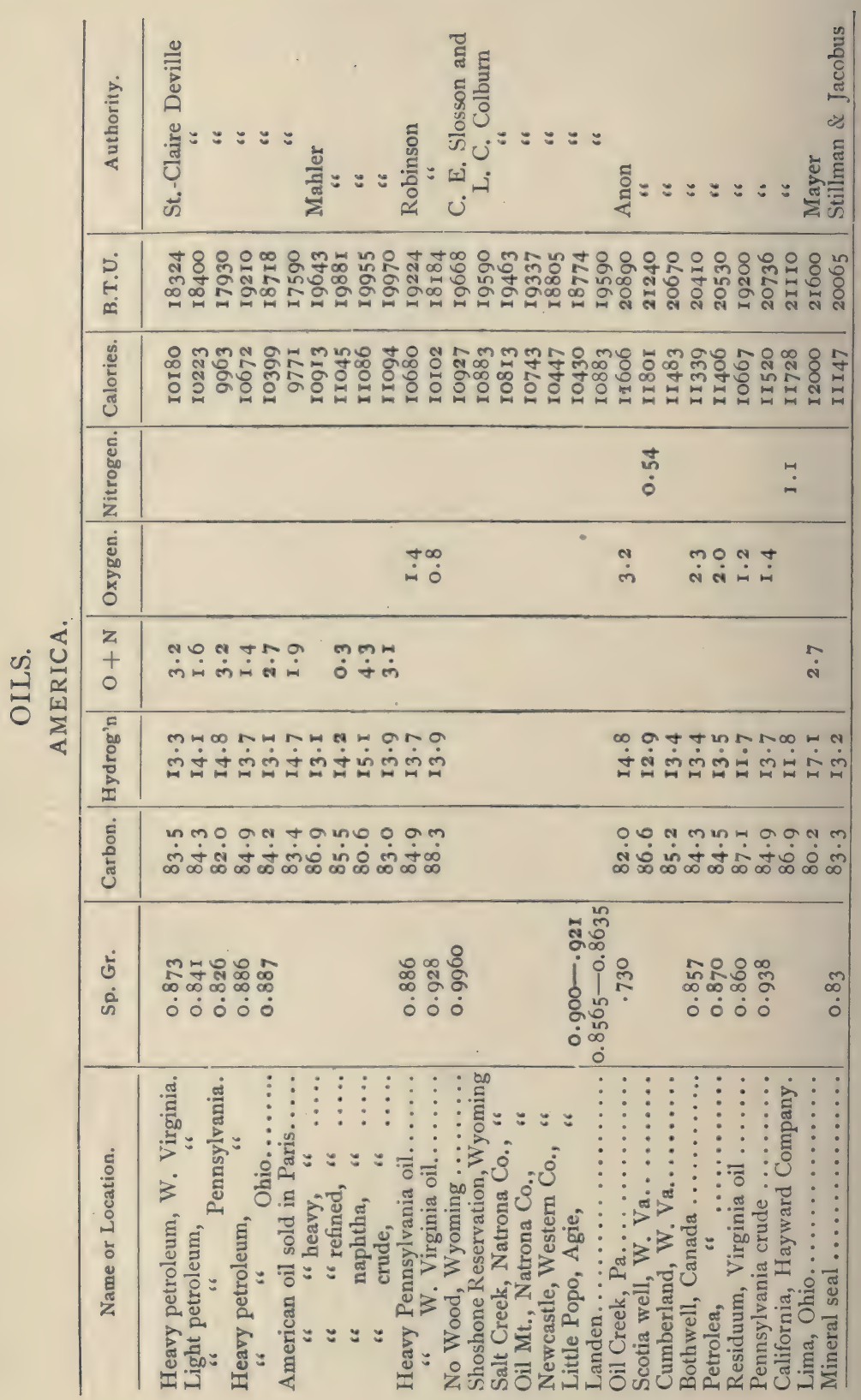


OILS.

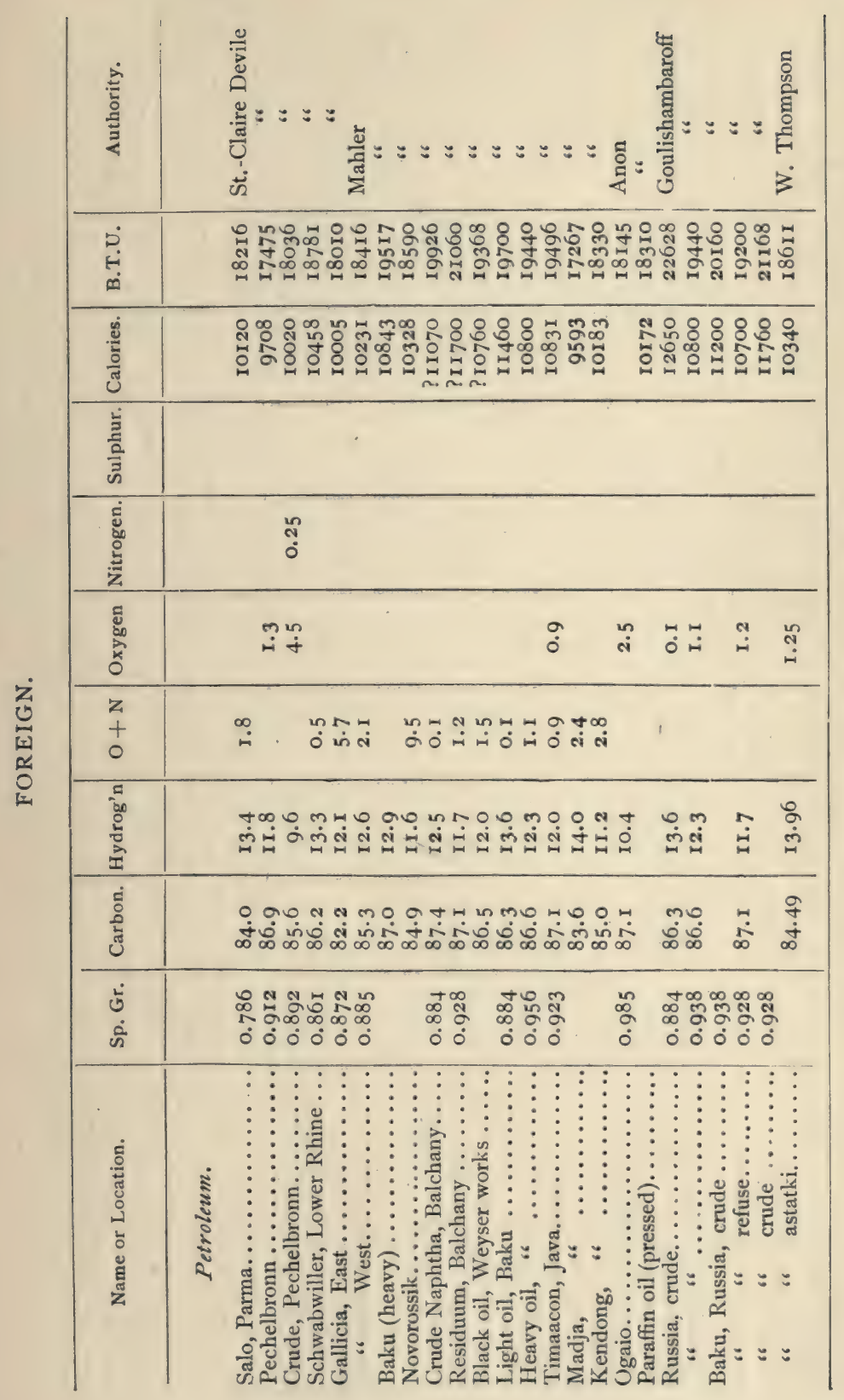




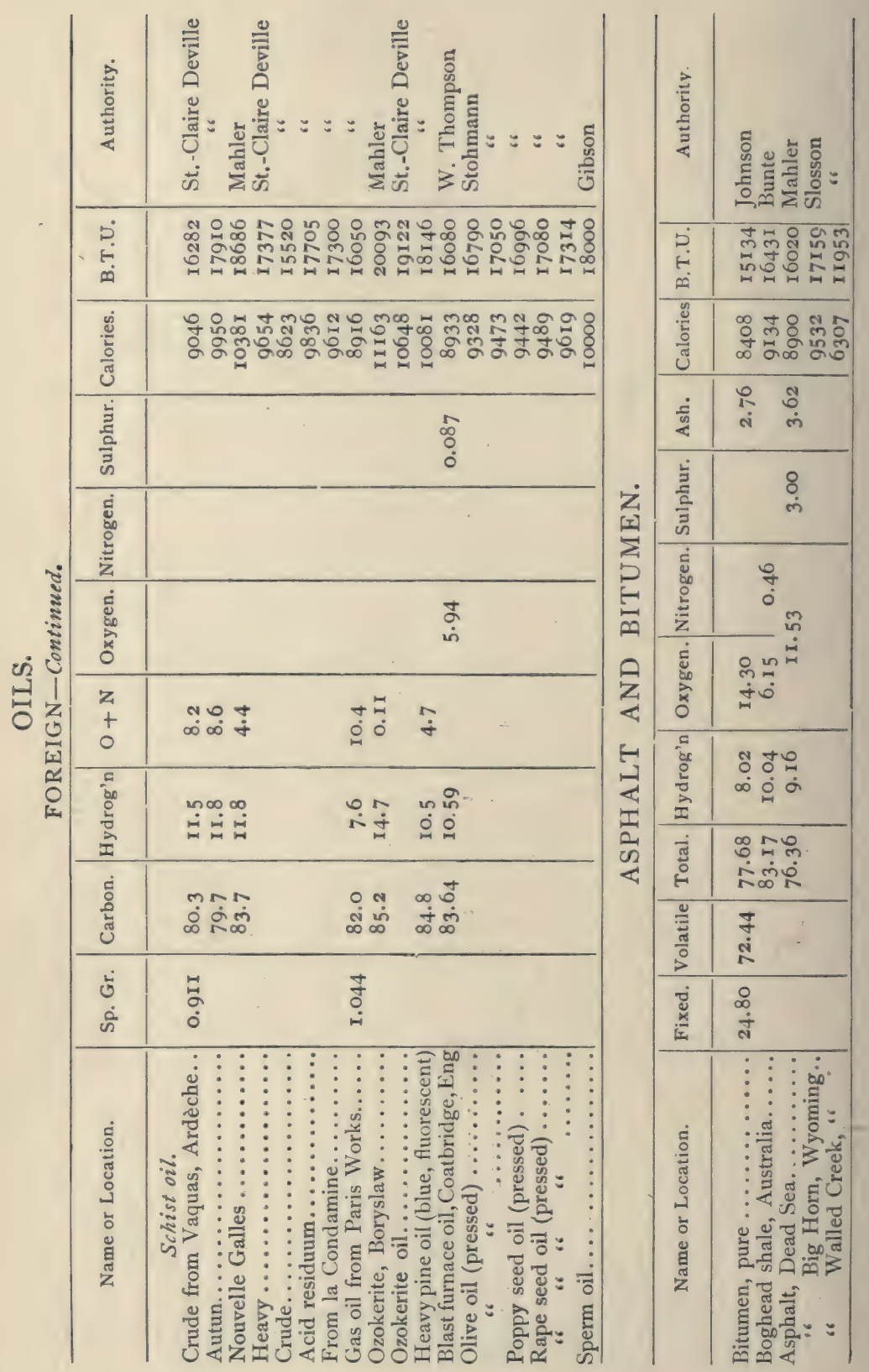




\begin{tabular}{|c|c|}
\hline 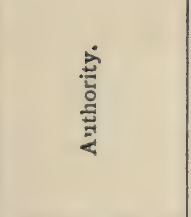 & 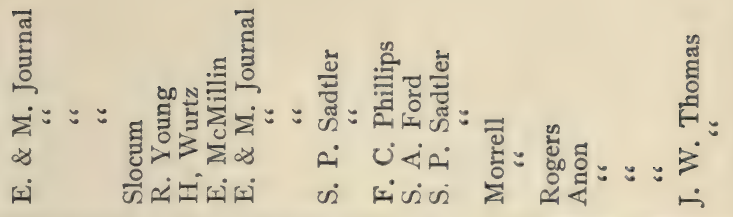 \\
\hline 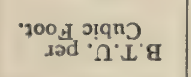 & 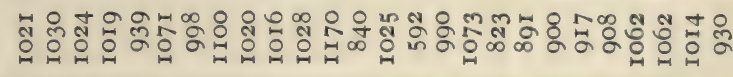 \\
\hline 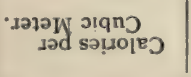 & 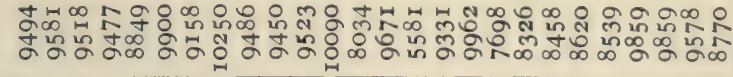 \\
\hline Us & 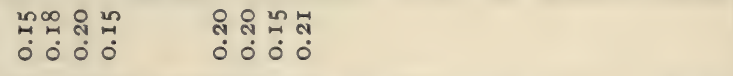 \\
\hline 'บวภัภก!ก & 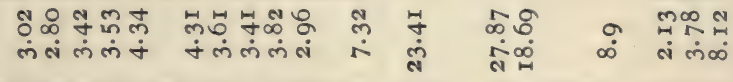 \\
\hline ' & 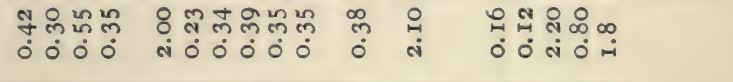 \\
\hline O & 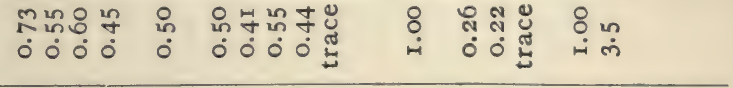 \\
\hline 8 & 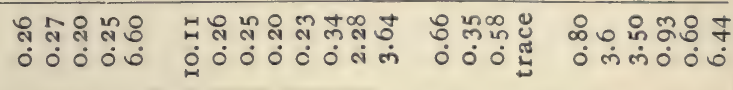 \\
\hline 'sıudụtun|II & 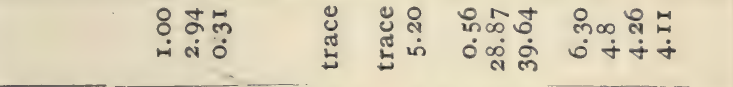 \\
\hline 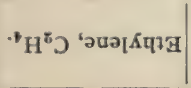 & 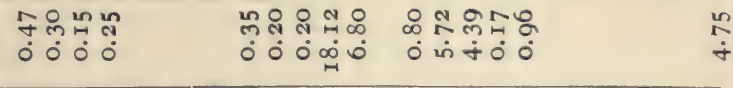 \\
\hline 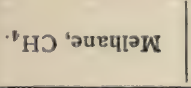 & 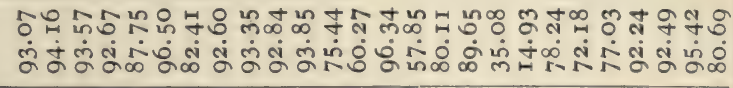 \\
\hline 'นวฐిం. $\mathrm{S}_{\mathrm{H}}$ & 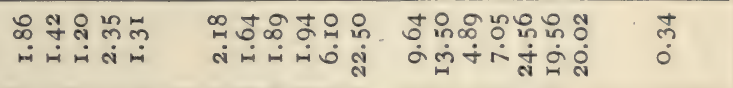 \\
\hline 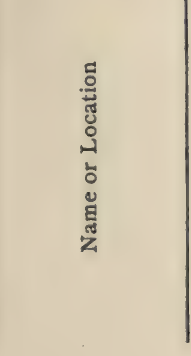 & 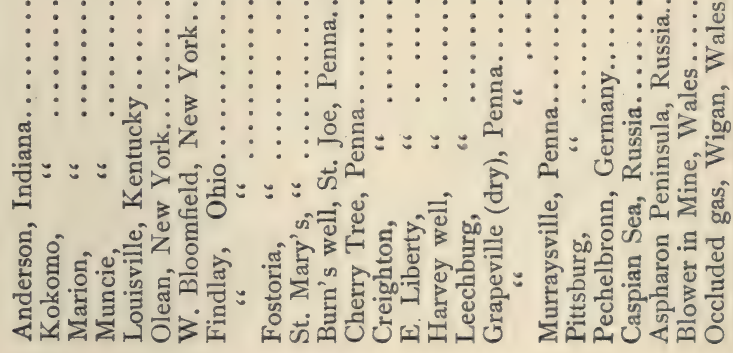 \\
\hline
\end{tabular}


FUEL TABLES.

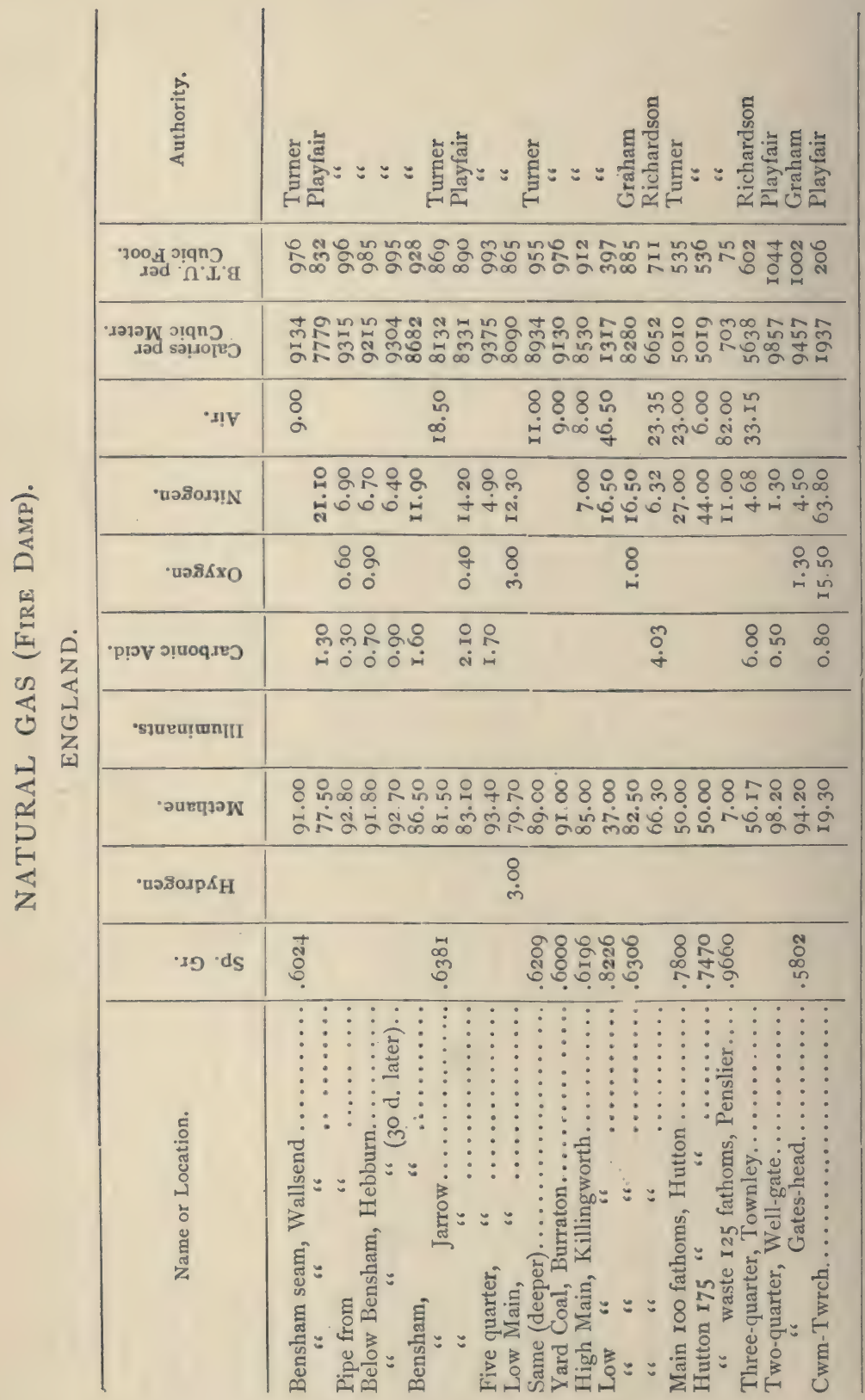




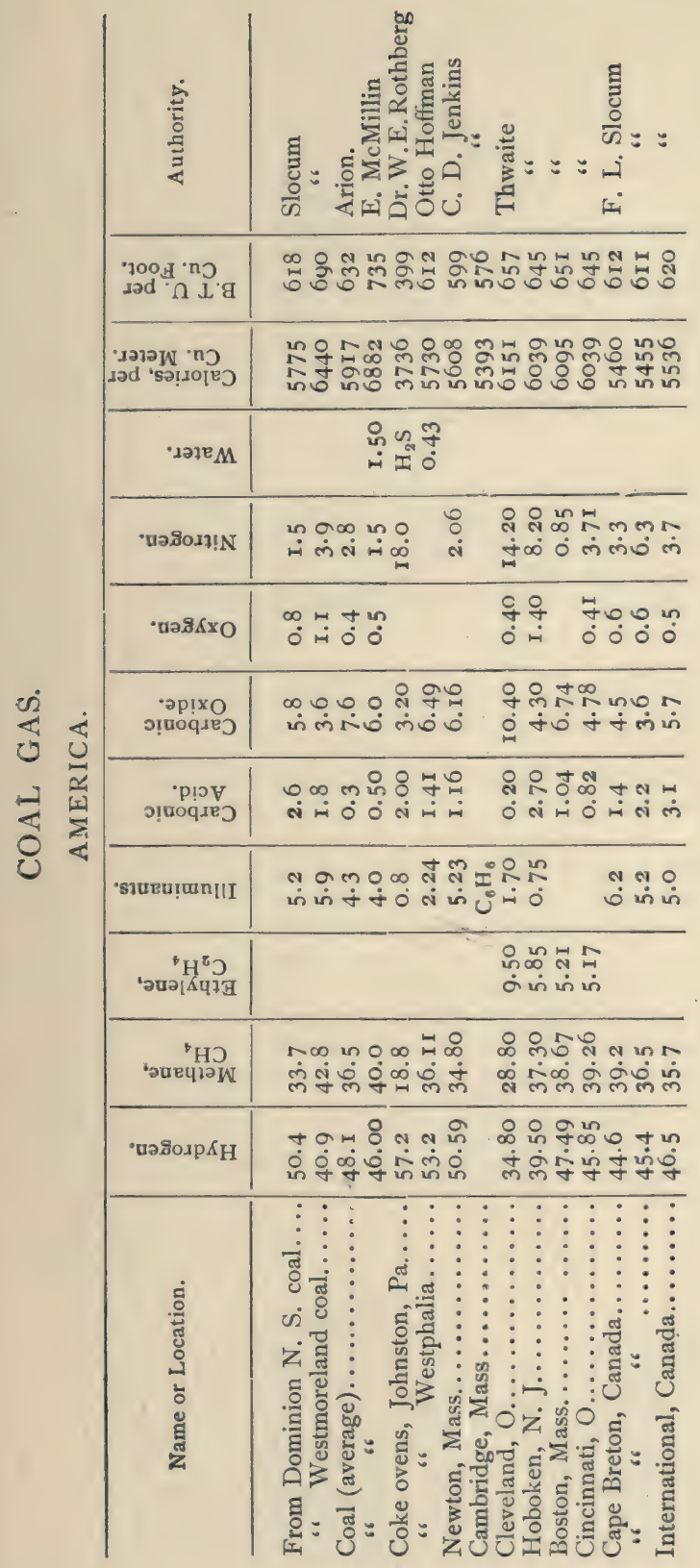

ह气 :

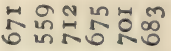

๓

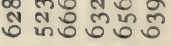

$\infty$

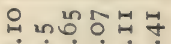
囟 ชั กิ $\circ \quad 00$

밈

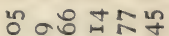

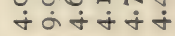
in म लंखं म

ํㅠㄴํํํำ

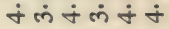

8 에는요

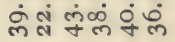

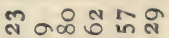
字字总战卞出

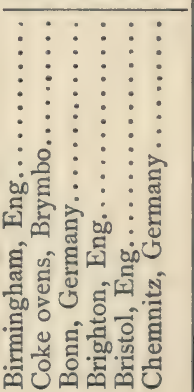




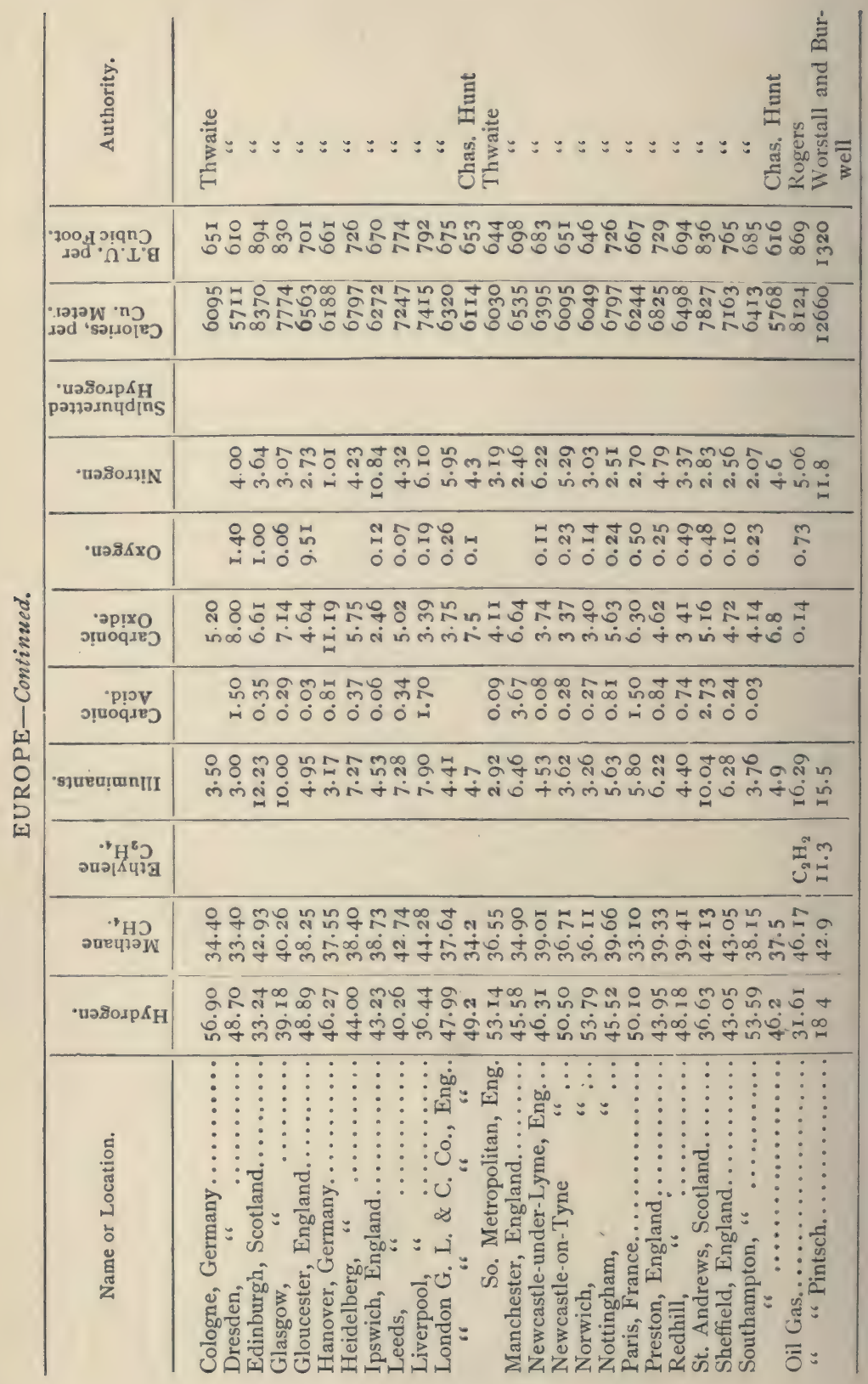




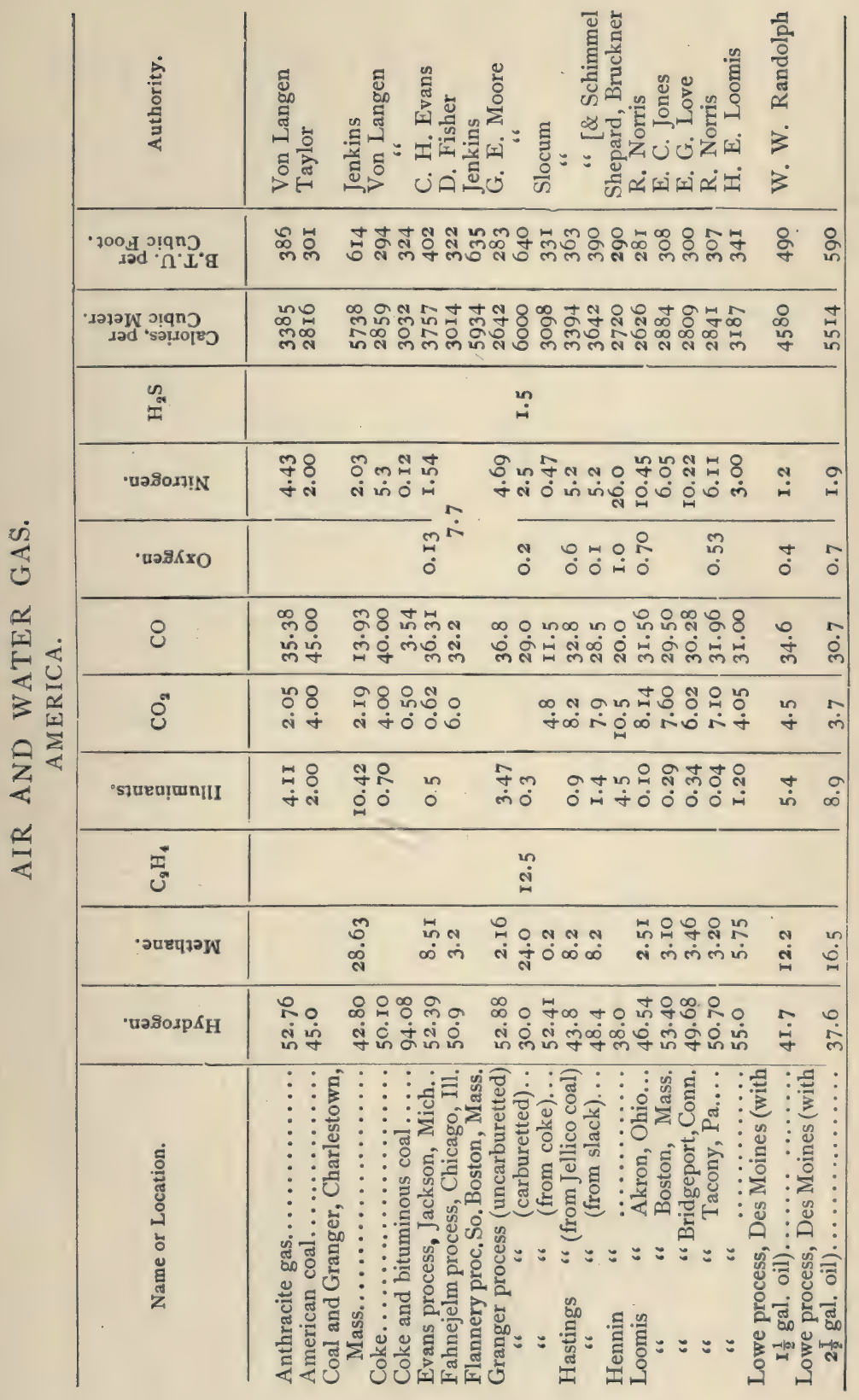




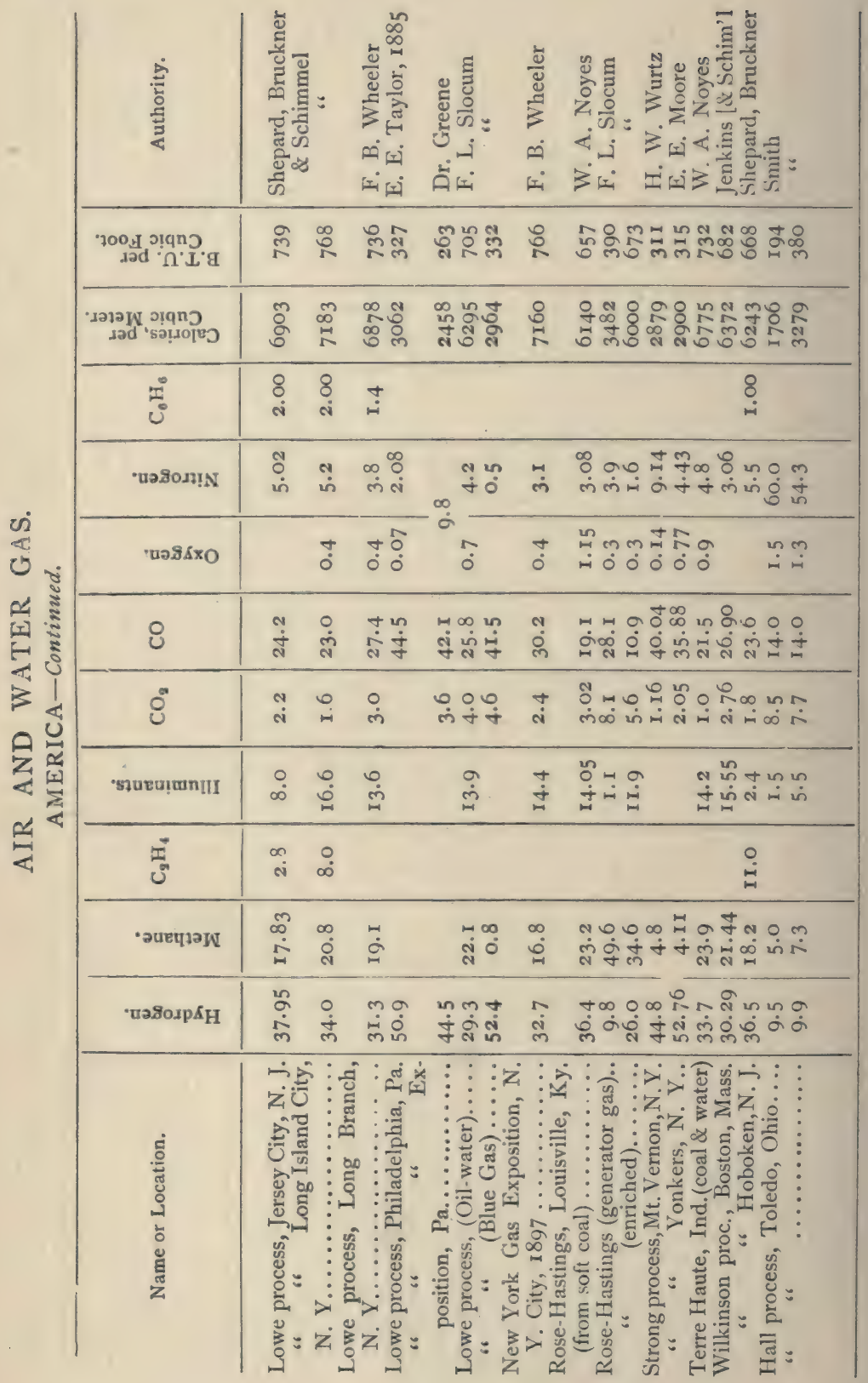


MIXED GAS.

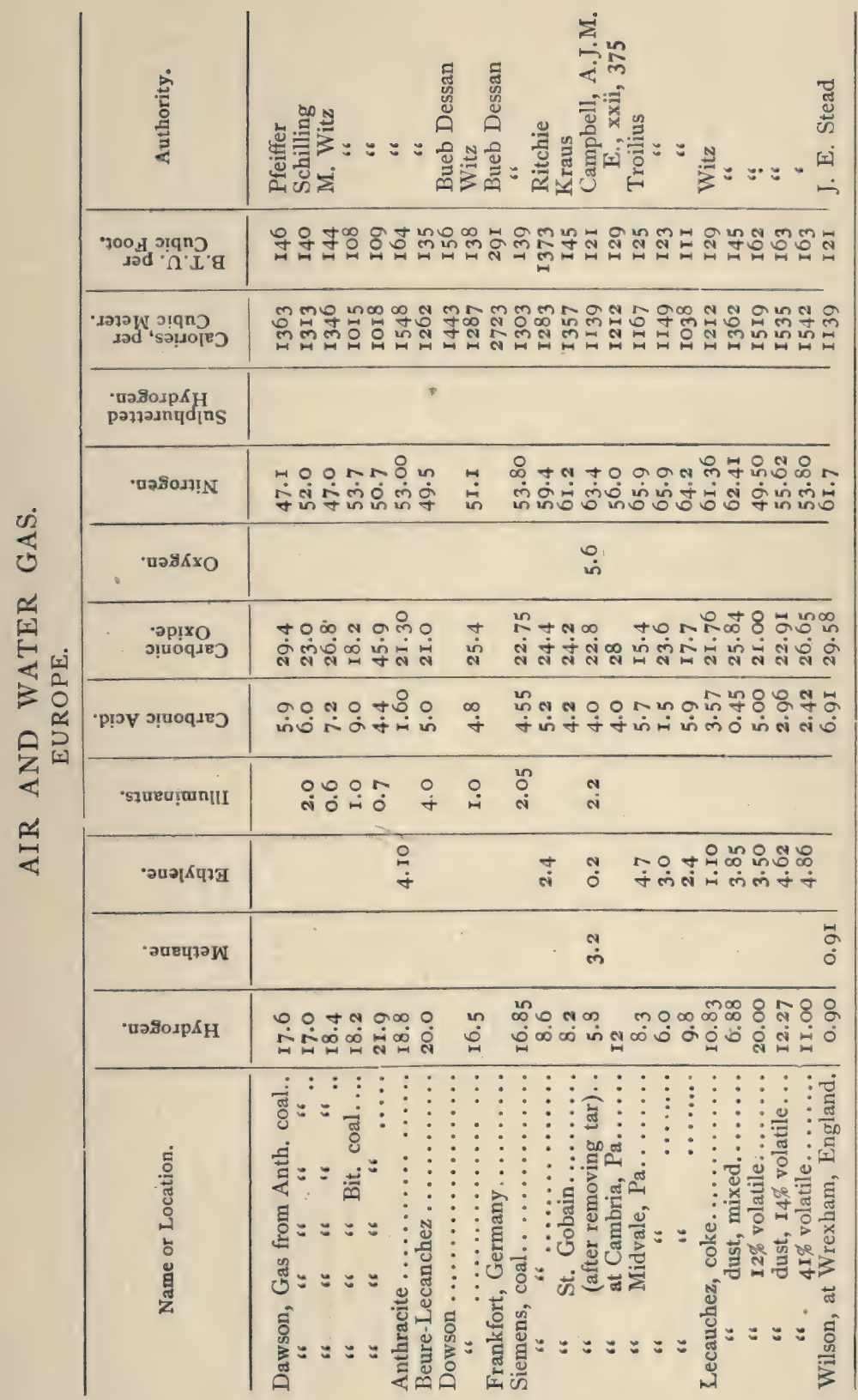




\begin{tabular}{|c|c|}
\hline 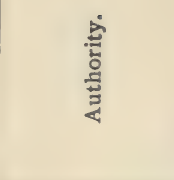 & 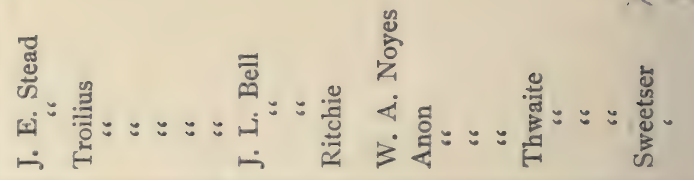 \\
\hline 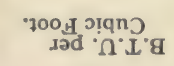 & 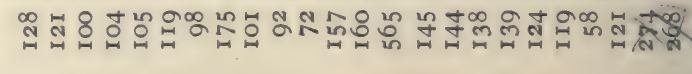 \\
\hline 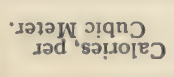 & 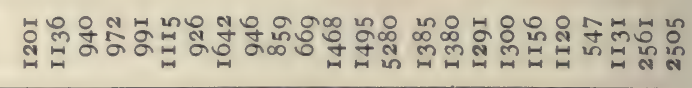 \\
\hline 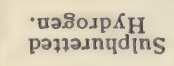 & \\
\hline 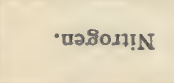 & 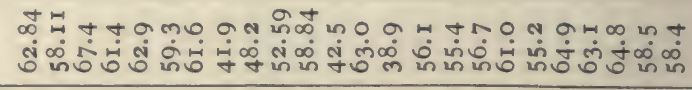 \\
\hline 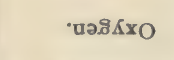 & $\dddot{M}$ \\
\hline $\begin{array}{l}\text { •əp!xo } \\
\text { ग!บoqueว }\end{array}$ & 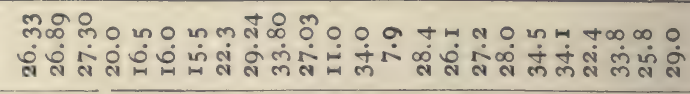 \\
\hline 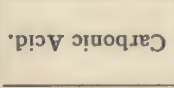 & 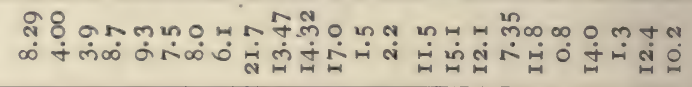 \\
\hline 'słueuịun|ll & $\stackrel{+}{\circ} \stackrel{0}{0}$ \\
\hline •วШગ[КЧРЯ & 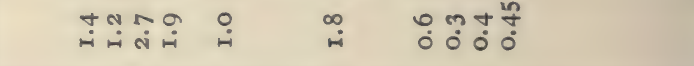 \\
\hline 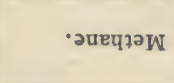 & 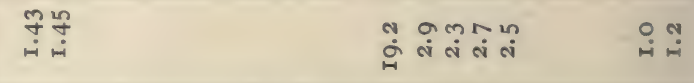 \\
\hline 'นəภ̊о. $\kappa_{H}$ & 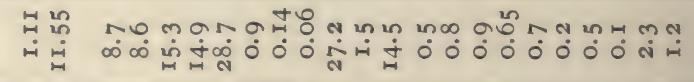 \\
\hline 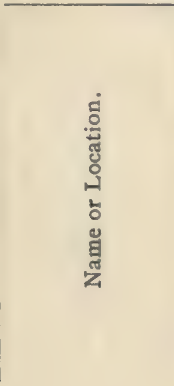 & 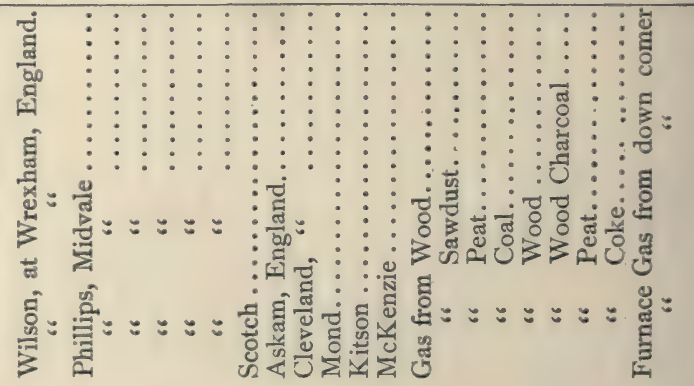 \\
\hline
\end{tabular}




\section{INDEX.}

AGITATOR, BERTHELOT'S, 27

Aguitton's exp'ments on coal gas, 95 Air, analysis (table), 207

necessary for combustion, 125; (table), 206

necessary for combustion

(table), 201, 202

used in combustion, 139

Alexejew's calorimeter, 28

American Society of Mechanical Engineers, boiler-test report, 177

Analysis, Cinders, II5

, Coal, ri3

- should show what, II4

, Coke, 82

, Gases, 133

, Lignite, 78

, Manchester gas, 93

, Peat, 80

, Proximate, 77

, Waste gases (table), 134, 135

, Wood, 84

Andrews' calorimeter, 47

Anemometer, Fan-wheel, I43

, Fletcher's, 144

, Volume of waste gases by, I43

Apparatus for steam-boiler testing should be correct, 183

, Installation of, I3

, Hirn's, 145

, Orsat-Muencke, I34

Aqueous vapor, Heat of, I59

Ash, Analysis of, II5

, Lignite, 78

, Peat, 80

, Treatment of, 189

Aspirator, Oil, 132

Atomic calorie, 2

Atwater's calorimeter, $7 \mathbf{I}$

BARRUS'S CALORIMETER, 38

Berthelot's agitator, 27

bomb, 48
Bituminous schist, 79

Boghead coal, 79

Boiler-testing. See Steam-boiler Testing

Bomb. See Calorimeter

Briquettes, how made, $5 \mathrm{I}$

British thermal units, 2

" " " to change to

calories, 3

Brix's experiments with charcoal, 84

Bueb-Dessau's experiments on coal gas, 95

Bunsen's researches on flame, 168

Bunte's experiments on coal, 76

gas-coke determinations, 9

experiments on waste gases, 135

Burnat's smoke tests, 155

CALCULATION;

Air necessary for combustion, 125

Air supplied, 139

Calories of the boiler test, 159

Calories of carbon, 54

Carpenter's calorimeter, 34

Carbon, 54

Coal, 66

Coke, 68

Colza oil, 64

Favre and Silbermann's calorimeter, 26

Flame temperature, 169

Gases, 67,94

Heat units of boiler trial, I59

Heat units by lead test, Io

Heat units from chemical composition, 7

Junker's calorimeter, $4 \mathrm{I}$

Mahler's calorimeter, $6 \mathrm{I}$ “" ; abridged, 70

Regnault and Pfaundler's, I8

Vapor of carbon, 173

Volume of waste gases, I43

Water value of calorimeters, I4, 63 
Calculation: Weight of waste gases, I 4 I

Calories, atomic or molecular, 2

Kilo-, 3

Pound-, 2

To change to B. T. U., 3. See Heat Units

Calorific power, 2

Ratio of, to fixed carbon, 78

Calorimeter, Alexejew, 28

Analytical, 74

Andrews, 47

Atwater, 7 I

Barrus, 38

Berthelot, 48

corrections, 53

examples, 54

operation, 53

Carpenter's, $3 \mathrm{I}$

calculation, 34

Constant pressure, 20

Constant volume, 45

Constant pressure and volume, ratio of, 45

Correction for F. and S., I6

Berthelot, 53

cooling, 18,60

Junker's, 42

Regnault and Pfaundler's, I 8

Cost of, 27

Dulong, 20

Evaluation in water. See Calorimeter, Water value

Favre and Silbermann, 2 I

Calculation, 26

in complete combustion with, 23, 25

Fischer, 29

Hartley, 40

Junker, 40

calculation, $4 \mathrm{I}$

errors, 42

Kroeker, 73

Mahler, 57

and Berthelot compared, 70

calculation, $6 \mathrm{I}$ , abridged, 70

enamel chips off, $5^{8}$ (foot-note)

examples, 64

for gases, 62

operation, 59

Protection for, $I_{3}$

Rumford, 20

Schwackhöfer, 35

waste gases, 37

Thompson, L., 43

Thompson, W., 37
Calorimeter, Thomsen, 30

Throttling, I I 7

Walther-Hempel, 74

Water value

, Berthelot's calorimeter, I4

by combustion, I4

by mixing, I5

Favre and Silbermann's calorimeter, 14

Fischer's calorimeter, 30

Lord and Haas' calorimeter, I4

Mahler's calorimeter, $\mathbf{1 4}, 63$

Witz, 47

Calorimeters, 12

Calorimetric endiometer, 47

Candle power and heat of combustion compared, 96

Cannel coal, 79

Carbon, calculation of calories, 54 calories by various authors, I2

in cinders, 115

" smoke, I54

" " ; analysis of, 154, I9I

oxygen necessary for, 125

vapor, weight, and calories, $\mathbf{I 7 3}$

Carpenter's calorimeter, 3 I

Carbonic acid, Automatic determination of, $147,148, r_{50}$

in producer gases. See Gas Producer

in waste gases, $8 \mathrm{I}, 84,9 \mathrm{I}, \mathrm{I} 34$, I37, I 55

, proper proportion in waste gases, I35

Carbonic oxide, Flame temperature of, 170

in producer gas, 99

in waste gases, $84,9 I$, IOI, I34, I 37 (table 135), I64

Cellulose, calories of, 85

Charbon roux, 83

Charcoal, peat, 80 wood, 83

; Brix's tests, 84

, half-burnt, 83

; Sauvage's tests, 83

; Scheurer-K.'s results, 84

, Waste gases of, 84

Cinder, Analysis of, II 5

Coal, Actual evaporation of, 76

, Air necessary, I26

, " supplied, I39

Analysis, II 3 ; (tables), 209-230

" should show, II4

Bunte's experiments, 76

Calories of, 66

Difference in samples of, II 3 
Coal, Gruner's table, 77

Heat of combustion (table), 198 , 209

Johnson's tests, 75

Moisture in, I12, 114, I88

Morin and Tresca's tests, 75

Pure, 75

Ratio of calories and fixed carbon, 77

Ratio of hyd'gen and carbon, 78

Sampling, II 2

Size for combustion, 24

Uniformity in same bed, II2

Weight of, III

Coal gas. See Gas, Coal

Coke analyses (table), 209

Calories of, 68

Composition of, 82

Heat of combustion (table), 230

Kinds of, 81

Use of, 82

Colza oil, Calories of, 64

Combustion. Air necessary, 125

Air supplied, I39

Heat of. See Heat of Combustion

incomplete in $\mathrm{F}$. and $\mathrm{S}$. calorimeter, 23

Constant pressure, 20, 45

"“ volume, 45

Cooling, Newton's law, 60

Regnault-Pfaundler's law, I8

Corrections for Berthelot calorim. eter, 53

Cooling, 18,60

Junker calorimeter, 42

DASYMETER, T46

Differential gauge, Segur's, I45

Dissociation, effect of, upon temperature, $\mathrm{I} 68$

Dulong's calorimeter, 20

Dulong's formula, 7

, Agreement of, with test, 9

, Mahler's limit to, ro (foot-note)

heat unit, 2 I

ECONOMETER, I48

Efficiency of steam-boilers, Igr

Electric igniter, Heat of, 70

Evaluation in water. See Water Value

Evaporative effect of coal, 76

, Factor for, 174

power of fuel, 174
Evaporative power of charcoal, 84

$$
\begin{array}{ll}
\text { “ } \quad \text { "gas, } 93 \\
\text { " lignite, } 79 \\
\text { “ peat, } 80 \\
\text { “ wood, } 86
\end{array}
$$

Evaporative power petroleum, 90 of natural gas, I07 unit, 180

Examples, Berthelot's cal'meter, 54 Carpenter's calorimeter, 34 Favre and S. " 26 Mahler's “. 64

FAN-WHEEL ANEMOMETER, I43

Favre and S.'s calorimeter, 21

Fischer's calorimeter, 29

Flame, 168

Bunsen's researches, 168

length, I69

not due to incandescence, 168

not due to solid particles, 168

Propagation of, 168

temperature, Calculation of, 169

, Loss due to dissociation, 168 acetylene, 170

bor-methyl, 168

carbon and carbonic oxide, 170 hydrogen, 169

marsh and olefiant gases, I I I

oils, 172

petroleum, $x 72$

producer and other gases, I7I

solid fuels, 172

table, 200

Fletcher's anemometer, I44

Flue-gas. See Waste Gases

Formula, Balling's, 8

Burnat's, I 43

Dulong's, 7

German Engineers', 8

Hirn's, 146

Jacobus's, 143

Mahler's, 9

Quality of steam, II

Regnault, for vaporization, 4

Regnault and Pfaundler's, I8

Schwackhöfer's, 8

Superheated steam, I23

Throttling calorimeter, 122

Vaporization of water, 4

Waste gases, weight, I4I, I43

Welter's, Io

Fuel, Air required for, I25; table, 206

Air supplied to, 139

Calorific power under steamboiler, rog 
Fuel, Evaporative power, 174

Gaseous, 92

Weight of, III

Fuels, I

, Division of, I

Tables, 209

GAS, COAL

Aguitton's experiments, 95

Bueb-Dessau's experiments, 95

Heat of combustion (table), 243

Mahler's experiments, 96

Variation in, 95

Gas-composimeter, 150

Gas, gasogene; heat theory, 97

Loss of calories, 98

Value, 97

Varieties, 98

Gas-holder, Oil, I32

Gas, Natural. See Natural Gas

Gas, Producer ; Heat theory of, 99

Heat of combustion (table)245,246

Mahler's experiments, Ior

Gas sampler, A. S. M. E., I3I

Scheurer-Kestner's, 128

Gas, water. See Water Gas

Gaseous fuels, 92

Heat of combustion of (tables), 245

Gases, Analysis, I33

as fuel, 92

Calculation of calories, 67

Comparative value, 107

Heat of combustion from analysis, 93

Heat units, r64; table, 203

“ “ example, I65

Ignition point (table), 207

Weight and volume (table), 200

Specific heat (table), 204

Gases, waste. See Waste Gases Specific heat of (table), 205

Gottlieb's wood tests, 86

Gruener's coal table, 77

HARTLEY'S CALORIMETER, 40

Heat, balance in boiler trials, I93

Loss of, in producer gas, 104

of aqueous vapor, I59

combination, 94

combustible gases, 164

combustion, 3

and candle power, 96

; Calculated vs. det'mined, 9

Cause of disagreement, Io

Determination of, 3, 4

From chem. composition, 7

, Litharge or lead test, Io
Heat, Methods of determining, 7

of carbon, 12, 54

carbon vapor, I73

coal, 66

coke, 68

colza oil, 64

constant pressure, 20

constant pressure and volume, 45

fuels (tables), 209

gas, 67

gases, calculation, 68,93

gases, difference in, 94

gases, modified by condensation, 94

gases (table), 203, 24I et sec.

hydrogen, 97

marsh gas, 97

natural gas, Io6; table, 24 I

oils (table), 238

olefiant gas, 97

petroleum, 90

various subst. (table), 198

electric igniter, 70

hygroscopic water, 162

sensible of the temperature, 160 soot, 166

vaporization of water, 4 ; table, 205

water of combustion, I62

Specific ; gases (table), 204

waste gases (table), 205

water (table), 205

Heat units, Dulong's, 2I

from chemical composition, 7

lead reduction test, ro

Ratio of, to fixed carbon, 77

of steam-boiler tests, Cal'tion, I59

of steam-boiler tests Distribu. tion, 167

Heat value, 2

of fuels (tables), 209

Heating by charcoal, 84

coke, 82

gas, 92

lignite, 78

oil, 89,90

peat, 80

wood, 84

Hirn's waste-gas apparatus, I 45

formula, I 46

Horse-power, Commercial, I80

Hydrocarbons, Unconsumed, 25

Hydrogen, Calories of, 4

in cinders, 115

, Oxygen necessary for, 125 
IGNITER, ELECTRIC

Heat of, 70

Ignition point of gases (table), 207

Incandescence not flame, I68

Indiana natural gas analyses, 105

Installation of apparatus, 13

JACOBUS'S FORMULA, I43

Johnson's coal tests, 75

Junker's calorimeter, 40

KENT ON WASTE GASES, I4I

Kent's ratio of hydrogen and carbon in coal, 78

revision of Johnson's tests, 75

Kilo-calorie, 3

Kroeker calorimeter and correction for water, 73

LEAD OR LITHARGE TEST, IO is unreliable, II

Lignite, 78

, Heat of combustion (table), 23 I

Lord and Haas on Ohio and Pennsylvania coal, 9

Luminosity, 168

depends on pressure, 169 not due to solid particles, 168

MAHLER'S CALORIMETER, 57 determinations of gas, IOr experiments on coal gas, 96 formula, 9

Manchester gas, Analysis of, 93

Mixed gas, Ior , Calories of (table), 245

Moisture in coal, II2, II4

Moisture in steam, 119,187

Molecular calorie, 2

Morin and Tresca on coal, 75

Morin and Tresca's wood tests, 86

NAPHTHALIN, CALORIES OF , 46

Natural gas and analysis of, ro5

Calories of, ro6; (table), 24I

Value of, I06

Variation in, 105

Nitrogen, ratio of, to oxygen (table), 207

Nixon's coal; calories of, determined, 66

OHIO NATURAL GAS, I05

Oil aspirator or gas-holder, 132

Oils, Heat of combustion (table), 238

Orsat-Muencke'apparatus, I34
Oven cokes, Heat of combustion

(table), 234

Oxygen, Compressed, is dry, 52

in cylinders, 59

necessary for combustion, 125 " " " (table), 201, 202

, Ratio of, to nitrogen in air (table), 207

required to form water with coal, I40 ; (table), 206

To prepare, 24

PASTILLES, HOW MADE, 5I

Peat, 80

; Calories of (table), 232

Petroleum, 88

at Chicago, Canada, Moscow, 89

, Calorific power of, 90

heating tests, 90

, Calories of (tables), 238

, Steam used in atomizing, 91

Pittsburg natural gas, 105

Pneumatic pyrometer, 152

Pound-calorie, 2

Producer gas, 98. See Gas, Producer

Products of combustion of

Alexejew's calorimeter, 28

charcoal, 84

Favre and Silbermann's calorimeter, 26

oil, 9I

Schwackhöfer's calorimeter, 37 . See Waste Gases.

Pyrometer, Pneumatic, 152

REGNAULT'S FORMULA, 4

Regnault and Pfaundler's law, 18

Ringelmann's smoke scale, 158

Ronchamp coal, Smoke of, 156

Rothkohle, 83

Rumford's calorimeter, 20

SAMPLER, GAS, I28, I3I

Sampling, Coal, II2

Sauvage's exp'ments on charcoal, 83

Scheurer-Kestner's experiments on charcoal, 84

gas sampler, 128

smoke analysis, 155

and Meunier-Dollfus on coal, 75

Schist, Bituminous, 79

Schwackhöfer's calorimeter, 35

Segur's differential gauge, I 45

Sensitiveness of thermometers, 6

Shale oil, 88 
Smoke, Bunte's observations, 157 Burnat's experiments, 155

Carbon in, 154

Ringelmann's scale, 158

Scheurer-Kestner's analysis, I55

Tatlock's tests, 155

Soda-lime for absorbing moisture, 23

Soot, Heat units of, 166

Specific heat. See Heat, Specific

$$
\text { " " of water not consid- }
$$$$
\text { ered, } 3
$$

Steam, Moisture in, II7, II9, I87

, Quality of, II9, 187

Superheated, I23

- Temperature of, II6

used in atomizing petroleum, 9I

Steam-boilers, petroleum-fired, 89

, Lignite-fired, 79

Steam-boiler testing

apparatus to be correct, 183

Ashes and residues, 189

Analysis of cinders, II5

$$
\text { " "coal, II3 }
$$

“ "waste gases, I33,

I90

Boiler and chimney to be heated, 183

Calculation of air necessary, I25

$$
\begin{array}{lll}
\text { “ } & \text { " } & \text { " supplied, I } \\
\text {. } & \text { "6 } & \text { waste gases, I } 36,
\end{array}
$$

I 41,146

Carbon in smoke, 154

Coal used, 182

Corrections of apparatus, $\mathbf{I} 83$

determine what, rog

Distribution of calories, 167

$$
\text { " " heat, Iog }
$$

Duration of test, II 5

Early tests, Iog

Efficiency, I9I

Examination of boiler, etc., 182

Heat balance. I92

Heat tests and coal anal., I9o

Johnson's tests, rog

Keeping records, 186

Moisture in steam, II

Need of knowledge of calories in, rog

Preliminaries of, I8I

Quality of steam, II9, I87

Report of A. S. M. E. committee, 177

Report of trial, 193

Sampling the coal, II2

Scheurer-Kestner's tests, Iro

Starting and stopping, I84
Steam-boiler testing, Temperature of steam, ir 6

Temperature of waste gases, $15 \mathrm{I}$

Volume of air necessary, 125

" "* " supplied, I39

" "waste gases, I27

Waste gas samples and analysis, 133, I9o

Water evaporated, II 6

Weight of fuel, III

$$
\text { " " waste gases, I4I }
$$

What is necesary, Iro

Sulphur, oxygen necessary for, 126

TABLE; AIR COMPONENTS, 207

Air for combustion, 201, 202

" for perfect combustion, 206

Ash analyses, II5

Candle power and heat of combustion, 96

Coal (Gruner's), 77

Coke analyses, 82

Distribution of calories, 167

Flame temperatures, 200

Fuels, 209

Heat balance, 193

Heat of combustion, 198

$$
\begin{aligned}
& \text { " " " of fuels, } 209 \\
& \text { " “ “ "gases, } 202 \\
& \text { “ “ " "lignites, } 23 \text { I } \\
& \text { " " " "peat, } 232 \\
& \text { “ " " } \text { "wood, 86, } 233 \\
& \text { “ "vapor'n of water, } 205
\end{aligned}
$$

Ignition point of gases, 207

Natural gas, I05, I06, 24I, 242

Oxygen for combustion, 201, 202

Oxygen to form water, 206

Regnault and Pfaundler's law, is

Ronchamp coal waste gases, I34

Smoke analyses, 157

Specific heat of gases, 204

$$
\text { "، "“ " " waste gases, } 205
$$

Thermometer reduction, I99

Waste gas analyses, 134,135

Water value calculation, I5

Weight and volume of gases, 200

Wood, 86

Tatlock's smoke tests, I55

Temperature, Heat of sensible, I60

Thermal units, 2 of waste gases, I5I

Thermometer, 4

, Correction, mercury column, 6

, Favre and Silbermann's, 6

, Metastatic, 6

, reduction table, 199 
Thermometer, Sensibility of, 6

Thomsen's calorimeter, 30

Thompson's, L., calorimeter, 43

Thompson's, W.. “ 37

Throttling calorimeter, II7

\section{UNIT OF EVAPORATION, I79}

Units of heat, 3

VAPORIZATION OF WATER, 4 Vaporization of water (table), 205

Variation in coal gas, 95

$$
\text { " "natural gas, } 105
$$

\section{WALTHER-HEMPEL}

Calorimeter, 74

Waste gas analysis, Igo

Waste gases, Automatic apparatus for, 147

, Bunte's results, 135

from charcoal, 84

"i petroleum, 9r

“ Ronchamp coal, 134

, Heat of, I6o

, Hirn's apparàtus, 145

"' formula, 146

, Schwackhöfer's calorimeter, 37
Waste gases (table), I34, I35

, Temperature of, I5I

Volume of, I27

Water evaporated, II6

, Heat of combination, 162

, Heat of vaporization of, 4 ; table, 205

Hygroscopic, heat of, I62

in Lignite, 78

in peat, 80

, Kroeker's correction for, 73

, Specific heat (table), 205

, Specific heat of, not considered, 3

-value of cal'meters, I4, I5, 30, 63

Water gas, ror

- Heat of combustion of (table), 245 et seq.

Theory, 102

Loss of heat, I04

Weight of carbon vapor, 173 fuel, III waste gases, I4I

Witz calorimeter, 47

Wood, Condition for burning, 87

Gottlieb's tests, 86

Calories (table), 86, 233

Hydrate of carbon, 84

Morin and Tresca's tests, 86

Wood charcoal. See Charcoal Wood. 


\title{
SHORT-TITLE CATALOGUE
}

\author{
OF THE \\ PUBLICATIONS
}

OF

\section{JOHN WILEY \& SONS,}

NEW YORK.

London: CHAPMAN \& HALL, Limited.

\section{ARRANGED UNDER SUBJECTS.}

\section{Descriptive circulars sent on application.}

Books marked with an asterisk are sold at net prices only.

All books are bound in cloth unless otherwise stated.

\section{AGRICULTURE.}

Cattle Feeding-Dairy Practice-Dishases of AnrmalsGardenine, Etc.

Armsby's Manual of Cattle Feeding...................... \$1 75 Downing's Fruit and Fruit Trees.....................8 8 ro, 500

Grotenfelt's The Principles of Modern Dairy Practice.' (Woll.)

Kemp's Landscape Gardening.....................12mo, 250

Loudon's Gardening for Ladies. (Downing.)..........12mo, 150

Maynard's Landscape Gardening........................ 150

Steel's Treatise on the Diseases of the Dog............8vo, 350

“Treatise on the Disenses of the Ox..............8vo, 600

Stockbrilge's Rocks and Soils................. . 50

Woll's Handbook for Farmers and Dairymen...........12mo, 150

\section{ifulingl ARCHITECTURE.}

\section{BuILding-CarPentri-Stairs-Ventilation-Law, Etc.}

Berg's Buildings and Struetures of American Railroads.....4to, . 7. 50

Birkmire's American Theatres-Planning and.Construction.8vo, $=300$

67. " . Architectural Iron and Steel.............. \&.. 8vo, $\quad 3 \mathrm{~g} 0$

“. Compound Riveted Girders........................8vo, 200

1. 4. Skeleton Construction in Buildings .......... 8 8 , 300 
Birkmire's Planning and Construction of High Office Buildings.

8vo, \$350

Carpenter's Heating and Ventilating of Buildings........8vo, 300

Freitag's Architectural Engineering...............8vo, 250

Gerhard's Sanitary House Inspection...............16mo, 100

“ Theatre Fires and Panics...................mo, 150

Hatfield's American House Carpenter............... 8vo, | 500

Holly's Carpenter and Joiner........................18mo, 75

Kidder's Architect and Builder's Pocket-book...16mo, morocco, 400

Merrill's Stones for Building and Decoration...........8vo, 500

Monckton's Stair Building-Wood, Iron, and Stone.......4to, 400

Wait's Engineering and Architectural Jurisprudence......8vo, 600

Sheep, 650

Worcester's Snall Hospitals-Establishment and Maintenance, including Atkinson's Suggestions for Hospital Architecture... ................................ 125

World's Columbian Exposition of $1893 . \ldots \ldots \ldots$.... Large 4to, 250

\section{ARMY, NAVY, Etc.}

Military Engineering-Ordnance-Law, Etc.

Bourne's Screw Propellers...................... 500

Bruff's Ordnance and Gunnery .......................8vo, 600

Chase's Screw Propellers..................... 8vo, 300

Cooke's Naval Ordnance .......................8vo, 1250

Cronkhite's Gunnery for Non-com. Offlcers.....32mo, morocco, 200

Davis's Treatise on Military Law.................8vo, 700

Sheep, 750

" Elements of Law........................8vo, 250

De Brack's Cavalry Outpost Duties. (Carr.)...32mo, morocco, 200

Dietz's Soldier's First Aid.................16mo, morocco, 125

* Dredge's Modern French Artillery....Lagre 4to, Lalf morocco, 1500

“ Record of the Transportation Exhibits Building,

World's Columbian Exposition of 1893..4to, half morocco, 1000

Durand's Resistance and Propulsion of Ships...........8vo, 500

Dyer's Light Artillery. .................................12mo, $\quad 800$

Hoff's Naval Tactics...............................8vo, . 150

Ingalls's Ballistic Tables......................8

" Handbook of Problems in Direct Fire..........8vo, 400 
Mahan's Advanced Guard.............................. \$1 50

“ Permanent Fortifications. (Mercur.).8vo, half morocco, 750 Mercur's Attack of Fortified Places................12mo, 200

Elements of the Art of War............... 8 vo, 400

Metcalfe's Ordnance and Guunery.........12mo, with Atlas, 500

Murray's A Manual for Courts-Martial ...... 16mo, morocco, 150

“ Infantry Drill Regulations adupted to the Springfield

Rifle, Caliber .45. ..................32mo, paper, 10

Phelps's Practical Marine Surveying............... 8vo, ,2 50

Powell's Army Officer's Exwminer..................12mo, 400

Sharpe's Subsisting Armies : . . . .............32mo, murocco, 150

Very's Navies of the World................8vo, half morvcco, 350

Wheeler's Siege Operations........................8vo, 1200

Winthrop's Abridgment of Military Law.............12mo, 250

Woodhull's Notes on Military Hygiene.................16mo, 150

Young's Simple Elements of Navigation..16mo, morocco flaps, $\quad 200$

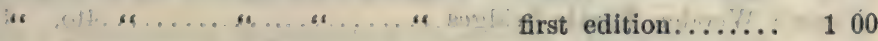

\section{ASSAYING.}

Smelting-Ore Dressing-Alloys, Etc.

Fletcher's Quant. Assaying with the Blowpipe..16mo, morocco, - 150

Furman's Practical Assaying........................ 8vo, 300

Kunhardt's Ore Dressing. .......................... 150

O'Driscoll's Treatment of Gold Ores....................8vo, 200

Ricketts and Miller's Notes on Ass̀aying...............8vo, 300

Thurston's Alloys, Brasses, and Bronzes............ 8 vo, 250

Wilson's Cyanide Processes........................... 150

" The Chlorination Process..................12mo, 150

\section{ASTRONOMY.}

Practical, Theoretical, and Descriptive.

Craig's Azimuth...........................4to, 350

Doolittle's Practical Astronomy .....................8vo, 400

Gore's Elements of Geodesy.....................8vo, 250

Hayford's Text-book of Geodetic Astronomy...........8vo. 300

Michie and Harlow's Practical Astronomy..............8vo, 300

White's Theoretical and Descriptive Astronomy.........12mo, 200 


\section{BOTANY.}

\section{Gardening fror Ladies, Etc.}

Baldwin's Orchids of New England............ Small 8vo, $\$ 150$ Loudon's Gardening for Ladies. (Downing.)..........12mo, 150 Thomé's Structural Botany.........................16mo, 225 Westermaier's General Botany. (Schneider.)........8vo, 200

\section{BRIDGES, ROOFS, Etc。}

\section{Cantilever-Draw-Highway-Sugpension.}

(See also EngINeErring, p. 7.)

Boller's Highway Bridges...................... 8vo, 200

* "The Thames River Bridge............4to, paper, 500

Burr's Stresses in Bridges.........................8vo, 350

Crehore's Mechanics of the Girder................... 8vo, 500

Dredge's Thames Bridges..............7 parts, per part, 125

Du Bois's Stresses in Framed Structures............. Small 4to, 1000

Foster's Wooden Trestle Bridges....................4to, 500

Greene's Arches in Wood, etc....................8vo, 250

". Bridge Trusses...........................8vo, 250

" Roof Trusses............................... 8vo, 125

Howe's Treatise on Arches ....................... 8ro, 400

Johuson's Modern Framed Structures.............Small 4to, 1000

Merriman \& Jacoby's Text-book of Roofs and Bridges.

Part I., Stresses................... 8vo, 250

* Triman \& Jacoby's Text-book of Roofs and Bridges.

Purt II., Graphic Statics ................... 8 vo, 250

Merriman \& Jacoby's Text-book of Roofs and Bridges.

Part III., Bridge Design.................... 8 vo, 250

Merriman \& Jacoby's Text-book of Roofs and Bridges.

Part IV., Continuous, Draw, Cantilever, Suspension, and

Arched Bridges......................... 250

* Morison's The Memphis Bridge................ Oblong 4to, 1000

Waddell's Iron Highway Bridges............... 8vo, 400

De Pontibus (a Pocket-book for Bridge Engineers).

$10 \mathrm{mo}$, moroco; 3,00

Wood's Construction of Bridges and Roofs............8vo, - 200

Wright's Designing of Drạ Spans. Parts I. and II..8vo, each 250

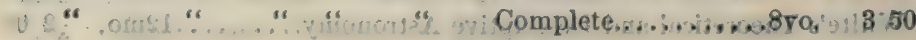




\section{CHEMISTRY.}

Qualitative-Quantitative-Organic-Inorganic, Etc.

Adriance's Laboratory Calculations...................12mo, \$1 25

Allen's Tables for Iron Analysis... .....................8vo, 300

Austen's Notes for Chemical Students...............12mo, 150

Bolton's Student's Guide in Quntitative Analysis........8vo, 150

Classen's Analysis by Electrolysis. (Herrick and Boltwood.).8vo, 300

Crafts's Qualitative Analysis. (Schaeffer.)............12mo, 150

Drechsel's Chemical Reactions. (Merrill.)............12mo, 125

Fresenius's Quantitative Chemical Analysis. (Allen.)......8vo, 600

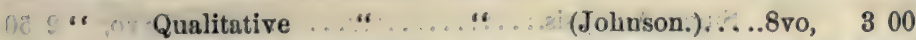

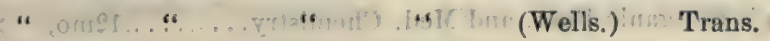

16th German Edition....................8vo, 500

Fuertes's Water and Public Health.....................mo, 150

Gill's Gas and Fuel Analysis........................... 125

Hammarsten's Physiological Chemistry. (Maudel.).......8vo, 400

Helm's Principles of Mathematical Chemistry. (Morgan).12mo, 150

Kolbe's Inorganic Chemistry.......................12mo, 150

Ladd's Quantitative Chemical Analysis...............12mo, 100

Landauer's Spectrum Anılysis. (Tingle.)...............8vo, 300

Löb's Electrolysis and Electrosynthesis of Organic Compounds.

(Lorenz.)................................... 100

Mandel's Bio-chemical Laboratory...................12mo, 150

Mason's Water-supply............................8vo, 500

" Examination of Water. (In the press.)

Miller's Chemical Physics...........................8vo, 200

Mixter's Elementary Text-book of Chemistry.............12mo, 150

Morgan's The Theory of Solutions and its Results.......12mo, 100

Nichols's Water-supply (Chemical and Sanitary)........8vo, 250

O'Brine's Laboratory Guide to Chemical Analysis........ .8vo, 200

Perkins's Qualitative Analysis............................ 100

Pinner's Organic Chemistry. (Austen.)...............12mo, 150

Poole's Calorific Power of Fuels.....................8vo, 300

Ricketts and Russell's Notes on Inorganic Chemistry (Nonmetallic)................... Oblong 8vo, morocco, $\quad 75$

Ruddiman's Incompatibilities in Prescriptions......... 8vo, 200

Schimpf's Volumetric Analysis....................12mo, 250

Spencer's Sugar Mauufacturer's Handbook.16mo, morocco flaps, 200 
Spencer's Handbook for Chemists of Beet Sugar Houses.

$16 \mathrm{mo}$, morocco, $\$ 300$

Stockbridge's Rocks and Soils................... 8vo, 2 50

Van Deventer's Physical Chemistry for Beginners. (Boltwood.)

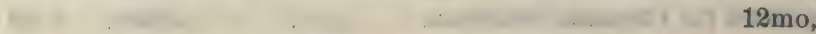

Wells's Inorganic Qualitative Analysis..............12mo, .150

" Laboratory Guide in Qualitative Chemical Analysis.

an i

Whipple's Microscopy of Drinking-water............8vo,

Wiechmann's Chemical Lecture Notes..............12mo, 300

. " Sugar Apalysis...................... Small 8vo, “2 50

Wulling's Inorganic Phar. and Med. Chemistry........12mo, 200

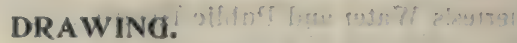

ELEMENTARY-GEOMETRICAL-MECHANICAL-TOPOGRAPHICAL,

Hill's Shades and Shadows and Perspective........... 8 vo, 200

MacCord's Descriptive Geometry.................... 8vo, 300

. "Kinematics.............................8vo, " 500

“ Mechanical Drawing...................8vo, 400

Mahan's Industrial Drawing. (Thompson.)........2 vols., 8vo, 350

Reed's Topographical Drawing. (H. A.)..............4to, 500

Reid's A Course in Mechanical Drawing ..............8vo. 200

“ Mechanical Drawing and Elementary Machine Design.

8vo. (In the press.)

Smith's Topographical Drawing. (Macmillan.).......... 8vo, . 2. 50

Warren's Descriptive Geometry..........k............2 vols., 8vo, : :3. 50

“ Drafting Instruments........................ 125

" Free-hand Drawing ..................... 12mo, 100

". Linear Perspective......................... $12 \mathrm{mo}, \ldots 10$

“ Machine Construction. .................2. vols., 8 vo, . 7.50

" Plane Problems...........................12mo, , 125

“ Primary Geometry....................12mo, 75

" Problems and Theorems..................8vo, 250

“ Projection Drawing......................12mo, 150

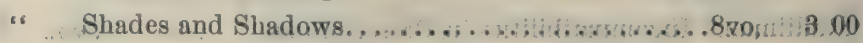

$\therefore \quad$. Stereotomy-Stone-cutting................ 8vo, ..2.50

Whelpley's Letter Engraving . . ..................12mo, . .2 00 


\section{ELECTRICITY AND MAGNETISM.}

\section{ILLUMINATION-BATteRIES-PHYsic8.}

Anthony and Brackett's Text-book of Physics. (Magie.)..8vo, $\$ 300$ Authony's Theory of Electrical Measurements..........12mo, 100

Barker's Deep-sea Soundings...................8vo, 200

Benjamin's Voltaic Cell............................8vo, 800

40 o , History of Electricity.................. $8 \mathrm{vo} \quad 300$

Cosmic Law of Thermal Repulsion...............12mo, 75

Crehore and Squier's Experiments with a New Polarizing Photo-

Chronograph. ............................8vo, 800

* Dredge's Electric Illuminations. . .2 vols., 4to, half morocco, 2500

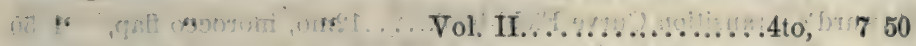

Gilbert's De maguete. (Mottelay.)................8vo, 250

Holman's Precision of Measurements...............8vo, 200

“Telescope-mirror-scale Method...........Large 8vo, 75

Michie's Wave Motion Relating to Sound and Light,......8vo, 400

Morgan's The Theory of Solutions and its Results........12mo, 100

Niaudet's Electric Batteries. (Fishback.)...........12mo, 250

Pratt and Alden's Street-railway Road-beds...........8vo, 200

Reagan's Steam and Electric Locomotives............12mo, 200

Thurston's Stationary Steam Engines for Electric Lighting Pur-

pite poses................................12mo,

Tillman's Heat.............................8vo, 150

\section{ENGINEERING.}

\section{Civil-Mechanical-SaNitaRY, ETC.}

(See also Bridges, p. 4; Hydraulics, p. 9; Materials of ENgineering, p. 10 ; Mechanics and Machinery, p. 12 ; Steam Engines AND BoIlers, p. 14.)

Baker's Masonry Construction................... 8vo, 500

(4.) Surveying Instruments.....................12mo, 300

Black's U. S. Public Works................. Oblong 4to, 500

Brooks's Street-railway Location.............16mo, morocco, 150

Byrne's Highway Construction.................... 8vo, 500

“ Inspection of Materials and Workmanship.......16mo, 3.00

Carpenter's Experimental Engineering ............. 8vo, 600 
Church's Mechanics of Engineering-Solids and Fluids...8vo, $\$ 600$

"Notes and Exumples in Mechanics............8vo, 200

Crandall's Earthwork Tables......................... 8 vo, 150

(1) The Trnnsition Curve.........,.,.16mo, morocco, 150

* Dredge's Penn. Railroad Construction, etc. . Folio, half mor., 2000

* Drinker's Tunnelling...............,...4to, half morocco, . 2500

Eissler's Explosives-Nitroglycerine and Dynamite...... 8vo, 400

Folwell's Sewerage.........................8vo, 300

Fowler's Coffer-dam Process for Piers...............8vo. 250

Gerhard's Sanitary House Inspection..............12mo, 100

Godwin's Railroad Engineer's Field-book......16mo, morocco, 250

Gore's Elements of Geodesy...........................8vo, 2.50

Howard's Transition Curve Field-book....12mo, morocco flap, 150

Howe's Retaining Walls (New Edition.)............... $12 \mathrm{mo}, \quad 125$

Hudson's Excavation Tables. Vol. II. ................. 8vo, 100

Hutton's Mechanical Engineering of Power Plauts.......8vo, 500

Johnson's Materials of Construction................... 8vo, 600

" Stadia Reduction Diagram. . Sheet, $22 \frac{1}{2} \times 28 \frac{1}{2}$ inches, $\quad 50$

" Theory and Practice of Surveying......... Small 8vo, 400

Kent's Mechanical Engineer's Pocket-book.....16mo, morocco, 500

Kiersted's Sewage Disposal.......................12mo, 125

Mahan's Civil Engineering. (Wood.)................ 500

Merriman and Brook's Handbook for Surveyors....16mo, mor., 200

Merriman's Geodetic Surveying. .................. 8 vo, 200

“ Retaining Walls and Masonry Dams........8vo, 200

“ Sanitary Engineering................... 8 vo, 200

Nagle's Manual for Raibroad Engineers........16mo, morocco, 300

Patton's Civil Engineering. .......................... 750

“ Foundations..........................8vo, 500

Pratt and Alden's Street-railway Road-beds...........8vo, 200

Rockwell's Roads and Pavements in France.............12mo, 125

Ruffner's Non-tidal Rivers. . . . . . . . . . . . . . . . . . . 8vo, , 125

Searles's Field Eugineering............16mo, morocco flaps, 300

“ Railroad Spiral .............16mo, morocco flaps, 150

Siebert and Biggin's Modern Stone Cutting and Masonry...8vo, 150

Smart's Engineering Laboratory Practice.............12mo, 250

Smith's Wire Manufacture and Uses.............Small 4to, 300

Spalding's Roads and Pavements..................... 200 
Spalding's Hydraulic Cement.....................12mo,

Taylor's Prismoidal Formulas and Earthwork..........8vo,

Thurston's Materials of Construction...................8vo, 500

* Trautwine's Civil Engineer's Pocket-book...16mo, mor. flaps, 500

* I " Cross-section.......................... Sheet, ma 25

* “ “. Excavations and Embankments.............8vo, 200

* " ". Laying Out Curves................12mo, morocco, 250

Waddell's De Pontibus (A Pocket-book for Bridge Engineers);

What

Wait's Engineering and Architectural Jurisprudence......8vo, 600

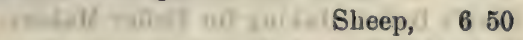

“ Law of Field Operation in Engineering, etc...... . .8vo.

Warren's Stereotomy-Stone-cutting...................8vo, 250

Webb's Engineering Instruments. . ..........16mo, morocco, 100

Wegmann's Construction of Masonry Dams...........4to, 500

Wellington's Location of Railways...

Wheeler's Civil Engineering...................... 400

Wolff's Windmill as a Prime Mover............... 8 vo, 800

\section{HYDRAULICS.}

Water-wheels-Windmills-Service Pipe-Drainage, Etc.

(See also Engineming, p. 7.)

Bazin's Experiments upon the Contraction of the Liquid Vein.

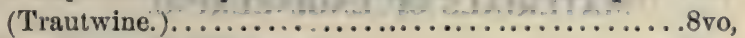

Bovey's Treatise on Hydraulics................ 8 ro,

Coffin's Graphical Solution of Hydraulic Problems.......12mo,

Ferrel's Treatise on the Winds, Cyclones, and Tornadoes. .. 8vo,

Fuertes's Water and Public Health.................12mo,

Ganguillet \& Kutter's Flow of Water. (Hering \& Trautwine.)

Hazen's Filtration of Public Water Supply............ 8 vo, 200

Herschel's 115 Experiments ......................8vo, 200

Kiersted's Sewage Disposal..................... 12mo, 125

Mason's Water Supply........................... 8 vo, 500

Merriman's Treatise on Hydraulics. .................. 8vo, 400

Nichols's Water Supply (Chemical and Sanitary)........ 8 vo, 250

Ruffner's Improvement for Non-tidal Rivers............ 8vo, 125

Wegmann's Water Supply of the City of New York ......4to, 1000

Weisbach's Hydraulics. (Du Bois.)..................8yo, 500

Wilson's Irrigation Engineering..................8 8vo, 400

“ Hydraulic and Placer Mining................. 200

Wolff's Windmill as a Prime Mover..................8vo, 300

Wood's Theory of Turbines......................8vo, 250 
Botlers-Explosives-Iron-Sugar-Watcheis - Woollens, Etc.

Allen's 'Tables for Iron Analysis.................. 8vo, \$3 00

Beaumont's Woollen and Worsted Manufacture........12mo, 150

Bolland's Encyclopædia of Founding Terms............12mo, 800

$\because \quad$ The Iron Founder.............................12mo," 250

" " " " Supplement.............12mo, 250

Bouvier's Handbook on Oil Painting..................12mo, 200

Eissler's Explosives, Nitrogiycerine and Dynamite.......8vo, 400

Ford's Boiler Making for Boiler Makers...............18mo, 100

Metcalfe's Cost of Manufactures..........................8vo, 500

Metcalf's Steel-A Manual for Steel Users............12mo, 200

* Reisig's Guide to Piece Dyeing. ..........................8vo, 2500

Spencer's Sugar Manufacturer's Handbook....16mo, mor. flap, 200

"H Handbook for Chemists - of Beet Sugar Houses.

17. $\quad 16 \mathrm{mo}$, mor. flap, 300

Thurston's Manual of Steam Boilers................. 8vo, 500

Walke's Lectures on Explosives....................8vo, 400

West's American Foundry Practice.................12mo, 250

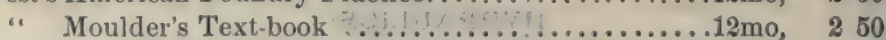

Wiechmaun's Sugar Aualysis................. Small 8vo, 250

Woodbury's Fire Protection of Mills..............8vo, 250

\section{MATERIALS OF ENGINEERING.}

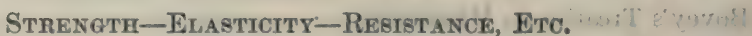

(See also Enginening, p. 7.)

Baker's Masonry Construction. . ....................... 8vo, 600

Beardslee and Kent's Strength of Wrought Iron.........8vo, 150

Bovey's Strength of Materials.....................8vo, 750

Burr's Elasticity and Resistance of Materials............ 8vo, 500

Byrne's Highway Construction......................8vo, 500

Church's Mechanics of Engineering-Solids and Fluids... ..8vo, 600

Du Bois's Stresses in Framed Structures............ Small 4to, 1000

Johnson's Materials of Construction.................8vo, 600

Lanza's Applied Mechanics. ..................... 8vo, 750

Martens's Materials. (Henning.)........8vo. (In the press.)

Merrill's Stones for Building and Decoration...........8vo, 500

Merriman's Mechanics of Materials....................8vo, 400

Strength of Materials....................... 100

Patton's Treatise on Foundations.................... 8 vo, 500

Rockwell's Roads and Pavements in France...........12mo, 125

Spalding's Roads and Pavements.....................12mo, 200 
Thurston \& Materials of Construction ................. . $8 \mathrm{vo}, \$ 500$

Materials of Engineering.............3 vols., 8vo, 800

Vol. I., Non-metallic .....................8vo, 200

Vol. II., Iron and Steel.......................8vo, 350

Vol. III., Alloys, Brasses, and Bronzes..........8vo, 250

Wood's Resistance of Materials................... 8 vo, 200

\section{MATHEMATICS.}

\section{Calculus-Geometri-Trigonometri, Eto.}

Baker's Elliptic Functions...................... 8vo, 150

Ballard's Pyramid Problem. ........................8vo, 150

Barnard's Pyramid Problem.......................8vo, 150

Bass's Differential Calculus................................. 400

Briggs's Plane Analytical Geometry....................... 100

Chapman's Theory of Equations. .....................12mo, 150

Compton's Logarithmic Computations................12mo, 150

Davis's Introduction to the Logic of Algebra..........8vo, 150

Halsted's Elements of Geometry......................8vo, 175

" Synthetic Geometry........................8vo, 150

Johnson's Curve Tracing ..........................12mo, 100

" Differential Equations-Ordinary and Partial.

(17) Small 8vo, 350

" Integral Calculus......................12mo, 150

“ . ......... Unabridged. 12mo. (In the press.)

“ Least Squares........................12mo, 150

Ludlow's Logarithmic and Other Tables. (Bass.).......8vo, 200

“. Trigonometry with Tables. (Bass.).............8vo, 300

Mahan's Descriptive Geometry (Stone Cutting).......... 8vo, 150

Merriman and Woodward's Higher Mathematics........8vo, 500

Merriman's Method of Least Squares .................. 8 vo, 200

Parker's Quadrature of the Circle.................. 8vo, 250

Rice and Johnson's Differential and Integral Calculus,

“ Differential Calculus...........Small 8vo, 300

........ Abridgment of Differential Calculus.

Small 8vo, 150

Totten's Metrology..............................8vo, 250

Warren's Descriptive Geometry..................2 vols., 8vo, 350

“" Drafting Instruments........................12mo, 125

Free-hand Drawing.......................... 100

“ Higher Linear Perspective................. 8vo," 350

، Linear Perspective.....................12mo, 100

“ Primary Geometry.............................. 75

“ Plane Problems............................12mo, 125 
Warren's Problems and Theorems................. 8 vo, \$2 50

" Projection Drawing...,....................12mo, " 150

Wood's Co-ordinate Geometry.......................8vo, 200

\&. Trigonometry..........................12mo, 100

Woolf's Descriptive Geometry...............Royal 8vo, 300

\section{MECHANICS-MACHINERY.}

\section{Text-Books and Practical Works.}

(Bee also ENGINEERING, p. 7.)

Baldwin's Steam Henting for Buildings...............12mo, 250

Benjamin's Wrinkles and Recipes........................ 200

Chordal's Letters to Mechanics.....................12mo, 200

Church's Mechanics of Engineering.............. 8vo, 600

". Notes and Examples in Mechanics.............. 8vo, 200

Crehore's Mechanics of the Girder................. 8 vo, 500

Cromwell's Belts and Pulleys........................ 150

" Toothed Gearing.......................12mo, 1. 50

Compton's First Lessons in Metal Working............12mo, 150

Compton and De Groodt's Speed Lathe...............12mo, 150

Dana's Elementary Mechanics....................12mo, 150

Dingey's Machinery Pattern Making.................. 200

Dredge's Trans. Exhibits Building, World Exposition.

4to, half morocco, 1000

Du Bois's Mechanics. Vol. I., Kinematics ........... 8vo, 350

" . Vol. II., Statics............. 8vo, 400

" " $\quad$ Vol. III., Kinetics............. 8vo, 350

Fitzgerald's Boston Machinist.....................18mo, 100

Flather's Dynamometers.......................12mo, . 200

“ Rope Driving......................... 200

Hall's Car Lubrication.............................. 100

Holly's Saw Filing ........................16mo, , 75

Johnson's Theoretical Mechanics. An Elementary Treatise. (In the press.)

Jones's Machine Design. Part I., Kinematics..........8vo, " " " Part II., Strength and Proportion of

Mrchine Parts. ............................8vo,

Lanza's Applied Mechanics ..................... 750

MacCord's Kinematics......................... $8 \mathrm{vo}, \quad 500$

Merriman's Mechanics of Materials...................8vo, 400

Metcalfe's Cost of Manufactures....................8vo, 500

Michie's Analytical Mechanics......................8vo, 400

Richards's Compressed Air......................12mo, 150

Robinson's Principles of Mechanism................ 8vo, , 300

Smith's Press-working of Metals.................... 8vo, \& 00

Thurston's Friction and Lost Work.................8vo, 300 
Thurston's The Animal as a Machine ..................12mo, $\$ 100$

Warren's Machine Construction................2 vols., 8vo, 750

Weisbach's Hydraulics and Hydraulic Motors. (Du Bois.)..8vo, 500

“ Mechanics of Engineering. Vol. III., Part I.,

Sec. I. (Klein.).........................8vo, 500

Weisbach's Mechanics of Engineering. Vol. III., Part I.,

Sec. II. (Klein.)...................... 8 vo, 500

Weisbach's Steam Engines. (Du Bois.)...............8vo, 500

Wood's Analytical Mechanics.......................8vo, 300

"f Elementary Mechanics....................12mo, 125

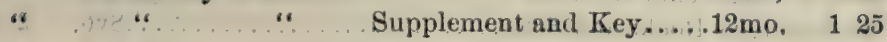

\section{METALLURGY.}

IroN-GoLD-SiLveR-AlLoYs, Etc.

Allen's Tables for Iron Analysis..................8vo, 300

Egleston's Gold and Mercury..................Large 8vo, 750

“ Metallurgy of Silver...................... 8vo, 750

* Kerl's Metallurgy - Copper and Iron...............8vo, 1500

* “ “ $\quad$ Steel, Fuel, etc...............8vo, 1500

Kunbardt's Ore Dressing in Europe.................. 8vo, 150

Metcalf's Steel-A Manual for Steel Users..............12mo, 200

O'Driscoll's Treatment of Gold Ores................. $8 \mathrm{vo}, \quad 200$

Thurston's Iron and Steel..................... 8 vo, 350

" Alloys...................................... 250

Wilson's Cyanide Processes........................... 150

\section{MINERALOGY AND MINING.}

Mine Accidents-Ventilation-Ore Dressing, Etc.

Barringer's Minerals of Commercial Value....Oblong morocco, 250

Beard's Ventilation of Mines........................12mo, 250

Boyd's Resources of South Western Virginia.......... 8vo, 300

" Map of South Western Virginia.....Pocket-book form, 200

Brush and Penfịeld's Determinative Mineralogy. New Ed. 8vo, 400

Chester's Catalogue of Minerals .......................8vo, 125

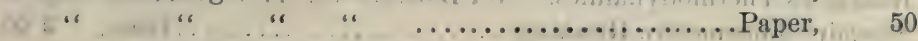

“ i Dictionary of the Names of Minerals...........8vo, 300

'Dana's American Localities of Minerals. . .................8vo, 100

"Descriptive Mineralogy: (E. S.)....8vo, half morocco, 1250

“ Mineralogy and Petrography (J.D.)...........12mo, 200

$\because \quad$ Minerals and How to Study Them. (E. S.).......12mo, 150

“Text-book of Mineralogy (E. S,) : . New Edition. 8vo, in 400

*Drinker's Tunuelling, Explosives, Compounds, apd Rock Drills.

10 i1 kisma :

4to, half morocco, 2500 
Egleston's Catalogue of Minerals and Synonyms.........8vo, - \$2 50 Eissler's Explosives-Nitroglycerine and Dynamite......8vo, -400 Hussak's Rock-forming Minerals. (Smith.)........Small 8vo, 200 Ihlseng's Manual of Mining. . .......................8vo, 400 Kunhardt's Ore Dressing in Europe...................8vo, 150 O'Driscoll's Treatment of Gold Ores....................8 8vo, . 200

* Penfield's Record of Mineral Tests................Paper, 8vo, - 50

Rosenbusch's Microscopical Physiography of Minerals and

Rocks. (Iddings.)......................8vo, 500

Saw yer's Accidents in Mines.......................Large 8vo, 700

Stockbridge's Rocks and Soils.......................8vo, 250

Walke's Lectures on Explosives. .................... 8vo, 400

Williams's Lithology. . . . . . ..................... 8 vo, 300

Wilson's Mine Ventilation.........................mo, 125

“ Hydraulic and Placer Mining................. 250

\section{STEAM AND ELECTRICAL ENGINES, BOILERS, Etc.}

\section{Stationaky-Marine-Locomotive-Gas Engines, Etc.} (See also ENGINEERING, p. 7.)

Baldwin's Steam Heating for Buildings...............12mo, 250

Clerk's Gas Engine................................. 8vo, 400

Ford's Boiler Making for Boiler Makers.................18mo, 100

Hemenway's Indicator Practice.....................12mo, 200

Hoadley's Warm-blast Furaace.....................8vo, 150

Kneass's Practice and Theory of the Injector ..........8vo, 150

MacCord's Slide Valve.........................8vo, 200

Meyer's Modern Locomotive Construction................4to, 1000

Peabody and Miller's Steam-boilers.......................8vo, 400

Peabody's Tables of Saturated Steam................ 8vo, 100

" Thermodynamics of the Steam Engine......... 8vo, 500

“ Valve Gears for the Steam-Engine.............8vo, 250

Pray's Twenty Years with the Indicator............Large 8vo, 250

Pupin and Osterberg's Thermodynamics..............12mo, 125

Reagan's Steam and Electric Locomotives............12mo, 200

Röntgen's Thermodynamics. - (Du Bois.)..............8vo, 500

Sinclair's Locomotive Running.....................12mo, 200

Snow's Steam-boiler Practice............8vo. (In the press.)

Thurston's Boiler Explosions.....................12mo, 150

" Engine and Boiler Trials. ..................8vo, 500

“ Manual of the Steam Engine. Part I., Structure and Theory.........................8vo, $\quad 600$

“ Manual of the Steam Eugine. Part II., Design, Construction, and Operation..............8vo, 600 2 parts, 1000 
Thurston's Philosophy of the Steam Engine..........12mo, \$ 75

. Reflection on the Motive Power of Heat. (Carnot.) ,

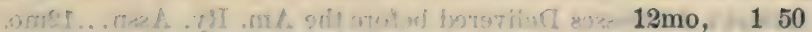

Stationary Steam Engines................. $12 \mathrm{mo}$, 50

a $x$ Steam-boiler Construction and Operation.......8vo, $\quad 5.00$

Spangler's Valve Gears. . .............................8vo, 250

Weisbach's Steam Engine. (Du Bois.).................8vo, 1500

Whitham's Constructive Steam Engineering.............8vo, 1000

" Steam-engine Design..................8vo, 500

Wilson's Steam Boilers. (Flather.)...................... 250

Wood's Thermodynamics, Heat Motors, etc...........8vo, 400

\section{TABLES, WEIGHTS, AND MEASURES.}

For Actuaries, Chemists, Engineers, Mechanics-Metric TABLES, Erc.

Adriance's Laboratory Calculations....................... 125

Allen's Tables for Iron' Analysis.....................8vo, 300

Bixby's Graphical Computing Tables...................Sheet, 25

Compton's Logarithms..........................12mo, 150

Crandall's Railway and Earthwork Tables............8vo, 150

Egleston's Weights and Measures....................18mo, 75

Fisher's Table of Cubic Yards...................Cardboard, $\quad 25$

Hudson's Excavation Tables. Vol. II............... 8vo, 100

Johnson's Stadia and Earthwork Tables ..............8vo, 125

Ludlow's Logarithmic and Other Tables. (Bass.) .......12mo, 200

Totteu's Metrology...........................8vo, 2 50

\section{VENTILATION.}

\section{Steam Heating-Houge Inspection-Mine Ventilation.}

Baldwin's Steam Heating............................ 250

Beard's Ventilation of Mines......................12mo, 250

Carpenter's Heating and Ventilating of Buildings......... 8 vo, 300

Gerhard's Sanitary House Inspection ............ Square 16mo, 100

Mott's The Air We Breathe, and Ventilation...........16mo, 100

Reid's Ventilation of American Dwellings ............12mo, 150

Wilson's Mine Ventilation........................... 16mo, 125

\section{MISCELLANEOUS PUBLICATIONS,}

Alcott's Gems, Sentiment, Language.................tt edges, 500

Bailey's The New Tale of a Tub...................8vo, $\quad 75$

Ballard's Solution of the Pyramid Problem............8vo, 150

Barnard's The Metrological System of the Great Pyramid..8vo, 150

Davis's Elements of Law..........................8vo, \& 00 
Emmon's Geological Guide-book of the Rocky Mountains. .8vo, \$1 50

Ferrel's Treatise on the Winds.....................8vo, 400

Haines's Addresses Delivered before the Am. Ry. Assn...12mo. 250

Mott's The Fallacy of the Present Theory of Sound..Sq. 16mo, 100

Perkins's Cornell University..................... Oblong 4to, 150

Ricketts's History of Rensselaer Polytechnic Institute....8vo, 300

Rotherham's The New Testament Critically Emphasized.

$12 \mathrm{mo}, 150$

“... The Emplasized New Test. A new translation.

Large 8vo, 200

Totten's An Important Question in Metrology..........8vo, 250

Whitehouse's Lake Mœris............................... 25

* Wiley's Yosemite, Alaska, and Yellowstone ............4to, 300

\section{HEBREW AND CHALDEE TEXT-BOOKS.}

For Schools aNd Theological Seminaries.

Gesenius's Hebrew and Chaldee Lexicon to Old Testament.

(Tregelles.)................ Small 4to, half morocco, .500

Green's Elementary Hebrew Grammar............... 12 mo, 125

“ Grammar of the Hebrew Language (New Edition).8vo; 300

“ Hebrew Chrestomathy.......................8vo, 2 00

Letteris's Hebrew Bible (Massoretic Notes in English).

8vo, arabesque, 225

\section{MEDICAL.}

Bull's Maternal Management in Health and Disense.......12mo, 100

Hammarsten's Physiological Chemistry. (Mandel.)......8vo, 400

Mott's Composition, Digestibility, and Nutritive Value of Food.

Large mounted chart, 125

Ruddiman's Incompatibilities in Prescriptions.........8vo, 200

Steel's Treatise on the Diseases of the Ox........... 8vo, 600

" Treatise on the Diseases of the Dog.............8vo, " 350

Woodhull's Military Hygiene......................... 150

Worcester's Small Hospitals-Establishment and Maintenance, including Atkinson's Suggestions for Hospital Architecture..............................12mo, 125

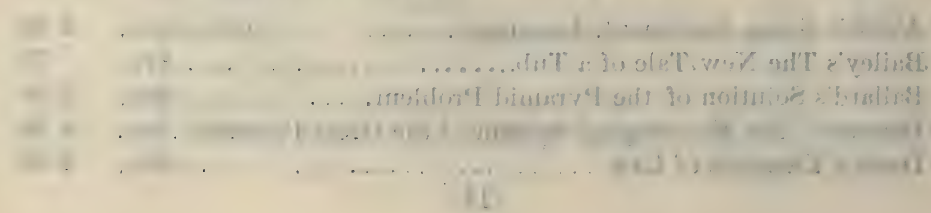




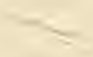






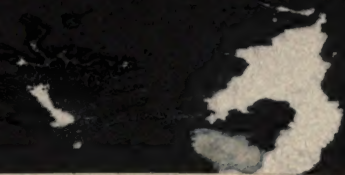

PLEASE DO NOT REMOVE CARDS OR SLIPS FROM THIS POCKET

\section{UNIVERSITY OF TORONTO LIBRARY}

S\&M

A 285 
